Portland State University

PDXScholar

Spring 6-6-2013

\title{
Bridging the Missing Link between "Top-down" and "Bottom-up": A Strategic Policy Model for International Collaboration in Science and Technology
}

Pattharaporn Suntharasaj

Portland State University

Follow this and additional works at: https://pdxscholar.library.pdx.edu/open_access_etds

Part of the Other International and Area Studies Commons, Strategic Management Policy Commons, and the Technology and Innovation Commons

Let us know how access to this document benefits you.

\section{Recommended Citation}

Suntharasaj, Pattharaporn, "Bridging the Missing Link between "Top-down" and "Bottom-up": A Strategic Policy Model for International Collaboration in Science and Technology" (2013). Dissertations and Theses. Paper 1077.

https://doi.org/10.15760/etd.1077

This Dissertation is brought to you for free and open access. It has been accepted for inclusion in Dissertations and Theses by an authorized administrator of PDXScholar. Please contact us if we can make this document more accessible: pdxscholar@pdx.edu. 
Bridging the Missing Link between "Top-down" and "Bottom-up":

A Strategic Policy Model for International Collaboration in Science and Technology

by

Pattharaporn Suntharasaj

A dissertation submitted in partial fulfillment of the

requirements for the degree of

\author{
Doctor of Philosophy \\ in \\ Technology Management
}

Dissertation Committee:

Dundar F. Kocaoglu, Chair

Robert D. Dryden

Ronald L. Tammen

Wayne W. Wakeland

Portland State University

2013 
C 2013 Pattharaporn Suntharasaj 


\begin{abstract}
Success in International Collaboration in Science and Technology (ICST) depends on various factors, different players have different perspectives. Governments participate in collaboration in order to meet their country's policy goals. Scientists and researchers establish their contacts through their personal channels or scientific networks in order to pursue their own academic interest. There are two significant approaches in ICST Policy making which are "top-down" and "bottom-up" approaches. Both approaches are important. One approach can not fit all. Each approach has its own advantages and disadvantages. A balance between these two approaches is necessary.
\end{abstract}

The objective of this research is to develop a strategic policy model for international collaboration in science and technology to bridge the gap between “top-down" and "bottom-up" approaches. A strategic policy model was developed in which the characteristics of ICST proposals and expert judgments are quantified to determine the relative importance the country's international S\&T Vision and Objectives and R\&D Strategies, and to evaluate the proposals accordingly. Four international evaluation criteria are proposed in this research: strategic importance (SI), potential impact (PI), human resource development (HRD), and matching fund from international partners (MF). Each proposal is 
evaluated with respect to each criterion and related sub-criteria. The value of each ICST proposal is then calculated by incorporating all of the elements at each level of the model.

The output of this model is the ranking of the ICST proposals coming from the "bottom-up" approach that satisfy the national priorities and organizational requirements represented by the "top-down" approach. The model facilitates the national policymakers to make better decisions about participating in ICST research, and the researchers to have a better understanding of the entire international scientific collaboration system by identifying research opportunities to fit in. 


\section{Dedication}

To my Dad and my Mom, it is impossible to thank you adequately for everything you have done, from loving me unconditionally to raising me in a heartwarming family, where you taught me to embrace my life and do not forget to love others as well. I could not have asked for anything else in this world. 


\section{Acknowledgements}

Being through this $\mathrm{Ph} . \mathrm{D}$. process is one of the most challenging, yet rewarding experiences in my life. Many things happened and changed along the way, both good and bad. However, I am extremely blessed to have great people around me who always there for me through this long journey.

First of all, I would like to express my great appreciation to my advisor and the chairman of my dissertation committee, Dr. Dundar F. Kocaoglu. His valuable suggestion and contribution during the entire process of my Ph.D. research means so much to me.

Second, I would like to express my sincere thanks to all of my dissertation committee, Dr. Robert Dryden, Dr. Ronald Tammen and Dr. Wayne Wakeland. Their academic support and input are greatly appreciated.

Third, I would like to acknowledge Dr. Kwan Sitathani, an executive deputy director of National Electronics and Computer Technology Center (NECTEC) in Thailand who was my former boss. He was the one who passed me the great opportunity to pursue my Ph.D. at Portland State University.

Next, I would like to thank professors whom I used to work with from Engineering and Technology Management (ETM) department, other universities, and various organizations around the world. You all provided me the valuable knowledge and ideas that I use them to conduct my dissertation research. Thanks Dr. Neil Berglund, Dr. Federick Betz, Dr. Dilek Cetendimar, Dr. Gulgun Kayakutlu, Dr. Tugrul Daim, Dr. Timothy Anderson, Dr. Charles Weber, and Dr. Antonie Jetter. 
I could not be able to finish my dissertation research without the valuable information and insights from this wonderful people from Thailand. Thank you very much to Dr. Itti Rittaporn, Dr. Surapan Meknavin, Prof. Apinetr Unakul, Dr. Ladawan Krasachol, Dr. Uthai Chareonwong, Mr. and Mrs. Indaraprasirt, Dr. Alisa Kongthon, Dr. La-or Kovavisaruch, Dr. Sissadej Thongsima, Dr. Kritsachai Somsaman, Dr. Namchai Chewawiwat, Mrs. Kullaprapha Navanugraha, Mrs. Reutai Chongsarid, Mrs. Orapannee Yuan, all executive directors and executive deputy directors of the four national research centers of National Science and Technology Development Agency (NSTDA), and all project analysts from NSTDA. Thank you very much.

Thank you to all my sponsors who gave me the great opportunity and the financial supports to conduct my Ph.D. research which are A PhD Scholarship from the Royal Thai Government Scholarship, Thailand, A Maseeh Fellowship from the Maseeh College of Engineering and Computer Science at Portland State University, U.S., An Outstanding Award from the Dean Office at Portland State University, U.S., and A Sasakawa Young Leaders Fellowship Fund (Sylff) Graduate Fellowships for International Research from Tokyo Foundation and Oregon University System (OUS), Japan.

I was born as an only child in my family however I am fortunately enough to have so many people in my life that I can call them my sisters and brothers. I would like to thank them who were always with me whenever I need them. Your unconditional love and support have brought me to this point. Thank you so much for your encouragement and humor, Nok Chamaporn Klangrat, Ning Nuntasiri Renusawasdi, Arm Pakdeekasem. Kai Sarot Charoenkul, Jaaey Sineenart, Moo La-or, Anne Piyawan. Chueng Phakphoom, In Inthrayuth, Jew Montira, Lhing Watcharin, Koy Phanrunee, Linda Lin, Rosine Hanna, and Alexander Smirnov. 
Thanks to my ETM family, my Fabulous Life Club, my Omega Rho Society, my DFK research group, my Hiking Club, and all Thai Students in Oregon. Without the joyful activities, it would be harder to get through this journey.

Last but not least, I would like to express my deepest gratitude to the greatest teachers in my life, my mom and my dad. My mom taught me how to learn the alphabets by singing the songs. My dad taught me how to count the number by playing the cards. These are the fantastic lessons I learned during my childhood. Through their eyes I have seen myself as a capable person who could do anything if I would like to do. Thank you very much mom and dad.

Pattharaporn (Patt) Suntharasaj

May, 2013

Portland, Oregon 


\section{Table of Contents}

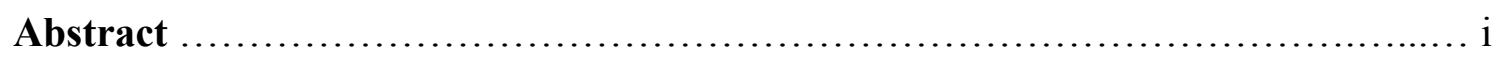

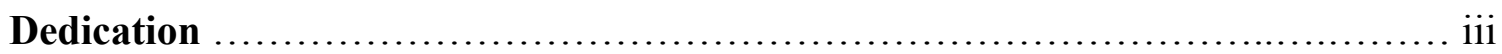

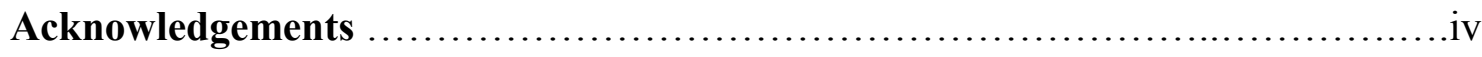

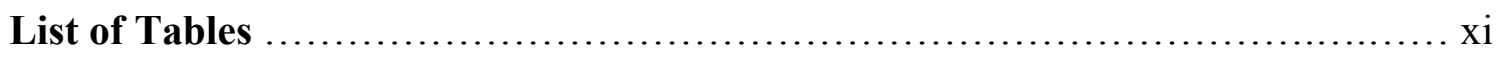

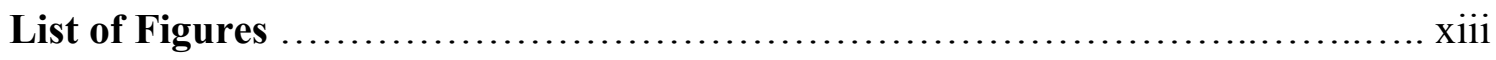

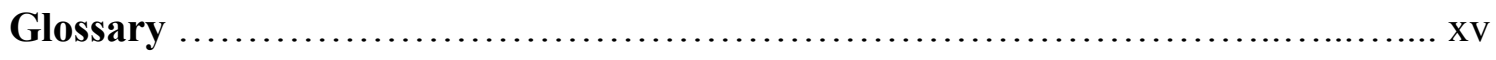

\section{Chapter 1: Introduction}

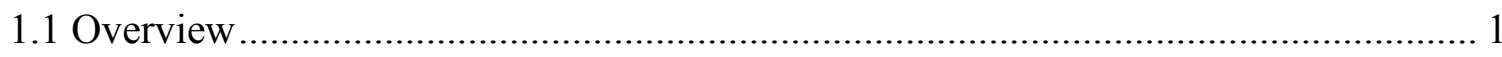

1.2 Research Objective, Research Methodology, and Research Outcome ....................... 4

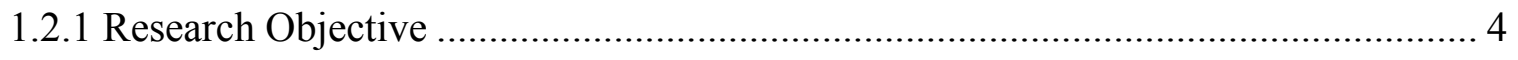

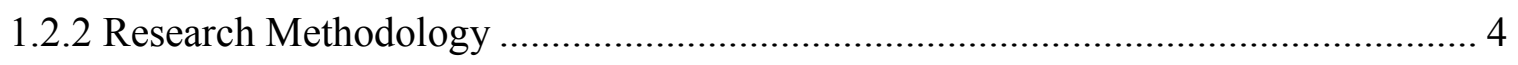

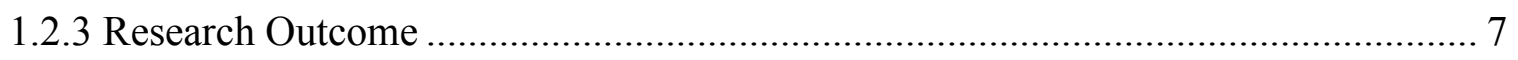

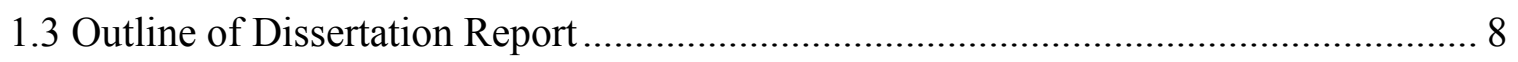

\section{Chapter 2: Literature Review}

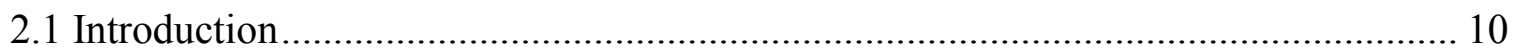

2.2 International Collaboration in Science and Technology (ICST) ............................ 11

2.2.1 What Is International Collaboration in Science and Technology? ........................ 11

2.2.2 Types of International Collaborations in Science and Technology ........................ 13

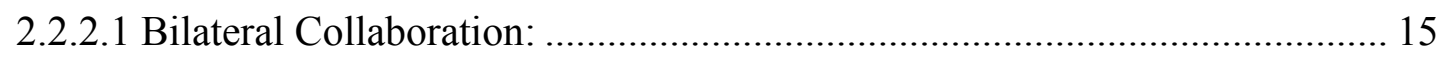

2.2.2.2 Multinational Science and Technology Collaboration: .............................. 15

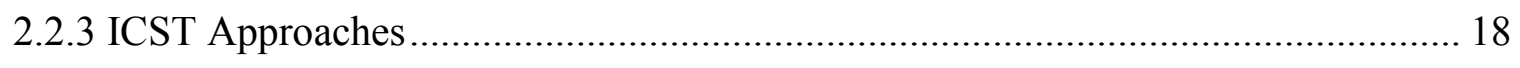

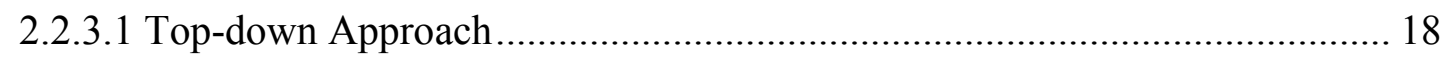


2.2.3.2 Bottom-up Approach 19

2.2.4 Stages of International Collaboration in Science and Technology .......................... 21

2.2.5 Drivers and Barriers of International Collaboration in Science and Technology ... 23

2.2.6 Growth of International Collaboration in Science and Technology ........................ 27

2.3 Top-down approach: Technology Policy Planning................................................... 32

2.4 Bottom-up Approach: Individual and Networking ................................................ 39

2.5 A Comparative Study of top-down and bottom-up approaches................................. 47

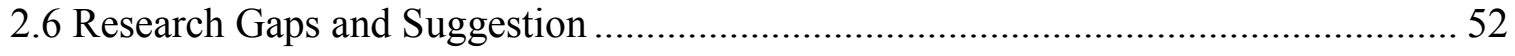

\section{Chapter 3: Research Methodology}

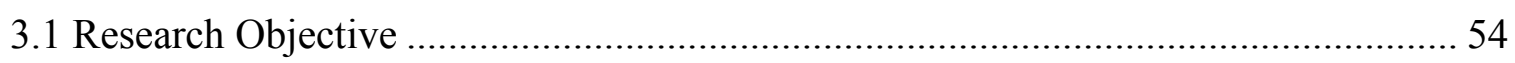

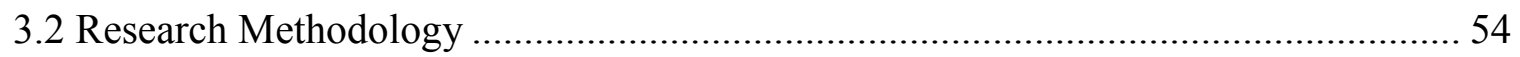

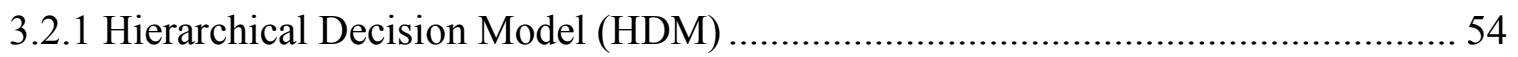

3.3 Research Framework: Conceptual Framework …………........................................ 58

3.4 Research Approach: A 12-step approach............................................................... 59

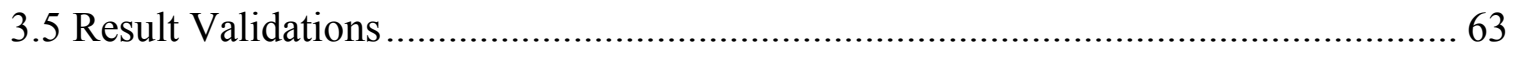

\section{Chapter 4: Development of the Case Study}

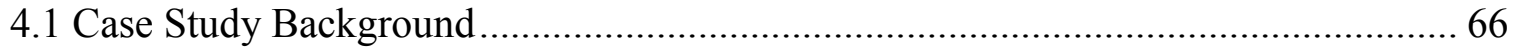

4.1.1 Science and Technology Development in Thailand ................................................. 66

4.1.2 National Science and Technology Development Agency (NSTDA) ...................... 71

4.1.3 International Collaboration in Science and Technology in Thailand ..................... 73

4.2 Development of a Strategic Policy Model for International Collaboration in S\&T:

A Case Study of Thailand ........................................................................................... 74

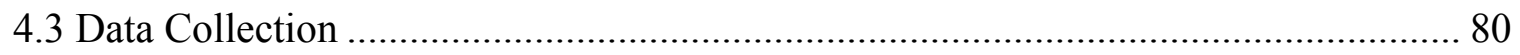

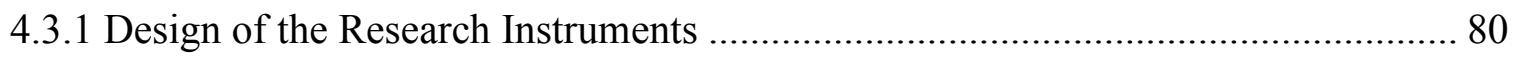

4.3.2 Collecting the Quantification of Expert Judgment ……………………............... 82

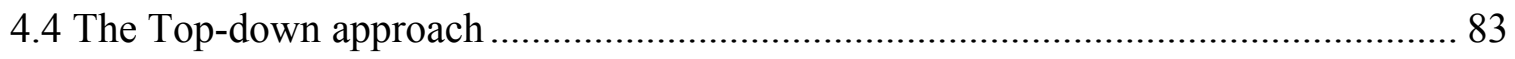




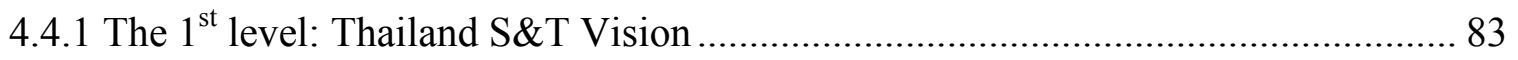

4.4.2 The $2^{\text {nd }}$ level: Thailand S\&T Objectives................................................................. 84

4.4.3 The $3^{\text {rd }}$ level: NSTDA's R\&D Strategy - NSTDA Target Sectors ............................ 86

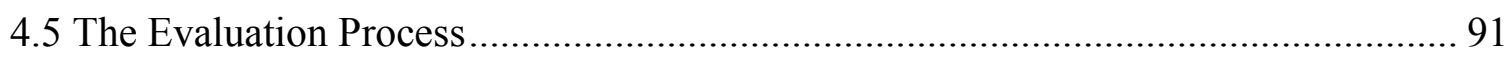

4.5.1 The $4^{\text {th }}$ level: ICST Evaluation Criteria ………………………………………….... 92

4.5.2 The $4^{\text {th }}$ level: ICST Evaluation Sub-criteria ………………………………...... 92

4.5.3 The $4^{\text {th }}$ level: Desirability Curves of ICST Evaluation Sub-criteria ........................ 93

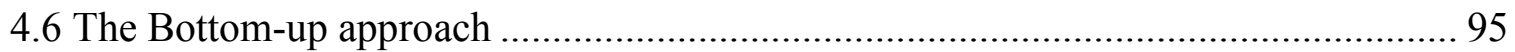

4.6.1 The $5^{\text {th }}$ level: ICST Proposals from NSTDA Researchers ........................................ 95

4.7 A Strategic Policy Model for International Collaboration in S\&T for Thailand ........ 97

\section{Chapter 5: Case Study Results and Analysis}

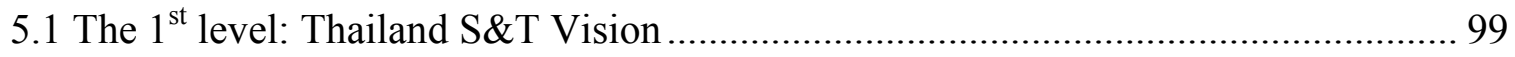

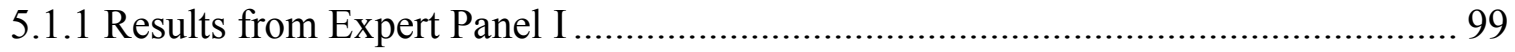

5.2 The $2^{\text {nd }}$ level: Thailand S\&T Objectives............................................................... 100

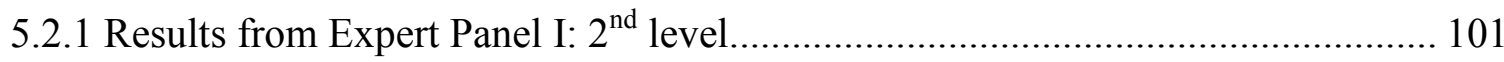

5.2.2 Analysis of the Results from Expert Panel I: $2^{\text {nd }}$ level .......................................... 103

5.3 The $3^{\text {rd }}$ level: NSTDA's R\&D Strategy - NSTDA Target Sectors ............................. 104

5.3.1 Results from Expert Panel II: $3^{\text {rd }}$ level............................................................. 105

5.3.2 Analysis of the Results from Expert Panel II Results: $3^{\text {rd }}$ level............................. 117

5.4 The $4^{\text {th }}$ level: ICST Evaluation Criteria \& Sub-Criteria \& Desirability Curves ....... 120

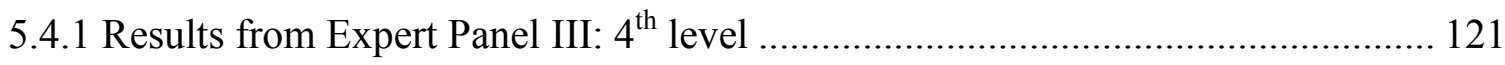

5.4.2 Analysis of the Results from Expert Panel III: $4^{\text {th }}$ level ....................................... 131

5.5 The $5^{\text {th }}$ level: ICST Proposals from Bottom-up approach ........................................ 143

5.5.1 Profiles of the Four ICST Proposals from the Bottom-up approach ..................... 144

5.6 Results and Analysis of the Policy Model for International Collaboration in

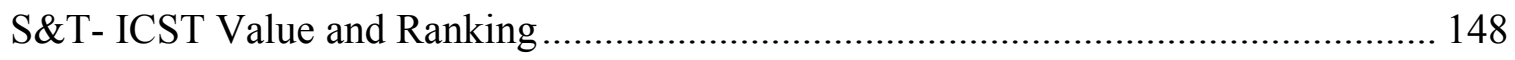

5.6.1 The Calculation of the International Collaboration in S\&T Value ( ICST i) ......... 149 
5.6.2 The Ranking of the International Collaboration in S\&T Proposals

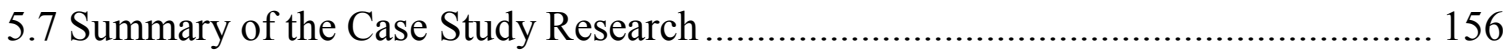

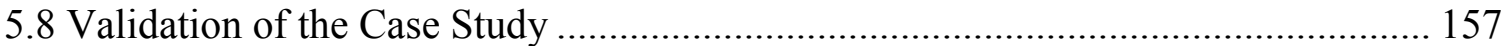

\section{Chapter 6: Conclusions, Contributions, Limitations and Challenges, and Future}

\section{Research}

6.1 Conclusions

6.2 Contributions

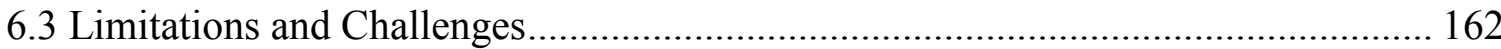

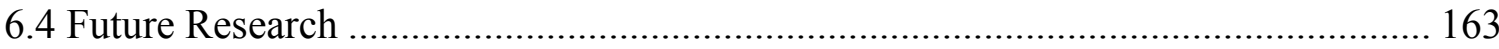

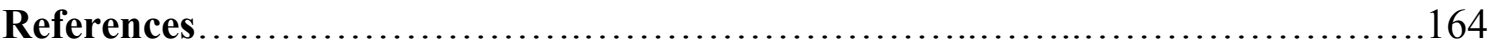

\section{Appendices}
A: Description of Desirability Value of ICST Evaluation Sub-criteria...........176
B: Desirability Curves of all ICST Evaluation Sub-criteria ....................182
C: Research Instruments- all forms......................................206
D: Calculation of the ICST Value of Proposal 2, 3, and 4 .......................230 


\section{List of Tables}

Table 1: Factors that Impact Each Stage of Scientific Collaboration [24] ..................... 23

Table 2: International Co-authorship of Science and Engineering Articles .................... 29

Table 3: Phases of Science and Technology Policy Development ................................. 34

Table 4: Comparison between top-down and bottom-up approaches............................ 47

Table 5: Expert Panel II (twenty expert members) ....................................................... 77

Table 6: Expert Panel III and their area of expertise ................................................... 79

Table 7: The 1st Level of the Policy Model in International Collaboration in S\&T ........ 84

Table 8: The 2nd Level of the Policy Model in International Collaboration in S\&T ....... 86

Table 9: The 3rd Level of the Policy Model in International Collaboration in S\&T ....... 90

Table 10: The five desirability levels of one PI sub-criterion - Meeting Local

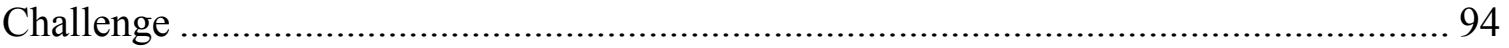

Table 11: The 4th Level of the Policy Model in International Collaboration in S\&T..... 95

Table 12: The 5th Level of the Policy Model in International Collaboration in S\&T...... 96

Table 13: The relative importance and inconsistency of Expert Panel I ...................... 101

Table 14: Relative Importance of Thailand S\&T Objectives .................................... 101

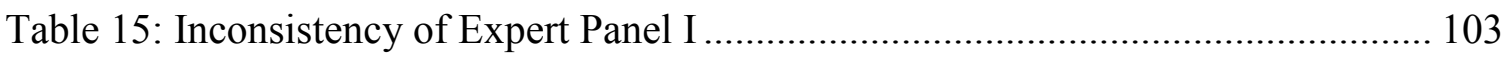

Table 16: The Summary of the Relative Importance of Each Target Sector ................. 106

Table 17: Relative Importance of NSTDA Target Sectors ...................................... 111

Table 18: Inconsistency of Expert Members in Every Subgroup of Expert Panel II ..... 117

Table 19: Disagreement Value of Thailand's Four S\&T Objectives............................. 118

Table 20: Intraclass Correlation Coefficient and F-value of All Objectives ................. 119

Table 21: Relative Importance of the Four Evaluation Criterion ................................ 122

Table 22: Relative Importance of Strategic Importance (SI) Sub-criterion................... 123

Table 23: Relative Importance of Potential Impact (PI) Sub-criterion ......................... 125

Table 24: Relative Importance of Human Resource Development (HRD)

Sub-criterion 
Table 25: Relative Importance of Human Resource Development (MF)

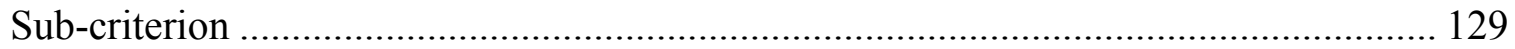

Table 26: Inconsistency Value of Expert Panel III ..................................................... 138

Table 27: Disagreement Value, Intraclass Correlation Coefficient of Four Criteria ...... 139

Table 28: Disagreement Value and Intraclass Correlation Coefficient of SI

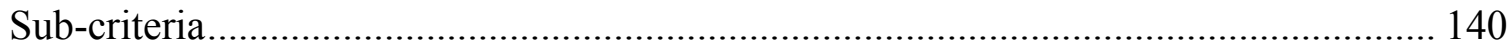

Table 29: Disagreement Value and Intraclass Correlation Coefficient of PI

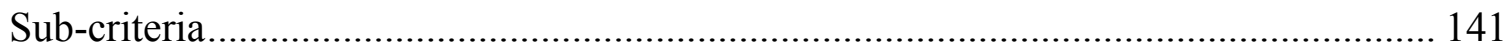

Table 30: Disagreement Value and Intraclass Correlation Coefficient of HRD

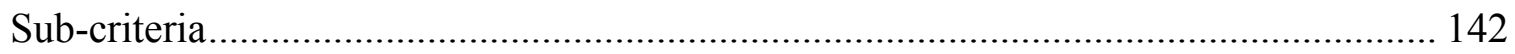

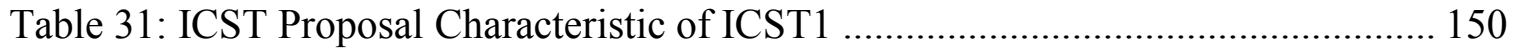

Table 32: The Summary of the ICST Value of the Four Proposals .............................. 152

Table 33: The ICST Value of the Four Proposals.................................................... 154 


\section{List of Figures}

Figure 1: General Form of the Hierarchical Decision Model (HDM) ............................ 5

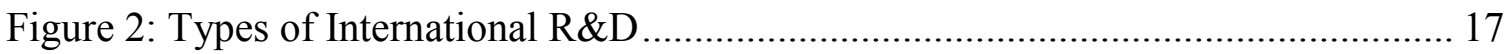

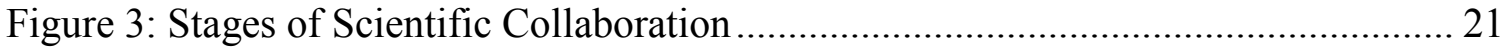

Figure 4: International Co-authorship of S\&E Articles, by Region/Country .................. 28

Figure 5: Share of Patents with Foreign Co-inventors during 2003-2005 ...................... 30

Figure 6: Strategy planning process of a large organization that combines top-down

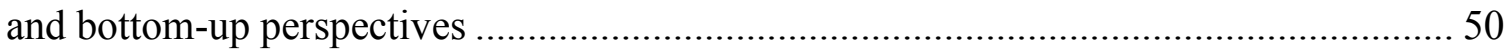

Figure 7: An Advocacy Coalition Framework (ACF) of Policy Change ....................... 51

Figure 8: A Modified Hierarchical Decision Model for a Policy Model for ICST .......... 55

Figure 9: A Conceptual Framework of a Strategic Policy Model for ICST ..................... 58

Figure 10: A 12-step approach to develop a Policy Model in ICST ............................... 59

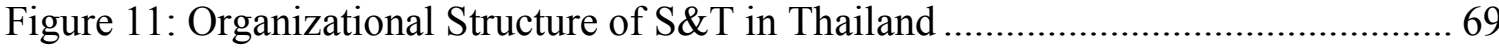

Figure 12: PI 1- Meeting Local Challenge for Agriculture and Food Sector .................. 94

Figure 13: A Strategic Policy Model for International Collaboration in S\&T

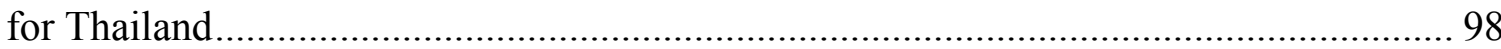

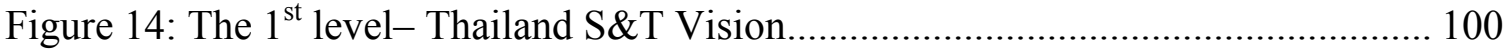

Figure 15: The $2^{\text {nd }}$ level - Thailand S\&T Objective Level........................................ 100

Figure 16: Relative Importance of Thailand S\&T's Objectives .................................. 102

Figure 17: The 3rd level - NSTDA Target Sector .................................................... 105

Figure 18: Relative Importance of NSTDA Target Sectors with respect to

the Thailand's Sustainable Competitiveness Objective ............................................. 107

Figure 19: Relative Importance of NSTDA Target Sectors with respect to the Thailand's Community Economy Objective.

Figure 20: Relative Importance of the NSTDA Target Sectors with respect to the Thailand's Learning Society Objective

Figure 21: Relative Importance of each NSTDA Target Sector with respect to the Thailand's Quality of Life and Environment Objective 
Figure 22: Relative Importance of the five NSTDA target sectors

Figure 23: The 4th level - ICST Evaluation Criteria \& Sub-criteria \&

Desirability Curves

Figure 24: S1-To build up National S\&T Capabilities through International

Collaboration in S\&T. 130

Figure 25: Relative Importance of the Four Evaluation Criteria 131

Figure 26: Relative Importance of the Four Sub-criteria of SI 133

Figure 27: Relative Importance of the Five Sub-criteria of PI 135

Figure 28: Relative Importance of the Five sub-criteria of HRD 137

Figure 29: The four ICST Proposal at the $5^{\text {th }}$ level 143

Figure 30: The ICST Values of the four Proposals 153

Figure 31: Value and Ranking of ICST Proposals between Expert Panel I vs. Outlier . 155

Figure 32: The Schematic Framework of the Research: Gaps and Contributions 160 


\section{Glossary}

\begin{tabular}{|c|c|}
\hline Abbreviation & Meaning \\
\hline ICST & $\begin{array}{l}\text { International Collaboration in Science and } \\
\text { Technology }\end{array}$ \\
\hline HDM & Hierarchical Decision Model \\
\hline AHP & Analytical hierarchy Process \\
\hline $\mathrm{ACF}$ & Advocacy Coalition Framework \\
\hline MOST & Ministry of Science and Technology (Thailand) \\
\hline NSTDA & $\begin{array}{c}\text { National Science and Technology Development } \\
\text { Agency (Thailand) }\end{array}$ \\
\hline NECTEC & $\begin{array}{l}\text { National Electronics and Computer Technology } \\
\text { Center (Thailand) }\end{array}$ \\
\hline MTEC & National Material and Engineering (Thailand) \\
\hline BIOTEC & $\begin{array}{l}\text { National Center for Genetic Engineering and } \\
\text { Biotechnology (Thailand) }\end{array}$ \\
\hline NANOTEC & National Nanotechnology Center (Thailand) \\
\hline EXP & Expert Panel \\
\hline SI & Strategic Importance \\
\hline PI & Potential Impact \\
\hline HRD & Human Resource Development \\
\hline $\mathrm{MF}$ & Matching Fund Ratio \\
\hline$r_{i c}$ & Interclass correlation coefficient \\
\hline ICST $_{i}$ & $\begin{array}{c}\text { International Collaboration in Science and } \\
\text { Technology Proposal i }\end{array}$ \\
\hline $\mathrm{D}\left(\mathrm{P}_{\mathrm{jkl}}\right)_{\mathrm{i}}$ & $\begin{array}{c}\text { Desirability value of the project characteristic of } \\
\text { Proposal I corresponding to Sub-criteria jkl to } \\
\text { Criteria }\end{array}$ \\
\hline$S_{\mathrm{jkl}}^{\mathrm{c}}$ & Contribution of Sub-criteria $\mathrm{jkl}$ to Criteria \\
\hline $\mathrm{C}_{\mathrm{kl}}^{\mathrm{t}}$ & Contribution of Criteria $\mathrm{kl}$ to Target Sectors \\
\hline $\mathrm{T}_{\mathrm{l}}^{\mathrm{O}}$ & Contribution of Target Sector 1 to Objectives \\
\hline $\mathrm{O}_{\mathrm{M}}^{\mathrm{V}}$ & Contribution of Objective $\mathrm{m}$ to the Vision \\
\hline
\end{tabular}




\section{Chapter 1: Introduction}

\subsection{Overview}

More and more attention is being given to international collaboration in science and technology (ICST) because it allows countries to share the costs and risks of global challenges. It enables cost sharing of scientific instrumentation and laboratory infrastructures that would not be possible to have in every country. It helps to stimulate knowledge, skills, and techniques across borders. ICST sustains the research goals and motivation through human interaction across fields, and it accelerates development of scientific knowledge. Additionally, it helps to improve the international mobility of human resources for S\&T around the world (brain circulation phenomena).

There are various factors that contribute to the growth of ICST. First, information and communication technology (ICT) helps scientists to share ideas and information quickly and easily. Second, modern advances and ease of transportation increase the dynamics of knowledge sharing. Researchers increasingly interconnect across the world and from robust networks of scientists. Third, the emergence of the new global players in S\&T, i.e., BRIC countries (Brazil, Russia, India, and China), is an important driving force. Fourth, the new global challenges such as climate change, health, infectious 
diseases, security, and energy deficiency increasingly encourage scientists to collaborate with their colleagues in other countries.

Currently, many national and international organizations around the world such as the European Commission (EC), Organization for Economic Co-operation and Development (OECD), United Nations Educational, Scientific and Cultural Organization (UNESCO), and RAND Corporation (Research And Development) are paying attention to ICST. Also, many governments such as the U.S., Ireland, Germany, Japan, and China have initiatives to strengthen international $R \& D$ collaboration through agreements with other countries and regions. This is because linking domestic resources to foreign resources for research and innovation collaborations is judged to be a great opportunity for everybody.

Various programs to provide opportunities for international collaboration have been established. Examples in Europe include FP (the Research Framework Program), COST (European Cooperation in S\&T basic research networks), EUREKA (Intergovernmental network for market-oriented, industrial R\&D), and ESFRI (European Strategy Forum for Research Infrastructures.

To participate in ICST, the success of collaborative projects depends on various factors. Governments use the top-down approach in order to meet their country's policy 
goals. Coping with the rapid pace of technological change is increasingly difficult. Thus, the decision of national policymakers to invest in a suitable project is one of the most important factors. They face a number of questions and complex choices such as: Has this program been worth the effort? Is this program reaching its goals? The national policymaker needs a clear rationale for government sponsorship and participation in the collaboration based on better priority-setting.

On the other hand, scientists and researchers participate in international collaboration (through the bottom-up approach) when it helps them with their specific purposes, regardless of the national S\&T policy, e.g., finding answers to specific research questions or pursuing their own academic or scientific agenda. Scientists and researchers often establish contacts with former colleagues or supervisors abroad or through their personal channels or scientific networks.

Balancing these two approaches, top-down and bottom-up, will help create effective international scientific collaborations that achieve the desired results, which will benefit both individual researchers and their organizations. 


\subsection{Research Objective, Research Methodology, and Research Outcome}

\subsubsection{Research Objective}

The objective of this research is to develop a strategic decision-making model in the area of international collaboration in science and technology for bridging the gap between top-down and bottom-up approaches.

This model provides the linkage between national policymakers and researchers by integrating the "curiosity-driven" ICST project with the bottom-up approach to serve the country's goals and objectives. The outcomes of the model benefit every stakeholder. It helps national policymakers to make better decisions about participating in ICST research. The researchers have a better understanding of the entire international scientific collaboration system and can find more research opportunities to fit in. Project analysts have a better systematic evaluation system for international collaboration in science and technology.

\subsubsection{Research Methodology}

This research comprises a 12-step approach using a hierarchical decision model (HDM) and quantified expert judgments. The methodology is briefly described below.

The model is an HDM, which is illustrated in its general form (M-O-G-S-A) in Figure 1. 


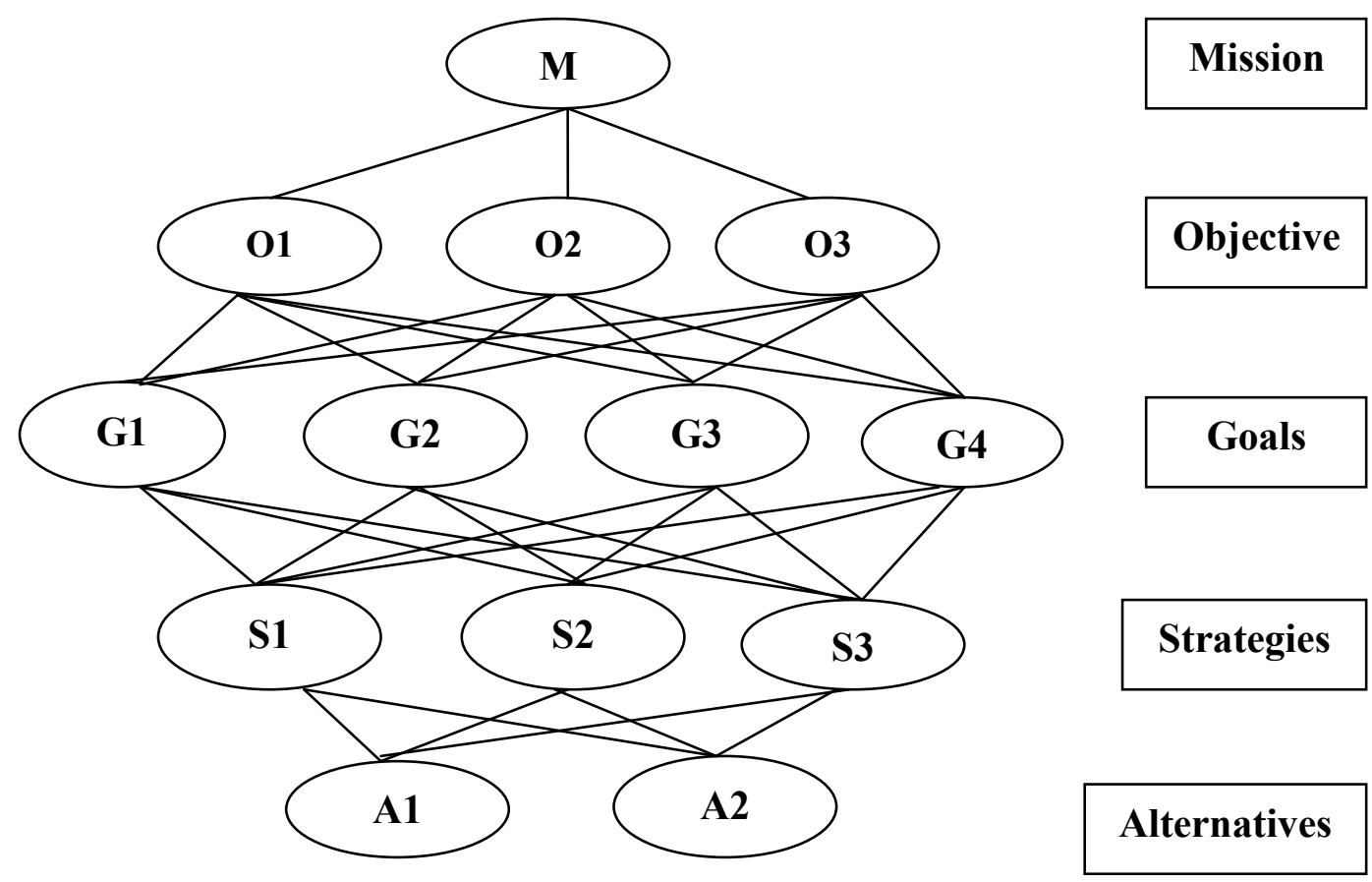

Figure 1: General Form of the Hierarchical Decision Model (HDM)

Level 1: Mission is what the decision maker wants to accomplish

Level 2: Objectives are the elements that contain different achievements in order to satisfy the mission.

Level 3: Goals are targets to reach in order to fulfill the objectives.

Level 4: Strategies present the pathways to follow in order to meet the goals.

Level 5: Alternatives are the available choices or solutions. 
An HDM is a structured technique to decompose and analyze a complex decision system into hierarchies that are more easily comprehended. The basic HDM was developed by Dundar F. Kocaoglu[1]and has been expanded and applied to various applications. The fundamental concepts of the HDM approach are similar to AHP(Analytical Hierarchy Process)developed by Thomas L. Saaty [2]. Both HDM and AHP are composed of three steps: decomposition, comparative judgments, and synthesis of priorities. However, the HDM uses the constant-sum method, whereas the AHP uses the eigenvectors method for judgment quantification.

HDM helps the decision maker to make a better decision by gathering judgments from expert panels such as the relative priority of objectives, the relative contribution of technological goals, and the relative contribution of the research strategies. There are various applications of this HDM model, for example, to help policymakers develop the policy planning for emerging technologies [3] or to help build a technology roadmap [4].

In this research, the constant-sum measurement was used because of its greater flexibility. A five-level strategic policy model in international collaboration in science and technology was developed. A brief description of each level is given below:

- $\quad$ The $1^{\text {st }}$ level defines the international vision for S\&T development.

- $\quad$ The $2^{\text {nd }}$ level defines the international S\&T objectives to fulfill the vision. 
- The $3^{\text {rd }}$ level lists all of the organizational R\&D strategies serving each international S\&T objective.

- The $4^{\text {th }}$ level comprises three main elements which are evaluation criteria, evaluation sub-criteria, and desirability curves of sub-criteria.

- The $5^{\text {th }}$ level is the list of all international collaboration in science and technology proposals obtained through any channel of the bottom-up approach, e.g., socialnetworking forum or open access from researchers.

Expert judgments were quantified in order to determine the relative importance of an element at a level with respect to the elements at the next higher level. Expert panels were formed for this purpose. Details of the decision-making model and the expert panels are given in Chapter Four.

\subsubsection{Research Outcome}

The outcome of this research is the prioritization of the ICST proposals, which serves the nation's vision and meets the researcher's needs through the linkage between top-down and bottom-up approaches. The results of the model help in shaping the plan for the development of S\&T priority setting in ICST projects in order to strengthen the research efforts and improve the international S\&T capability. 
To demonstrate and validate this model, data from the National Science and Technology Development Agency (NSTDA) of the Ministry of Science and Technology in Thailand, were used in a case study. The ICST proposals were obtained through the bottom-up approach via interviews with NSTDA researchers. The Science and Technology's Vision and Mission from Thailand's National Science and Technology Strategic Plan (2004-2013) were used as the input for the top-down approach through the judgments of NSTDA's executives.

\subsection{Outline of Dissertation Report}

Chapter One presents the introduction and outline of the dissertation.

Chapter Two presents the literature review of the three research areas - ICST, the top-down and bottom-up approaches, and the comparative study between top-down and bottom-up approaches_-followed by a discussion of the research gaps.

Chapter Three focuses on the research by articulating the research objective, research methodology, research framework, research approach, result validation and linking the model to a specific Case.

Chapter Four describes the step-by-step demonstration of a Strategic Policy Model in International Collaboration in Science and Technology with a case study from Thailand. 
Chapter Five presents the results of the model at each level, from the first level to the fifth level. The summary of the case study is also presented.

Chapter Six discusses the contributions, limitations and challenges, and future research. 


\section{Chapter 2: Literature Review}

\subsection{Introduction}

International collaboration in science and technology (ICST) has long been seen as a significant issue. The idea of international scientific collaboration may have originated with President Dwight D. Eisenhower's speech “Atoms for Peace” in 1953 [5]. Eisenhower presented the necessity of repurposing the nuclear weapons technology to peaceful ends. This speech called for the end of nuclear weapons for military purposes and inspired the creation of the International Atomic Energy Agency (IAEA) in 1957. IAEA brings the research institutes from developing and developed countries together to collaborate on topics of mutual interest in order to accelerate and enlarge the contribution of atomic energy to peace.

A literature review of academic journal articles, country reports, etc. about ICST was conducted to address the following questions: What is International Collaboration in Science and Technology? What are the types of International Collaboration in Science and Technology? What are the significant approaches to International Collaboration in Science and Technology? 


\subsection{International Collaboration in Science and Technology (ICST)}

\subsubsection{What Is International Collaboration in Science and Technology?}

ICST can be defined as "the sharing of science and technology knowledge between people from both public and private sectors from two or more different nations within the context of mutually acceptable conventions for the exchange of knowledge "[6]. J. Sylvan Katz and Ben R. Martin from the University of Sussex, UK, gave a simple definition of international collaboration as, "The collaboration between nations while intra-national collaboration means collaboration within a single nation" [7].

Various authors such as Sonnennwald, Olson et al., and Duque et al.[8],[9],[10] proposed that international scientific collaboration is "The collaboration that happens when participants from different countries work altogether including researchers from both developed and developing countries." This definition includes international collaborations that cross international boundaries or collaborations that are located within the same cultural region or cultural heritage. Caroline Wagner also presented an interesting idea about ICST: "It is also the case with a researcher or group of researchers who have the same nationality but live in the different countries, different parts of the world, but work altogether" [11]. The most important aspect of ICST is the collaboration of the stakeholders working together to produce scientific and technological knowledge. 
ICST can happen in various forms, e.g., data source sharing, foreign laboratory site visits, exchange of researchers and students, exchange of knowledge embedded in products and services, joint research facilities and work meetings, organization of international conferences, and division of tasks in a larger and broadly defined research programs[6],[12],[13].

According to Lipsett and Holbrook [6], there are two paradigms to indicate an international collaboration: "systematic paradigm" and the "neoclassical paradigm". The systematic paradigm looks at the cooperation agreement, which can take many forms and dimensions as listed below:

- Detailed agreements: how the parties to the agreement will act or how disputes will be solved.

- Types of agreements: framework agreement, bilateral agreements (country to country, multilateral or transnational agreements).

- Parties to the agreements: government organizations or business enterprises.

The neo-classical paradigm concentrates on the investment of knowledge. It views ICST on a transaction basis. The investment in S\&T knowledge can be classified in three categories for both public and private sectors:

- Investment in the $\mathrm{R} \& \mathrm{D}$ or innovation process through the development of new products, processes and services 
- Acquisition of intangible intellectual property through the purchase of licenses or technical services, hiring knowledge consultant, etc.

- Purchase of knowledge embedded in high-technology products

Frame and Carpenter [13],in their study on international collaborative behavior among scientists, proposed three rules:

- the more basic the field, the more international the collaboration,

- the larger the national research system, the smaller the international collaboration and external factors play a major role in international collaboration.

Narin and Whitlow[14] added a fourth rule of international collaboration:

"Generally, internationally co-authored papers are cited more than single-country papers."

\subsubsection{Types of International Collaborations in Science and Technology}

Typically, the principal forms of international scientific collaboration are researcher or scientist exchange programs, fellowship programs, international technical meetings or workshops, cooperative projects, access to high tech instruments or largescale scientific facilities, sponsorship of or participation in national programs of the 
partner countries, establishment of subsidiary research units in the partner countries, and so on.

According to Luke Georghiou [15], ICST can be grouped into four types: informal cooperation, formalized cooperation, big science cooperation, and global collaborative programs.

Informal cooperation in S\&T is an interesting concept. It is most likely based on small-scale projects with very small-scale funding. It is often useful as a preliminary project to move towards a more formal collaboration project, which will eventually move far beyond the limits of the individual scientist or researcher.

Scientists and researchers like to connect, stay in touch, or network with their colleagues who have the same areas of interest, technical expertise, and specialized knowledge [16],[17]. This informal scientific collaboration via collaborative papers and academic research projects is often built on international exposure to ideas, which are generated from international workshops, conferences or seminars.

Generally, there are two types of international scientific collaboration-bilateral collaboration and multilateral collaboration - as defined by Australia's Science and Technology Priorities for Global Engagement report [18]. 


\subsubsection{Bilateral Collaboration:}

Its advantage is that it is more flexible and responsive to urgent issues than other types of collaborations. Sometimes it occurs as an exploratory project before developing into a major investment project. The bilateral relationship can take place at various levels with various partners, e.g., collaboration between funding agency and funding agency, government and government, researcher and researcher, university and university, industry and industry. It can also be initiated across the different types of partners, e.g., between university and industry or university and government. A bilateral collaboration project takes several forms as described below.

- Firstly, where a country benefits by gaining or maintaining access to worldleading S\&T.

- Secondly, when countries have inherent similarities and complementary interests.

- Thirdly, the most common type of bilateral agreement is the collaboration among individual scientists on a specific area of interest. This type of collaboration is normally a small-scale project but is often a seeding ground for larger and multipartner programs in the future.

\subsubsection{Multinational Science and Technology Collaboration:}

This type of collaboration can be further divided into two subcategories, multinational project and networking of bilateral collaboration, as follows: 


\subsection{Multinational Projects or Global Collaborative Program}

This type of collaboration is inherently multinational and has a government body, a managing structure and a member agency, e.g. Global Earth Observation Systems of Systems (GEOSS), International Thermonuclear Experiment Reactor (ITER), SentinelAsia, Human Frontier Science, Intelligence Manufacturing System, and CERN.

\subsection{Networking of Bilateral Collaboration}

This type of collaboration is more flexible, Japan's Model [19]. It takes advantage of existing bilateral collaborations by networking them to increase effectiveness. For example, the international collaboration projects in infectious disease control between Japan and Thailand are networking with another international project between Japan and Zambia. It is the Network by regions e.g. Asia; or the network by issues, e.g. HIV.

There is another classification of the types of ICST, especially for International R\&D, presented by Von Zedtwitz [20]. He identified the types of international R\&D by looking at the private company or multinational company (MNC) relationship between the host countries and the home countries as shown in Figure 2. 


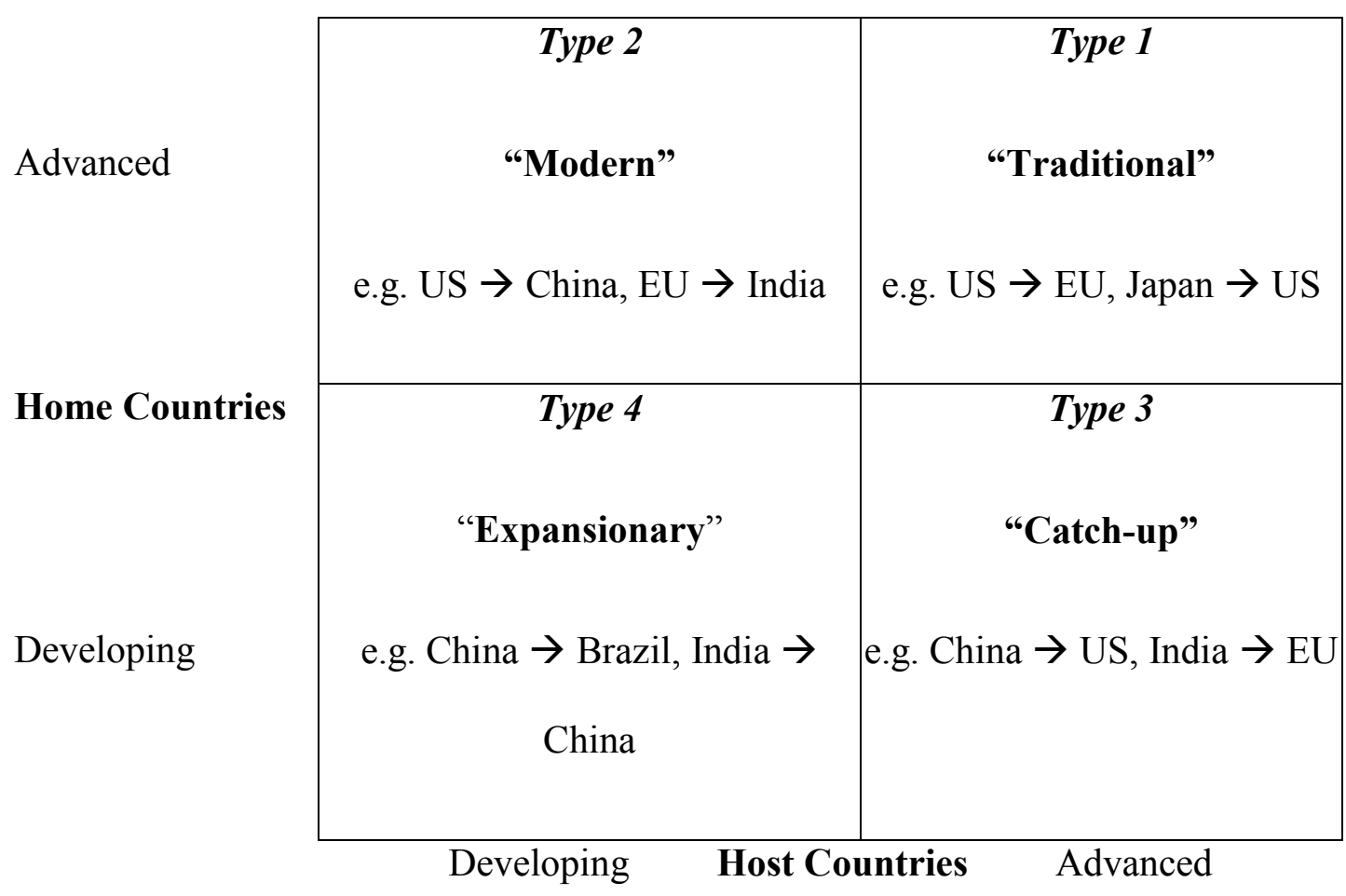

Figure 2: Types of International R\&D

Figure 2 shows four types of international R\&D collaborations. Type 1 is collaboration between or among developed countries, currently the primary source of international $R \& D$ collaboration. Type 2 is companies from developed countries which set up R\&D collaboration units in developing countries. Type 3 is companies from developing countries establishing their R\&D collaboration centers in advanced countries in order to catch up with the developing countries. Type 4 is the international $R \& D$ collaboration which happens between or among developing countries.

These types of ICST differ from each other in at least one of three dimensions: i) the nature of stake holders or partners, ii) specificity of scientific and technological area of interest, and iii) the scale of funding. 


\subsubsection{ICST Approaches}

The type of ICST may vary because the collaboration may serve various objectives, including personnel research, basic research, applied research, large science projects, problem solving of global issues, diplomatic engagement, government mission, national or multi-national efforts.

There are two classical approaches for developing international scientific collaboration projects: top-down and bottom-up.

\subsubsection{Top-down Approach}

The top-down approach, or "need to do" type of project, of ICST can occur in two kinds of projects:mission-oriented research and policy-oriented research[11].

Mission-oriented research is the set of S\&T acitivities which are defined by anorganization or agency offical. Mission-oriented projectsare usually applied research or development that will advance an agency's knowledge or organization's needs to carry out itsmission.

Policy-oriented research is the set of S\&T activities which are defined by the country's government agency, e.g., Ministry of Science and Technology or Ministry of Health. This collaboration serves at national and international levels,e.g., projects involving multiple countries that collaborate at the global level to solve large-scale multination problems such as global warming. 


\section{- Advantages of the top-down approach}

It is a mission or policy-driven project, so the funding is waiting to be allocated. It focuses on national or global challenges.

\section{- Disadvantages of the top-down approach}

It starts from the perspective of decision makers, and thus it is likely to ignore other actors, e.g., ideas from the private sector or local needs. And the difference between policy formulation and policy implementation might be misleading or useless [21].

\subsubsection{Bottom-up Approach}

The bottom-up approach, or "want to do"type of project, is the curiosity-driven project. It is the group of S\&T activities, e.g. research project, collaborativeworkshop, or visiting scholar,initiated and conducted by scientists or researchers. They normally begin their cooperation through personal channels such as international conferences or workshops or as experts in the same techical field.This approachhas the potential to address scientific issues related to short-term targets.

Yezril etal.define two sub-groups of this bottom-up project:"resource dependent" and "participatory." The resource-dependent project happens when researchers or scientists are self-organized into collaborative teams that work together to share or 
access rare or localized resources [22]. Examples arethe botanists who study plants in a rainforest or geologists who study lava rock formationsin Hawaii.

The other type of bottom-up project is "participatory," which happens when scientists or researchers self-select their partners independently based on mutually beneficialfactors such as access to high-techlaboratories or research equipment, or a common interest in the same funding institutions, normally because each partner has new ideas or complimentary capabilities, e.g., research in mathematics or economics areas. These collaborations also happen when scientists or researchers from the same nationality but living in different parts of the world collaborate.

\section{- Advantages of the bottom-up approach}

This bottom-up approach is fast and dynamicbecause it is built on the partners' needs and interests. It requires the same area of interest or something in common which the partners share in order to achieve greater results. Examples include knowledge, methodologies, project costs and expensive physical resources.

\section{- Disadvantages of the bottom-up approach}

Based on Dodgson and Hagedoorn's studies about technology partnering in technological collaborations, there are some important issues that should be taken into account,e.g.,learning and working process mechanisms, trust between partners, and how to choose the appropriate partner [23],[24], [25]. 


\subsubsection{Stages of International Collaboration in Science and Technology}

Examining the stages of scientific collaboration provides an understanding of the complexity of international scientific collaboration. Donald Beaver [26] presented some interesting ideas about how collaborations begin as follows.

- By chance, at a colloquium or lecture, or at a conference, because of a presentation, or because of working sessions, or while on leave at another institution in order to learn new skills or catch up with the field.

- By intention, by letter or phone call of solicitation.

- By recommendation or referral by trusted colleagues.

- Because it's a part of one's job - to mentor, to educate.

Diane H. Sonnenwald[8] proposed that there are four stages of scientific collaboration - foundation, formulation, sustainment and conclusion—as illustrated in Figure 3. Sonnenwald created these stages based on the work of authors such as Kraut, Gallagher and Egido[27].

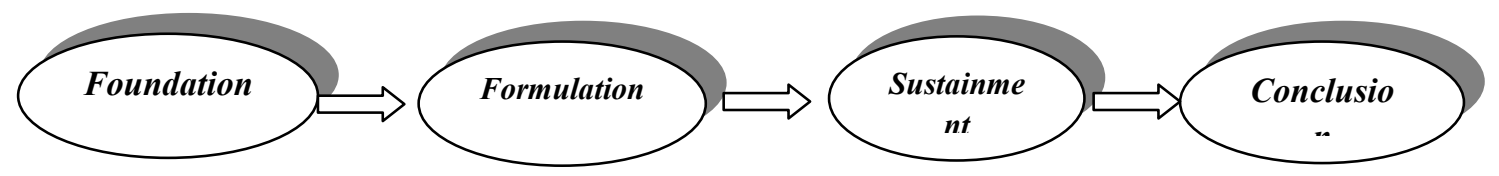

Figure 3: Stages of Scientific Collaboration 
The Foundation Stage focuses on factors that allow the foundation to form collaborations, e.g., scientific factors, political factors, socio-economic factors, resource accessibility, social networks and personal factors. It can also be termed the "identification phase." The strengths, weaknesses, threats and opportunities of the potential partners need to be identified during this stage [28].

The Formation Stage is where scientists or researchers initiate and set the plan for their collaborative projects. To have a successful scientific collaboration project, some significant factors need to be taken into account, e.g., research vision, goal, and tasks setting; leadership and organization structure (bureaucratic, leaderless, non-specialized, and participatory [29]); information and communication technology; and intellectual property and other legal issues.

The Sustainment Stage occurs after the collaboration is formulated. In order to achieve the goal, collaborative projects need to be sustained until the results come out. Emergent challenges, learning and trust, and communication are the fundamental components of collaboration in this stage.

The Conclusion Stage is where the results of the collaboration are determined. The creation of new scientific knowledge needs to be defined and disseminated via presentations and publications.

The related factors that impact scientific collaboration in each stage are summarized in Table 1. 
Table 1: Factors that Impact Each Stage of Scientific Collaboration [24]

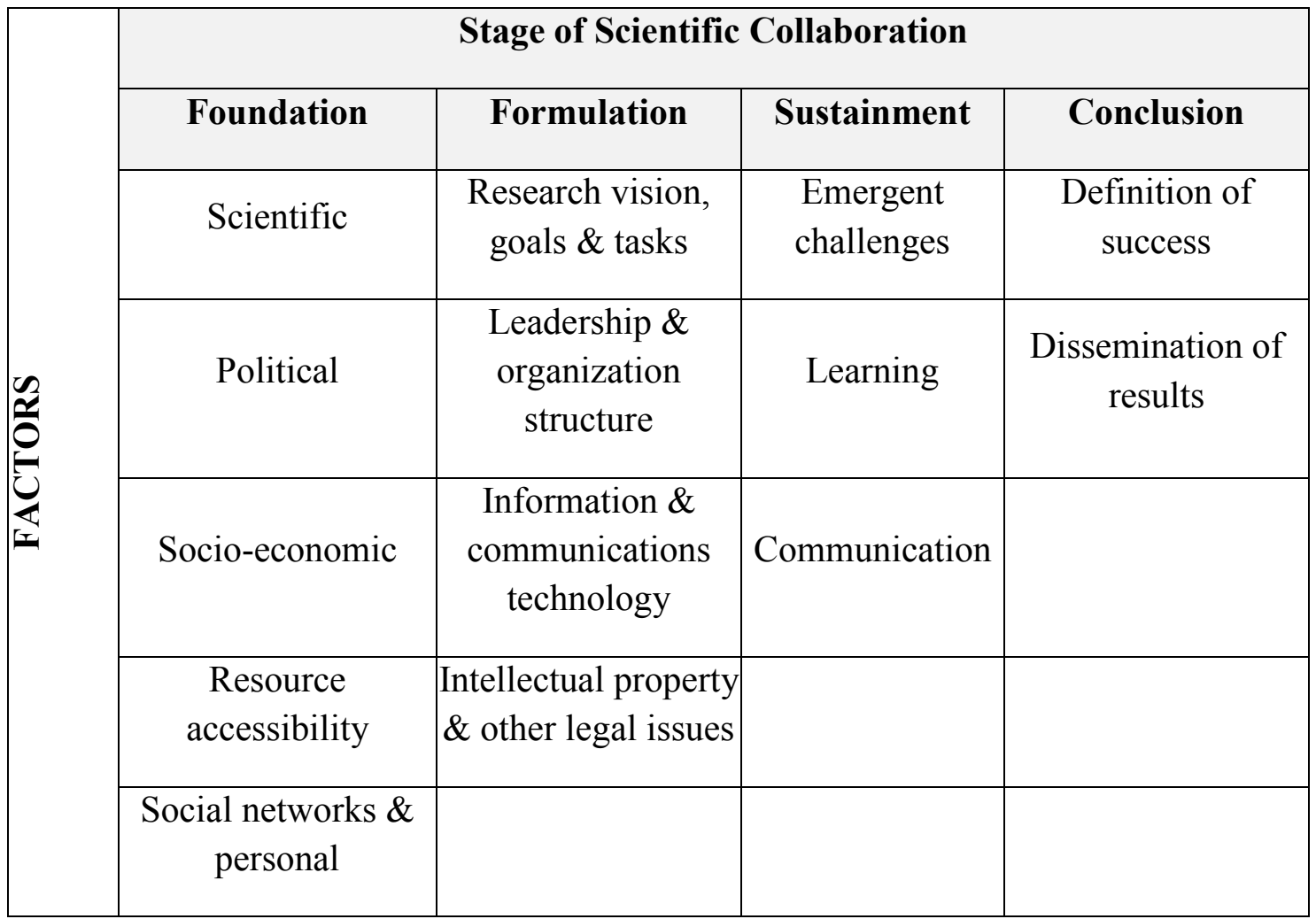

Scientific collaboration is a dynamic process, and this fact should not be ignored. Many changes might occur during each stage. Policymakers or stakeholders involved in a collaboration project should be prepared for new challenging factors that might happen throughout the collaboration process, e.g., new partners or emerging research questions.

\subsubsection{Drivers and Barriers of International Collaboration in Science and Technology}

In this fast-changing global environment, there are various reasons for scientists or researchers to work together. In general, the objectives of ICST are multifarious 
aspects. They are driven by various factors, e.g., scientific or economic factors, and other interests.

According to the European Research Area (ERA) report [30] for the European countries, their participation in ICST can be grouped into four predominant reasons as follows:

- Economic competitiveness

- Responding to global challenges

- Meeting the demographic and educational challenge of human resources

- Promoting political cooperation, dialogue and trust

Different countries have different rationales for their participation in ICST[31]. Also, indifferent technology areas, researchers or scientists have different rationales to collaborate in different ways as well. Nanotechnology, information and communication technology (ICT), life sciences, and energy and environment are the four dominant technologies that play significant roles in contributing to the European countries' competitiveness [30].

Ireland's International Engagement in Science, Technology and Innovation report [32]identified the key drivers and benefits of the country's participation in international scientific collaboration along seven dimensions, which are listed below. 
- Tackling global scientific and societal challenges

- Building critical mass and sharing risk

- Stimulating excellence through international competition

- Sharing expensive and specialist research infrastructure

- Enabling the international mobility of researchers

- Achieving reputational and other strategic benefits

- Providing access to new technology pathways and standards

Caroline S. Wagner [11] has identified five major reasons for which scientists take part in international collaborations:

- They can increase scientists' visibility among peers and exploit complementary capabilities.

- The costs of projects that are large in scale or scope can be shared.

- Expensive physical resources can be shared.

- Better results can be achieved by sharing their data.

- The exchange of ideas encourages greater creativity.

The rationales to participate in any ICST are also different for the actors at the different levels. The motivations for researchers are most likely based on funding and knowledge, the opportunity to work with highly skilled professional or researchers, and access to distant research infrastructures. For the institution itself, the reasons for 
international collaborations are access to the scientific and technological pool of experts and access to global resources and markets for cost reduction, risk sharing or alliance creation [28].

Globalization has affected all stakeholders. Not only public organizations, but also the private sector and multinational companies (MNC) collaborate with each other. Strategic technology partnering with international inter-firm alliances or international $R \& D$ alliances appears to be a significant issue nowadays. Past research reveals the motives for strategic inter-firm technology cooperation [24],[33],[34],[35].

- Motives related to basic and applied research and other innovative activities

- Motives related to concrete innovation processes

- Motives related to market access and search for opportunities

ICST has a number of benefits that motivate various groups of people to participate. However, along the process, there might be some barriers or obstacles as well. Following are some significant barriers, drawbacks, or obstacles that were presented in Luke Georghiou's research [15], OECD [36] and CREST Working Group reports [37].

- Intellectual Property Rights (IPR): insecure IPR regimes, missing standards of IPR management, etc.

- Partnerships: technological capabilities of each partner, trust issues, cooperation or competition, etc. 
- Legal Frameworks: Incompatible legal frameworks for joint institutions and infrastructures.

- Infrastructure and Expertise: non-existing or insufficient local S\&T infrastructure, lack of highly skilled professionals (e.g., because of brain drain).

- Visa Requirements: Visa difficulties preventing international research collaboration.

- Cultural Differences: Challenging cultural issues might arise from national or regional collaborations.

More challenges may be added to the lists of drivers and barriers of ICST at the project management level, e.g., distance between home and host countries, a common language and economic integration between two countries and joint membership, and cultural differences[38].

\subsubsection{Growth of International Collaboration in Science and Technology}

The significance of S\&T in the global context has been increasing dramatically in the past decade [39]. Governments are increasingly working with other government and non-governmental organizations to foster ICST to overcome various issues. 
The growth of ICST is happening in every area of scientific interest. There are various supporting factors such as the advancement of ICT and the ease of travel (lower cost and easier travelling than in the past).There is much evidence that ICST has grown noticeably over the past 20 years. According to the NSF publication Science and Engineering Indicators2010[40], international research collaboration has been expanding as can be seen from Figure 4 and Table 2 .

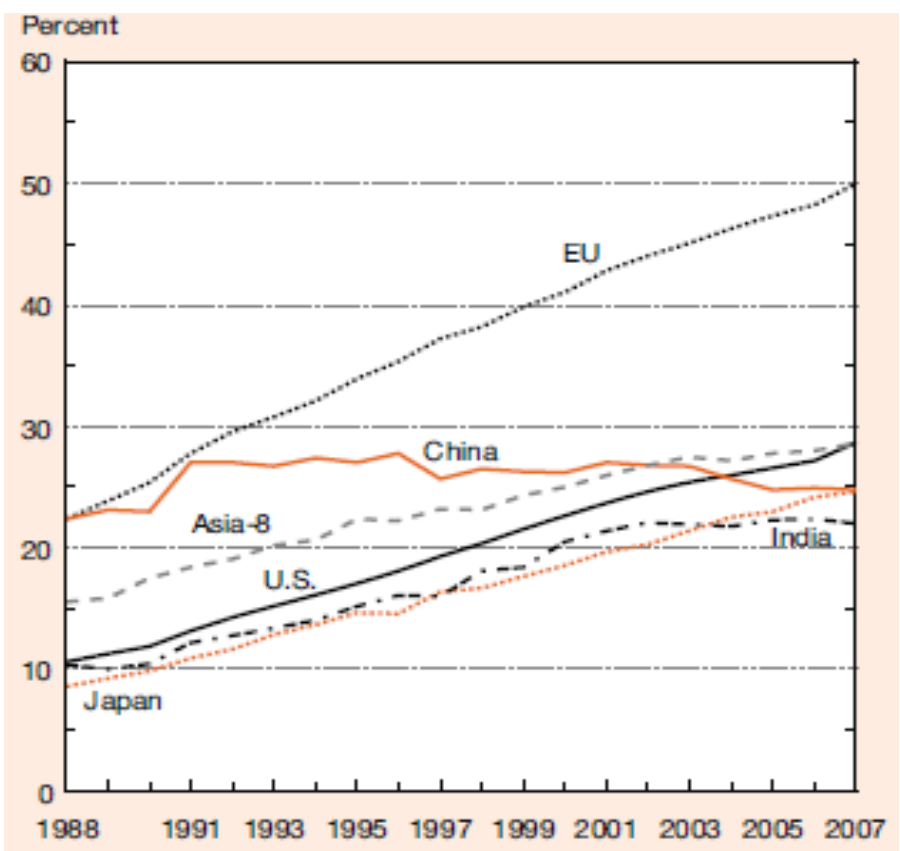

Figure 4: International Co-authorship of S\&E Articles, by Region/Country 
Table 2: International Co-authorship of Science and Engineering Articles

International coauthorship of S\&E articles, by region/country: 1988-2007 (Percent)

\begin{tabular}{lrrrrrr}
\hline Year & U.S. & EU & Japan & China & India & Asia-8 \\
\hline 1988 & 10.6 & 22.4 & 8.6 & 22.4 & 10.4 & 15.6 \\
1989 & 11.3 & 23.9 & 9.3 & 23.1 & 10.0 & 15.9 \\
1990 & 11.9 & 25.4 & 9.9 & 23.0 & 10.5 & 17.5 \\
1991 & 13.2 & 27.8 & 10.9 & 27.0 & 12.2 & 18.4 \\
1992 & 14.3 & 29.6 & 11.7 & 27.0 & 12.8 & 19.1 \\
1993 & 15.2 & 30.8 & 12.9 & 26.7 & 13.4 & 20.2 \\
1994 & 16.2 & 32.1 & 13.7 & 27.4 & 14.1 & 20.7 \\
1995 & 17.1 & 33.9 & 14.7 & 27.0 & 15.2 & 22.4 \\
1996 & 18.1 & 35.3 & 14.6 & 27.8 & 16.1 & 22.2 \\
1997 & 19.3 & 37.2 & 16.4 & 25.7 & 16.0 & 23.2 \\
1998 & 20.4 & 38.2 & 16.7 & 26.5 & 18.1 & 23.1 \\
1999 & 21.6 & 39.8 & 17.7 & 26.3 & 18.4 & 24.3 \\
2000 & 22.6 & 41.0 & 18.6 & 26.2 & 20.5 & 25.0 \\
2001 & 23.7 & 42.8 & 19.7 & 27.0 & 21.4 & 26.0 \\
2002 & 24.6 & 44.0 & 20.3 & 26.8 & 22.1 & 26.8 \\
2003 & 25.4 & 45.1 & 21.4 & 26.7 & 21.9 & 27.5 \\
2004 & 26.0 & 46.3 & 22.5 & 25.7 & 21.8 & 27.2 \\
2005 & 26.6 & 47.3 & 23.0 & 24.8 & 22.3 & 27.8 \\
2006 & 27.2 & 48.2 & 24.2 & 24.9 & 22.4 & 28.0 \\
2007 & 28.7 & 49.9 & 24.6 & 24.8 & 22.0 & 28.6 \\
\hline
\end{tabular}

Not only the information from publications, but also the information from patent data has shown the significant trends of international S\&T collaboration projects. According to the previous research from the 2008 OECD Compendium of Patent Statistics report [42], the share of patents with foreign co-inventors during 2003-2005 demonstrates that the world share of patents involving international co-inventions increased from 5.8\% in the mid-1990s to more than 7\% in 2003-05 as shown in Figure 5. 


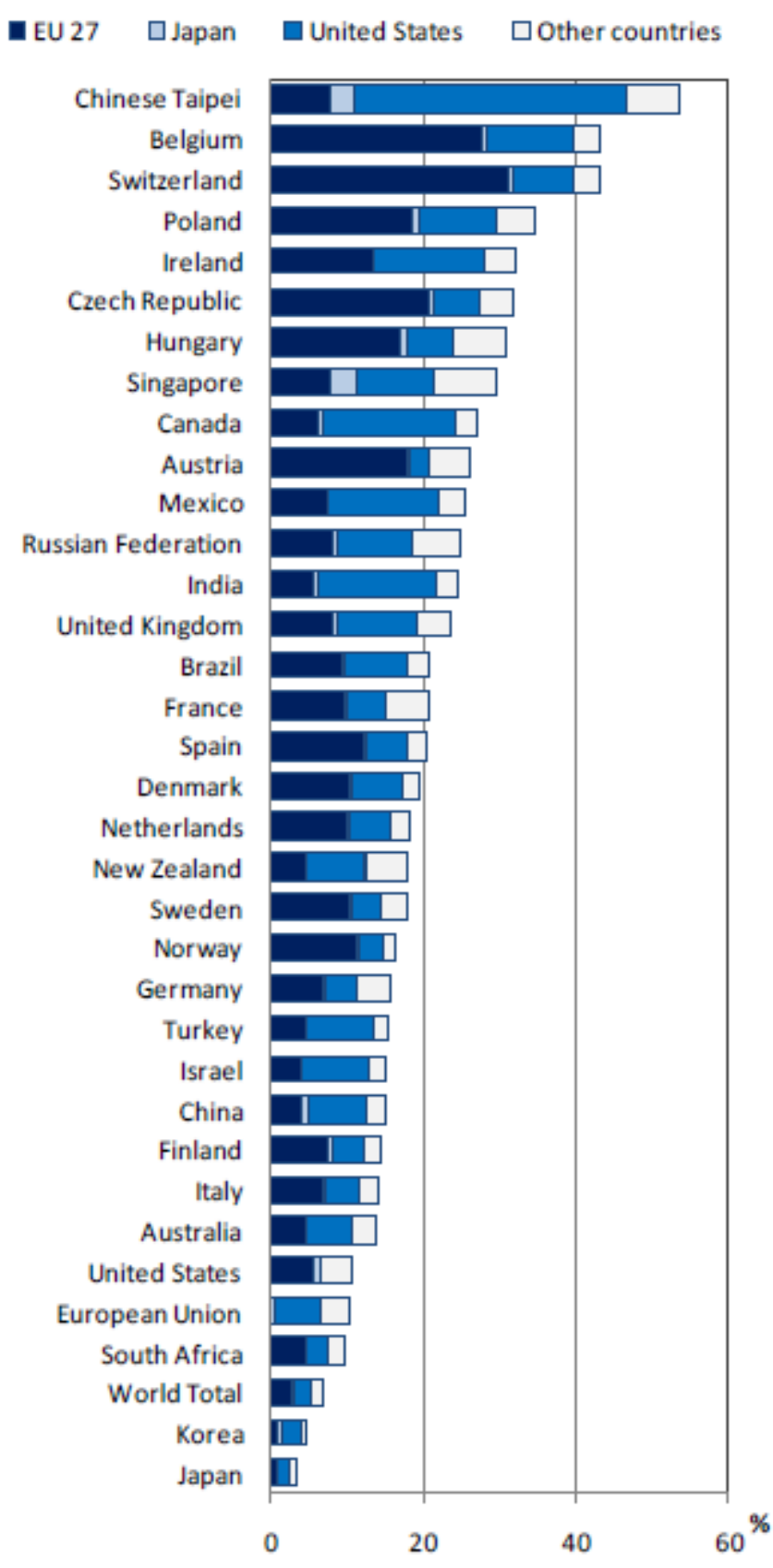

Figure 5: Share of Patents with Foreign Co-inventors during 2003-2005

A number of studies attempt to explain the growth of ICST by examining several fields of interest, e.g., bibliometrics analysis, patent analysis and mapping [43], [44],[45], 
[46],[47], [48], [49],[41]. Suttmeier [50] proposed that there are four traditional theoretical approaches to explain the growth of ICST: center-periphery thesis, S\&T for development thesis, specialization thesis, and extra scientific factors thesis.

Wagner and Leydesdorff [17] proposed that they can be grouped into two categories: "internal to science" or "external to science." Various studies have examined these concepts: center-periphery theory or lagging countries seeking to cooperate with leading countries [51],[52], [53];internal disciplinary differentiation of science [54];fieldspecific characteristics of mega science [55]; professionalization of scientific institutes [56]; growth of information and communications technologies [57], etc.

Wagner and Leydesdorff argued that the various approaches from the previous studies have been used to analyze the ICST, but none of them can really explain the rapid growth of this collaboration. By using the network theory analysis, they proposed that international collaboration is a self-organizing network based on rules of special attachment with social constraints. The growth of international collaboration may be due to the self-interest of an individual scientist rather than other factors, e.g., institutional or policy-driven factors, and this network of international collaboration is very dynamic and quickly changing. 
Success in ICST depends on various factors, and different players have different perspectives.

- Governments participate in collaborative projects in order to meet their country's goals and objectives.

- Scientists and researchers establish their contacts through their personal channels or scientific networks in order to pursue their own academic interests, regardless of the national S\&T policy.

There are two significant approaches in S\&T policy making: top-down and bottom-up, which will be described in more detail in the next section.

\subsection{Top-down approach: Technology Policy Planning}

\subsubsection{What is policy?}

There are various definitions of policy by various scholars as listed below.

- Friedrich (1963) proposed a course of action within a given environment providing obstacles or opportunities that the policy is proposed to utilise or overcome in an effort to reach a goal or objective[58].

- Rose (1969) presented the long series of more or less related activities and their consequences [59]. 
- Eyestone (1971) presented the relationship of a government to its environment [60].

- Thomas R. Dye (1972) presented about what governments do or don't do [61].

- William Jenkins (1978) proposed that a policy is "a set of interrelated decisions taken by a political actor or group of actors concerning the selection of goals and the means of achieving them within a specified situation where those decisions should, in principle, be within the power of those actors to achieve" [62].

- Anderson (1984) presented the purposeful course of action in dealing with a problem or matter of concern.

- Thomas A. Birkland (2005) mentioned that policy is a statement by a government of what it intends to do or not do, such as a law, regulation, ruling, decision, or order, or a combination of these [63].

In conclusion, a policy is a deliberate plan of action that guides decisions in order to achieve a rational outcome (s). The term may apply to governments, private sector organizations and groups, and individuals. Policies can be understood as political, management, financial, and administrative mechanisms arranged to reach explicit goals. 


\subsubsection{What Is Science and Technology Policy?}

Science and technology policy can be defined as:

- Government plans, programs and initiatives in support of S\&T;

- Making optimal decisions with regard to the allocation and mobilization of resources devoted to $\mathrm{S} \& \mathrm{~T}$

- S\&T policy research is the research to understand how we decide on what S\&T is to be prioritized and funded.

Table 3: Phases of Science and Technology Policy Development

\begin{tabular}{|c|c|}
\hline Period & Paradigm (Advance Countries) \\
\hline Post WW II & "Science push" and "public mission" \\
\hline 1960s -1970s & $\begin{array}{c}\text { "Large scale technology projects" } \\
\text { "Prestige project" }\end{array}$ \\
\hline 1980s - early 1990s & $\begin{array}{c}\text { "Critical" and "strategic" technologies } \\
\text { "Science as productive factor" }\end{array}$ \\
\hline Late 1990s & $\begin{array}{c}\text { "Systematic approaches" and "functional" } \\
\text { "Science as source of wealth creation" and } \\
\text { "Innovation" }\end{array}$ \\
\hline
\end{tabular}

From Table 3, Science and Technology is moving from the old model, in which governments drive economics through policy decisions and incentives, to the new model, in which economic development is a collaborative process at multiple levels involving governments, companies, teaching and research institutions, and private sector organizations. The world's technological development landscape is also moving from 
S\&T to science, technology and innovation (STI) because of globalization and the quest for economic advancement [64].

Additionally, knowledge production in research and technology has changed from "Mode 1" to "Mode 2" [65]. In Mode 1, problems are set and solved by the largely academic interests of a specific community; while in Mode 2, knowledge is carried out in the context of application. Mode 1 is disciplinary, while Mode 2 is trans-disciplinary. "Mode 3"is a multilateral, multilevel systems approach to knowledge creation [66].

As a consequence, the economic landscape has changed from the "labor-intensive era" to a "knowledge-based society" to the "information era" and then to the "creative economy era" [67].

Success in science and technology is not by chance but by design. S\&T policy is a part of the entire public policy scheme, the policymaking system [69]. The S\&T policymaking process is built around the understanding of the policy circle. There are various discussions about the stages of policy-making activities. The typical stages of the policymaking circle are described blow [70].

- Policy Analysis: Clarify policy issue and define policy problem and objectives

- Policy Formulation: Create policy alternatives; consult with stakeholders

- Policy Adoption: Obtain policy approval and prepare policy document

- Policy Implementation: The policy mandate is aimed at public programs and the federal bureaucracy, often with citizen, state, and local government cooperation 
- Policy Analysis and Evaluation: Examining the consequences of policy actions to obtain feedback

There are various definitions of the top-down and bottom-up approaches used in science and technology policy. Most of the definitions are based on engineering economic modeling and the material fabrication process [73] - [78].

This research concentrates only on the science and technology policy aspect.

The top-down approach starts with a policy decision by government (often central government) officials. The top-down project is a "mission-oriented project" or a "need to do" project. For the top-down approach, policy is imposed from the top level or center unit with no thought given to involvement of those at the bottom or local level. The key main player is the government.

A significant number of scholars support the idea of the top-down approach for policy making.

- Jeffrey Pressman and Aaron Wildavsky: The founding fathers[77]. They presented obstacles that can occur with policy implementation. Policymakers create policy without preparing or thinking about how to implement it. 
- $\quad$ Donald Van Meter and Carl Van Horn: System building [78]. They proposed the model to points out the six elements that effect the policy implementation process which the relevance of policy standards and objectives, policy resources, interorganizational communication and enforcement activities, the characteristics of the implementing agencies, the economic, social, and political environment.

- $\quad$ Eugene Bardach: Fixing the game [79]. He presented good analysis of policy implementation.

- Brian Hogwood and Lewis Gunn: Recommendations for policymakers about policy analysis[80]

- Paul Sabatier and Daniel Mazmanian: Process modeling [81]. They studied the factors that are conditions for successful implementation. Generally, the following questions are asked to determine the factors.

- To which extent were the actions of implementing officials and target groups consistent with (the objectives and procedures outlined in) that policy direction?

- To what extent were the objectives attained over time, i.e., to what extent were the impacts consistent with the objectives?

- What were the principal factors affecting policy outputs and impacts, both those relevant to the official policy as well as other politically significant ones?

- How was the policy reformulated over time on the basis of experience? 
According to Thomas Birkland, the top-down policy making approach is based on a set of important assumptions as listed below [63].

- Policies contain clearly defined goals against which performance can be measured.

- Policies contain clearly defined policy tools for the accomplishment of goals.

- There is an "implementation chain" that "starts with a policy message at the top and sees implementation as occurring in a chain.”

Top-down policy making refers to the use of vision statements and issues of national priority articulated by the political leadership, national policy and strategy. Modern policy makers have faced growing technical complexities and uncertainties in addressing policy, thus having tools and experts significantly help the decision-making process. A number of strategic policy planning mechanisms have been tried and used to complement the top-down policy-making process in each period of time.

- Delphi, Technology Planning and Forecasting (1960s, 1970s) [82], [83], [84], [85], [86]

- Think Tanks, Technology Foresight and Technology Roadmapping (1980s, 1990s) [87], [88], [89], [90]

- Benchmarking, Epistemic (Expertised-supported consultation) [91],[92] 
An epistemic community is a network of experts in which members share technical knowledge related to a particular field, e.g., normative principle, causal beliefs, a shared conception of interests, etc.[92].For example, Korea used technology foresight as a tool to help its policymakers implement Korea's HAN Project (1992-2001), thereby using the top-down approach more effectively [93].Japan's Basic S\&T Plan $1^{\text {st }}-4^{\text {th }}$ is another example [94], [95].

\subsection{Bottom-up Approach: Individual and Networking}

In a reaction to the structured top-down approach, which starts with a policy decision and focuses on the extent to which its objectives are attained over time and why, the bottom-up approach starts by identifying the network of actors involved in the same area of expertise, who may or may not be in the same geographical area [11]. The key main player is an individual such as a researcher or scientist. Researchers view the implementation from their perspective and not from the top point of view, which Michael Lipsky refers to as "street level bureaucrats"[96].

This approach is driven by personal contacts or common interests as vehicles for developing a network of interests through various activities, e.g., a collaborative workshop, international conference, collaboration project, visiting program, etc. Researchers also self-organize spontaneously into collaborative teams from the bottom up. They may work together to share information or meet while accessing relatively rare 
or localized resources [11]. Researchers tend to form the core group and work together locally or globally [17].

Below are selected authors who support this concept.

- Michael Lipsky presented the concept of "Street-level Bureaucracy" [96]

Michael Lipsky, a professor from MIT, introduced the theory of street-level bureaucrats. As the front-line workers of an organization, these people can deal with the customer's needs and ensure that policies are properly implemented.

- Benny Hjern proposed the Implementation structures [97]

Hjern viewed activities as being within implementation structures formed within polls of organizations and formed through the processes of consensual selfselection.

- Susan Barrett and Colin Fudge: Policy and Action[98]. They viewed policy as it is dynamically. Policy is a problematic concept. Different people may make different claims.

- Richard Elmore: Backward mapping[99]. The implementation process and the relevant relationships are mapped backwards, from the ultimate implementer to the topmost policy designers. 
Nowadays, because of globalization and the advancement of ICT, people are getting closer and closer. There are numerous channels for people to communicate with each other. It is an open society with open access and open innovation [100]. It is also an era of user-led innovation [101] in which bottom-up innovation has played a significant role in the current economy.

\subsubsection{How Research Opportunities are Identified through the Bottom-up approach}

Scientific collaboration is a social process and, like all social process, it is governed by the complexity of human interaction. Through the bottom-up approach, researchers identify their research areas or topics by various traditional or emerging channels. Some scientific activities need to be pulled from the bottom level, from the researcher, e.g., MSI projects. Normally this bottom-up approach leads to small grants for scientists [17].

There are several methods to promote the $S \& T$ capability of a nation. $R \& D$ is one mechanism to help strengthen a country's competitiveness. Finding a suitable research topic to work on and the budget to fund the research are the significant aspects. The research opportunities are identified through various channels, which can be categorized in two different channels as described below. 


\subsubsection{The Typical Way}

There is a "scientific society" which helps to facilitate communication through channels such as scientific conferences or journals. This scientific society and scientific communication are important to the advancement of S\&T development.

According to Frederick Betz [102], in order to identify research opportunities, which include research topics and research funding, the researcher looks through academic papers from relevant journals from the previous five years, summarizes the present state of knowledge, discovers the gaps, and explores state-of-the-art research that could become a research topic. Try to choose the right problem to work on [103]. To find the research funding, there are various channels such as:

- through a funding agency such as NSF or NIH in the USA [104][105], or European Commission Research and Innovation in Europe [era], e.g., the Seventh Framework Program (FP7) [106],

- through the university research center, or

- through a private company's webpage.

Data mining tools such as bibliometrics analysis, citation analysis, and social network analysis are very useful for identifying the research topic, trends, key researchers, etc. [109] - [120]. 


\subsubsection{The Emerging Channel}

Researchers can increasingly find their own research opportunities because of globalization and the advancement of information, communication and technology (ICT); the world is getting smaller and researchers from developing countries have more opportunities to access information via the following sources.

\section{- Open Access}

According to the definition of open access from Peter Suber [119], "Open-access (OA) literature is digital, online, free of charge, and free of most copyright and licensing restrictions."

The emergence of the Internet constitutes a new and attractive channel for accessing the latest in scientific research. Open access is free access to online publications, e.g., KEMRI [120], HINARI [121], and NIH via PubMed [122].The first online-only, free-access journals (eventually to be called "open access journals") began appearing in the late 1980s. The first free scientific online archive was arXiv.org, which began in 1991.

In 1997, the U.S. National Library of Medicine (NLM) made Medline, the most comprehensive index of medical literature on the planet, freely available in the form of PubMed (http://www.ncbi.nlm.nih.gov/pubmed/). When access becomes free, the use of this database increased significantly. 
In 2001, the Public Library of Science (PLoS) [123] was established as an advocacy organization which became open access. Its publisher aims to compete at the high quality end of the scientific spectrum with commercial publishers and other open access journals (http://www.plos.org/).

There is the clear definition of open access publishing by Bethesda [124] as quoted here. "An Open Access Publication is one that meets the following two conditions:

- The author(s) and copyright holder(s) grant(s) to all users a free, irrevocable, worldwide, perpetual right of access to, and a license to copy, use, distribute, transmit and display the work publicly and to make and distribute derivative works, in any digital medium for any responsible purpose, subject to proper attribution of authorship, as well as the right to make small numbers of printed copies for their personal use.

- A complete version of the work and all supplemental materials, including a copy of the permission as stated above, in a suitable standard electronic format is deposited immediately upon initial publication in at least one online repository that is supported by an academic institution, scholarly society, government agency, or other wellestablished organization that seeks to enable open access, unrestricted distribution, interoperability, and long-term archiving (for the biomedical sciences, PubMed Central is such a repository)." 
The concept of open access is very useful to researchers around the world, especially those from developing countries. An example is the contribution of IT to the professional performance of malaria researchers in Africa [125].

Lately, many research funding agencies have been driving the change toward open-access publishing. For example, scientists or researchers who obtain NIH funding have to submit their final peer-reviewed journal manuscripts upon acceptance for publication, and these papers are accessible to the public on PuBMed Central within 12 months after publication [126].

\section{- Crowdsourcing}

Crowdsourcing is a distributed problem-solving and production model that has emerged in recent years. It provides sources of ideas or scientific knowledge through intermediaries' infrastructure [127], [128]. One of the most notable examples is InnoCentive [129].

\section{- InnoCentive}

The concept of open innovation, which is innovation beyond boundaries, is quite simple and straight forward; it is the concept behind the InnoCentive company[130]. Henry Chesbrough presents that knowledge and resources are around the world, not only within organization [100]. 
InnoCentive is a new model of business based on open innovation that moves R\&D to another dimension, the global challenge. It was launched in 2001 by the two Eli Lilly Executives, Alpheus Bingham and Aaron Schacht [131]. Bingham and Schacht have developed a new business vision, termed the "challenge driven enterprise," (CDE)and an approach that drives the CDE vision, "challenge driven innovation" (CDI). CDI is comprised of the following six aspects [132].

- More cost effective problem solving

- A greater diversity of approaches to innovation

- Better management of risk

- Not reinventing the wheel

- Accelerated innovation

- Ability to pay for results and not just efforts InnoCentive is a new channel for a "scientist solver" to meet with a "company seeker." The scientist can find a lot of challenging problems in either small or large R\&D projects. The company exchanges technical expertise from the scientist solver for a cash reward [133], [134].

\section{- Social Network in the Scientific Community}

Networking through various communication channels such as conferences or social networking sites enables scientists, engineers, and other technical professionals to connect, collaborate, and learn from each other(e.g. labroots.com)[135]. 


\subsection{A Comparative Study of top-down and bottom-up approaches}

\subsubsection{The Comparison}

Both the top-down and bottom-up approaches are important. One approach cannot fit all needs. Each approach has its own advantages and disadvantages as is shown in Table 4 below. A balance between these two approaches is necessary. However, coordinating and integrating them is difficult.

Table 4: Comparison between top-down and bottom-up approaches

\begin{tabular}{|c|c|c|}
\hline \multirow{2}{*}{ Aspects } & \multicolumn{2}{|c|}{ Approach } \\
\hline & Top-down & Bottom-up \\
\hline Key player & Government/Policymaker & Researcher/Scientist \\
\hline Initial focus & (Central) government decision & $\begin{array}{c}\text { Local implementation } \\
\text { structure (network) involved } \\
\text { in a policy area }\end{array}$ \\
\hline Type of initiatives & A few big bets & Many small bets \\
\hline Goal & Clear objective or goal & No clear goal at first \\
\hline $\begin{array}{l}\text { Identification of major } \\
\text { actors in the process }\end{array}$ & $\begin{array}{l}\text { From top-down and from } \\
\text { government out to the target } \\
\text { group. }\end{array}$ & From bottom up \\
\hline Level of interaction & $\begin{array}{l}\text { Low emphasis on picking the } \\
\text { right target }\end{array}$ & $\begin{array}{l}\text { Highly built on } \\
\text { experimentation }\end{array}$ \\
\hline Evaluative criteria & $\begin{array}{c}\text { Focus on extent of attainment of } \\
\text { formal objectives. May look at }\end{array}$ & $\begin{array}{l}\text { Mush less clear. Basically } \\
\text { anything the analyst chooses }\end{array}$ \\
\hline
\end{tabular}




\begin{tabular}{|c|c|c|}
\hline \multirow{2}{*}{ Aspects } & \multicolumn{2}{|c|}{ Approach } \\
\hline & Top-down & Bottom-up \\
\hline & $\begin{array}{l}\text { other politically significant } \\
\text { criteria and unintended } \\
\text { consequences, but these are } \\
\text { optional. }\end{array}$ & $\begin{array}{c}\text { which is somehow relevant to } \\
\text { the policy issue or problem. } \\
\text { Certainly does not require any } \\
\text { careful analysis of official } \\
\text { government decisions. }\end{array}$ \\
\hline Expected results & Big successes & Many successes \\
\hline Output & More structural & More innovative \\
\hline Advantage & $\begin{array}{l}\text { It comes with the funding, } \\
\text { budget. }\end{array}$ & $\begin{array}{l}\text { It is fast and active because it } \\
\text { is built on the partner's needs } \\
\text { and interests. }\end{array}$ \\
\hline \multirow{4}{*}{ Disadvantage } & $\begin{array}{l}\text { The result might mislead from } \\
\text { the goal when implementing } \\
\text { because it goes through many } \\
\text { hierarchies. }\end{array}$ & $\begin{array}{l}\text { Project is driven by the } \\
\text { interest of individual or group } \\
\text { (local needs), which is } \\
\text { unlikely to link to the } \\
\text { project's mission or the } \\
\text { national needs. }\end{array}$ \\
\hline & $\begin{array}{l}\text { It starts from the perspective of } \\
\text { the decision maker, thus it is } \\
\text { likely to ignore other actors' } \\
\text { opinions, e.g., private sector or } \\
\text { local needs. }\end{array}$ & $\begin{array}{l}\text { Trust between partner, how to } \\
\text { choose the appropriate } \\
\text { partner, etc. are the issues of } \\
\text { concern. }\end{array}$ \\
\hline & The solution is limited. & $\begin{array}{l}\text { Normally, it is a small-scale } \\
\text { budget. }\end{array}$ \\
\hline & & $\begin{array}{c}\text { Lack of a focus on a particular } \\
\text { program. }\end{array}$ \\
\hline
\end{tabular}




\subsubsection{The Integration of "Top-down" and "Bottom-up" Approaches}

Various scholars have attempted to integrate the top-down and bottom-up approaches at different levels as summarized below.

\subsubsection{The Systemic Macro level}

"Glocal" or "glocalization" is an example of the integration model at the macro level. This is a concept of combining the idea of globalization with the local considerations. How to make the local needs to meet with the global objective or market can be seen from the chapter of Thomas Friedman's book titled "The World is Flat: Globalization of the Local" [136] or from JK Gibson-Graham's book Geographies of Power: Beyond Global vs. Local: Economic Politics outside the Binary Frame[137].

\subsubsection{The Structural and Organizational Meso Level}

Richard Elmore combined his idea of "backward mapping" with a "forward mapping element" [138].

Gigginet al., developed a policy implementation model that relies on sending messages between policymakers and implementers [139]. 
Frederick Betz, in his book Executive Strategy: Strategic Management and Information Technology, proposed a model that represents the big picture of the entire strategic planning process; it links top-down and bottom-up strategic thinking in large organizations as is illustrated in Figure 6 [140].

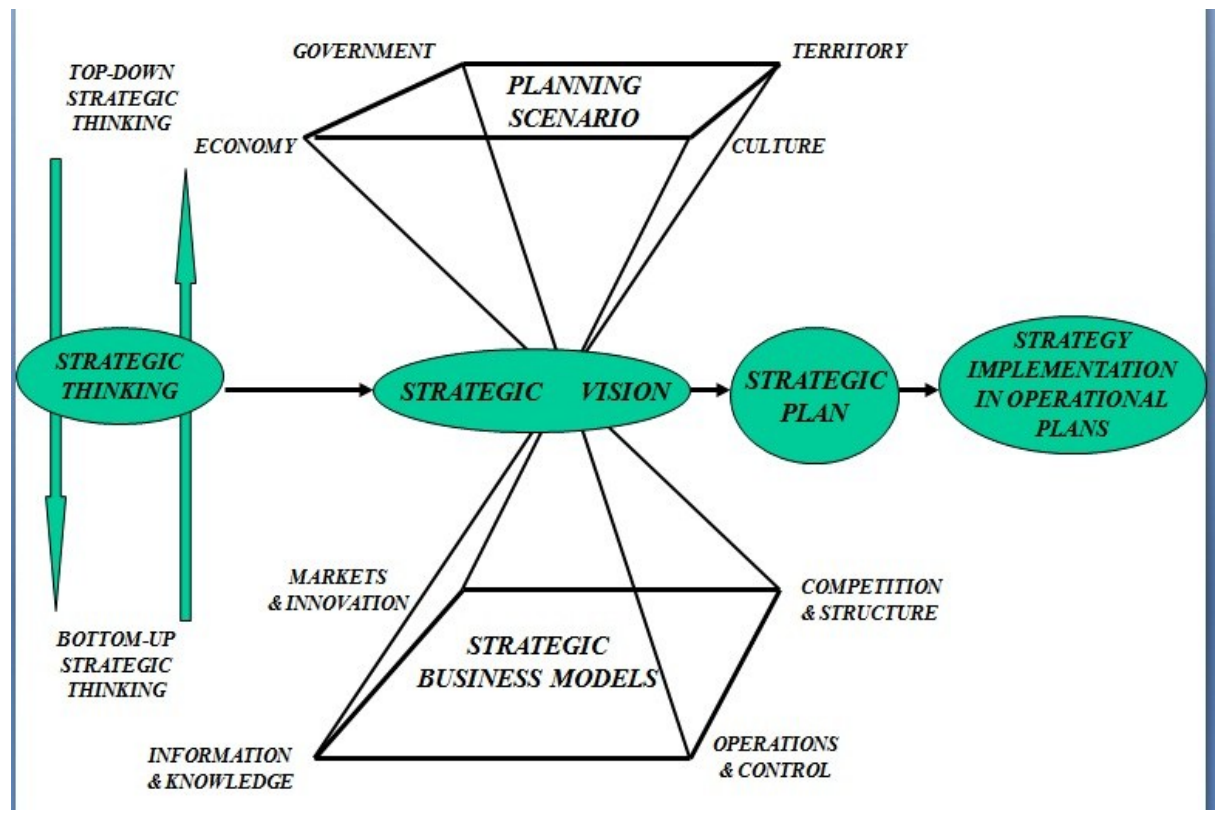

Figure 6: Strategy planning process of a large organization that combines top-down and bottomup perspectives

Paul Sabatier argued that top-down is best when there is a dominant program (e.g. law) that is well structured and where the researcher's resources are limited. In contrast, the bottom-up approach is best when one is interested in the dynamics of local implementation and where there is no dominant program. He proposed a model to integrate the top-down and bottom-up policy implementation, which he referred to as an “Advocacy Coalition Framework”(ACF)[141], [142], [143], [144](see Figure 7). 


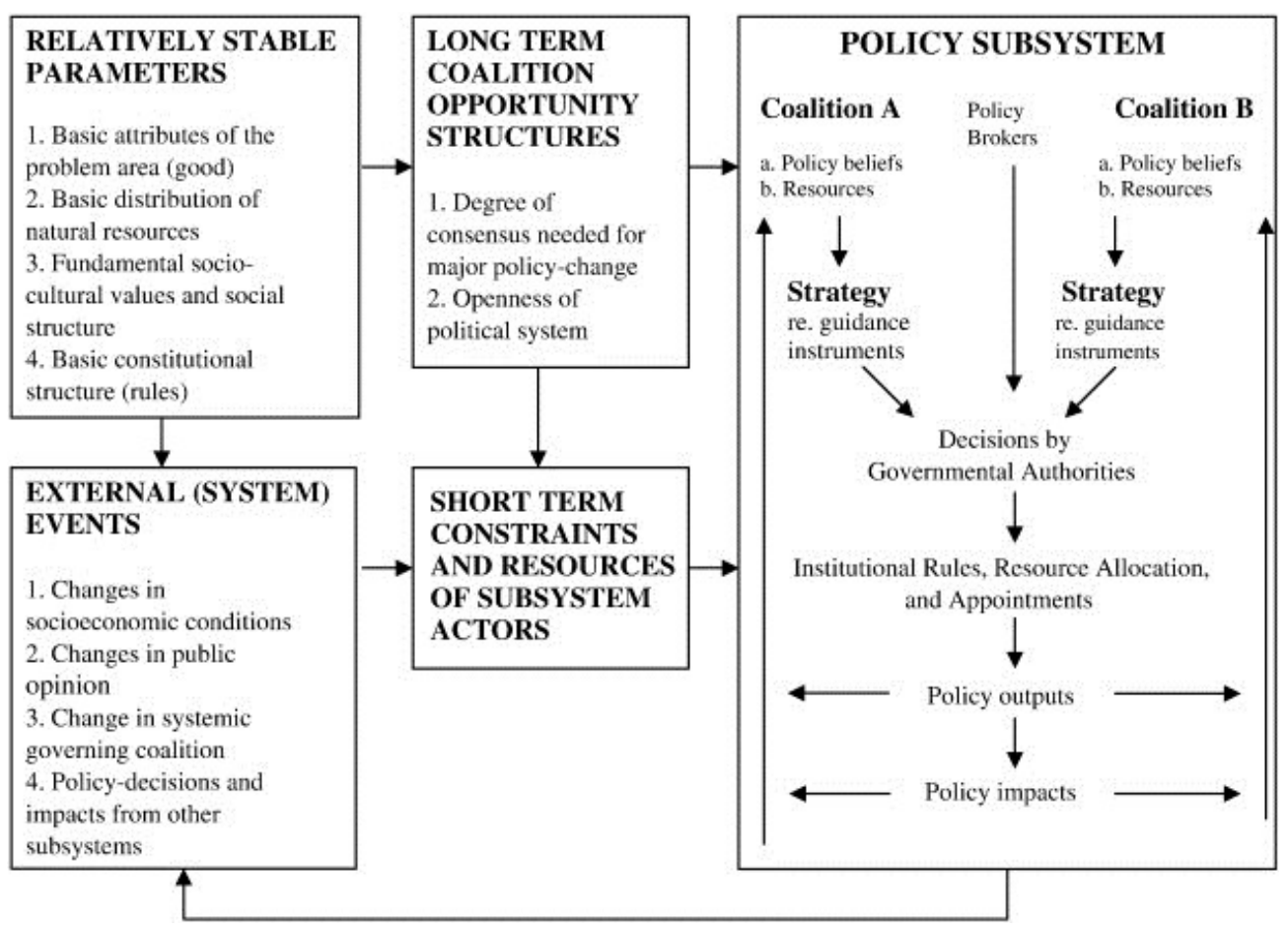

Figure 7: An Advocacy Coalition Framework (ACF) of Policy Change

According to Sabatier, the ACF model looks at "a whole variety of public and private actors involved with a policy problem as well as their concerns with understanding the perspectives and strategies of all major categories of actors." Sabatier also adopted the top-down perspective by providing a simplified model of a complex system. 


\subsubsection{The Individual Micro Level}

Numerous articles discuss the merging and integrating of these top-down and bottom-up approaches. However, they are not in the area of decision and policymaking. Some selected publications are listed as follows:

Engineering economic analysis, especially for the energy sector and global warming applications: This is a very popular area of research, e.g., Ian Sue Wing developed an integrated model to bridge the gap between bottom-up engineering and topdown macroeconomic models by integrating the former's energy technology detail into the latter's macroeconomic framework [145].

\subsection{Research Gaps and Suggestion}

\subsubsection{Research Gaps}

Gap 1: There are some social policy implementation models such as ACF or Elmore's framework that try to combine the advantages of top-down and bottom-up approaches, but there is no systematic decision-making model for national policymaker in the ICST area.

Gap 2: There is no model to integrate the top-down and bottom-up approaches and capture the opportunities provided by the newly emerging channels of the bottom-up approach, e.g., open innovation. 
Gap 3: A framework is needed to help national policymakers make better decisions about prioritizing bottom-up projects that will align with the organization's vision and mission.

\subsubsection{Suggestion}

A systematic approach is needed to create a linkage between top-down and bottom-up approaches, which will aid national policymakers in making better decisions regarding their country's participation or collaboration in ICST. The gaps in the literature can be filled by developing an HDM for systematically evaluating the ICST program/project, which is obtained through the bottom-up approach by the individual researcher. In this dissertation the researcher develops a systematic and comprehensive approach to a Policy Model in International Collaboration in Science and Technology in order to close the gaps revealed in this dissertation.

In the case of Thailand, adopting the proposed model proposed in this dissertation will significantly help the country to create a link between national policymakers and research worldwide in order to acquire the benefits of participating in the international collaboration in science and technology research. 


\section{Chapter 3: Research Methodology}

\subsection{Research Objective}

The objective of this research is to develop a strategic policy model in the area of international collaboration in science and technology to bridge the gap between top-down and bottom-up approaches.

The outcome of this model provides a linkage between national policymakers and scientists and researchers by integrating the "problem-driven" ICST project with the bottom-up approach to serve the national goals and objectives and to help national policymakers make better decisions.

\subsection{Research Methodology}

Several research methodologies are applied in this research to develop a strategic policy model for international collaboration in science and technology as follows:

\subsubsection{Hierarchical Decision Model (HDM)}

Hierarchical decision model (HDM) is a structured tool to decompose a complex decision system into a hierarchy that is easier to comprehend and analyze. 
In order to integrate the top-down approach into HDM, the top level of the model was developed by using the national S\&T vision, and then the related elements of each level were determined. The structure of the Policy Model for International Collaboration in S\&T is shown in Figure 8.

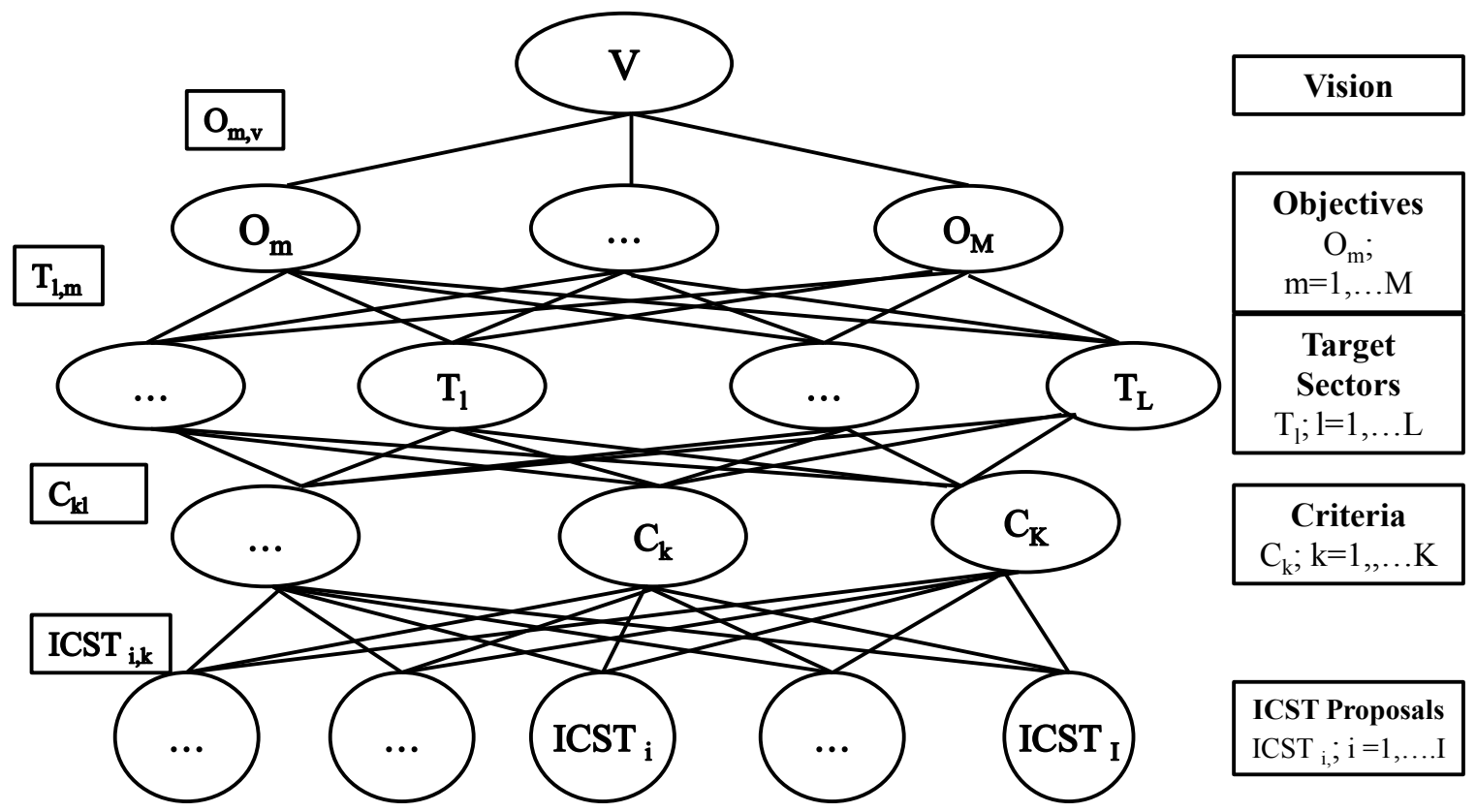

Figure 8: A Modified Hierarchical Decision Model for a Policy Model for ICST

Input from the bottom-up approach, i.e., the list of ICST proposals from researchers, were gathered and incorporated into the model at the lowest level. Research instruments were designed to gather the input data, e.g., pair-wise comparison for the relative importance of Thailand National S\&T Objectives. 


\section{Expert Panels}

An expert panel is a group of experts who have expertise in a particular area. Expert panels are formed to validate the elements in the HDM, and to quantify the relationships among the decision elements at all levels of the decision hierarchy in HDM. Each expert panel is required to have a balanced representation of opinions.

The criteria for selecting the expert panels are summarized as follows.

- The expert panel members should have in-depth knowledge in relevant areas.

- The expert panel should be well-balanced, meaning the members come from different backgrounds such as academia, industry, and government.

- The expert panel members should be selected from the ones who have no bias and gain no benefit from the study.

- Bias should be balanced.

- Dominance by loudness and silent bystanders should be avoided.

In order to address these concerns, experts were selected from different backgrounds and different segments such as industry, academia, and government. This helps to assure that the individual biases are balanced. 
In order to balance the perspectives, experts were from various levels of authority; e.g., those who makes decisions in an organization (CEO), those who manage the implementation of the decisions (project manager), and those who evaluate the proposals.

Several approaches were used to identify the experts, including 1) asking the local expert in that area of expertise and 2) using social network analysis data mining software. Expert members were invited because of their positions and their related work, e.g., the executive directors from NSTDA Research Centers, head of the Strategic Planning Division, etc.

In this research, there are three expert panels: Expert Panel I, Expert Panel II, and Expert Panel III.

- The members of Expert Panel I are the top-level executives (executive directors, executive deputy directors) from the four NSTDA Research Centers.

- The members of Expert Panel II are president, executive director, director of strategic planning division, executive assistant director, lecturers, new business development department head, president of non-profit organization, consultant, technology \& R\&D manager, etc.

- The members of Expert Panel III are NSTDA project analysts. 


\subsection{Research Framework: Conceptual Framework}

A conceptual framework of a Strategic Policy Model for International Collaboration in S\&T is illustrated in Figure 9.

The conceptual framework shows the entire model, including all stakeholders, the evaluation process and the result of the model as are briefly described as follows:

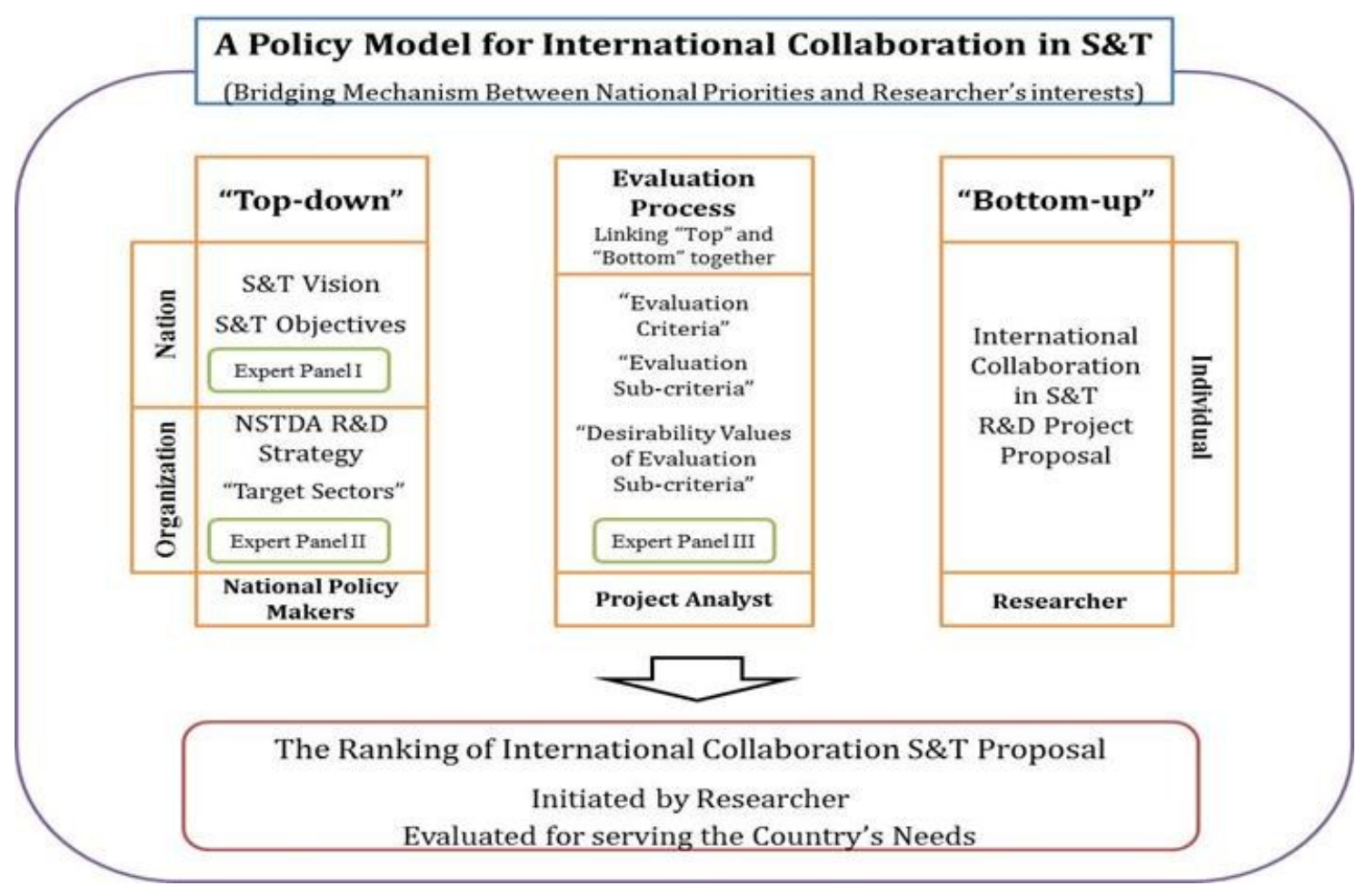

Figure 9: A Conceptual Framework of a Strategic Policy Model for ICST

- The top-down approach comprises two levels, i.e., the national level and the organization level. Expert Panels I and II are involved in these levels. 
- The bottom-up approach is the individual aspect, which is researcher.

- The evaluation process is linking the top-down and bottom-up approaches by evaluating ICST proposals to serve the country's needs.

\subsection{Research Approach: A 12-step approach}

The research objective can be achieved by this 12-step approach, which is listed in Figure 10. Each step is designed to accomplish the research objectives.

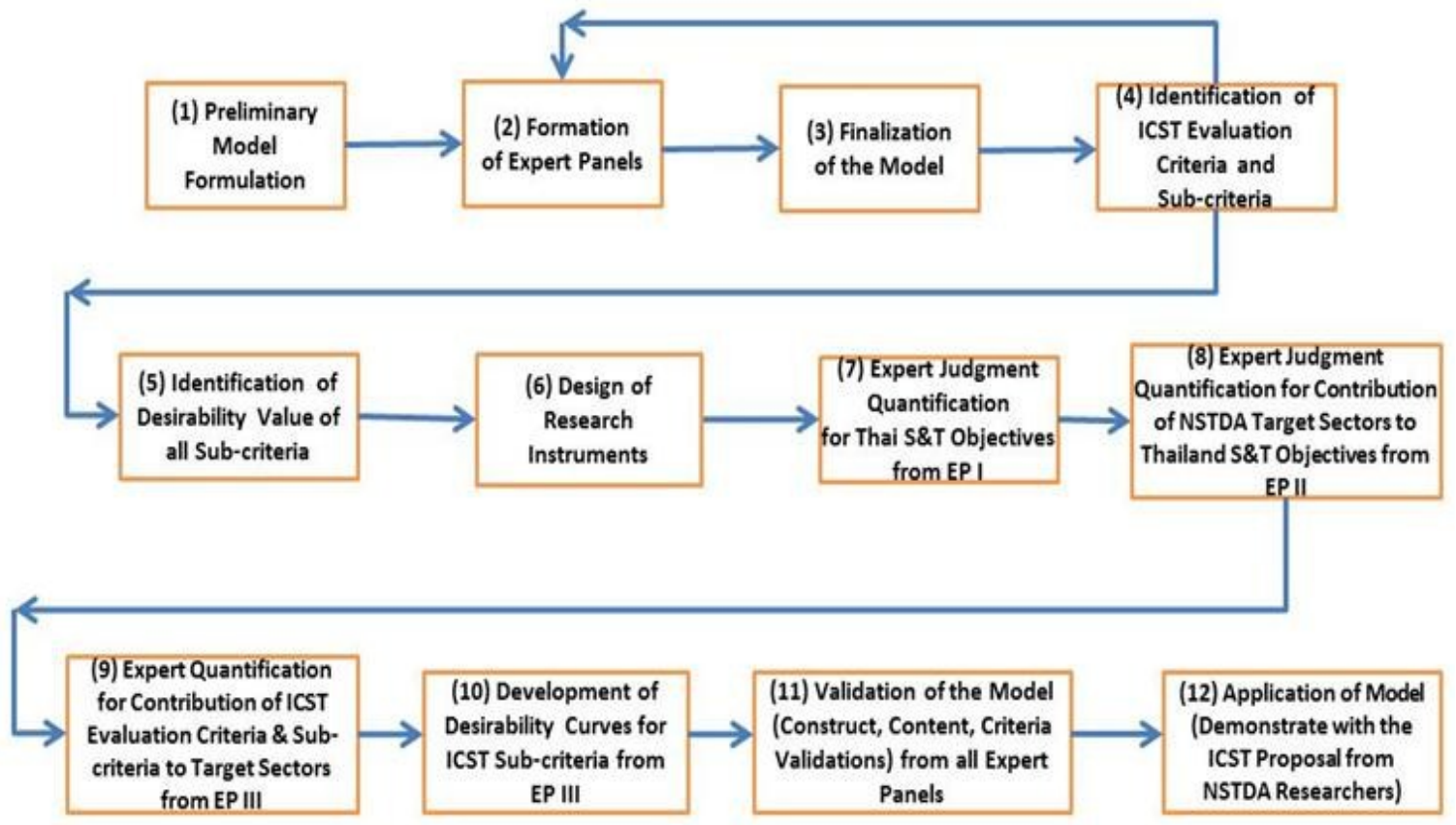

Figure 10: A 12-step approach to develop a Policy Model in ICST 


\section{Step 1: Preliminary Model Formulation}

The preliminary hierarchical decision model for Policy Making in International Collaboration in S\&T was formulated after gathering relevant information from the Thailand Science and Technology Strategic Plan and NSTDA’s R\&D strategies.

\section{Step 2: Formation of Expert Panels}

In order to incorporate qualitative and quantitative aspects of complex decisionmaking problems, expert opinions were obtained and quantified. Three expert panels were formed to validate the model and determine the relative importance of the elements of the model.

\section{Step 3: Finalization of the Model}

The preliminary model was finalized by the three expert panels.

\section{Step 4: Identification of ICST Evaluation Criteria and Sub-criteria}

Four evaluation criteria and 11 evaluation sub-criteria were proposed. Then they were verified by Expert Panel III.

\section{Step 5: Identification of Desirability Value of All Sub-criteria}

The desirability value of each evaluation sub-criteria was determined by Expert Panel III. More detail is provided in Appendix B and Appendix C. 


\section{Step 6: Design of Research Instruments}

The related research instruments were designed to gather the data from the expert panels, e.g., a questionnaire to obtain the relative importance of Thailand's S\&T objectives, a questionnaire for NSTDA researchers to submit their ICST proposals, etc. Details of the research instruments are given in Appendix D.In order to make sure that the research instruments were useable and easy to understand, they were validated twice, the first time by Department of Engineering and Technology Management Ph.D. students and the second time by the three expert panels.

\section{Step 7: Expert Judgment Quantification for Contribution of Thailand S\&T Objectives to Thailand's S\&T Vision}

Expert Panel I members, who are executive directors and executive deputy directors of NSTDA, were asked to determine the relative importance of the Thailand S\&T Objective.

They were informed about the details and objective of this research project, roles of their participation, and their human subject protection. Then they were asked to provide their opinions about the relative importance of each objective that contributes to the Thailand S\&T Vision.

\section{Step 8: Expert Judgment Quantification for NSTDA Target Sectors to Thailand}

\section{S\&T Objectives}

Members of Expert Panel II, including a president, executive director, director of strategic planning division, executive assistant director, lecturers, new business 
development department head, president of a non-profit organization, consultant, and technology \& R\&D manager, were asked to provide their quantified judgments about the relative importance of each target sector to each objective.

\section{Step 9: Expert Judgment Quantification of ICST Evaluation Criteria and Sub- criteria to NSTDA Target Sectors}

Members of Expert Panel III, who are project analysts in the national research centers under NSTDA (NECTEC, MTEC, BIOTEC, and NANOTEC), were asked to provide their quantified judgments about the contribution of each ICST evaluation criteria and sub-criteria to NSTDA target sectors.

\section{Step 10: Development of Desirability Curves for ICST Evaluation Sub-criteria}

Expert Panel III was asked to provide information about the desirability value of each ICST evaluation sub-criteria in order to develop the desirability curves for each ICST sub-criteria.

\section{Step 11: Validation of the Model}

The elements of the model in each level, the relative importance of each element, the research instruments, and the results of the model, which were confirmed by three validations (construct, content, and criteria-related), were determined by Expert Panels I, II and III. Further details are provided in Chapter 4. 


\section{Step 12: Application of the Model}

The Policy Model in International Collaboration in S\&T was demonstrated by using data from Thailand. The results of the model and the outcome of the proposed research will be presented to the Thai decision makers.

\subsection{Result Validations}

\subsubsection{Consistency of the Comparative Judgment and Quantification of Each Expert}

To test the internal consistency of the expert judgment quantifications, the inconsistency measure was used in this research. The concept of consistency is from the transitive property of inequality as follows:

If $\mathrm{A}$ is greater than $\mathrm{B}$ (i.e., $\mathrm{A}>\mathrm{B}$ ), and $\mathrm{B}>\mathrm{C}$, then $\mathrm{A}>\mathrm{C}$.

If $\mathrm{A}$ is less than $\mathrm{B}$ (i.e., $\mathrm{A}<\mathrm{B}$ ), and $\mathrm{B}<\mathrm{C}$, then $\mathrm{A}<\mathrm{C}$.

Inconsistency of each expert is defined in the constant sum method as shown in Equation 1.

$$
\text { Inconsistency }=\frac{1}{n} \sum_{j=1}^{n} \sqrt{\sum_{j=1}^{n !}\left(\mathrm{X}_{\mathrm{ij}}-\bar{X}_{i j}\right)^{2}} \quad \text { Equation } 1
$$




$$
\text { Where } \quad \begin{aligned}
\mathrm{X}_{\mathrm{ij}} & =\quad \text { Relative Value of element } \mathrm{j} \text { in } \mathrm{i}^{\text {th }} \text { orientation } \\
\bar{X}_{i j} & =\quad \text { Mean of } \mathrm{X}_{\mathrm{ij}} \text { values for element } \mathrm{j} \text { in } n \text { ! Orientations }
\end{aligned}
$$

The maximum acceptable inconsistency value is 0.10 [1]. The level of inconsistency is computed using Equation 1 for $n$ ! values of each decision element obtained by $n$ ! orientation of the elements, such as ABCDE, ACBDE, ACBDE, ADCAB, etc.

\subsubsection{Agreement among Members of the Expert Panel}

In order to confirm the acceptance level of agreement among experts, the group disagreement value was calculated by using Equation 2.

$$
\begin{aligned}
& \text { Disagreement }=\left[\frac{1}{m} \sum_{j=1}^{m}\left[\left(\frac{1}{n} * \sqrt{\sum_{=1}^{n}\left[V_{i j}-V_{j}(\text { mean })\right]^{2}}\right]\right] \quad \text { Equation } 2\right. \\
& \text { Where } \mathrm{i}=1, \ldots \ldots, \mathrm{n} \text { are the experts, } \\
& \mathrm{j}=1, \ldots \ldots ., \mathrm{m} \text { are the decision elements } \\
& \qquad \mathrm{Vij}=\text { Value assigned to element }(\mathrm{j}) \text { by respondent }(\mathrm{i}) \\
& \mathrm{V}_{\mathrm{ij}}(\text { mean })=\left(\frac{1}{\mathrm{~m}}\right) \sum_{\mathrm{i}=1}^{\mathrm{n}} \mathrm{V}_{\mathrm{ij}}
\end{aligned}
$$


According to Dundar Kocaoglu's research, the acceptance threshold of the disagreement value is 0.10 [1].

\subsection{Linking the Model to a Specific Case: A Case Study of Thailand}

To demonstrate the Policy Model for International Collaboration in S\&T, a case study of international scientific collaboration in S\&T of Thailand via NSTDA was used as a case study.

Detailed information about Thailand's case study is presented in Chapter 4. 


\section{Chapter 4: Development of the Case Study}

\subsection{Case Study Background}

A Policy Model for International Collaboration in S\&T is demonstrated by applying it to Thailand with data from the National Science and Technology Development Agency (NSTDA) of the Thai Ministry of Science and Technology $(\operatorname{MOST})$.

A brief description of the background of the case study is given in this chapter.

\subsubsection{Science and Technology Development in Thailand}

\section{- Overview}

Thailand is a country in Southeast Asia which has never been under colonial rule. The history of science and technology development in Thailand can be traced back to the era of King Rama V, King Chulalongkorn, who founded the first Thai University, Chulalongkorn University, in 1916. Thailand's education has been developed under the influence of the European education system [150].

Thailand has had a National Development Plan since 1961, which is a four-year duration plan. However, science and technology were not incorporated in the previous plans until the $5^{\text {th }}$ National Development Plan (1982-1986). 
The economic structure of Thailand has changed from an agriculture-based economy to a manufacturing-based economy and then to a knowledge-based economy; and for the 21 st century, Thailand is attempting to drive the economy toward being a "creative economy."

Currently, Thailand is running under the ten-year Science and Technology Strategic Plan (2004-2013) issued by the National Science and Technology Policy Committee (NSTPC). This S\&T points out the importance of the concepts of a national innovation system (NIS) and industrial clusters. The main objectives of this plan are to enhance Thailand's capabilities in response to the rapid changes in the age of globalization and to strengthen the country's long-term competitiveness. The Thai S\&T vision is, "The Thai economy will be strong, the Thai knowledge-based society will be able to compete internationally, the Thai nation will be secure, and Thai people will have a good quality of life"[151].

In driving towards the goals of this vision, the following four broad fundamental aspects are emphasized [151].

- The strength of the national innovation system

- The strength of human resources

- The encouraging environment for development

- The capacities of four core technologies for the future, i.e., information and communications technology, biotechnology, material technology, and nanotechnology 
The following five strategies are outlined in the policy document for the development of Thai's NIS:

- Development of industrial clusters, community economy and quality of life

- Development of S\&T human resources

- Development of S\&T infrastructure and institutions

- $\quad$ Promotion of public awareness of S\&T

- $\quad$ Reform of the S\&T management system

Thailand's NIS is in transition. It is moving from a "weak and fragmented" system toward a "stronger and more synergistic" system [152]. This science and technology plan marks the country's official transition from a "science and technology (S\&T) policy country" to a "science, technology and innovation (STI) policy country."

\section{- Thailand's Science and Technology Policy Structure}

The changes of S\&T policy in Thailand over time have been accompanied by a restructuring of the innovation system. The new actor has been added in and old actors adjusted their function within the system.

The current Thailand S\&T organization structure is shown in Figure 11. The structure comprises three levels described below [146]. 


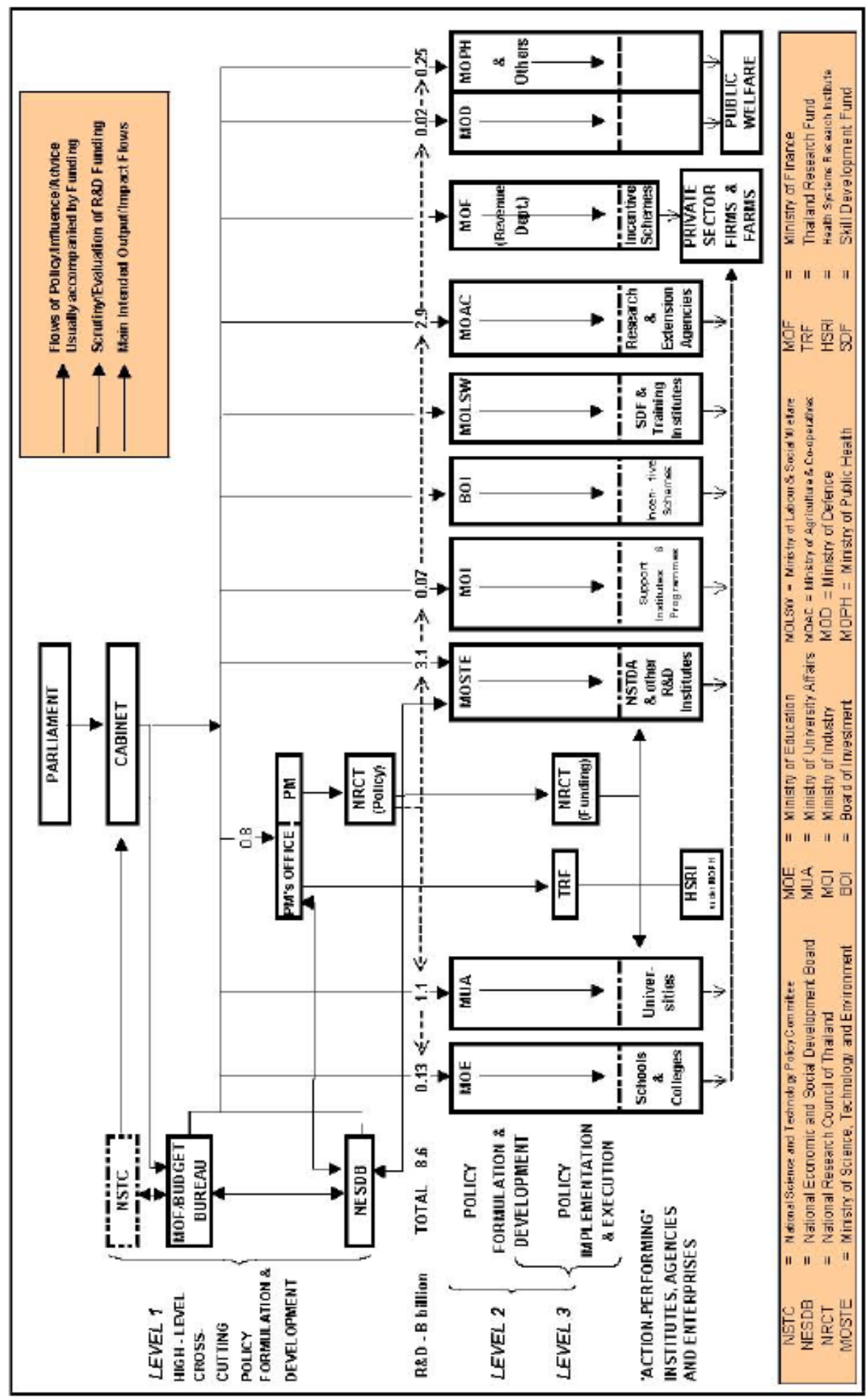

Figure 11: Organizational Structure of S\&T in Thailand 


\section{- Level 1: National level}

This is a high-level policy formulation among various line-ministries and government agencies, e.g., parliament, cabinet, and budget bureau.

\section{- Level 2: Ministry level}

Policy formulation and development at the ministerial level are concerned with developing and articulating policy designed to meet ministry missions and mandates.

\section{- Level 3: Policy implementation agencies level}

Policy implementation level is concerned with managing and funding the delivery of program and activities intended to achieve the policy goals of ministries and departments. There are sub-categories under this level that depend on each specific assignment, e.g., research and new knowledge production, technology development, and support for business enterprises in developing innovation capabilities. The vertical management among ministries is typically independent. There are some crosscutting policy and planning agencies, e.g., MOST, NRCT, and NSTDA.

The two government organizations in the area of science and technology are discussed below:

\section{- Ministry of Science and Technology (MOST)}

MOST was established in 1979 under the name Ministry of Science, Technology and Energy (MOSTE) and then renamed to just Ministry of Science and Technology 
(MOST)[147]. MOST plays a more central role in STI policy planning and implementation.

\section{- Office of National Research Council of Thailand (NRCT)}

NRCT was established in 1956 and is responsible for supporting the research funding in the area of science and technology for universities [148].

\subsubsection{National Science and Technology Development Agency (NSTDA)}

Thailand's National Science and Technology Development Agency (NSTDA), an autonomous agency under MOST, was created by the special National Science and Technology Development Act of 1991 and officially commenced its operations in 1992. NSTDA was founded with the goal to "conduct, support, coordinate, and promote efforts in scientific and technological development between public and private sectors towards maximizing benefit for national development."

Since then NSTDA has been responsible for 1) the formation of national science and technology policy, 2) the funding for R\&D projects, and 3) the management of four national research centers. These four national research centers are 1) the National Center for Genetic and Biotechnology (BIOTEC), 2) the National Metal and Materials Technology Center (MTEC), 3) the National Electronics and Computer Technology Center (NECTEC), and 4) the National Nanotechnology Center (NANOTEC). More details about each national research center are provided below. 
- The National Center for Genetic and Biotechnology (BIOTEC)

BIOTEC's main objective is to conduct the R\&D and application of biotechnology and bio-engineering to support technology development, transfer and adoption in both public and private sectors. BIOTEC research projects cover a broad spectrum of sciences including agricultural, biomedical, and environmental.

\section{- The National Metal and Materials Technology Center (MTEC)}

MTEC's main objective is to support R\&D in metals and materials, which are instrumental in the growth of the industrial sector and the overall development of the country.

- The National Electronics and Computer Technology Center (NECTEC)

NECTEC's main objective is to undertake, support and promote the development of electronics and computer technologies through R\&D activities.

\section{- The National Nanotechnology Center (NANOTEC)}

NANOTEC's main objective is to conduct and support research, development, design and engineering in nanotechnology, and transfer the technology to industrial 
sector to increase Thailand's competitiveness and improve the quality of life and the environment.

\subsubsection{International Collaboration in Science and Technology in Thailand}

Science and technology (S\&T) is a global activity. The international collaboration in S\&T is an important paradigm for advancing S\&T knowledge across borders.

In Thailand, international collaboration in S\&T is regarded as an important mechanism for Thailand's technological development. It helps to leverage national investment with the greater benefit, for example, advancing scientific knowledge, finding solutions for global problems, and developing a healthier, more secure, and better quality of life.

NSTDA is working to raise its profile in the international scientific community by building strategic partnerships with leading agencies and institutions from different regions of the world. Thailand international partnership is primarily based on the strength of the area of expertise of their scientists. So far, NSTDA has established and maintained various types of international collaborations in line with NSTDA's development target sectors as follows: 
- Bilateral collaborations with Japan, Korea, China, Germany, Canada, UK, France, India, Malaysia, Taiwan, Singapore, etc.

- Multilateral collaborations with the EU, ASEAN, APEC, UN, UNIDO, UNCTAD, USTDA, etc.

- Joint collaboration projects at the regional and global level, e.g., CERN and SEAEU-NET.

\subsection{Development of a Strategic Policy Model for International Collaboration in S\&T: A Case Study of Thailand}

The decision-making process in international collaboration in S\&T is complicated and it is composed of multiple levels and multiple criteria. A hierarchical decision model (HDM) was used to analyze the decision process. To simplify the analysis, the decision situation is decomposed into a hierarchy. In HDM, the hierarchy is organized into multiple levels with a number of decision elements on each level. At each level, the decision elements are connected to other decision elements on the level above or below them. Judgment quantification methods are used to derive the relative importance of each decision element, which is calculated by using the pair-wise comparison method.

Step-by-step details about how to construct each level and design each element of the model from the top level to the lowest level are provided in this section. 


\subsubsection{Expert Panels}

Three expert panels were formed for this research to validate the model and to obtain quantified expert judgments quantification for the relative importance of each elements of the model. In order to provide a balanced representation of opinions, the experts were selected from different backgrounds and different sectors: academic, government, and industry.

Experts came from various levels of authority, e.g., those who make decisions in an organization, those who manage the implementation of the decisions, and those who evaluate research proposals.

All expert members had in-depth knowledge in their area of expertise, e.g. strategic planning, R\&D management, S\&T policy, agriculture and food, health and medicine, energy and environment, technology for rural development, etc.

The details of the three expert panels are described in the next sections.

\subsubsection{Expert Panel I}

The six members of Expert Panel I are executive directors and executive deputy directors of the national research centers at the National Science and Technology Development Agency (NSTDA) in the Ministry of Science and Technology (MOST). They are from the following four national research centers in Thailand: National Electronics and Computer Technology Center (NECTEC), National Metal and Materials 
Technology Center (MTEC), National Center for Genetic Engineering and Biotechnology (BIOTEC), and National Nanotechnology Center (NANOTEC).

Expert Panel I had two roles:

- $\quad$ To verify the Thailand Science and Technology Vision and Objective.

- To determine the relative importance of each Thailand S\&T Objective to fulfill the Thailand S\&T Vision.

\subsubsection{Expert Panel II}

The 20 members of Expert Panel II hold high-level executive management positions from private companies, universities, and government organizations. Their affiliations are listed below:

- Geo-Informatics and Space Technology Development Agency (GISTDA)

- Leading University in Thailand

- Leading Consulting Company in Thailand

- Thai Health Promotion Foundation

- Toyota Tsusho Electronics (Thailand) Co., Ltd. (TTET)

- Thai Embedded System Association (TESA)

- National Science and Technology Development Agency (NSTDA)

- National Metal and Materials Technology Center (MTEC) 
- National Center for Genetic Engineering and Biotechnology (BIOTEC)

- National Center for Electronics and Computer Technology Center (NECTEC)

- National Nanotechnology Center (NANOTEC).

- Information Technology Associates Program (ITAP)

Expert Panel II was divided into four sub-groups related to the four Thailand S\&T objectives. Each group evaluated one Thailand S\&T objective except for expert no.3, who served in all four sub-groups.

The list of expert members in Expert Panel III in each sub-group is shown in Table 5 .

Table 5: Expert Panel II (twenty expert members)

\begin{tabular}{|c|c|c|}
\hline $\begin{array}{c}\text { Sub-group of } \\
\text { Expert Panel II } \\
(20 \text { expert members total })\end{array}$ & Thailand S\&T Objectives & Expert Members \\
\hline \multirow{6}{*}{$\begin{array}{c}\text { Sub-groupII-1 } \\
\text { (6 expert members) }\end{array}$} & \multirow{6}{*}{ Sustainable Competitiveness } & EXP II-1 \\
\hline & & EXP II-2 \\
\hline & & EXP II-3 \\
\hline & & EXP II-4 \\
\hline & & EXP II-5 \\
\hline & & EXP II-6 \\
\hline \multirow{6}{*}{$\begin{array}{c}\text { Sub-group II-2 } \\
\text { (6 expert members) }\end{array}$} & \multirow{6}{*}{ Community Economy } & EXP II-3 \\
\hline & & EXP II-7 \\
\hline & & EXP II-8 \\
\hline & & EXP II-9 \\
\hline & & EXP II-10 \\
\hline & & EXP II-11 \\
\hline
\end{tabular}




\begin{tabular}{|c|c|c|}
\hline $\begin{array}{c}\text { Sub-group of } \\
\text { Expert Panel II } \\
(20 \text { expert members total })\end{array}$ & Thailand S\&T Objectives & Expert Members \\
\hline \multirow{5}{*}{$\begin{array}{c}\text { Sub-group II-3 } \\
(5 \text { expert members })\end{array}$} & \multirow{5}{*}{ Learning Society } & EXP II-3 \\
\hline & & EXP II-12 \\
\hline & & EXP II-13 \\
\hline & & EXP II-14 \\
\hline & & EXP II-15 \\
\hline \multirow{6}{*}{$\begin{array}{c}\text { Sub-group II-4 } \\
(5 \text { expert members })\end{array}$} & \multirow{6}{*}{$\begin{array}{l}\text { Quality of Life and } \\
\text { Environment }\end{array}$} & EXP II-3 \\
\hline & & EXP II-16 \\
\hline & & EXP II-17 \\
\hline & & EXP II-18 \\
\hline & & EXP II-19 \\
\hline & & EXP II-20 \\
\hline
\end{tabular}

The role for Expert Panel II was to determine the relative importance of each NSTDA target sector to fulfill the Thailand S\&T objectives.

\subsubsection{Expert Panel III}

The 20 members of Expert Panel III were project analysts from NSTDA in every sub-sector of the five target sectors: rice, seed, sustainable energy, hospital practice and medical devices, and technology for impaired and under-privileged people.

Expert Panel III was divided into five sub-groups according to the NSTDA target sectors. There were four expert members in each sub-group. Each expert served only one target sub-group as shown in Table 6. 
Table 6: Expert Panel III and their area of expertise

\begin{tabular}{|c|c|c|}
\hline $\begin{array}{c}\text { Sub-group of } \\
\text { Expert Panel III } \\
\text { (20 expert members total) }\end{array}$ & $\begin{array}{c}\text { NSTDA Target } \\
\text { Sector (Five Target } \\
\text { Sectors) }\end{array}$ & Area of Expertise \\
\hline $\begin{array}{c}\text { Sub-group III-1 } \\
\text { (4 expert members) }\end{array}$ & Agriculture\& Food & $\begin{array}{ll}\text { - } & \text { Shrimp } \\
\text { - } & \text { Rice, Potato, Sugar Cane } \\
\text { - } & \text { Seed } \\
\text { - } & \text { Animal }\end{array}$ \\
\hline $\begin{array}{c}\text { Sub-groupIII-2 } \\
\text { (4 expert members) }\end{array}$ & $\begin{array}{c}\text { Energy \& } \\
\text { Environment }\end{array}$ & $\begin{array}{ll}\text { - } & \text { Sustainable Environment } \\
\text { - } & \text { Effective Uses of Resources } \\
& \text { and Energy } \\
\text { - } & \text { Renewable Energy } \\
\text { - } & \text { New Energy Technology }\end{array}$ \\
\hline $\begin{array}{c}\text { Sub-groupIII-3 } \\
\text { (4 expert members) }\end{array}$ & Health \& Medicine & $\begin{array}{ll}\text { - } & \text { Medical } \\
\text { - } & \text { Health } \\
\text { - } & \text { Impaired People } \\
\text { - } & \text { Genomic Medicine }\end{array}$ \\
\hline $\begin{array}{l}\text { Sub-group III-4 } \\
\text { (4 expert members) }\end{array}$ & $\begin{array}{c}\text { Manufacturing \& } \\
\text { Service }\end{array}$ & $\begin{array}{ll}\text { - } & \text { Manufacturing Tech. } \\
\text { - } & \text { Digital Device } \\
\text { - } & \text { Intelligence Transportation } \\
& \text { System } \\
\text { - } & \text { Automobile }\end{array}$ \\
\hline $\begin{array}{l}\text { Sub-group III-5 } \\
\text { (4 expert members) }\end{array}$ & $\begin{array}{c}\text { Resources, } \\
\text { Communities, and } \\
\text { Under-privileged } \\
\text { People }\end{array}$ & $\begin{array}{ll}\text { - } & \text { S\&T Youth Project } \\
\text { - } & \text { IT-Valley, Remote Learning } \\
\text { - } & \text { Digital Media } \\
\text { - } & \text { Education for Hill Tribe } \\
& \text { People }\end{array}$ \\
\hline
\end{tabular}


The roles for Expert Panel III were: 1) to determine the relative importance of evaluation criteria, 2) to determine the relative importance of evaluation sub-criteria of international collaboration in the S\&T proposal to fulfill each of NSTDA's target sectors, and3) to obtain the desirability value for each evaluation sub-criteria.

There were 46 experts in all three expert panels.

\subsection{Data Collection}

The data collection process comprises two main activities which are described as follows:

\subsubsection{Design of the Research Instruments}

After the strategic policy model for international collaboration in S\&T was developed, the related research instruments were designed for each group. Six research instruments were designed and used for collecting data from Expert Panels I, II, II, and NSTDA researchers as follows:

\section{- Research Instrument I}

The research instrument I, Questionnaire for Thailand S\&T Objectives, was used by Expert Panel I to obtain the relative importance of Thailand S\&T Objective with respect to the Thailand S\&T Vision. 
- Research Instrument II

Research instrument II, Questionnaire for NSTDA Target Sectors, was used by Expert Panel II to obtain the relative importance of the NSTDA target sector with respect to the Thailand S\&T Objective.

\section{- Research Instrument III}

Research instrument III, Questionnaire for International Collaboration in S\&T Evaluation Criteria, was used by Expert Panel III to obtain the relative importance of the four evaluation criteria (SI, PI, HRD and MF) with respect to each NSTDA target sector.

\section{- Research Instrument IV}

Research instrument IV, Questionnaire for International Collaboration in S\&T Evaluation Sub-criteria, was used by Expert Panel III to obtain the relative importance of the evaluation sub-criteria with respect to each evaluation criteria.

\section{- Research Instrument V}

Research instrument V, Questionnaire for Desirability Value for Evaluation Subcriteria, was used by Expert Panel III to describe the desirability value of each subcriterion for plotting the desirability curve. 
- Research Instrument VI

Research instrument VI, ICST Research Proposal Form for ICST Project, was used by NSTDA researchers in order to obtain their ICST proposals.

Before presenting the research instruments to the users, expert panels and researchers, all of them were tested and validated by two groups of people: 1) $\mathrm{PhD}$ students from the Department of Engineering and Technology Management, Maseeh College of Engineering \& Computer Science at Portland State University, and 2) NSTDA staff.

The examples of the six research instruments are shown in Appendix C.

\subsubsection{Collecting the Quantification of Expert Judgment}

The research instruments were presented to each expert member in order to obtain their judgment quantification. The three approaches to obtain the data from the experts were:1) web-based online questionnaires; 2) phone interviews; and 3) face-to-face meetings.

The data collection procedure started with giving an overview of the research project. Then, the questionnaire was explained and discussed in detail. After that, each member of Expert Panels I, II, and III was asked to provide their quantified judgments by making pair-wise comparisons. 
For research instrument VI, the ICST Research Proposal Form was distributed to NSTDA researcher via email, and then an appointment was scheduled to interview each researcher and to collect their proposal.

After finishing the data collecting process, all of the data from all the research instruments were gathered and analyzed. The results were presented to the experts via face-to-face meetings or email so that the experts could provide their feedback on the final results.

\subsection{The Top-down approach}

The concept of the top-down approach, or the "mission-oriented" project, is applied to HDM on the first three levels of the model.

\subsubsection{The $1^{\text {st }}$ level: Thailand S\&T Vision}

The first level of the model is the National S\&T Vision in International Science and Technology. At the time the model was developed, Thailand did not have an international science and technology policy plan yet. Hence, the National S\&T Vision of Thailand was obtained from the National Science and Technology Strategic Plan 20042013, which was issued by the National Science and Technology Policy Committee (NSTPC). That National S\&T Vision is used as an input to construct the first level of the 
model. The Thailand S\&T's Vision presents the main statement about transforming the country into a knowledge-based society as follows:

\section{"Strong economy with a knowledge society and a better quality of social well-being"}

The vision of the Thailand National Science and Technology Strategic Plan 20042013 can be interpreted as an adjustment of the government S\&T policy in order to enhance Thailand's capability of responding to the rapid changes and to strengthen the country's long-term competitiveness while Thai citizens have opportunities for a good quality of life in this globalization era.

The information on how to develop the $\mathbf{1}^{\text {st }}$ level is summarized in Table 7.

Table 7: The $1^{\text {st }}$ Level of the Policy Model in International Collaboration in S\&T

\begin{tabular}{|c|c|c|c|}
\hline Input & Operation & Actor & Output \\
\hline $\begin{array}{l}\text { The Thailand National } \\
\text { Science and Technology } \\
\text { Strategic Plan 2004-2013 }\end{array}$ & $\begin{array}{l}\text { First Level } \\
\text { Model } \\
\text { Validation }\end{array}$ & Expert Panel I & $\begin{array}{c}\text { The Thailand S\&T } \\
\text { Vision }\end{array}$ \\
\hline
\end{tabular}

\subsubsection{The $2^{\text {nd }}$ level: Thailand S\&T Objectives}

The information for constructing the second level of the model was also obtained via the National Science and Technology Strategic Plan 2004-2013.In order to fulfill the Thai Science and Technology's Vision, there are four Thai science and technology 
objectives that try to balance between economic development and social development as follows:

\section{- Objective 1: Sustainable Competitiveness}

This objective is for Thailand to have a strong and sustainable competitiveness by applying science and technology development. Thailand is trying to raise its level of innovation in order to move from being a labor-intensive manufacturer exporting country to being a high-technology intensive manufacturing and knowledge-intensive services country.

\section{- Objective 2: Community Economy}

It is an objective for Thailand to have a strong community economy and enhance its self-management capability by strengthening its technological capability and upgrading manufacturing productivity such as the One - Tambon - One - Products (OTOP). (Tambon means "village" in the Thai language.)

\section{- Objective 3: Learning Society}

It is an objective for Thailand to have a life-long leaning society and to encourage the acquisition of new knowledge by the use of science and technology development. 


\section{- Objective 4: Quality of Life and Environment}

This objective is for Thailand to create and ensure equal opportunities for all of its population groups, which include the impoverished, the disadvantaged, the disabled and minority groups, so they can have a good quality of life in a safe environment.

Information on developing the $2^{\text {nd }}$ level is summarized in Table 8.

Table 8: The $2^{\text {nd }}$ Level of the Policy Model in International Collaboration in S\&T

\begin{tabular}{|c|c|c|c|}
\hline Input & Operation & Actor & Output \\
\hline $\begin{array}{c}\text { The Thailand National } \\
\text { Strategic Plan 2004- } \\
2013\end{array}$ & $\begin{array}{c}\text { Second Level } \\
\text { Model } \\
\text { Validation }\end{array}$ & Expert Panel I & $\begin{array}{c}\text { List of the Thailand } \\
\text { S\&T Objectives }\end{array}$ \\
\hline $\begin{array}{c}\text { Quantification of Expert } \\
\text { Judgment }\end{array}$ & Pair-wise \\
Comparison & Expert Panel I & $\begin{array}{c}\text { The relative } \\
\text { importance of each } \\
\text { Thailand S\&T } \\
\text { objective that } \\
\text { contributed to the } \\
\text { Thailand S\&T } \\
\text { Vision }\end{array}$ \\
\hline
\end{tabular}

\subsubsection{The $3^{\text {rd }}$ level: NSTDA's R\&D Strategy - NSTDA Target Sectors}

In addition to the first two top levels of the model, the third level, which is the organization's R\&D strategy, is constructed in order to fulfill Thailand's S\&T objectives.

The R\&D strategy of NSTDA was used as a case study to demonstrate the third level of this model. At NSTDA, unlike the other agencies that have specific 
concentrations on the four main aspects ( $R \& D$, human resource development, technology transfer and S\&T Infrastructure), the sector-based mechanism under the close cooperation among government, academia and private sector networks was officially introduced in 2006. The formation of this sector-based concept is not limited to the R\&D projects of Thailand only. NSTDA actively works with all international organizations. Bilateral and multilateral collaborations in line with the NSTDA's targets are developed and conducted with counterpart governments and institutions from the different regions of the world.

At NSTDA, the R\&D strategy is built around the following five target sectors which directly reflect national social and economic priorities.

\section{- Agriculture and Food}

Agriculture and food play major roles in Thailand's economic development. Thailand has long been known as an agricultural country. The majority of products were exported overseas worth $\$ 17.11$ Billion Baht in 2010 with rice being the main product. The country also produces significant quantities of sugar cane, cassava, palm oil and maize.

As in many developing countries around the world, the development of major industrial and service sectors in Thailand from the 1970s onward contributed to a major shift toward urban migration. This continuing shift of workers from rural areas has had a significant effect on the future of Thailand's farming system. Suitable agricultural development plan and programs for Thailand are necessary for strengthening the roles and capabilities of farmers and their organizations, improving the effective of resource management, and so on. 
NSTDA is trying to increase the competitiveness and sustainability of the agriculture and food sector by using technology to help in improving yields, developing high quality seeds, improving soil quality, enhancing the production efficiency, and so on. The agriculture and food sector is focused on several areas: rice, cassava, seeds, livestock, animal health, and food innovation.

\section{- Energy and the Environment}

Currently, energy and the environment are serious challenges globally. The Thai government has taken energy and environmental issues seriously. Thailand is working on highlighting the alternative energy resources and turning towards renewable energy. In the energy sector, Thailand is an energy exporter for many energy products but also an energy importer at the same time. The Thai government is supporting various programs of the energy development while also protecting the environment. For Thailand, the future development of the energy sector depends heavily on its ability to respond to various challenges, e.g., how to meet the Euro IV emission standards for vehicle fuels. Thailand also has a commitment to the mitigation of climate change by reducing carbon emissions and promoting green energy.

At NSTDA, their energy and environment sector covers the following three main $R \& D$ areas which are 1) Sustainable environment 2) effective uses of resources and energy 3) renewable energy and new energy technology. 


\section{- Health and Medicine}

Thailand's health and medical services sector has gained more and more international attention because of its high standards at a reasonable cost. NSTDA researchers have obtained research funding not only from the Thai government, but also from international funding agencies, e.g., Bill and Melinda Gates Foundation, World Health Organization, Howard Hughes Medical Institute (HHMI), which means that the quality of NSTDA's research is on a par with international standards.

The goal of Thailand's health and medical research program is to improve the quality of life for Thai citizens through public health innovation with regard to endemic diseases, e.g., thalassemia, leptospirosis, avian influenza, SARS, malaria, and so on. However, the research projects under this target sector are not only designed for Thai people but also for transnational research on disease, e.g., cancer, obesity, and heart disease.

The focus of NSTDA's R\&D activities for the health and medical R\&D sector are on four areas: 1) emerging and re-emerging diseases 2) personalized medicine 3) material and technology for the disabled and elderly 4) support systems in hospital and materials for hospital devices.

\section{- Manufacturing and Service}

The manufacturing and service sector has a high economic impact on the nation. At NSTDA the R\&D projects in the three strategic areas under this sector are supported as follows: 1) hard disk drives, 2) air conditioners and coolers, and 3) automobiles and automotive parts. The R\&D programs at NSTDA focus on process improvement, product 
design and development, alternative energy systems and also the incorporation of information, telecommunications and computing technologies into a system that increases the effectiveness, quality, and safety.

\section{- Resources, Communities, and Underprivileged People}

The resources, communities, and underprivileged people sector aims to create communities that can integrate science and technology with the local knowledge and practice. NSTDA's R\&D project under this cluster focuses on the various application research and innovation that can provide a better quality of life for the elderly and disabled, provide the education access for the rural community, and also promote scientific interest for the next generation of scientists in Thailand.

The information on developing the $3^{\text {rd }}$ level is summarized in Table 9.

Table 9: The $3^{\text {rd }}$ Level of the Policy Model in International Collaboration in S\&T

\begin{tabular}{|c|c|c|c|}
\hline Input & Operation & Actor & Output \\
\hline $\begin{array}{c}\text { The NSTDA's Research } \\
\text { and Development } \\
\text { Strategy }\end{array}$ & $\begin{array}{c}\text { Third Level } \\
\text { Model } \\
\text { Validation }\end{array}$ & Expert Panel II & $\begin{array}{c}\text { List of the NSTDA } \\
\text { Target Sectors }\end{array}$ \\
\hline $\begin{array}{c}\text { Quantification of Expert } \\
\text { Judgment }\end{array}$ & $\begin{array}{c}\text { Pair-wise } \\
\text { Comparison }\end{array}$ & Expert Panel II & $\begin{array}{c}\text { The relative } \\
\text { importance of each } \\
\text { NSTDA target } \\
\text { sector that } \\
\text { contributed to the } \\
\text { Thailand S\&T } \\
\text { objectives }\end{array}$ \\
\hline
\end{tabular}




\subsection{The Evaluation Process}

Base on the literature search, different criteria from various organizations, e.g., Department of Energy (DOE), National Aeronautics and Space Administration (NASA), European Research Area (ERA), and National Science Foundation (NSF), are used for evaluating the international collaboration in science and technology proposal.

For example, the NSF's Merit Review Criteria are used to evaluate the ICST proposals [149]. All NSF proposals are evaluated based on the two National Science Board (NSB) criteria: 1) intellectual merit and 2) broader impacts.

Another example, under the Pakistan and U.S. Science and Technology Cooperation program of the National Academies, the international collaboration proposals are evaluated in separate processes organized by Pakistani and U.S. based on the five criteria: 1) the relevance to the goals, 2) the scientific and technical merit of the proposal, 3) the cost-effectiveness of the project, 4) the capabilities of the participating institutions and individuals to successfully complete the project, and 5) the nature and quality of the collaboration [150].

From the European Commission report on "Drivers of International Collaboration in Research" [151], it presented the rationales behind international collaboration in science and technology research policies which are the "narrow STI cooperation paradigm" and the "broad STI cooperation paradigm". These two paradigms are the great concepts which can be used as a guide to derive the set of evaluation criteria for international collaboration. 
In this research, four evaluation criteria and eleven evaluation sub-criteria were proposed to use for evaluating the ICST proposals in this research. All evaluation criteria and sub-criteria were validated and tested by twenty members of Expert Panel III.

The lists of all evaluation criteria and sub-criteria are present in the next sections.

\subsubsection{The $4^{\text {th }}$ level: ICST Evaluation Criteria}

- Strategic Importance (SI): How important is this international collaboration project?

- Potential Impact (PI): What is the benefit of having this collaboration project?

- Human Resource Development (HRD): How many researchers can benefit from this project? What is the significance level of benefit to the researcher?

- $\quad$ Matching Fund (MF): What is the ratio of the matching fund from the international partner to the total funds needed?

\subsubsection{The $4^{\text {th }}$ level: ICST Evaluation Sub-criteria}

There are four sub-criteria for the Strategic Importance (SI) criterion:

- $\quad$ Building up national S\&T capabilities through international collaboration

- $\quad$ Establishing a global partnership

- $\quad$ Providing access to state-of-the-art knowledge abroad

- $\quad$ Attracting highly skilled professionals (brain gain) 
There are five sub-criteria for the Potential Impact (PI) criterion:

- Meeting the local challenge, e.g., white spot on the leaf of Thai jasmine rice

- $\quad$ Tackling the global challenge, e.g., global warming, HIV, natural disaster

- Having knowledge or technology transfer

- $\quad$ Creating joint academic papers

- $\quad$ Creating joint research programs or consortia

There are two sub-criteria for the Human Resource Development (HRD) criterion:

- Number of researchers who would benefit from a particular international collaboration project

- Significant benefits from this international collaboration project to the researcher

\subsubsection{The $4^{\text {th }}$ level: Desirability Curves of ICST Evaluation Sub-criteria}

The desirability curves of all sub-criteria were developed based on the judgments of Expert Panel III members. Each expert was asked to give a score from 0 to 100 for all of the desirability levels.

The example of desirability levels of the Potential Impact sub-criterion is shown in Table 10. 
Table 10: The five desirability levels of one PI sub-criterion - Meeting Local Challenge

\begin{tabular}{|c|c|}
\hline Level & \multicolumn{1}{c|}{ Description } \\
\hline Excellent & $\begin{array}{r}\text { There is a serious interest to solve the national challenge(s) and } \\
\text { the result will come out soon, in a year. }\end{array}$ \\
\hline Good & $\begin{array}{r}\text { There is a serious interest to solve the national challenge(s) and } \\
\text { the result will come out within the next3-5 years. }\end{array}$ \\
\hline Medium & $\begin{array}{r}\text { There is a serious interest to solve the national challenge(s) but } \\
\text { there is no committed result. }\end{array}$ \\
\hline Low & There is a possibility to solve the national challenge(s). \\
\hline None & No interest in problem solving for the national issues. \\
\hline
\end{tabular}

After obtaining the desirability value from all expert members in the same subgroup, the desirability curve was plotted. Each coordinate on the graph represents desirability level, average of desirability values. The example of the desirability curve of the PI sub-criterion, "Meeting Local Challenges in Agriculture and Food," is shown in Figure 12.

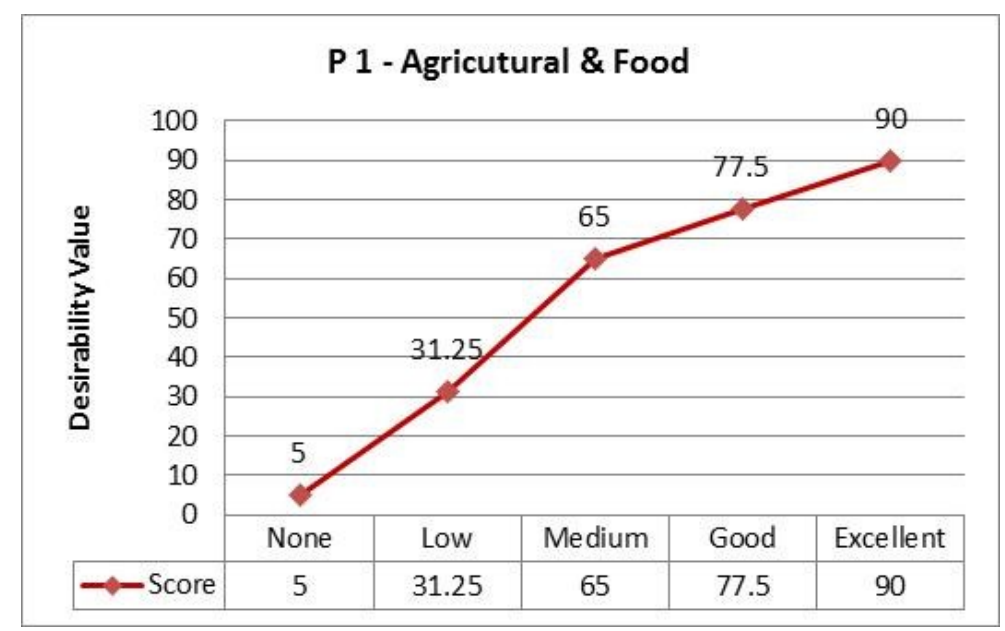

Figure 12: PI 1- Meeting Local Challenge for Agriculture and Food Sector 
The desirability curves of all sub-criteria in all five target sectors (60 curves) are presented in Appendix B.

The information on developing the $4^{\text {th }}$ level is summarized in Table 11.

Table 11: The $4^{\text {th }}$ Level of the Policy Model in International Collaboration in S\&T

\begin{tabular}{|c|c|c|c|}
\hline Input & Operation & Actor & Output \\
\hline $\begin{array}{c}\text { Quantification of } \\
\text { Expert Judgment }\end{array}$ & $\begin{array}{c}\text { Pair-wise } \\
\text { Comparison }\end{array}$ & $\begin{array}{c}\text { Expert } \\
\text { Panel III }\end{array}$ & $\begin{array}{c}\text { (1) The relative importance of } \\
\text { evaluation criteria that } \\
\text { contributed to the NSTDA } \\
\text { target sector. }\end{array}$ \\
$\begin{array}{c}\text { The list of } \\
\text { evaluation sub- } \\
\text { criteria with their } \\
\text { descriptions }\end{array}$ & $\begin{array}{c}\text { Scoring and } \\
\text { Desirability } \\
\text { Curve Fitting }\end{array}$ & Expert & $\begin{array}{c}\text { Panel III } \\
\text { evaluation sub-criteria that } \\
\text { contributed to the criteria }\end{array}$ \\
\hline
\end{tabular}

\subsection{The Bottom-up approach}

The concept of the bottom-up approach or the "problem-driven" approach is applied to the HDM at the fifth level of the model.

\subsubsection{The $5^{\text {th }}$ level: ICST Proposals from NSTDA Researchers}

The data used on the fifth level of the model was obtained from the international collaboration in S\&T proposals from NSTDA researchers. The proposals were created by 
their personal interest and through the emerging new channels, e.g., personal network or open access, etc.

Each NSTDA researcher was asked to provide information about his/her interest in creating an international collaboration in S\&T research project by filling in the form as shown in Appendix C.

The NSTDA researchers needed to provide the information about their International Collaboration in Science and Technology proposal with respect to various aspects, e.g., target sector, strategic importance and potential impact of the proposed project, etc.

Data on the four ICST proposals have been obtained to demonstrate the model. The information on developing the $5^{\text {th }}$ level is summarized in Table 12.

Table 12: The $5^{\text {th }}$ Level of the Policy Model in International Collaboration in S\&T

\begin{tabular}{|c|c|c|c|}
\hline Input & Operation & Operator & Output \\
\hline $\begin{array}{c}\text { Personal network, } \\
\text { emerging channels, e.g., } \\
\text { open access, scientific } \\
\text { network, personal } \\
\text { interest }\end{array}$ & $\begin{array}{c}\text { Proposal writing } \\
\text { following the } \\
\text { guideline\& } \\
\text { submission }\end{array}$ & NSTDA & $\begin{array}{c}\text { List of International } \\
\text { Collaboration in } \\
\text { S\&T Research } \\
\text { Proposal }\end{array}$ \\
\hline
\end{tabular}




\subsection{A Strategic Policy Model for International Collaboration in S\&T for Thailand}

After demonstrating the model by applying data from Thailand at all five levels of the model, a strategic policy model for ICST is shown in Figure 13.

Then the results from the model, level by level, and from all Expert Panels were analyzed and are presented in the next chapter, Chapter 5. 


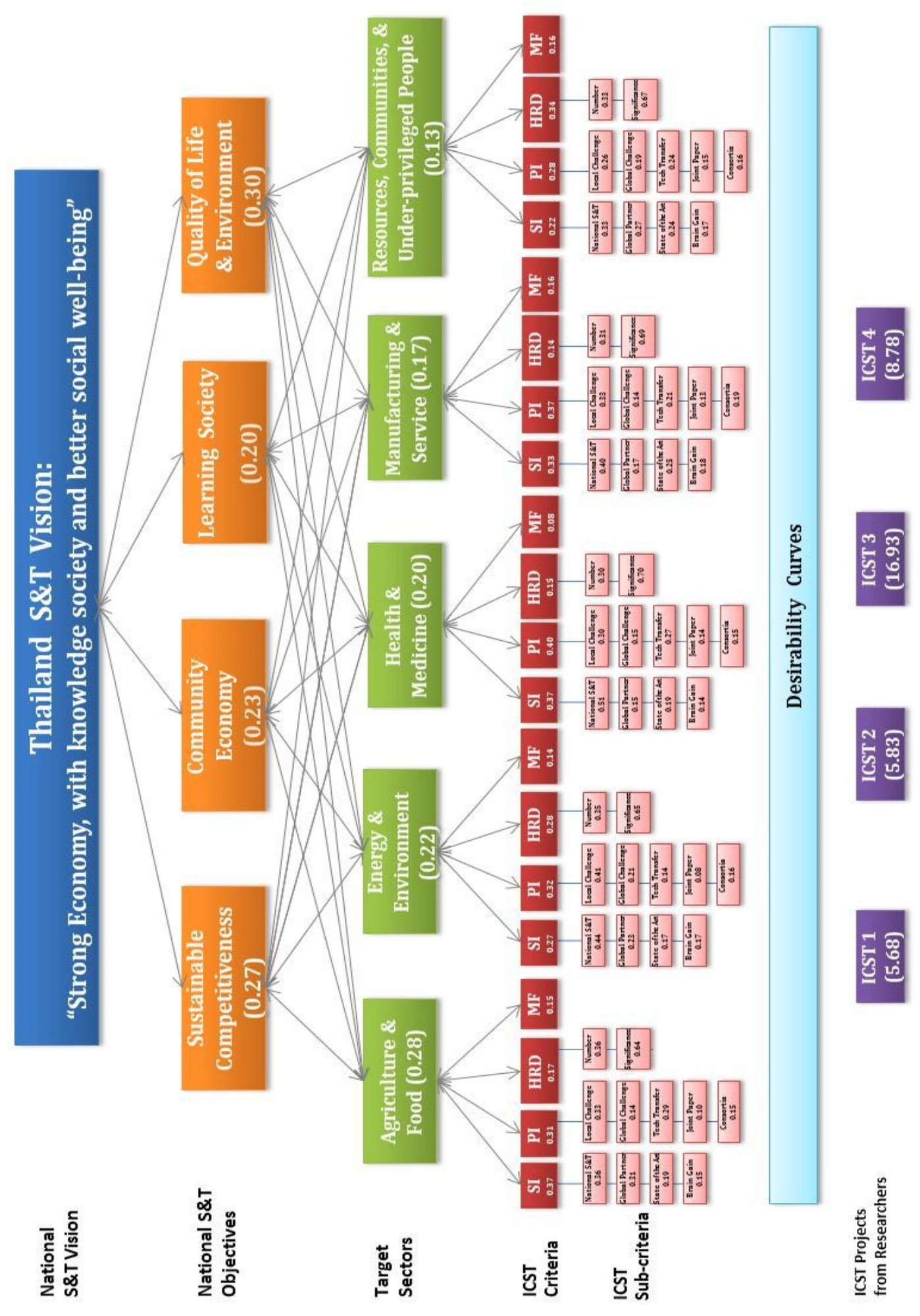

Figure 13: A Strategic Policy Model for International Collaboration in S\&T for Thailand 


\section{Chapter 5: Case Study Results and Analysis}

This chapter presents the research results of the model of all the expert panels, namely,1) results and 2) analysis of the results which are consistency of the quantified judgments of each expert and the degree of agreement among members of the panels. These results, analysis of results are explained for each level of the model from top to bottom.

\subsection{The $1^{\text {st }}$ level: Thailand S\&T Vision}

\subsubsection{Results from Expert Panel I}

For the $1^{\text {st }}$ level of the model, the Thailand S\&T Vision was obtained from the National Science and Technology Strategic Plan 2004-2013, issued by the National Science and Technology Policy Committee (NSTPC).It is stated as below.

\section{"Strong economy with a knowledge society and better social well-being."}

The vision of this National Science and Technology Strategic Plan 2004-2013 can be interpreted as an adjustment of the government S\&T policy to enhance Thailand's capability in order to be able to respond to the rapid changes and to strengthen the 
country's long-term competitiveness while ensuring that Thai citizens have a good quality of life. Expert Panel I was asked to validate the Thailand S\&T Vision as the first level of the model. They agreed with the statement.

The result from Expert Panel I at the first level of the model is shown in Figure

14.

\begin{tabular}{l|c|c}
\multicolumn{1}{c}{ The $\mathbf{1}^{\text {st }}$ level } \\
\cline { 2 - 2 } $\begin{array}{l}\text { National } \\
\text { S\&TVision }\end{array}$ & Thailand S\&T Vision: \\
\cline { 2 - 3 } & "Strong Economy, with knowledge society and better social well-being"
\end{tabular}

Figure 14: The $1^{\text {st }}$ level- Thailand S\&T Vision

\subsection{The $2^{\text {nd }}$ level: Thailand S\&T Objectives}

For the $2^{\text {nd }}$ level, in order to fulfill the Thailand S\&T Vision, the four Thailand S\&T Objectives from the National Science and Technology Strategic Plan 2004-2013 were used to develop the model as shown in Figure 15.

\section{The $1^{\text {st }}$ and the $2^{\text {nd }}$ level}

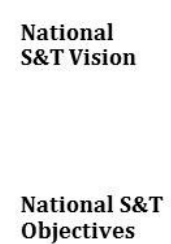

objectives

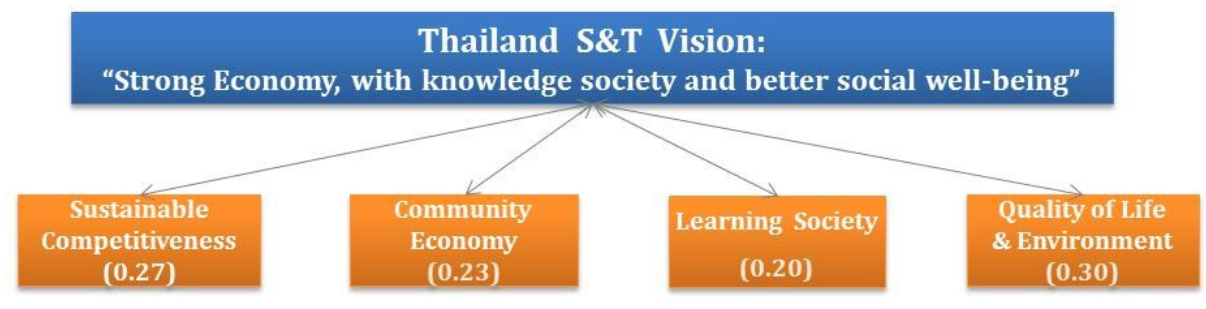

Figure 15: The $2^{\text {nd }}$ level - Thailand S\&T Objective 


\subsubsection{Results from Expert Panel I: $2^{\text {nd }}$ level}

The members of Expert Panel I were asked to evaluate the relative importance of the four Thailand S\&T Objectives with respect to the Thailand S\&T Vision. The individual results are shown in Table 13.

Table 13: The relative importance and inconsistency of Expert Panel I

\begin{tabular}{|c|c|c|c|c|}
\hline \multirow{2}{*}{$\begin{array}{c}\text { Thailand } \\
\text { S\&T Vision }\end{array}$} & \multicolumn{4}{|c|}{ Thailand S\&T Objectives } \\
\cline { 2 - 5 } & $\begin{array}{c}\text { Sustainable } \\
\text { Competitiveness }\end{array}$ & $\begin{array}{c}\text { Community } \\
\text { Economy }\end{array}$ & $\begin{array}{c}\text { Learning } \\
\text { Society }\end{array}$ & $\begin{array}{c}\text { Quality of Life and } \\
\text { Environment }\end{array}$ \\
\hline EXP I-1 & 0.14 & 0.20 & 0.36 & 0.30 \\
\hline EXP I-2 & 0.33 & 0.27 & 0.18 & 0.22 \\
\hline EXP I-3 & 0.44 & 0.08 & 0.03 & 0.44 \\
\hline EXP I-4 & 0.16 & 0.24 & 0.24 & 0.36 \\
\hline EXP I-5 & 0.35 & 0.18 & 0.25 & 0.22 \\
\hline EXP I-6 & 0.19 & 0.40 & 0.16 & 0.25 \\
\hline Mean & 0.27 & 0.23 & 0.20 & 0.30 \\
\hline
\end{tabular}

By using the arithmetic mean of the quantified expert judgments from Expert Panel I, the relative importance of the four Thailand S\&T Objectives $\left(\mathrm{O}_{\mathrm{m}}\right)$ were obtained as shown in Table 14.

Table 14: Relative Importance of Thailand S\&T Objectives

\begin{tabular}{|c|c|}
\hline Thailand S\&T Objectives & Relative Importance \\
\hline Quality of Life \& Environment & 0.30 \\
\hline Sustainable Competitiveness & 0.27 \\
\hline Community Economy & 0.23 \\
\hline Learning Society & 0.20 \\
\hline
\end{tabular}


According to the quantified expert judgments, the "quality of life and environment" objective has the highest relative importance $(0.30$ or $30 \%)$. In fulfilling the Thailand S\&T Vision, the "sustainable competitiveness" objective ranks second with a relative importance of 0.27 or $27 \%$. The third-ranked objective is "community and economy," while the "learning society" objective has the lowest importance $(0.20$ or $20 \%$ ) as shown in Figure 16.

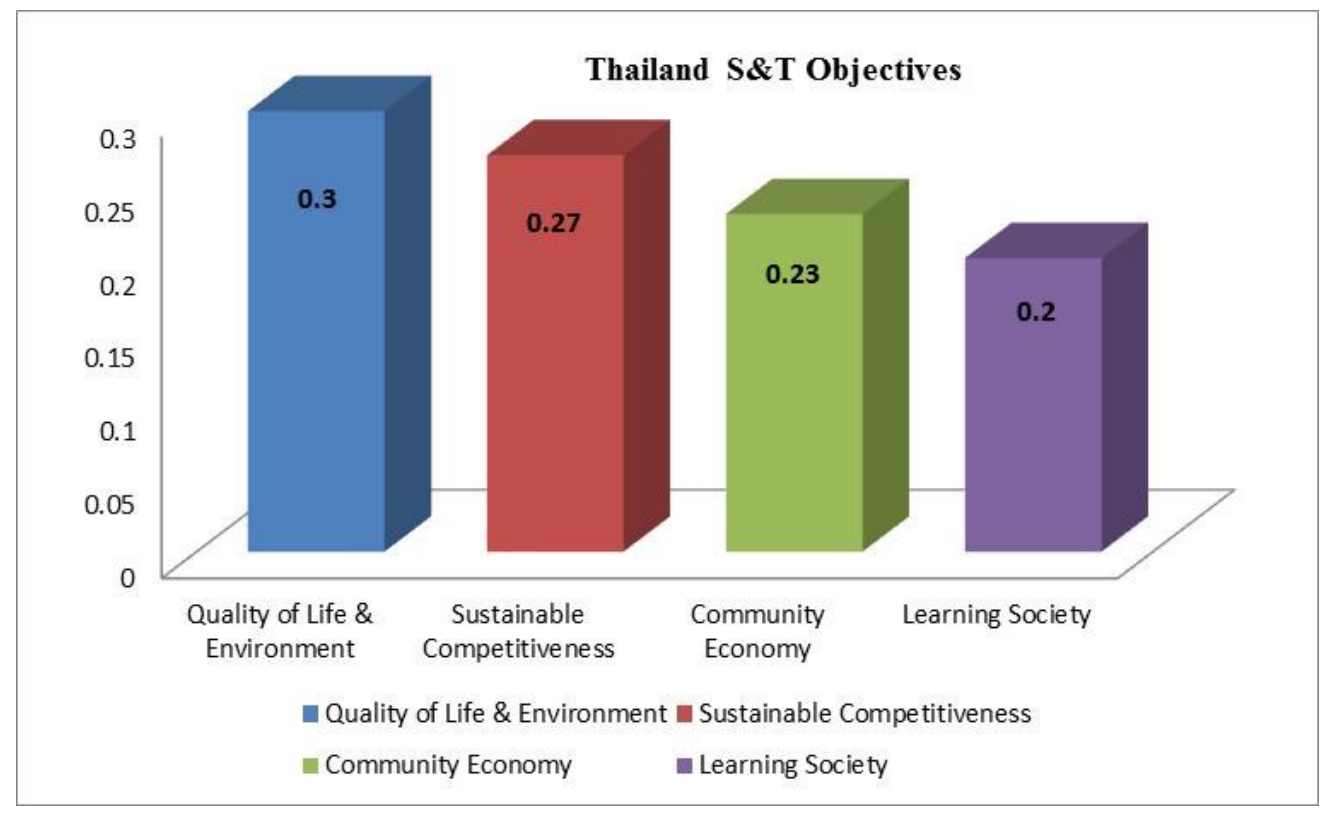

Figure 16: Relative Importance of Thailand S\&T's Objectives

Quality of life and environment is an increasingly important issue in developing countries in general and in Thailand in particular. The two significant contributors to Thais' quality of life are economic well-being and better education. That is why the "quality of life and environment" objective is ranked at first place, followed by "community economy" and "learning society" as the supporting objectives. 
Another observation is that the global competitive environment is changing dramatically. To be able to compete in the long-term, it is important for Thailand to embrace science and technology for competitiveness. That is why the "sustainable competitiveness" objective has the second priority for Thailand.

\subsubsection{Analysis of the Results from Expert Panel I: $2^{\text {nd }}$ level}

\subsubsection{Consistency of the Comparative Judgment and Quantification of Each Expert}

To test the internal consistency of the expert judgment quantifications, the inconsistency measure was used in this research. According to Kocaoglu, the recommended range of inconsistency value is between "0 to 0.10 " [1]. By using Equation 1 from Chapter 3, section 3.5.1, the individual inconsistency of each member of Expert Panel I was calculated and is shown in Table 15.

Table 15: Inconsistency of Expert Panel I

\begin{tabular}{|c|c|}
\hline Expert Panel I & Inconsistency Value \\
\hline EXP I-1 & 0.08 \\
\hline EXP I-2 & 0 \\
\hline EXP I-3 & 0.04 \\
\hline EXP I-4 & 0 \\
\hline EXP I-5 & 0 \\
\hline EXP I-6 & 0.03 \\
\hline
\end{tabular}


All of the inconsistency values from the members of Expert Panel 1 are below 0.10 , which is considered the acceptable limit for inconsistency. This allows us to conclude that the input from the individual members of Expert Panel I is consistent.

\subsubsection{Disagreement among Expert Panel I members}

In order to confirm the acceptance level of agreement among experts, the group disagreement value was calculated by using Equation 2 in Chapter 3, section 3.5.2.

From the calculation, the disagreement among the members of Expert Panel I is 0.10 .

The group judgment quantification is accepted when the disagreement value is less than or equal to 0.10 [1]. It can therefore be concluded that there is disagreement among experts in Expert Panel I, but the disagreement is within the acceptable limit. So the collective expert opinion of Expert Panel I is accepted.

\subsection{The $3^{\text {rd }}$ level: NSTDA's R\&D Strategy - NSTDA Target Sectors \\ In order to fulfill the four Thailand S\&T Objectives, the five NSTDA target sectors (in line with their R\&D strategy) were used for developing the third level of the model as shown in Figure 17.}


The $2^{\text {nd }}$ and the $3^{\text {rd }}$ Level

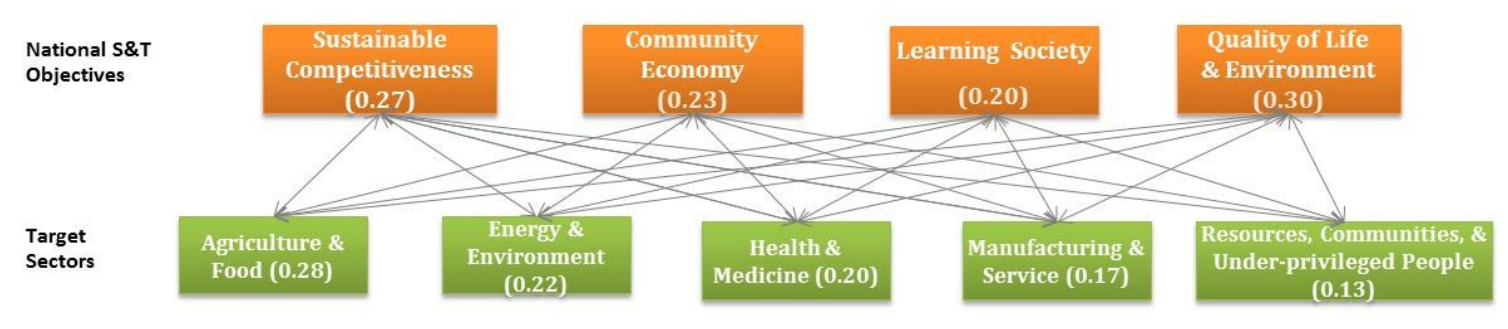

Figure 17: The 3rd level - NSTDA Target Sector

\subsubsection{Results from Expert Panel II: $3^{\text {rd }}$ level}

The members of Expert Panel II were asked to validate the elements in the $3^{\text {rd }}$ level of the model and to determine the relative importance of the five NSTDA target sectors to fulfill the Thailand S\&T Objectives. Expert Panel II included 20high-profile professionals from various different sectors, i.e., government, academia, a non-profit organization, and private companies. The panel members included a president, executive directors, an executive director of a strategic planning division, executive assistant directors, lecturers, a new business development department head, a president of a nonprofit organization, a consultant, technology \& R\&D managers, etc. The organizations represented in Expert Panel II are listed in Chapter 4, section 4.2.1.2.

The members of Expert Panel II were divided into four subgroups corresponding to the four Thailand S\&T Objectives. Each group evaluated only the objective relevant to their interests. (Note that expert member no. 3 is an executive director of the strategic planning division and was included in all four sub-groups.) 


\subsubsection{Relative Importance of NSTDA Five Target Sectors Contributing to Each Thailand S\&T Objectives}

The results of the relative importance of the five NSTDA target sectors with respect to each Thailand S\&T Objective $\left(\mathrm{T}_{\mathrm{m}}^{\mathrm{T}}\right)$ are summarized in Table 16.

Table 16: The Summary of the Relative Importance of Each Target Sector $\left(\mathrm{T}_{\mathrm{m}}^{\mathrm{T}}\right)$

\begin{tabular}{|c|c|c|c|c|c|}
\hline \multirow[b]{2}{*}{$\begin{array}{c}\text { Thailand } \\
\text { S\&T Objectives }\end{array}$} & \multicolumn{5}{|c|}{ NSTDA Target Sectors } \\
\hline & $\begin{array}{l}\text { Agricultu } \\
\text { re\& Food }\end{array}$ & $\begin{array}{c}\text { Energy \& } \\
\text { Environme } \\
\text { nt }\end{array}$ & $\begin{array}{l}\text { Health \& } \\
\text { Medicine }\end{array}$ & $\begin{array}{l}\text { Manufacturi } \\
\text { ng \& Service }\end{array}$ & $\begin{array}{c}\text { Resources, } \\
\text { Communities, } \\
\text { Under- } \\
\text { privileged } \\
\text { people } \\
\end{array}$ \\
\hline $\begin{array}{c}\text { Sustainable } \\
\text { Competitiveness }\end{array}$ & 0.28 & 0.24 & 0.18 & 0.21 & 0.10 \\
\hline $\begin{array}{l}\text { Community } \\
\text { Economy }\end{array}$ & 0.29 & 0.19 & 0.19 & 0.19 & 0.10 \\
\hline Learning Society & 0.27 & 0.23 & 0.22 & 0.16 & 0.13 \\
\hline $\begin{array}{c}\text { Quality of Life \& } \\
\text { Environment }\end{array}$ & 0.27 & 0.23 & 0.22 & 0.12 & 0.17 \\
\hline
\end{tabular}

\section{- Objective 1: Sustainable Competitiveness}

The relative importance of the five NSTDA Target Sectors with respect to the Thailand Sustainable Competitiveness Objective is illustrated in Figure 18. 


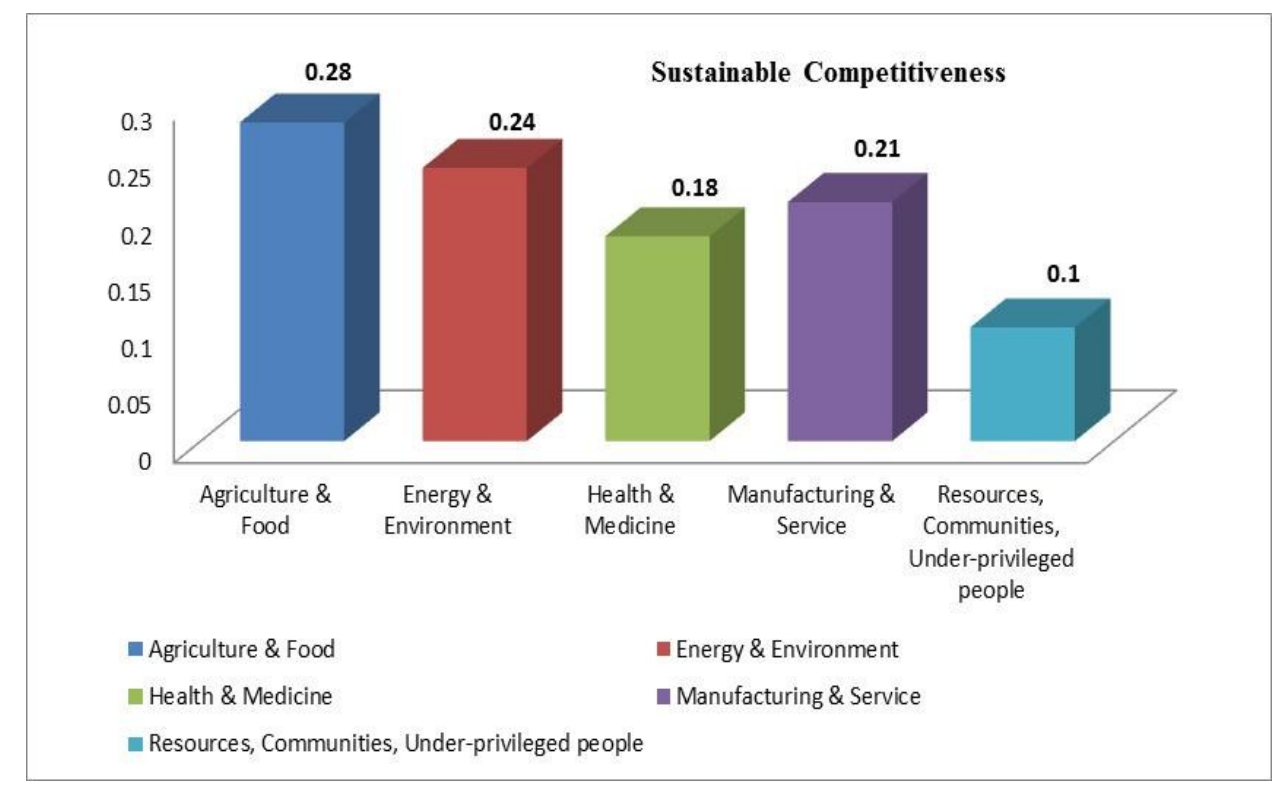

Figure 18: Relative Importance of NSTDA Target Sectors with respect to the Thailand's Sustainable Competitiveness Objective

The six members of Expert Panel II in sub-group 1 were asked to determine the relative importance of the five NSTDA target sectors to fulfill the Thailand S\&T's Sustainable Competitiveness objective.

The results show that the "agriculture and food" sector has the highest relative importance at 0.28 , followed by the "energy and environment" sector at 0.24 . The "manufacturing and service" sector is ranked third at 0.21 . The relative importance of the "health and medicine" and "resources, communities and under-privileged people' sectors is 0.18 and 0.10 respectively. 


\section{- Objective 2: Community Economy}

The relative importance of the five NSTDA target sectors that contributed to the Thailand S\&T Community Economy objective is illustrated in Figure 19.

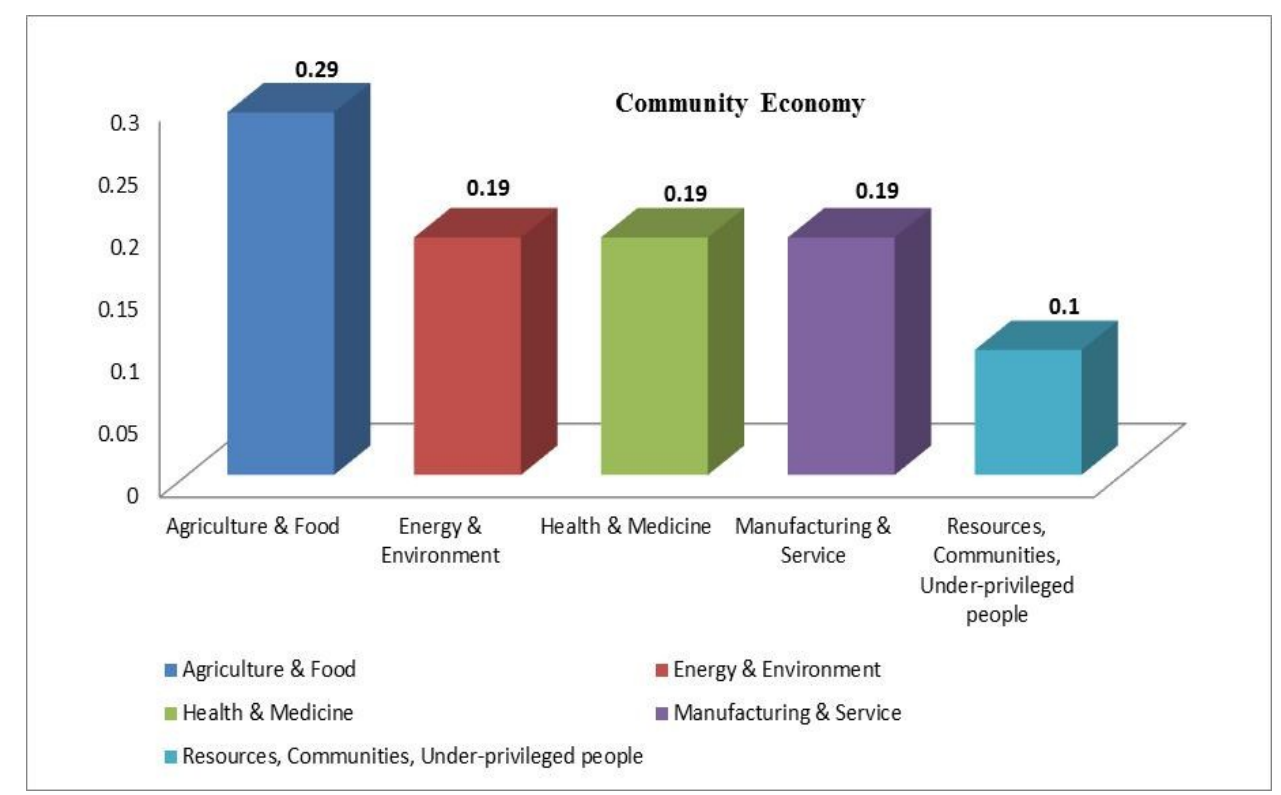

Figure 19: Relative Importance of NSTDA Target Sectors with respect to the Thailand's Community Economy Objective

The six members of Expert Panel II in sub-group 2 were asked to determine the relative importance of the five NSTDA target sectors to fulfill the Thailand Community Economy objective.

The results show that "agriculture and food" sector has the highest relative importance at 0.29 , followed by "energy and environment", "health and medicine" and "manufacturing and Service" sector is ranked second at 0.19. The "resources, communities and under-privileged people" sector ranks last at 0.10 . 


\section{- Objective 3: Learning Society}

The relative importance of the five NSTDA target sectors that contributed to the Thailand S\&T's Learning Society objective is illustrated in Figure 20.

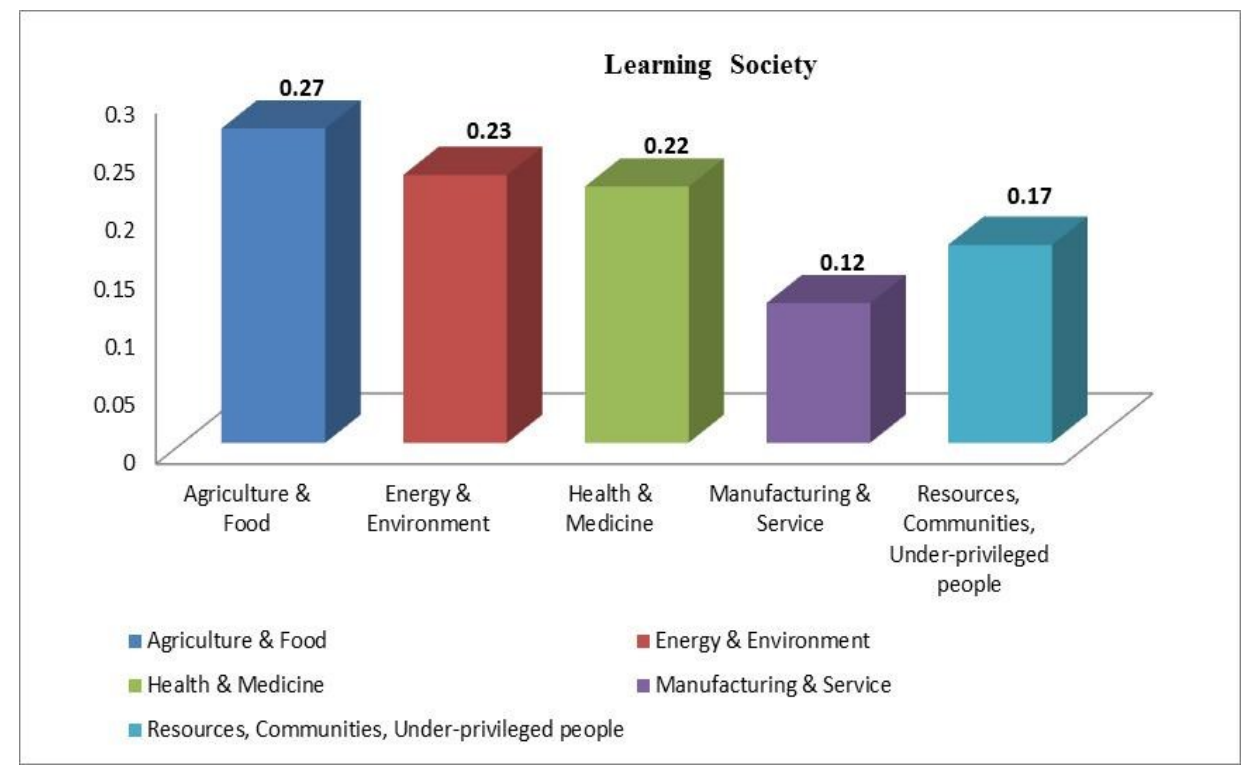

Figure 20: Relative Importance of the NSTDA Target Sectors with respect to the Thailand's Learning Society Objective

The five members of Expert Panel II in sub-group 3 were asked to determine the relative importance of the five NSTDA target sectors to fulfill the Thailand Learning Society Objective.

The results show that the "agriculture and food" sector has the highest relative importance at 0.27 , followed by the "energy and environment" sector at 0.23 . The "health and medicine" sector is ranked third at 0.22 . The "manufacturing and service" and "resources, communities and under-privileged people" sectors are ranked fourth and fifth at 0.17 and 0.12 respectively. 


\section{- Objective 4: Quality of Life and Environment}

The relative importance of the five NSTDA target sectors that contributed to the Thailand Quality of Life and Environment objective is illustrated in Figure 21.

The six members of Expert Panel II in sub-group 4 were asked to determine the relative importance of the five NSTDA target sectors to fulfill the Thailand Quality of Life and Environment objective.

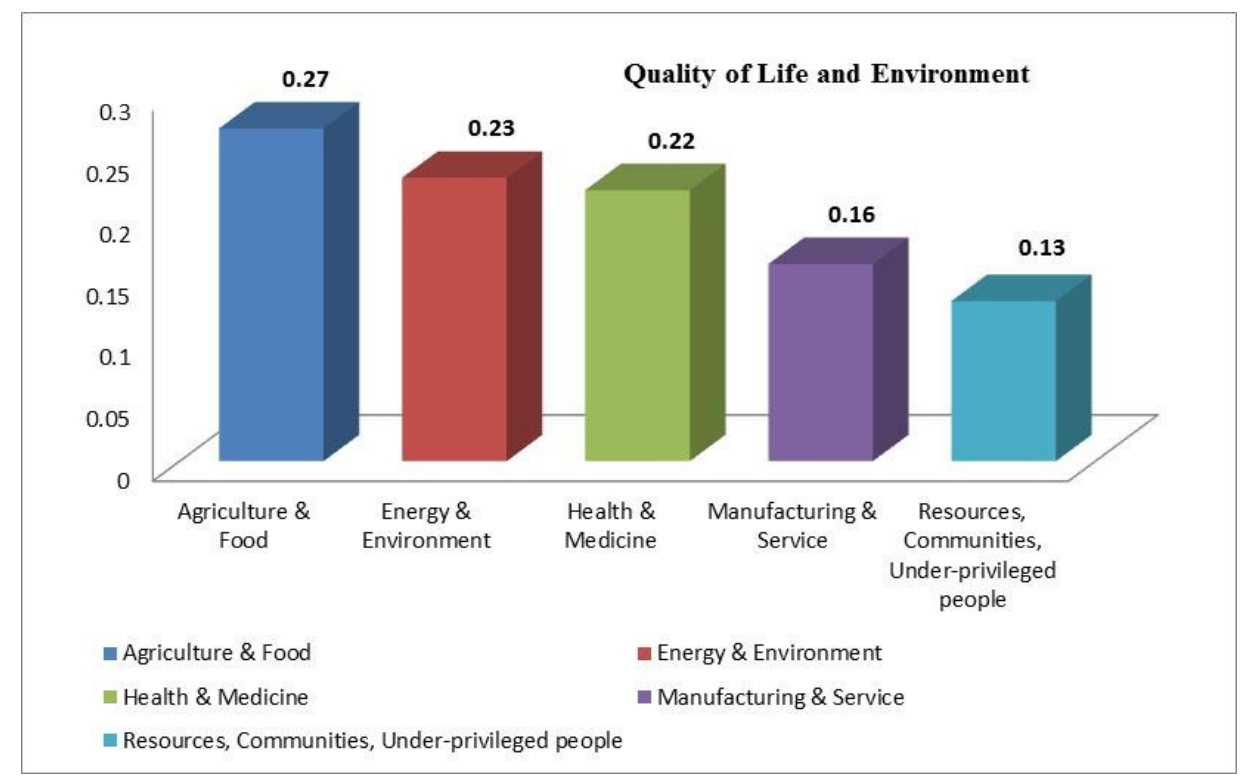

Figure 21: Relative Importance of each NSTDA Target Sector with respect to the Thailand's Quality of Life and Environment Objective

The results show that the "agriculture and food" sector has the highest relative importance at 0.27 , followed by the "energy and environment" sector at 0.23 . The "health and medicine" sector is ranked third at 0.22 . The "resources, communities and underprivileged people" and "manufacturing and service" sectors are ranked fourth and fifth at 0.16 and 0.13 respectively. 


\subsubsection{Relative Importance of the NSTDA Five Target Sectors}

The relative importance of the five NSTDA target sectors with respect to the four Thailand S\&T Objectives $\left(\mathrm{T}_{1}\right)$ is presented in Table 17.

Table 17: Relative Importance of NSTDA Target Sectors $\left(\mathrm{T}_{1}\right)$

\begin{tabular}{|c|c|}
\hline NSTDA Target Sector & Relative Importance \\
\hline Agriculture\& Food & 0.28 \\
\hline Energy \& Environment & 0.22 \\
\hline Health \& Medicine & 0.20 \\
\hline Manufacturing \& Service & 0.17 \\
\hline $\begin{array}{l}\text { Resources, Communities, } \\
\text { \&Under-privileged People }\end{array}$ & 0.13 \\
\hline
\end{tabular}

The calculation of the relative importance of each NSTDA target sector is derived by using Equation 3.

$$
\mathrm{T}_{1}=\mathrm{O}_{\mathrm{m}} * \mathrm{~T}_{\mathrm{m}}^{\mathrm{T}} \quad \text { Equation } 3
$$

Where Target Sectors $\quad \mathrm{T}_{1} ; 1=1, \ldots, \mathrm{L} \quad(\mathrm{L}=5)$

$$
\text { S\&T Objectives } \quad \mathrm{O}_{\mathrm{m}} ; \mathrm{m}=1, \ldots, \mathrm{M} \quad(\mathrm{M}=4)
$$

Target Sectors in specific Objective $\mathrm{T}_{\mathrm{m}}^{\mathrm{T}} ; \mathrm{m}=1, \ldots, \mathrm{M}$ and $\mathrm{t}=1, \ldots, \mathrm{T}(\mathrm{M}=4),(\mathrm{T}=1-5)$ 
Information about the Thailand S\&T objectives $\left(\mathrm{O}_{\mathrm{m}}\right)$ are shown in Table 14, and the relative importance of each target sector $\left(\mathrm{T}_{\mathrm{m}}^{\mathrm{T}}\right)$ is shown in Table 16.

The details of the calculation of relative importance of each NSTDA target sector are as follows:

- Relative Importance of Agriculture and Food Sector

The relative importance of the "Agriculture and Food" sector can be calculated by multiplying the relative importance of every Thailand S\&T objective $\left(\mathrm{O}_{\mathrm{m}=1 \ldots 4}\right)$ with the relative importance of agriculture and food in every objective $\left(\mathrm{T}_{\mathrm{m}=1 \ldots 4}^{1}\right)$ as follows:

$$
\begin{aligned}
& =(0.27,0.23,0.20,0.30) *\left[\begin{array}{l}
0.28 \\
0.29 \\
0.27 \\
0.27
\end{array}\right] \\
& =0.28
\end{aligned}
$$

- Relative Importance of the Energy and Environment Sector

The relative importance of the "Energy and Environment" sector can be calculated by multiplying the relative importance of every Thailand S\&T objective $\left(\mathrm{O}_{\mathrm{m}=1 \ldots 4}\right)$ withthe relative importance of energy and environment in every objective $\left(\mathrm{T}_{\mathrm{m}=1 \ldots 4}^{2}\right)$ as follows:

$$
\begin{aligned}
& =(0.27,0.23,0.20,0.30) *\left[\begin{array}{l}
0.24 \\
0.19 \\
0.23 \\
0.23
\end{array}\right] \\
& =0.22
\end{aligned}
$$


- Relative Importance of the Health and Medicine Sector

The relative importance of the "Health and Medicine" sector can be calculated by multiplying the relative importance of every Thailand S\&T objective $\left(\mathrm{O}_{\mathrm{m}=1 \ldots 4}\right)$ with the relative importance of health and medical in every objective $\left(\mathrm{T}_{\mathrm{m}=1 \ldots 4}^{3}\right)$ as follows:

$$
\begin{aligned}
& =(0.27,0.23,0.20,0.30) *\left[\begin{array}{l}
0.18 \\
0.19 \\
0.22 \\
0.22
\end{array}\right] \\
& =0.20
\end{aligned}
$$

- Relative Importance of the Manufacturing and Service Industry Sector

The relative importance of the "Manufacturing and Service sector" can be calculated by multiplying the relative importance of every Thailand S\&T objective $\left(\mathrm{O}_{\mathrm{m}=1 \ldots 4}\right)$ with the relative importance of manufacturing and service in every objective $\left(\mathrm{T}_{\mathrm{m}=1 \ldots 4}^{4}\right)$ as follows:

$$
\begin{aligned}
& =(0.27,0.23,0.20,0.30) *\left[\begin{array}{l}
0.21 \\
0.19 \\
0.16 \\
0.12
\end{array}\right] \\
& =0.17
\end{aligned}
$$


- Relative Importance of the Resources, Communities and Under-privileged People Sector

The relative importance of the "Resources, communities and under-privileged people" sector can be calculated by multiplying the relative importance of every Thailand S\&T objective $\left(\mathrm{O}_{\mathrm{m}=1 \ldots 4}\right)$ with the relative importance of resources, communities and under-privileged people in every objective $\left(\mathrm{T}_{\mathrm{m}=1 \ldots 4}^{5}\right)$ as follows:

$$
\begin{aligned}
& =(0.27,0.23,0.20,0.30) *\left[\begin{array}{l}
0.10 \\
0.10 \\
0.13 \\
0.17
\end{array}\right] \\
& =0.13
\end{aligned}
$$

The ranking of all five NSTDA target sectors is illustrated in Figure 22. The results of Expert Panel II are discussed in this section.

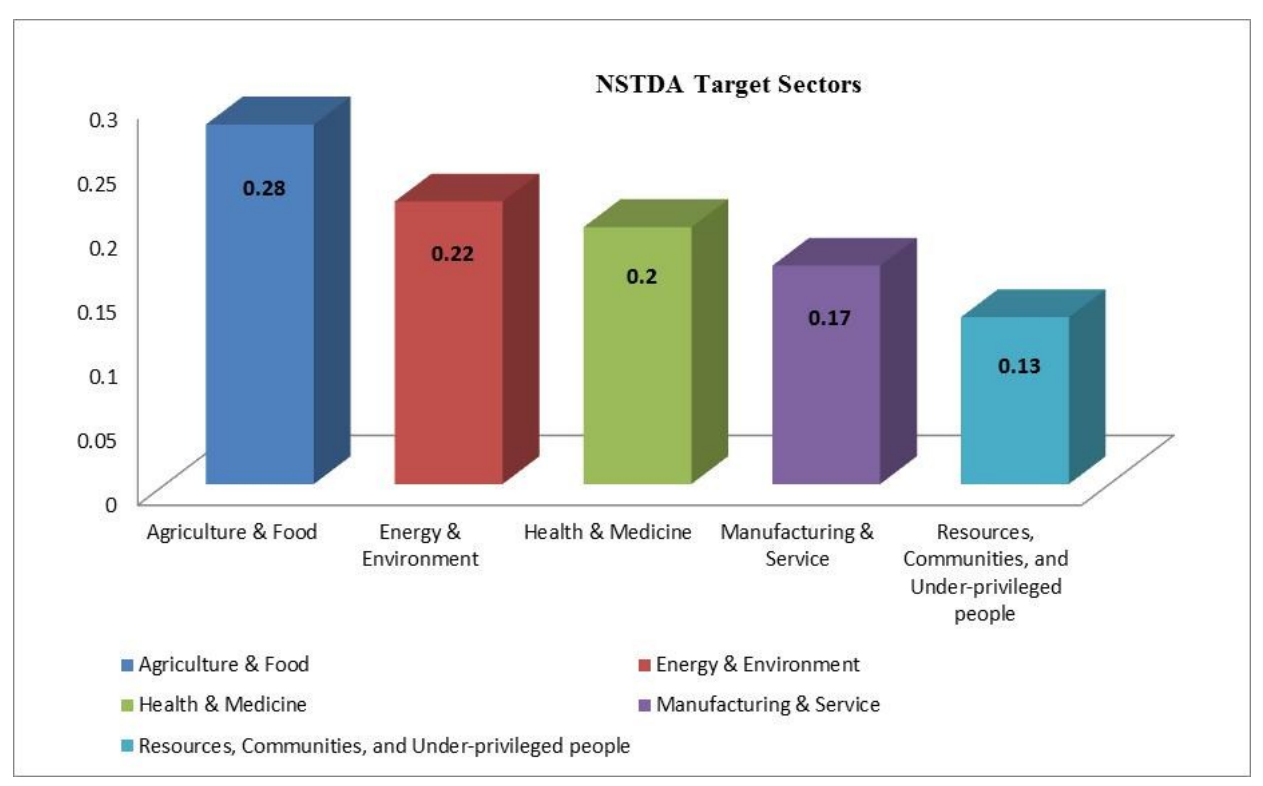

Figure 22: Relative Importance of the five NSTDA target sectors 
From Figure 22, the "Agriculture and Food" sector obtains the highest relative importance with respect to Thailand's five S\&T objectives. This result reflects the fact that Thailand is an agriculture-based country. According to the Asian Development Bank (ADB), the agricultural and food products are the main component of Thailand's GDP (11.6\% GDP in 2009). In this sector rice, rubber, shrimp, and cassava serve as the foundations of Thailand's agriculture-based manufacturing and exporting. It is worth noting that after more than 30 years, Thailand lost its position as the world's number one rice exporter (6.9 billion tons) to India (9.5 million tons) in 2012. The Thai Government has enthusiastically supported the rice science and technology research that could help increase Thai farmers' rice yields.

The "Energy and Environment" sector is perceived as ranking second by Expert Panel II. Energy use and supply is fundamentally critical to society. Thailand's energy and environmental concerns originally came from local problems. However, energy and environmental domains have now widened to cover regional and global issues such as acid rain and the greenhouse effect. Thailand is facing the energy crisis as are other countries around the world. Increasing attention has gone into $R \& D$ projects in the energy and environment sector, including alternative energy resources such as clean energy and renewable energy.

Ranking third is the "Health and Medicine" sector. First, health and medical care are greatly significance for public health. They contribute to improve people's functional ability and quality of life. Second, by applying new and innovative technologies to the 
healthcare system, Thai's health services are maintaining a high international standard and have made great progress during the past 10 years. Thailand has successfully emerged as a regional medical center in terms of the capabilities of its increasingly renowned doctors, attainment of international health delivery standards, and provision of excellent health services at relatively affordable prices.

The "Manufacturing and Service" sector is ranked as the fourth most important target sector for NSTDA to fulfill Thailand's S\&T objectives. The manufacturing and service industries of Thailand play important roles in driving the country's economy. Through NSTDA, Thailand is initiating and supporting various science and technology projects in the manufacturing and service industries in order to increase capability and create added value for the manufacturing and service industries, e.g., hard disk drives and automobiles.

Last but not least, the "Resources, communities, and under-privileged people" sector is perceived by Expert Panel II as ranking fifth. The problems in Thailand's rural areas affect all parts of Thai society. The problems of poverty, resource depletion and a shortage of knowledge affect the quality of life. One of NSTDA's national research centers, NECTEC, has initiated and managed to apply the use of IT to enhance the quality of life and to increase education and work opportunities of under-privileged groups such as rural school children and the disabled. 
5.3.2 Analysis of the Results from Expert Panel II Results: $3^{\text {rd }}$ level

\subsubsection{Consistency of the Comparative Judgment and Quantification of Each \\ Expert}

The inconsistencies of Expert Panel II members are calculated by using Equation

1 from Chapter 3, section 3.5.1, and are shown in Table 18.

Table 18: Inconsistency of Expert Members in Every Subgroup of Expert Panel II

\begin{tabular}{|c|c|c|c|}
\hline $\begin{array}{l}\text { Expert Panel II } \\
\text { Sub Group }\end{array}$ & $\begin{array}{c}\text { Thailand S\&T } \\
\text { Objective }\end{array}$ & Expert Member & Inconsistency \\
\hline \multirow{6}{*}{$\begin{array}{l}\text { Sub-group II-1 } \\
\text { (six experts) }\end{array}$} & \multirow{6}{*}{$\begin{array}{c}\text { Sustainable } \\
\text { Competitiveness }\end{array}$} & EXP II-1 & 0.01 \\
\hline & & EXP II-2 & 0.02 \\
\hline & & EXP II-3 & 0.01 \\
\hline & & EXP II-4 & 0.07 \\
\hline & & EXP II-5 & 0.01 \\
\hline & & EXP II-6 & 0 \\
\hline \multirow{6}{*}{$\begin{array}{l}\text { Sub-group II-2 } \\
\text { (six experts) }\end{array}$} & \multirow{6}{*}{ Community Economy } & EXP II-3 & 0 \\
\hline & & EXP II-7 & 0.07 \\
\hline & & EXP II-8 & 0.01 \\
\hline & & EXP II-9 & 0 \\
\hline & & EXP II-10 & 0.01 \\
\hline & & EXP II-11 & 0.01 \\
\hline \multirow{5}{*}{$\begin{array}{l}\text { Sub-group II-3 } \\
\text { (five experts) }\end{array}$} & \multirow{5}{*}{ Learning Society } & EXP II-3 & 0 \\
\hline & & EXP II-12 & 0 \\
\hline & & EXP II-13 & 0.02 \\
\hline & & EXP II-14 & 0 \\
\hline & & EXP II-15 & 0.02 \\
\hline \multirow{6}{*}{$\begin{array}{l}\text { Sub-group II-4 } \\
\text { (six experts) }\end{array}$} & \multirow{6}{*}{$\begin{array}{l}\text { Quality of Life and } \\
\text { Environment }\end{array}$} & EXP II-3 & 0 \\
\hline & & EXP II-16 & 0.02 \\
\hline & & EXP II-17 & 0.01 \\
\hline & & EXP II-18 & 0.02 \\
\hline & & EXP II-19 & 0.04 \\
\hline & & EXP II-20 & 0.03 \\
\hline
\end{tabular}


Overall, the inconsistency values of Expert Panel II members are highly reliable. Seven out of 20 members have the inconsistency of zero. Most of them have minor inconsistencies, e.g., 0.01 or 0.02 . There are only two expert members who have high inconsistency at 0.07 , but it is still below the acceptable inconsistency threshold of 0.10 .

\subsubsection{Disagreement among Expert Panel II members}

In order to confirm the acceptance level of agreement among experts, the disagreement value was calculated by using the formula from Equation 2 in Chapter 3, section 3.5.3. The disagreements of all four objectives are shown in Table 19.

Table 19: Disagreement Value of Thailand's Four S\&T Objectives

\begin{tabular}{|c|c|}
\hline Thailand S\&T Objectives & Disagreement Value \\
\hline Sustainable Competitiveness & 0.06 \\
\hline Community Economy & 0.06 \\
\hline Learning Society & 0.05 \\
\hline Quality of Life and Environment & 0.07 \\
\hline
\end{tabular}

In this research, the group judgment quantification is accepted when the disagreement value is less than or equal to 0.10 . According to the results from Table 18, the disagreement values from Expert Panel II for all four objectives are lower than 0.10 $(0.06,0.06,0.05$, and 0.07$)$. It can therefore be concluded that there is disagreement among 
the experts in the panel, but the disagreement is low enough to accept the collective expert opinion as being consistent.

In addition, to confirm the agreement level among Expert Panel II members, two statistical tests, intra-class correlation coefficient $\left(r_{i c}\right)$ and statistical hypothesis testing (F-test), were introduced.

By using the SPSS software, the intraclass correlation coefficients $\left(r_{i c}\right)$ and the F-values for all four Thailand S\&T objectives are calculated in order to measure the agreement of Expert Panel II. The results of intraclass correlation coefficients $\left(r_{i c}\right)$, F-Values, F-critical at 0.10 level are shown in Table 20.

Table 20: Intraclass Correlation Coefficient $\left(r_{i c}\right)$ and F-value of All Objectives

\begin{tabular}{|c|c|c|c|c|}
\hline Thailand S\&T Objectives & $\begin{array}{c}\boldsymbol{r}_{\boldsymbol{i c}} \\
\mathbf{0}<\boldsymbol{r}_{\boldsymbol{i c}}<\mathbf{1}\end{array}$ & F-test value & $\begin{array}{c}\text { F-critical } \\
\text { at 0.10 level }\end{array}$ & $\begin{array}{c}\text { F-test } \\
\text { result }\end{array}$ \\
\hline $\begin{array}{c}\text { Sustainable } \\
\text { Competitiveness }\end{array}$ & 0.36 & 3.71 & 2.25 & Reject $\mathrm{H}_{0}$ \\
\hline Community Economy & 0.35 & 3.60 & 2.25 & Reject $\mathrm{H}_{0}$ \\
\hline Learning Society & 0.45 & 3.14 & 2.33 & Reject $\mathrm{H}_{0}$ \\
\hline $\begin{array}{c}\text { Quality of Life and } \\
\text { Environment }\end{array}$ & 0.27 & 2.75 & 2.25 & Reject $\mathrm{H}_{0}$ \\
\hline
\end{tabular}

Note: $\mathrm{H}_{0}: \mathrm{r}_{\mathrm{ic}}=0$ (no correlation showing the disagreement among expert members)

If the intraclass correlation coefficients $\left(r_{i c}\right)$ of all four sub-groups of Expert Panel II are close to 1, that means there is a perfect agreement among that expert panel. For this case, the intraclass correlation coefficients $\left(r_{i c}\right)$ are higher than zero for all cases, which means there is no disagreement among the expert members. And the F-test values of all 
four objectives are higher than the F-critical at the $90 \%$ confidence level, which means the null hypothesis can be rejected.

\subsection{The $4^{\text {th }}$ level: ICST Evaluation Criteria $\&$ Sub-Criteria \& Desirability Curves}

At the $4^{\text {th }}$ level of the model, Expert Panel III members, who are 20 project analysts from NSTDA, were asked to perform the four main tasks, which are 1) to verify the evaluation criteria and related sub-criteria, 2) to determine relative importance of evaluation criteria, 3) to determine the relative importance of evaluation sub-criteria, and 4) to define the desirability curves for all sub-criteria.

The $4^{\text {th }}$ level of a Strategic Policy Model for International Collaboration in S\&T is shown in Figure 23.

The $3^{\text {rd }}$ and the $4^{\text {th }}$ level

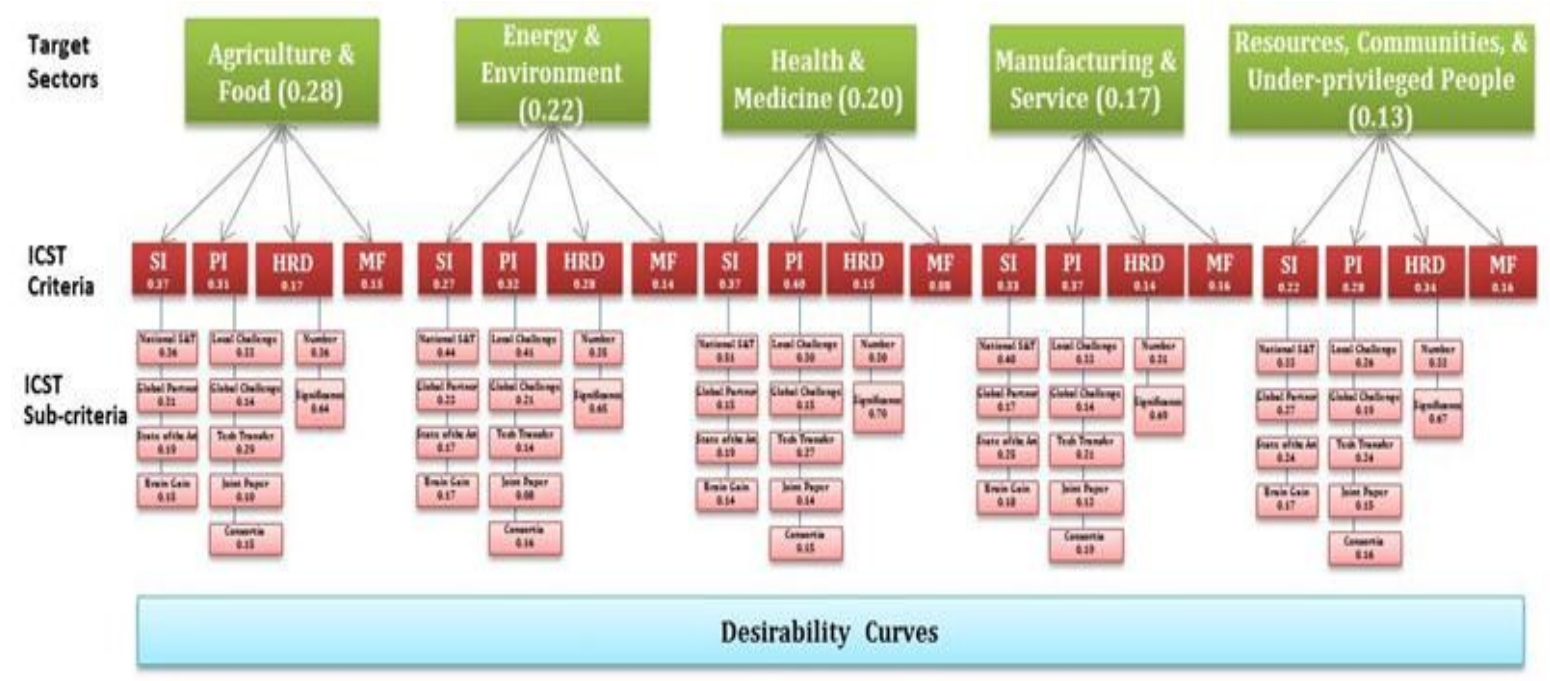

Figure 23: The 4th level - ICST Evaluation Criteria \& Sub-criteria \& Desirability Curves 


\subsubsection{Results from Expert Panel III: $4^{\text {th }}$ level}

Expert Panel III comprised of 20 project analysts from NSTDA, evaluated R\&D projects in the following areas: rice, shrimp, sustainable energy, genomic medicine, and automobiles. More details about Expert Panel III are provided in Chapter 4, section 4.2.1.3.

The members from Expert Panel III were divided into five sub-groups related to NSTDA target sectors. They were asked to give their judgment quantification on the relative importance of each criterion that fulfills the specific target sector, and the relative importance of each sub-criterion that fulfills related criterion in that target sector. The details of the evaluation criteria and sub-criteria are explained in Chapter 4, sections 4.5.2 and 4.5.3

\subsubsection{Summary of Relative Importance of the Four Evaluation Criteria}

According to the results from Expert Panel III, these four criteria were verified and confirmed as the significant ones to use as the evaluative criteria for international collaboration in S\&T research.

The results of the relative importance of the four evaluation criteria from all target sectors are shown in Table 21. 
Table 21: Relative Importance of the Four Evaluation Criterion

\begin{tabular}{|c|c|c|c|c|}
\hline \multirow{2}{*}{ NSTDA Target Sectors } & \multicolumn{4}{|c|}{ ICST Evaluation Criteria } \\
\cline { 2 - 5 } & SI & PI & HRD & MF \\
\hline Agriculture\& Food & 0.37 & 0.31 & 0.17 & 0.15 \\
\hline Energy \& Environment & 0.27 & 0.32 & 0.28 & 0.14 \\
\hline Health \& Medicine & 0.37 & 0.40 & 0.15 & 0.08 \\
\hline Manufacturing \& Service & 0.23 & 0.37 & 0.14 & 0.16 \\
\hline $\begin{array}{c}\text { Resources, Communities, } \\
\text { and Under-privileged People }\end{array}$ & 0.22 & 0.28 & 0.34 & 0.16 \\
\hline
\end{tabular}

According to the experts, the results of the relative importance of the four evaluation criteria that fulfill each target sector are described as follows:

- $\quad$ Agriculture and Food sector:

SI has the highest relative importance contribution to NSTDA's Agriculture and Food Sector (0.37), followed by PI (0.31), HRD (0.17) and MF (0.15).

- $\quad$ Energy and Environment sector:

PI has the highest relative importance contribution to NSTDA's Energy and Environment sector (0.32), followed by HRD (0.28), SI (0.27) and MF (0.14).

- $\quad$ Health and Medicine sector:

PI has the highest relative importance contribution to NSTDA's Health and Medicine sector (0.40), followed by SI (0.37), HRD (0.15) and MF (0.08).

- $\quad$ Manufacturing and Service sector:

PI has the highest relative importance contribution to NSTDA's Manufacturing and Service sector (0.37), followed by SI (0.23), MF (0.16) and HRD (0.16).

- $\quad$ Resources, Communities, and Under-privileged People sector: 
HRD has the highest relative importance contribution to NSTDA's Resources, Communities, and Under-privileged People sector (0.34), followed by PI (0.28), SI (0.22) and MF (0.16).

\subsubsection{Summary of Relative Importance of the Evaluation Sub-criteria of SI}

According to the quantification of Expert Panel III judgments, the results are presented in Table 22.

Table 22: Relative Importance of Strategic Importance (SI) Sub-criterion

\begin{tabular}{|c|c|c|c|c|}
\hline \multirow{2}{*}{ NSTDA Target Sectors } & \multicolumn{4}{|c|}{ Strategic Importance (SI) } \\
\cline { 2 - 5 } & $\begin{array}{c}\text { National } \\
\text { S\&T }\end{array}$ & $\begin{array}{c}\text { Global } \\
\text { Partnership }\end{array}$ & $\begin{array}{c}\text { State of } \\
\text { the Art }\end{array}$ & $\begin{array}{c}\text { Brain } \\
\text { Gain }\end{array}$ \\
\hline Agriculture\& Food & 0.36 & 0.31 & 0.19 & 0.15 \\
\hline Energy \& Environment & 0.44 & 0.23 & 0.17 & 0.17 \\
\hline Health \& Medicine & 0.51 & 0.15 & 0.19 & 0.14 \\
\hline Manufacturing \& Service & 0.40 & 0.17 & 0.25 & 0.18 \\
\hline $\begin{array}{c}\text { Resources, Communities, and } \\
\text { Under-privileged People }\end{array}$ & 0.33 & 0.27 & 0.24 & 0.17 \\
\hline
\end{tabular}

According to the experts, the results of the relative importance of the four evaluation sub-criteria of strategic importance (SI) that fulfills each target sector are described as follows: 
- $\quad$ Agriculture and Food sector:

National S\&T capability has the highest relative importance contribution to NSTDA's Agriculture and Food Sector (0.36), followed by global partnership (0.31), state of the art knowledge (0.19) and brain gain (0.15).

- $\quad$ Energy and Environment sector:

National S\&T capability has the highest relative importance contribution to NSTDA's Energy and Environment sector (0.44) followed by global partnership (0.23). State of the art knowledge and brain criteria receive the same relative importance at 0.17 .

- $\quad$ Health and Medicine sector:

National S\&T capability has the highest relative importance contribution to NSTDA's Health and Medicine sector (0.51), followed by state of the art knowledge (0.19), global partnership (0.15) and brain gain (0.14).

- $\quad$ Manufacturing and Service sector:

National S\&T capability has the highest relative importance contribution to NSTDA's Manufacturing and Service sector (0.40), followed by state of the art knowledge (0.25), brain gain (0.18) and global partnership (0.17).

- $\quad$ Resources, Communities, and Under-privileged People sector:

National S\&T capability has the highest relative importance contribution to NSTDA's Resources, Communities, and Under-privileged People sector (0.33), followed by global partnership (0.27), state of the art knowledge (0.24) and brain gain (0.17). 


\subsubsection{Summary of Relative Importance of the Evaluation Sub-criteria of PI}

According to the quantification of Expert Panel III judgments, the results are presented in Table 23.

Table 23: Relative Importance of Potential Impact (PI) Sub-criterion

\begin{tabular}{|c|c|c|c|c|c|}
\hline \multirow{2}{*}{ NSTDA Target Sectors } & \multicolumn{5}{|c|}{ Potential Impact (PI) } \\
\cline { 2 - 6 } & $\begin{array}{c}\text { Local } \\
\text { Challe } \\
\text { nge }\end{array}$ & $\begin{array}{c}\text { Global } \\
\text { Challenge }\end{array}$ & $\begin{array}{c}\text { Tech } \\
\text { Transfer }\end{array}$ & $\begin{array}{c}\text { Academic } \\
\text { Paper }\end{array}$ & Consortia \\
\hline Agriculture\& Food & 0.33 & 0.14 & 0.29 & 0.10 & 0.15 \\
\hline Energy \& Environment & 0.45 & 0.18 & 0.14 & 0.07 & 0.16 \\
\hline Health \& Medicine & 0.30 & 0.15 & 0.27 & 0.14 & 0.15 \\
\hline $\begin{array}{c}\text { Manufacturing \& Service } \\
\text { Resources, Communities, } \\
\text { \& Under-privileged } \\
\text { People }\end{array}$ & 0.33 & 0.14 & 0.21 & 0.13 & 0.19 \\
\hline
\end{tabular}

According to the experts, the results of the relative importance of the four evaluation sub-criteria of potential impact (PI) that fulfills each target sector as shown in Table 23 can be described as follows:

- $\quad$ Agriculture and Food sector:

Local challenge has the highest relative importance contribution to NSTDA's Agriculture and Food Sector (0.33), followed by technology transfer (0.29), consortia (0.15), global challenge $(0.14)$ and academic paper $(0.10)$. 
- $\quad$ Energy and Environment sector:

Local challenge has the highest relative importance contribution to NSTDA's Energy and Environment sector (0.45), followed by global challenge (0.18), consortia (0.16), technology transfer (0.14) and academic paper (0.07).

- Health and Medicine sector:

Local challenge has the highest relative importance contribution to NSTDA's Health and Medicine sector (0.30), followed by technology transfer (0.27), consortia \&global challenge at the same relative importance (0.15), and academic paper (0.14).

- $\quad$ Manufacturing and Service sector:

Local challenge has the highest relative importance contribution to NSTDA's Manufacturing and Service sector (0.33), followed by technology transfer (0.21), consortia (0.19), and global challenge (0.14) and academic paper (0.13).

- $\quad$ Resources, Communities, and Under-privileged People sector: Local challenge has the highest relative importance contribution to NSTDA's Resources, Communities, and Under-privileged People sector (0.26), followed by technology transfer (0.24), global challenge (0.19), consortia (0.16), and academic paper (0.15). 


\subsubsection{Summary of Relative Importance of the Evaluation Sub-criteria of HRD}

According to the experts, the results of the relative importance of the four evaluation sub-criteria of Human Resource Development (HRD) that fulfills each target sector is shown in Table 24 and can be described as follows:

Table 24: Relative Importance of Human Resource Development (HRD) Sub-criterion

\begin{tabular}{|c|c|c|}
\hline NSTDA Target Sectors & $\begin{array}{c}\text { No. of } \\
\text { Researcher }\end{array}$ & $\begin{array}{c}\text { Significant } \\
\text { Benefit to } \\
\text { Researcher }\end{array}$ \\
\hline Agriculture\& Food & 0.36 & 0.64 \\
\hline Energy \& Environment & 0.35 & 0.65 \\
\hline Health \& Medicine & 0.30 & 0.70 \\
\hline Manufacturing \& Service & 0.31 & 0.69 \\
\hline $\begin{array}{c}\text { Resources, Communities, \& } \\
\text { Under-privileged People }\end{array}$ & 0.32 & 0.68 \\
\hline
\end{tabular}

- $\quad$ Agriculture and Food sector:

Significant benefit to researcher sub-criterion has the higher relative importance contribution to NSTDA's Agricultural and Food sector (0.64) over the number of researcher sub-criterion $(0.36)$.

- $\quad$ Energy and Environment sector:

Significant benefit to researcher sub-criterion has the higher relative importance contribution to NSTDA's Energy and Environment sector (0.65) over the number of researcher sub-criterion (0.35). 
- $\quad$ Health and Medicine sector:

Significant benefit to researcher sub-criterion has the higher relative importance contribution to NSTDA's Health and Medical sector (0.70) over the number of researcher sub-criterion (0.30).

- Manufacturing and Service sector:

Significant benefit to researcher sub-criterion has the higher relative importance contribution to NSTDA's Manufacturing and Service sector (0.69) over the number of researcher sub-criterion (0.31).

- $\quad$ Resources, Communities, and Under-privileged People sector:

Significant benefit to researcher sub-criterion has the higher relative importance contribution to NSTDA's Resources, Communities, and Under-privileged People sector $(0.68)$ over the number of researcher sub-criterion $(0.32)$.

\subsubsection{Summary of Relative Importance of the Evaluation Sub-criteria of MF}

The relative importance of Matching Fund Ratio (MF) of all NSTDA target sectors is shown in Table 25. 
Table 25: Relative Importance of Human Resource Development (MF) Sub-criterion

\begin{tabular}{|c|c|}
\hline Target Sectors & MF Ratio \\
\hline Agricultural \& Food & 0.15 \\
\hline Energy \& Environment & 0.14 \\
\hline Health \& Medical & 0.08 \\
\hline $\begin{array}{c}\text { Manufacturing \& Service } \\
\text { Resources, Communities, \& Under- } \\
\text { privileged People }\end{array}$ & 0.16 \\
\hline
\end{tabular}

Note: Matching Fund Ratio = Requested Fund/ Total Fund

\subsubsection{Desirability Curve of Evaluation Sub-criteria}

The desirability curve is another strategic decision-making tool that is used in this research. The concept of a desirability curve is to measure the individual expert member's desirability and then calibrating or normalizing it to get the representative desirability value of the whole group.

For this research, the members of Expert Panel III were individually asked to give their desirability score corresponding to each sub-criterion. A detailed description of each sub-criterion is provided in Appendix A.

Then the desirability score from each expert member on the same panel was calculated and fitted into a graph. The desirability curve can be linear or non-linear based on the developed functional relationship defined by experts. For example, the desirability 
curves of one of the strategically important sub-criterion, SI-1: to build up national capabilities for the Agricultural and Food sector, is illustrated in Figure 24.

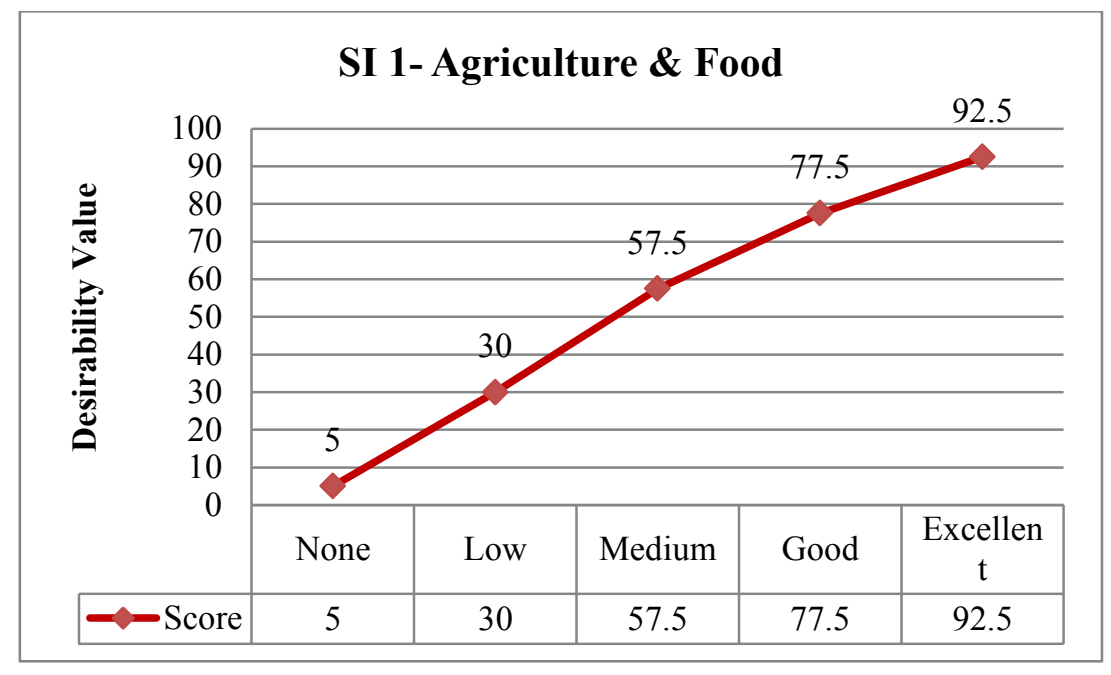

Figure 24: S1-To build up National S\&T Capabilities through International Collaboration in S\&T

The way to interpret the desirability value is by using the desirability curve to obtain the specific desirability value. For example, from Figure 24, if one expert evaluates a proposal and the result shows that this proposal helps build up the national S\&T capability in the Agricultural and Food sector at the medium level, then the desirability value of SI-1 is 57.5 .

The desirability curves of all sub-criteria of the five NSTDA target sectors are illustrated in Appendix B. 


\subsubsection{Analysis of the Results from Expert Panel III: $4^{\text {th }}$ level}

\subsubsection{Analysis of the Relative Importance of the Four Evaluation Criteria}

The graphs of four evaluation sub-criteria of all NSTDA target sectors are illustrated in Figure 25.

From the results shown in Figure 24, the strategic importance (SI) criterion of the "Agriculture and Food" sector obtains the highest relative importance at 0.37 . This is because Thailand is currently placing a strong emphasis on supporting the S\&T research at both national and international levels to improve the yield and quality of various agricultural products, especially rice, which resulted in the high score of the SI criterion (note: especially, the building national S\&T capability sub-criterion).

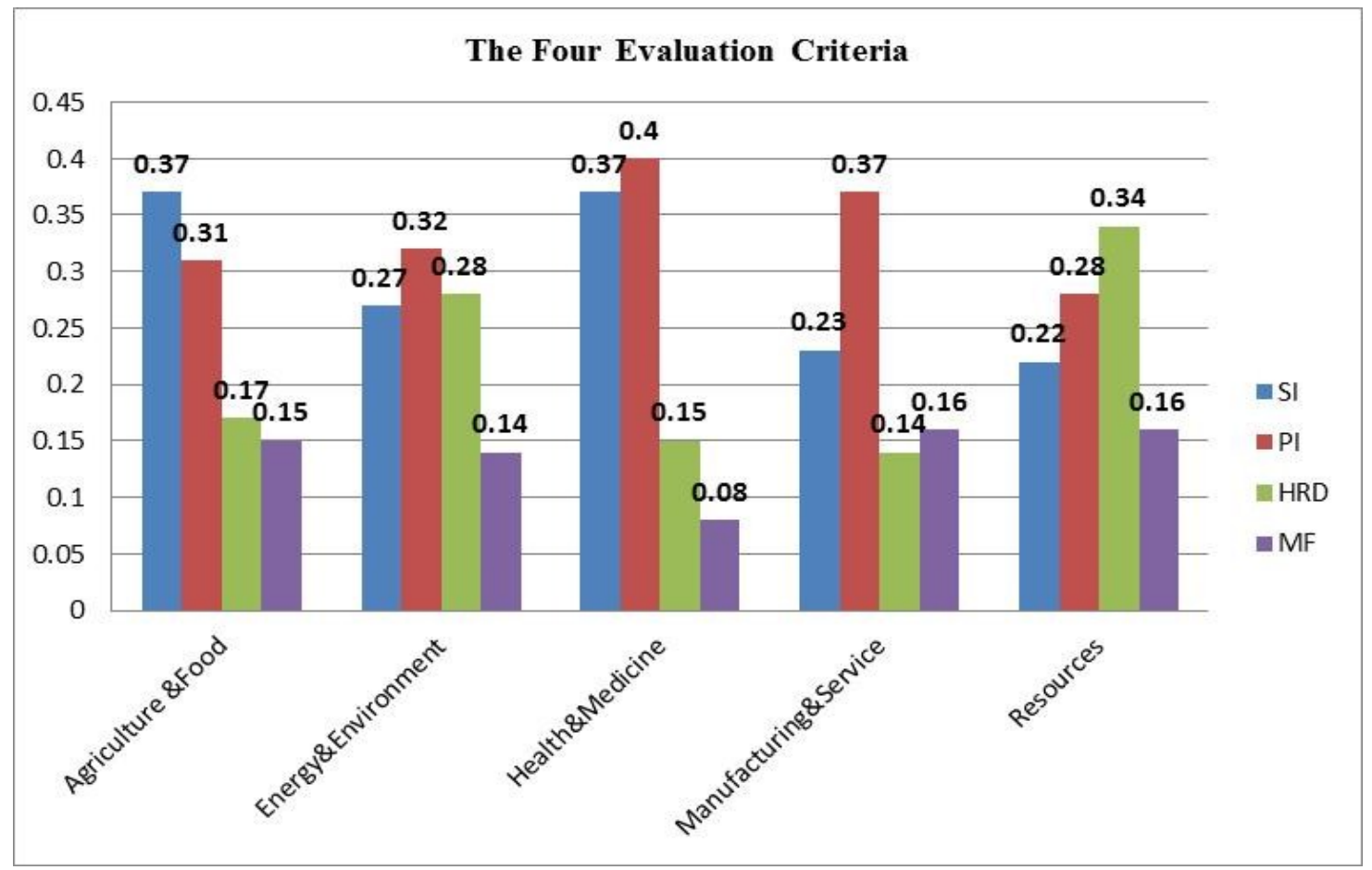

Figure 25: Relative Importance of the Four Evaluation Criteria 
The potential impact (PI) criterion is the most important criterion for the three target sectors "Energy and Environment," "Health and Medicine," and "Manufacturing and Service." For these three target sectors, the local challenge is the most important aspect (from Figure 26) for the S\&T development in Thailand, which drives the PI criterion to obtain the highest score. Many R\&D projects that deliver the output and outcome to help solve the country's challenges gain the high priority right now.

For the "Resources, communities, and under-privileged people" sector, the most important aspect for allocating the $\mathrm{R} \& \mathrm{D}$ funding is to help strengthen human resource abilities because the main objective of this target sector is to apply science and technology to help people, especially those who are under-privileged, e.g., hill tribe people.

Matching Fund obtains the less relative importance score among the four strategic importance sub-criteria. Technology development and the potential output gain are of more concern than the budget. The main reason to collaborate with the global partner is not to obtain the funding but to pursue issues such as transferring technology or knowledge between partners or sharing research topic or research interests. 


\subsubsection{Analysis of Relative Importance of the Four Evaluation Sub-criteria of SI}

From the strategic importance (SI) evaluation sub-criteria, it is obvious that building the National S\&T Capability sub-criterion has the highest relative importance contribution to all five of NSTDA's Target Sectors as illustrated in Figure 26.

The National Science and Technology Strategic Plan (2004-2013) emphasizes applying science and technology to respond to the demands of the economy and society. Improving and maintaining competitive advantage globally will be accomplished through a strong foundation of the country's science and technology. And international collaboration in S\&T for Thailand is viewed as an important tool that helps in building up the country's competitiveness.

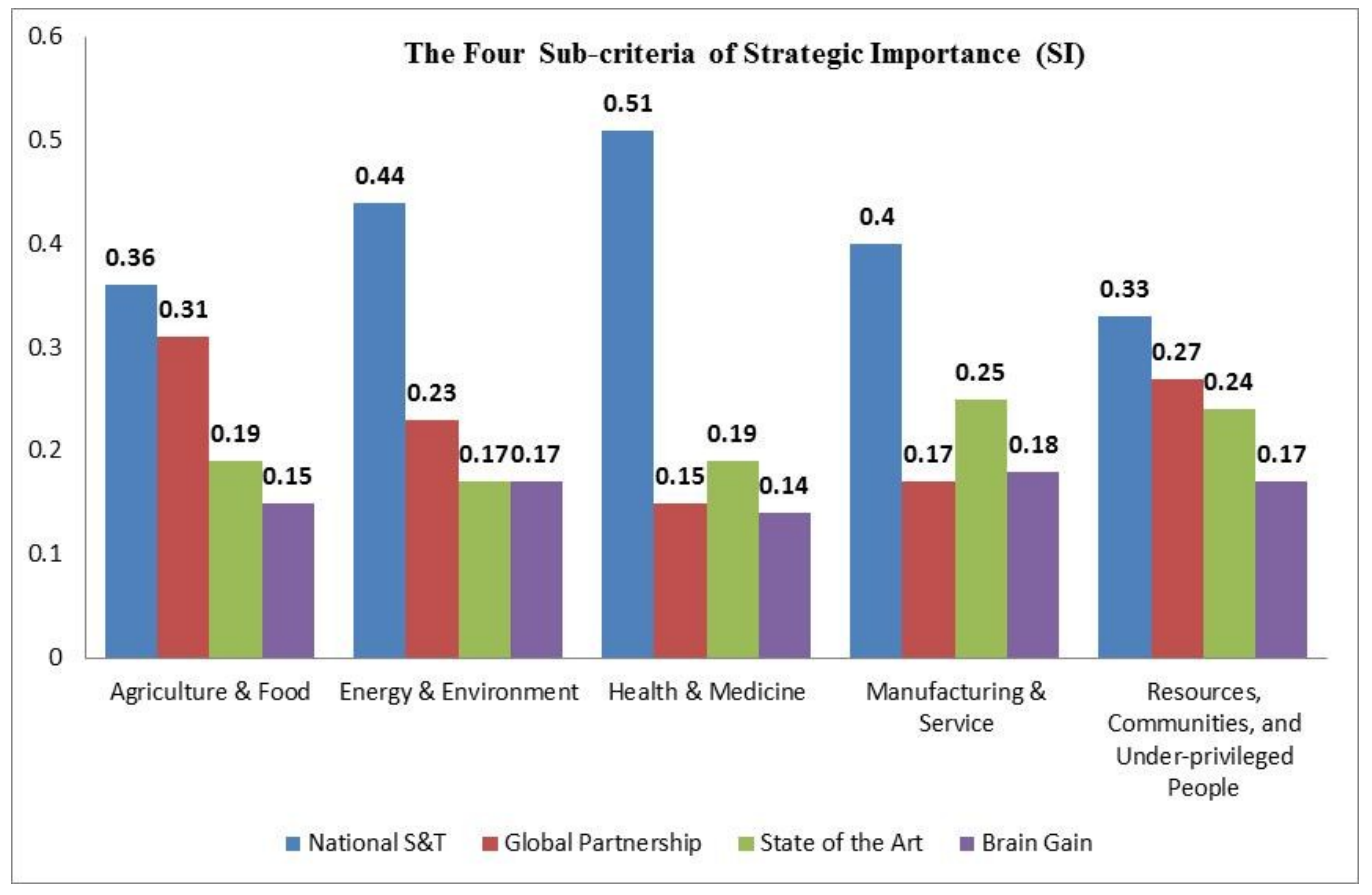

Figure 26: Relative Importance of the Four Sub-criteria of SI 
Initiating global partnerships and obtaining state of the art are the next two following orders which obtained the higher relative importance than the brain gain subcriterion. This is because Thailand is more interested in working with international partners and exchanging technology or knowledge rather than trying to bring its highly professional talent back to their home country.

The concept of collaborating works well with the Thai's scientific society, there are various successful projects of international collaboration in S\&T from different areas in the past. Thus, the Thai government places more emphasis on working with partners worldwide in order to create stronger and better R\&D projects.

Bringing Thai professionals who are overseas back to Thailand is not easy because of the various factors in real life, e.g., family relocation, children's education, different working style and living environment, etc. Thus, the Thai government has been paying more attention to other approaches; having high-profile professionals around the world come to work in Thailand (brain gain) is perceived as another good alternative.

\subsubsection{Analysis of Relative Importance of the Four Evaluation Sub-criteria of PI}

Under the Potential Impact (PI) criterion, the local challenge sub-criterion is judged by Expert Panel III to be the most important sub-criterion for all five NSTDA target sectors as illustrated in Figure 27. 


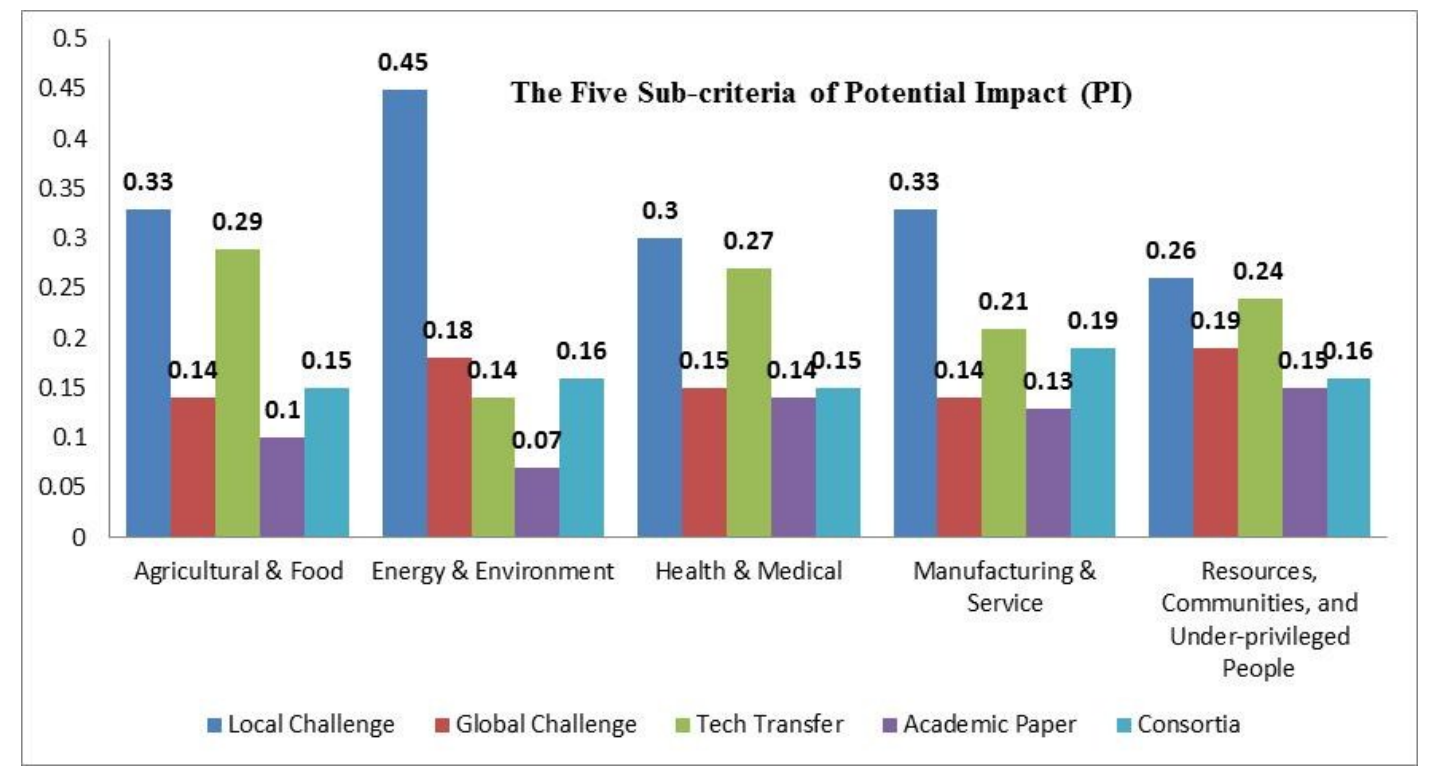

Figure 27: Relative Importance of the Five Sub-criteria of PI

Solving the local challenge sub-criterion has the highest relative importance from all five NSTDA target sectors. Thailand is a developing country in the stage of fast-paced S\&T development. Tackling the local needs and challenges are the most significant issues for Thailand.

The technology and knowledge transfer sub-criterion obtains the second rank in almost every target sector except the energy and environment sector. This is because to attain sustainable development, Thailand must have its scientific knowledge at a certain level that is able to further knowledge development from various sources at an effective rate. This means new knowledge has to be acquired and accumulated consistently, and one of the effective sources is knowledge transfer and technology acquisition through the global scientific partners around the world. However, for the energy and environment 
sector, tackling or participating in global issues seems to be the second most important aspect because energy and environment is a global issue, and one country cannot solve all the issues. It is a multinational mission.

For almost every target sector except the "resources, communities, and underprivileged people," the third rank is the initiating consortia sub-criterion. The academic paper is the sub-criterion that receives the lowest relative importance score from all target sectors. Under the development of research-driven sector, or the "R\&D target sector management," NSTDA puts more emphasis on applied research or problem-solving projects so that various stakeholders, e.g. scientific partners and industrial partners, can work together through the consortia concept.

\subsubsection{Analysis of Relative Importance of the Four Evaluation Sub-criteria of HRD}

According to Expert Panel III, it is obvious that the significant benefit to researcher criterion obtained higher relative importance than the number of researchers who can benefit from project as illustrated in Figure 28. 


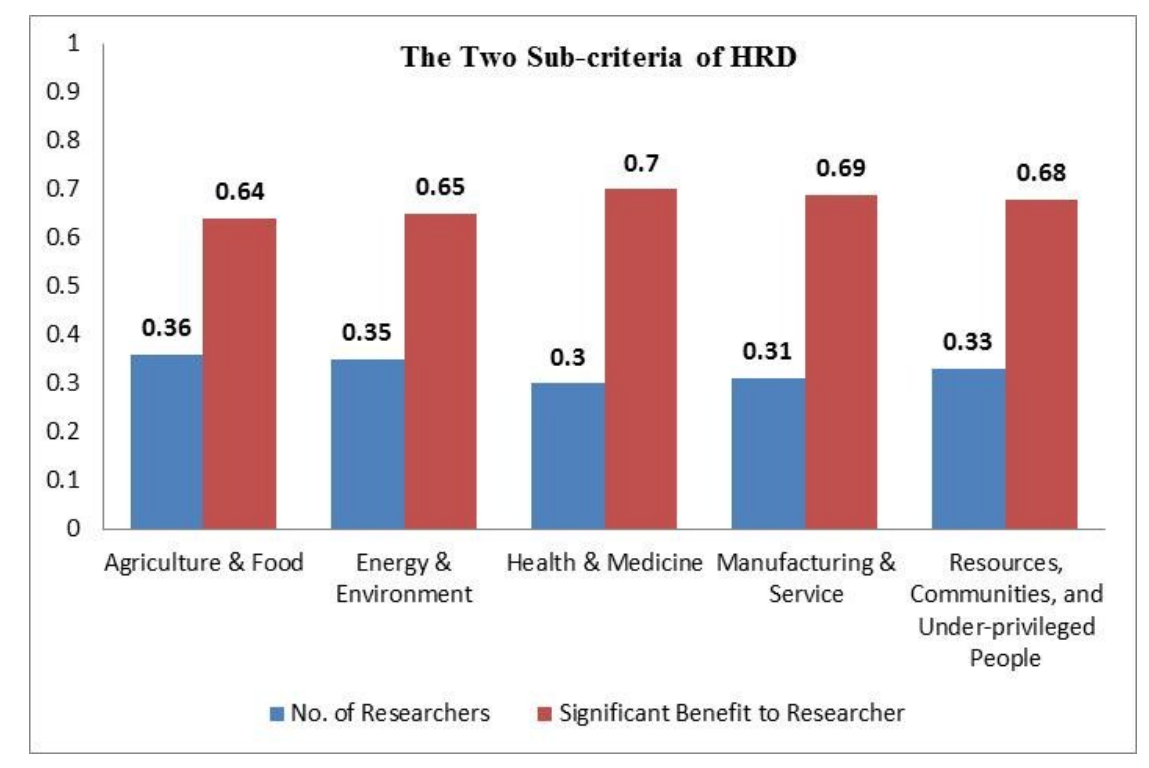

Figure 28: Relative Importance of the Five sub-criteria of HRD

This is based on the fact that even if there is only one researcher who can benefit from the international collaboration project but at the high significance level, it is better than the project that serves many people but at a low level of significance.

\subsubsection{Consistency of the Comparative Judgment and Quantification of Each Expert}

The inconsistency of each expert member is shown in Table 26. 
Table 26: Inconsistency Value of Expert Panel III

\begin{tabular}{|c|c|c|c|c|}
\hline \multirow{2}{*}{$\begin{array}{l}\text { Expert Panel III } \\
\text { Sub-group }\end{array}$} & \multicolumn{4}{|c|}{ Inconsistency Value } \\
\hline & Criteria & SI & PI & HRD \\
\hline \multirow{4}{*}{$\begin{array}{l}\text { Agriculture\& } \\
\text { Food }\end{array}$} & 0.01 & 0.01 & 0.03 & 0 \\
\hline & 0.04 & 0.04 & 0.01 & 0 \\
\hline & 0.01 & 0.01 & 0.01 & 0 \\
\hline & 0.03 & 0.01 & 0.01 & 0 \\
\hline \multirow{4}{*}{$\begin{array}{c}\text { Energy \& } \\
\text { Environment }\end{array}$} & 0.01 & 0.01 & 0.01 & 0 \\
\hline & 0.04 & 0.05 & 0.04 & 0 \\
\hline & 0.02 & 0.02 & 0.08 & 0 \\
\hline & 0.02 & 0 & 0.01 & 0 \\
\hline \multirow{4}{*}{$\begin{array}{l}\text { Health \& } \\
\text { Medicine }\end{array}$} & 0.04 & 0.02 & 0.01 & 0 \\
\hline & 0.04 & 0 & 0.01 & 0 \\
\hline & 0.03 & 0.01 & 0.04 & 0 \\
\hline & 0 & 0 & 0.01 & 0 \\
\hline \multirow{4}{*}{$\begin{array}{c}\text { Manufacturing \& } \\
\text { Service }\end{array}$} & 0.01 & 0.01 & 0.02 & 0 \\
\hline & 0.01 & 0 & 0.03 & 0 \\
\hline & 0.02 & 0.01 & 0.11 & 0 \\
\hline & 0 & 0 & 0.07 & 0 \\
\hline \multirow{4}{*}{$\begin{array}{c}\text { Resources, } \\
\text { Communities, and } \\
\text { Under-privileged } \\
\text { People }\end{array}$} & 0.03 & 0.03 & 0.04 & 0 \\
\hline & 0.01 & 0.04 & 0.02 & 0 \\
\hline & 0.01 & 0.07 & 0.03 & 0 \\
\hline & 0.08 & 0 & 0.02 & 0 \\
\hline
\end{tabular}

The inconsistency values of all expert members in Expert Panel III for both criteria and sub-criteria judgment quantifications are quite low, e.g., $0,0.01$ or 0.02 . Only a few expert members have high inconsistency, e.g., 0.07, 0.08. However, these values are still below the acceptable inconsistency threshold of 0.10 .Thus, it can be concluded that each expert member in Expert Panel III is consistent. 


\subsubsection{Disagreement among Expert Panel III members}

\subsection{The Four Evaluation Criteria}

The disagreement value and the intraclass correlation coefficient $\left(\boldsymbol{r}_{\boldsymbol{i c}}\right)$ for all five target sectors are calculated in order to indicate the agreement among the four expert members about each target sector (20 expert members in total). The disagreement value and intraclass correlation coefficient of SI sub-criteria values are shown in Table 27.

Table 27: Disagreement Value, Intraclass Correlation Coefficient of Four Criteria

\begin{tabular}{|c|c|c|}
\hline Thailand S\&T Objective & Disagreement Value & $\begin{array}{c}\boldsymbol{r}_{\boldsymbol{i c}} \\
\mathbf{0}<\boldsymbol{r}_{\boldsymbol{i c}}<\mathbf{1}\end{array}$ \\
\hline Agriculture\& Food & 0.07 & 0.56 \\
\hline Energy \& Environment & 0.11 & -0.21 \\
\hline Health \& Medicine & 0.07 & 0.70 \\
\hline Manufacturing \& Service & 0.07 & 0.60 \\
\hline $\begin{array}{c}\text { Resources, Communities, } \\
\text { and Under-privileged } \\
\text { People }\end{array}$ & 0.09 & 0.11 \\
\hline
\end{tabular}

For all target sectors except the energy and environment sector, the disagreement values fall in the acceptable range (between 0 and 0.10 ). Same as the intraclass correlation coefficients $\left(\boldsymbol{r}_{\boldsymbol{i c}}\right)$ of all target sectors except the energy and environment sector, its $\boldsymbol{r}_{\boldsymbol{i c}}$ is between $0.11-0.70$ which is lower than 1.0. 
According to the data above, it can be concluded that there is disagreement among Expert Panel III members; however, the disagreement values are still acceptable.

For the energy and environment sector, there is disagreement among members of subgroup 2 from Expert Panel III. Because there are four experts from the four different programs (sustainable environment, resource and energy efficiency, renewable energy and new technology research), the expert from the environmental program has different opinions than the other members of subgroup 2.

\subsection{The evaluation sub-criteria: SI}

The disagreement value and intraclass correlation coefficient of the strategic importance sub-criteria of each target sector are calculated in order to indicate the agreement among Expert Panel III members. The results are shown in Table 28.

Table 28: Disagreement Value and Intraclass Correlation Coefficient of SI Sub-criteria

\begin{tabular}{|c|c|c|}
\hline NSTDA Target Sector & Disagreement Value & $\begin{array}{c}\boldsymbol{r}_{\boldsymbol{i c}} \\
\mathbf{0}<\boldsymbol{r}_{\boldsymbol{i c}}<\mathbf{1}\end{array}$ \\
\hline Agriculture\& Food & 0.07 & 0.54 \\
\hline Energy \& Environment & 0.08 & 0.62 \\
\hline Health \& Medicine & 0.09 & 0.64 \\
\hline Manufacturing \& Service & 0.09 & 0.42 \\
\hline $\begin{array}{c}\text { Resources, Communities, } \\
\text { and Under-privileged } \\
\text { People }\end{array}$ & 0.10 & 0.10 \\
\hline
\end{tabular}


In all cases, the disagreement value of expert members of all target sectors falls within the acceptance value at 0.10 , and the intraclass correlation coefficients of all sectors are between 0 and 1. Thus, it can be concluded that the members of Expert Panel III agree on the relative importance of the strategic importance sub-criteria for every target sector.

\subsection{The evaluation sub-criteria: PI}

The disagreement value and intraclass correlation coefficient of potential impact sub-criteria of every target sector are calculated in order to indicate the agreement among expert panel III. The results are shown in Table 29.

Table 29: Disagreement Value and Intraclass Correlation Coefficient of PI Sub-criteria

\begin{tabular}{|c|c|c|}
\hline NSTDA Target Sector & Disagreement Value & $\begin{array}{c}\boldsymbol{r}_{\boldsymbol{i c}} \\
\mathbf{0}<\boldsymbol{r}_{\boldsymbol{i c}}<\mathbf{1}\end{array}$ \\
\hline Agriculture\& Food & 0.04 & 0.81 \\
\hline Energy \& Environment & 0.04 & 0.86 \\
\hline Health \& Medicine & 0.08 & 0.10 \\
\hline Manufacturing \& Service & 0.07 & 0.43 \\
\hline $\begin{array}{c}\text { Resources, Communities, } \\
\text { and Under-privileged } \\
\text { People }\end{array}$ & 0.06 & 0.12 \\
\hline
\end{tabular}

It is clear that the disagreement value of expert members of all target sectors is lower than the acceptance threshold at 0.10 ; and the intraclass correlation coefficients of all sectors are $0.10,0.12,0.43,0.81$ and 0.86 , which all fall between 0 and 1 . Thus, it can 
be concluded that the members of Expert Panel III agree on the relative importance of the potential impact sub-criteria for all five target sectors.

\subsection{The Evaluation Sub-criteria: HRD}

The disagreement value and intraclass correlation coefficient of the human resource development sub-criteria of every target sector are calculated in order to indicate the agreement among Expert Panel III members. The results are shown in Table 30.

Table 30: Disagreement Value and Intraclass Correlation Coefficient of HRD Sub-criteria

\begin{tabular}{|c|c|c|}
\hline NSTDA Target Sector & Disagreement Value & $\begin{array}{c}\boldsymbol{r}_{\boldsymbol{i c}} \\
\mathbf{0}<\boldsymbol{r}_{\boldsymbol{i c}}<\mathbf{1}\end{array}$ \\
\hline Agriculture\& Food & 0.17 & 0.32 \\
\hline Energy \& Environment & 0.11 & 0.69 \\
\hline Health \& Medicine & 0.07 & 0.92 \\
\hline Manufacturing \& Service & 0.18 & 0.52 \\
\hline $\begin{array}{c}\text { Resources, Communities, } \\
\text { and Under-privileged People }\end{array}$ & 0.07 & 0.71 \\
\hline
\end{tabular}

Although the disagreement values of the expert members in agricultural and food, energy and environment, and manufacturing and service sectors are higher than the acceptance threshold at 0.10 ,theirintraclass correlation coefficients are between 0 and $1.00(0.32,0.69$, and 0.52). Despite the disagreements among Expert Panel III members regarding these three target sectors, they still agree on the relative importance of the human resource development sub-criterion. 


\subsection{The $5^{\text {th }}$ level: ICST Proposals from Bottom-up approach}

The $5^{\text {th }}$ level of the model was not constructed by the expert panel. The main actor at this level is the individual researcher from the four national research centers of NSTDA, which are BIOTEC, MTEC, NECTEC and NANOTEC.

The international collaboration in S\&T proposal that was initiated by individual researchers through their personal channels based on their own interests is the important input used to construct this lowest level of the model.

The proposal template for the international collaboration in S\&T project was announced and distributed to researchers from the four national researcher centers. With the time constraint, four proposals were submitted and plugged into the model as shown in Figure 29.

The $5^{\text {th }}$ Level

Figure 29: The four ICST Proposal at the $5^{\text {th }}$ level 


\subsubsection{Profiles of the Four ICST Proposals from the Bottom-up approach}

The profiles of the four ICST proposals from NSTDA researchers are as follows:

\section{- Proposal 1:}

Proposal 1 serves the NSTDA's Manufacturing and Service Industry sector. It proposes creating a two-year bilateral collaboration between NSTDA and a top-ranked university in the U.S. The requested budget is $\$ 10,000$ (300,000 THB) and another $\$ 10,000$ will be invested in this project by the international collaborative partner.

The objective of this proposed project is to improve the algorithm used in the thesauri to facilitate text cleaning function in the specific software. The new algorithm based on text associate rule mining will be explored to help identify the hidden relationship between terms and keywords. Then the relationships will be used in the thesauri for further analyses.

This proposed project is expected to help establish a licensing of the new algorithm with a top-ranked university in U.S.

The output of this proposed project is a joint academic paper to be presented at a related international conference and to be published in an international journal. At least four researchers would benefit from this international collaboration project, e.g., by educating and updating themselves with the new techniques in the text mining area. 


\section{- Proposal 2:}

Proposal 2 serves two target sectors at the same time. The first one is the Manufacturing and Service Industry sector and the other is the Resources, Communities, and Under-privileged People sector at the 50:50 ratio. It proposes to create a multilateral collaboration with one reputable university in Thailand and another high profile university in Japan.

The duration of the proposed project is three years. The requested budget is $\$ 166,667(5,000,000 \mathrm{THB})$, and the matching fund request from the collaborative partnersis $\$ 166,667$.

There are two main objectives of this proposed project. The first one is to create an international museum network that can exchange information through different database standards, and the second one is to create an algorithm or engine to help search for and connect information across different languages in the museum network.

The output of this proposed project would be a pilot database capable of searching in different languages. There would be one academic paper on the inter-exchange database across different standards. This project would also attempt to create a consortia on Inter-Museum Data Exchange. Ten researchers would benefit from this collaboration project.

Proposal 2 is expected to build up Thai's S\&T capability because it would open opportunities for Thai researchers to learn from other countries in the areas of museum science and art. It would significantly aid in establishing Asian partnerships and possibly expanding to a global level in the future. There would be intensive knowledge and technology exchange among the three partners during the project. 


\section{- Proposal 3:}

Proposal 3 is about understanding the genetic diversity in Asian populations. It would serve NSTDA's health and medical sector. It would create a multilateral collaboration among NSTDA and various countries around Asia, e.g., Malaysia, Singapore, Indonesia, Philippines, Taiwan, China, Korea, and Japan, as well as some non-Asian countries such as Nepal, Kuwait, and the U.S.

The length of this project is five years. The requested budget is $\$ 166,667$ $(5,000,000 \mathrm{THB})$, with a significant amount of matching funds from the collaborative partners at $\$ 6,000,000$.

This proposed project would comprise many renowned scientists from various fields including medical doctors, ethical policy regulators, population geneticists, mathematicians, bio-informaticians, etc. who would take different roles toward the success of the project.

This proposed project would help build Thailand's capability in the genetics area and establish global partnerships. At the same time, Thailand would gain access to state of the art knowledge from partners in areas such as DNA sampling, genetic encoding and genetic diseases.

The goal of Project 3 is to understand the diversity among the Pan-Asian populations. Numerous benefits would be gained from this project such as meeting local challenges, tackling global challenges, and transferring technology and knowledge. At the end, at least one paper would be published in a high-impact factor journal and consortia of Pan-Asian Population Genomic Initiative. 


\section{- Proposal 4:}

The fourth proposal is to hold an international workshop in the area of social and cultural computing. It would serve the NSTDA's energy and environment sector. It would create a multilateral collaboration among NSTDA, Office of Naval Research Global, U.S. Army Research, and the Asian Office of Aerospace R\&D.

It is a one-year project with a budget of $\$ 8,333$ and a contribution of $\$ 25,000$ from the collaborative partners.

The objective of this workshop is to bring together international researchers from a wide range of social, cultural, behavioral, and engineering sciences including anthropology, sociology, linguistics, philosophy, criminology, and neuroscience. The workshop would aim to provide a better understanding of and capability to model social and cultural influences on human behavior to improve the effectiveness of information flow for humanitarian assistance (HA) missions such as the Natural Disaster Mission Tsunami Preparedness in Thailand.

The potential impact from this project would be an opportunity to acquire highend knowledge in the area of HA operations from various experts around the world.

At least 40 people would benefit from this project with its highly significant level of benefit. 


\subsection{Results and Analysis of the Policy Model for International Collaboration in S\&T- ICST Value and Ranking}

The final Strategic Policy Model for International Collaboration in S\&T is shown in Figure 13, Chapter 4.

In summary, the $1^{\text {st }}$ level comprises the Thailand S\&T Vision. The $2^{\text {nd }}$ level comprises four Thailand S\&T objectives. The $3^{\text {rd }}$ comprises five NSTDA target sectors. The first three levels of the model were developed by using the top-down approach.

The $4^{\text {th }}$ level comprises three main elements of the model which are evaluation criteria, evaluation sub-criteria, and desirability curves of the sub-criteria. The evaluation process is performed at this level.

The $5^{\text {th }}$ and bottom level lists the international collaboration in S\&T proposals that were obtained from NSTDA researchers through the bottom-up approach.

Based on the information above, the ICST value, ICST ${ }_{i}$, of the individual proposal was calculated, and the rankings of the proposals were determined. The ranking of the ICST proposals shows the result of the bridging mechanism between "top-down" and "bottom-up" approaches. It reflects the value that each ICST proposal contributed to every level of the model. 
The calculations of the ICST value ( ICST $\left.{ }_{i}\right)$ and the ranking of the international collaboration in S\&T proposals are described in the following sections of this chapter.

\subsubsection{The Calculation of the International Collaboration in S\&T Value ( ICST $\left._{i}\right)$}

The international collaboration in S\&T value $\left(\operatorname{ICST}_{i}\right)$ is the absolute value of each ICST proposal. It is computed by the summation of the multiply of Desirability value of the project characteristic of Proposal i corresponding to Sub-criteria jkl to Criteria with the Contribution of Sub-criteria $\mathrm{jkl}$ to Criteria with the Contribution of Criteria $\mathrm{kl}$ to Target Sectors with the Contribution of Target Sector 1 to Objectives with the Contribution of Objective $\mathrm{m}$ to the Vision as illustrated in Equation 4.

$$
\begin{aligned}
& \mathbf{I C S T}_{\mathbf{i}}=\sum_{m=1}^{\mathrm{M}} \sum_{\mathrm{l}=1}^{\mathrm{L}} \sum_{\mathrm{kl}=1}^{\mathrm{Kl}} \sum_{\mathbf{j k l}=\mathbf{1}}^{\mathrm{Jkl}} \mathbf{O}_{\mathbf{M}}^{\mathrm{V}} \cdot \mathbf{T}_{\mathbf{l}}^{\mathbf{O}} \cdot \mathbf{C}_{\mathbf{k l}}^{\mathbf{t}} \cdot \mathbf{S}_{\mathbf{j k l}}^{\mathbf{c}} \cdot \mathbf{D}\left(\mathbf{P}_{\mathbf{j k l}}\right)_{\mathbf{i}} \quad \text { Equation } 4 \\
& \text { Where } \operatorname{ICST}_{\mathrm{i}}=\text { The value of ICST Proposal } \mathrm{i} \quad ; \mathrm{i}=1, \ldots 4 \\
& \mathrm{D}\left(\mathrm{P}_{\mathrm{jkl}}\right)_{\mathrm{i}}=\text { Desirability value of the project characteristic of Proposal i } \\
& \text { corresponding to Sub-criterion } \mathrm{jkl} \\
& \mathrm{S}_{\mathrm{jkl}}^{\mathrm{c}}=\text { Contribution of Sub-criterion } \mathrm{jkl} \text { to Criteria } \\
& \mathrm{C}_{\mathrm{kl}}^{\mathrm{t}}=\text { Contribution of Criterion } \mathrm{kl} \text { to Target Sectors } \\
& \mathrm{T}_{\mathrm{l}}^{\mathrm{O}}=\text { Contribution of Target Sector } 1 \text { to Objectives } \\
& \mathrm{O}_{\mathrm{M}}^{\mathrm{V}}=\text { Contribution of Objective } \mathrm{m} \text { to the Vision }
\end{aligned}
$$

The example of the calculation of ICST Proposal 1 is provided below. 
Table 31: ICST Proposal Characteristic of ICST1

\begin{tabular}{|c|c|c|}
\hline Evaluation Criteria \& Sub-criteria & $\begin{array}{c}\text { Project } \\
\text { Characteristic }\end{array}$ & $\begin{array}{c}\text { Desirability } \\
\text { Value }\end{array}$ \\
\hline \multirow{2}{*}{\multicolumn{3}{|c|}{$\begin{array}{l}\text { 1) Strategic Importance }(\mathrm{SI}) \\
\text { Relative Importance of SI of Manufacturing Sector } \\
\left(\mathrm{C}_{14}\right) \text { is } 0.33\end{array}$}} \\
\hline & & \\
\hline - National S\&T Capability & 0 & 0 \\
\hline - Global Partnership & Good & 55 \\
\hline - State of the Art Knowledge & Good & 62.5 \\
\hline - Brain Gain & 0 & 0 \\
\hline \multicolumn{3}{|l|}{ 2) Potential Impact (PI) } \\
\hline \multicolumn{3}{|l|}{$\begin{array}{l}\text { Relative Importance of PI of Manufacturing Sector is } \\
0.37\end{array}$} \\
\hline - Local Challenge & 0 & 0 \\
\hline - Global Challenge & 0 & 0 \\
\hline - Tech/Knowledge Transfer & 0 & 0 \\
\hline - Joint Academic Paper & Excellent & 65 \\
\hline - Research Consortia & 0 & 0 \\
\hline 3) Human Resource Development (HRD) & & \\
\hline \multicolumn{3}{|l|}{$\begin{array}{l}\text { Relative Importance of HRD of Manufacturing Sector } \\
\text { is } 0.14\end{array}$} \\
\hline - Number of researcher(s) & $>20$ & 75 \\
\hline - Significant Benefit to researcher(s) & Excellent & 95 \\
\hline \multicolumn{3}{|l|}{ 4) Matching Fund (MF) } \\
\hline $\begin{array}{l}\text { Relative Importance of MF of Manufacturing Sector } \\
\text { is } 0.16\end{array}$ & $50 \%$ & 60 \\
\hline
\end{tabular}

The calculation of all relative values for the four criteria of ICST Proposal 1 is calculated by using the information from Tables $22-25$ and Table 31 .

- Relative Value of Strategic Importance

$$
=C_{14}^{4} * S_{j 14}^{1} * \mathrm{D}\left(\mathrm{P}_{\mathrm{j} 14}\right)_{1}
$$




$$
\begin{aligned}
& =0.33 *(0.40,0.17,0.25,0.18) *\left[\begin{array}{c}
0 \\
55 \\
62.5 \\
0
\end{array}\right] \\
& =8.24
\end{aligned}
$$

- Relative Value of Potential Impact

$$
=C_{24}^{4} * S_{j 24}^{2} * \mathrm{D}\left(\mathrm{P}_{\mathrm{j} 24}\right)_{1}
$$

$=0.37 *(0.33,0.14,0.21,0.13,0.19) *\left[\begin{array}{c}0 \\ 0 \\ 0 \\ 65 \\ 0\end{array}\right]$

$=3.13$

- Relative Value of Human Resource Development

$$
\begin{aligned}
& =C_{34}^{4} * S_{j 34}^{3} * \mathrm{D}\left(\mathrm{P}_{\mathrm{j} 34}\right)_{1} \\
& =0.14 *(0.31,0.69) *\left[\begin{array}{l}
75 \\
95
\end{array}\right] \\
& =12.43
\end{aligned}
$$

- Relative Value of Matching Fund

$$
\begin{aligned}
& =C_{44}^{4} * S_{j 44}^{4} * \mathrm{D}\left(\mathrm{P}_{\mathrm{j} 44}\right)_{1} \\
& =0.16 *[60] \\
& =9.6
\end{aligned}
$$

The ICST Proposal 1 serves NSTDA's manufacturing and service target sector, which has its relative importance $\left(\mathrm{T}_{4}^{\mathrm{O}}\right)$ at 0.17 . 
Thus, the ICST Value for Project 1 (ICST 1 ) is calculated as illustrated below.

$$
\begin{aligned}
\operatorname{ICST}_{1}= & 0.17(8.24+3.13+12.43+9.6) \\
= & 5.68
\end{aligned}
$$

Details about the calculation of the ICST value of Proposal 2, 3, and4 are provided in Appendix D.

The summary of all relative values of all four proposals is provided in Table 32 .

\begin{tabular}{|c|c|c|c|c|c|c|}
\hline & \multicolumn{5}{|c|}{ Proposal from Bottom-up Approach } \\
\hline & & \multirow{2}{*}{$\begin{array}{c}\text { Proposal } \\
1\end{array}$} & \multicolumn{2}{|c|}{ Proposal 2} & \multirow[b]{2}{*}{$\begin{array}{c}\text { Proposal } \\
3\end{array}$} & \multirow[b]{2}{*}{$\begin{array}{c}\text { Proposal } \\
4\end{array}$} \\
\hline & & & $\begin{array}{c}\text { Sector } 4 \\
(50 \%)\end{array}$ & $\begin{array}{c}\text { Sector } 5 \\
(50 \%)\end{array}$ & & \\
\hline \multirow{4}{*}{$\mathrm{C}_{\mathrm{kl}}^{\mathrm{t}}$} & SI & 8.24 & 17.98 & 18.45 & 29.39 & 3.35 \\
\hline & PI & 3.13 & 7.19 & 5.57 & 35.81 & 11.43 \\
\hline & HRD & 12.43 & 2.82 & 6.45 & 11.66 & 19.67 \\
\hline & MF & 9.60 & 9.60 & 10 & 7.80 & 5.47 \\
\hline \multirow[b]{2}{*}{$\mathrm{T}_{1}^{\mathrm{O}}$} & $\mathrm{T}_{1}^{\mathrm{O}}$ & 0.17 & 0.17 & 0.13 & 0.20 & 0.22 \\
\hline & $\begin{array}{l}\text { Ratio in } \\
\text { each } \mathrm{T}_{1}^{\mathrm{O}}\end{array}$ & & $\begin{array}{c}6.39 *(50 / 100) \\
=3.20\end{array}$ & $\begin{array}{c}5.26 *(50 / 100) \\
=2.63\end{array}$ & & \\
\hline & ICST $_{\downarrow}$ & 5.68 & \multicolumn{2}{|c|}{5.83} & 16.93 & 8.78 \\
\hline
\end{tabular}

Table 32: The Summary of the ICST Value of the Four Proposals 


\subsubsection{The Ranking of the International Collaboration in S\&T Proposals}

Based on the results of the top-down approach from the $1^{\text {st }}$ to the $3^{\text {rd }}$ level of the model, which include Thailand's S\&T objectives, NSTDA target sectors, and the input from the bottom-up approach from the $5^{\text {th }}$ level, the ICST values of the four proposals $\left(\right.$ ICST $\left._{i}\right)$ are calculated and shown in Figure 30.

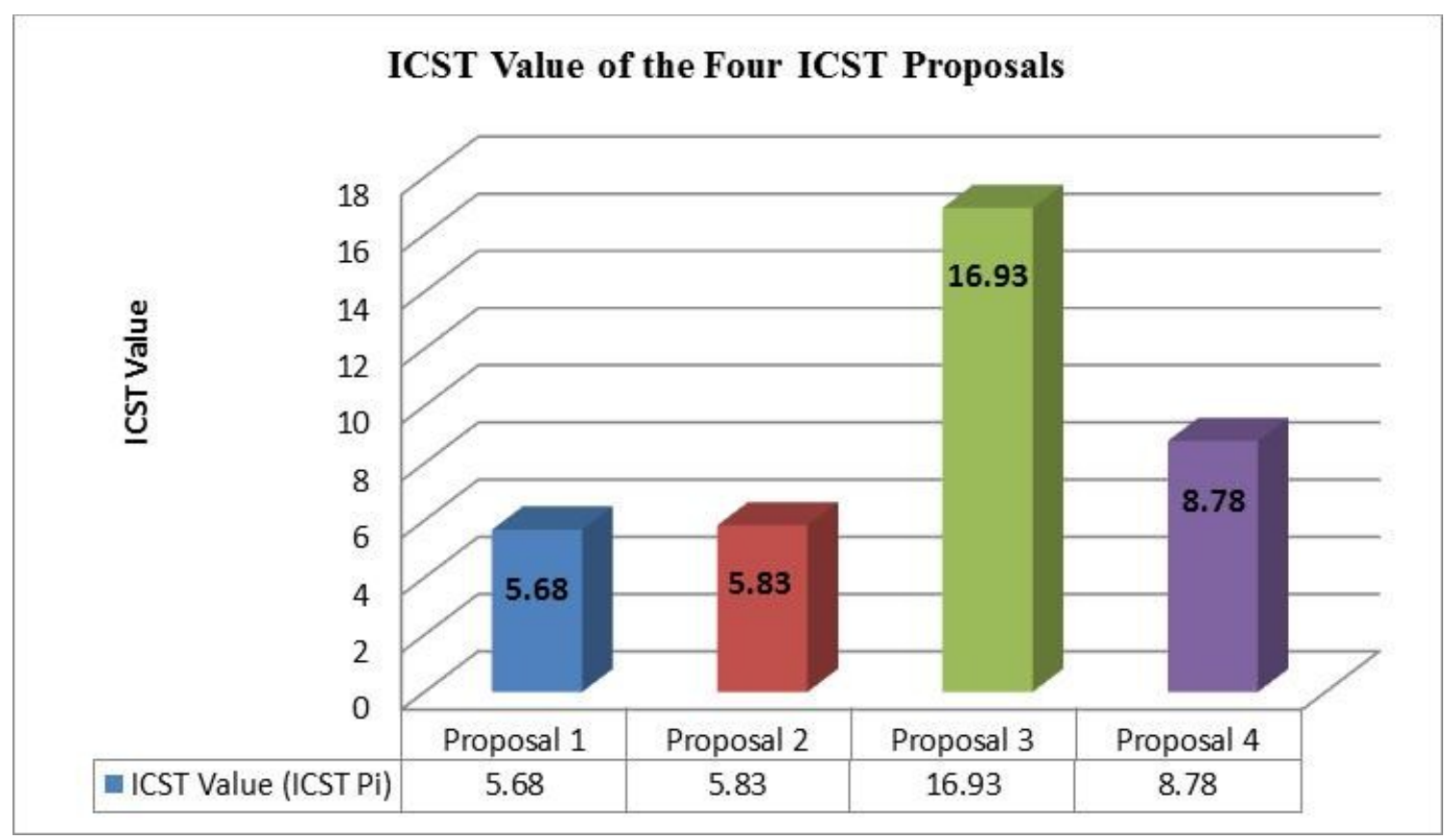

Figure 30: The ICST Values of the four Proposals

All of the four proposals were initiated by NSTDA researchers. The ICST proposals were initiated by researchers' interests through their personal network channels e.g. their former academic advisor, the group of researchers from other universities that they met at the international conferences, etc. The way to communicate between NSTDA researchers and others from different parts of the world is easier and faster because of the advantage of Information Communication Technology. 
According to the results from the Strategic Policy Model for International Collaboration in S\&T, Proposal 3 has the highest ICST value at 16.93, followed by Proposal 4 at 8.78 and Proposal 2 at 5.83. Proposal 1 is ranked at last place with the ICST value of 5.68.

Based on the results of relative importance of the Thailand S\&T objectives from Expert Panel I, another scenario is presented by having only one expert member from Expert Panel I as a decision maker. The results of the ICST value of the four proposals from both scenarios are presented in Table 33 and Figure 31.

Table 33: The ICST Value of the Four Proposals

\begin{tabular}{|c|c|c|c|c|}
\hline \multirow{4}{*}{$\begin{array}{c}\text { No. of Expert } \\
\text { (Expert Panel I) }\end{array}$} & \multicolumn{4}{|c|}{ ICST Value ( ICST $\mathbf{i}_{\mathbf{~}}$} \\
\cline { 2 - 5 } & ICST $_{\mathbf{1}}$ & \multicolumn{4}{|c|}{ ICST } & ICST $_{\mathbf{3}}$ & ICST $_{\mathbf{4}}$ \\
\cline { 2 - 5 } & $\begin{array}{c}\text { MSTDA Target Sectors } \\
\text { \& Service }\end{array}$ & $\begin{array}{c}\text { Manufacturing \& } \\
\text { Service and } \\
\text { Resources, } \\
\text { Communities, and } \\
\text { Under-privileged } \\
\text { People }\end{array}$ & $\begin{array}{c}\text { Health \& } \\
\text { Medicine }\end{array}$ & $\begin{array}{c}\text { Energy \& } \\
\text { Environment }\end{array}$ \\
\hline 6 experts & $5.68(4)$ & $5.83(3)$ & $16.93(1)$ & $8.78(2)$ \\
\hline $\begin{array}{c}1 \text { expert } \\
\text { (The Outlier) }\end{array}$ & $5.01(4)$ & $5.45(3)$ & $16.93(1)$ & $9.18(2)$ \\
\hline
\end{tabular}


One expert member from Expert Panel I was selected as an example to illustrate the different scenarios. This is because he emphasizes only two Thailand S\&T objectives, sustainable competitiveness (objective 1) and quality of life and environment (objective 4), because of his background and his professional experience.

Value \& Ranking of ICST Proposals Expert Panel I vs. Outline

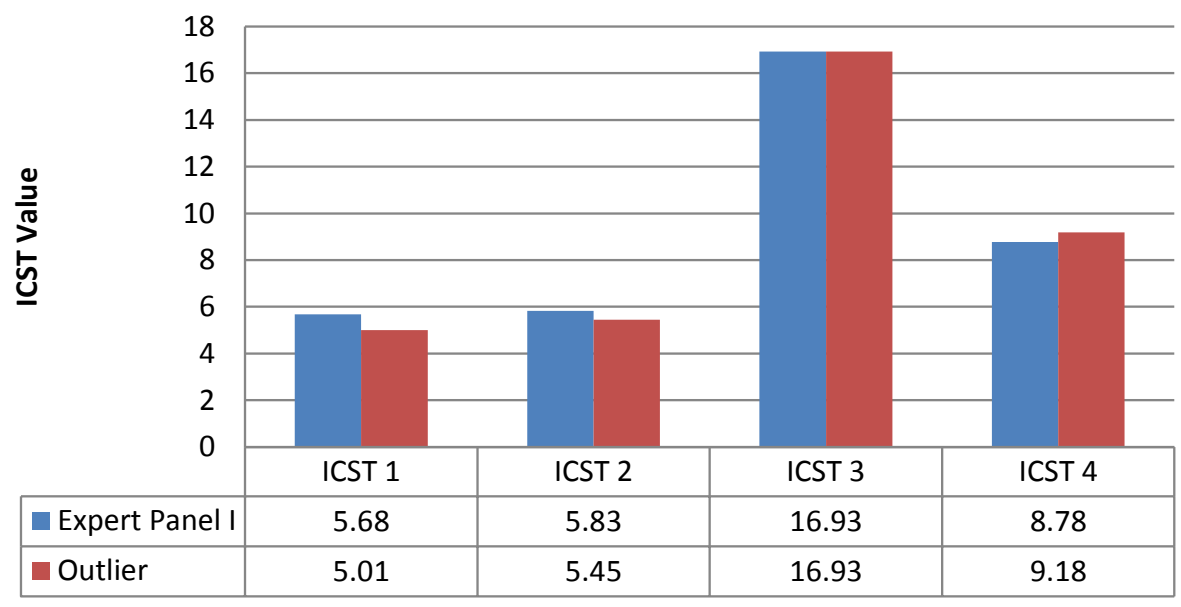

Figure 31: Value and Ranking of ICST Proposals between Expert Panel I vs. Outlier

However, as can be shown from the results in Table 33, if this expert is the only executive decision maker who makes a decision, the ranking of the four proposals will still be the same. The individual ICST value of Proposal 4 will slightly higher. The ICST values for Proposal 1 and Proposal 2 will be slightly lower, but the rank will remain the same. 


\subsection{Summary of the Case Study Research}

The main results of this research are presented as follows:

1. A five-level Strategic Policy Model for International Collaboration in Science and Technology (ICST) was developed based on two important methods. The first one is a hierarchical decision model (HDM) which elicits multiple objectives and multilevel decisions under multiple criteria. The second one is the expert quantification judgment for determining the relative importance of model's elements. The entire model acts as a linking mechanism between the top-down approach and bottom-up approach, which helps bridge the gap between national policymakers and researchers.

2. At each level of the model, the elements were identified, validated and determined by Expert Panels I, II, and III.

2.1 At the $2^{\text {nd }}$ level, Thailand S\&T Objectives, there are four objectives which were validated and their relative import and determined by Expert Panel I.

2.2 At the $3^{\text {rd }}$ level, NSTDA target sectors, five target sectors were validated and their relative importances were determined by Expert Panel II.

2.3 At the $4^{\text {th }}$ level, there are three important elements which are as follows:

- Evaluation Criteria

- Evaluation Sub-criteria

- Desirability Curve of Sub-criteria 
The relative importance of the evaluation criteria and sub-criteria and desirability values were validated and determined by Expert Panel III.

3. The 4 evaluation criteria and the 11 evaluation sub-criteria for international collaboration in S\&T were proposed in this research and validated by Expert Panel III.

4. The four ICST proposals, which were initiated by NSTDA researchers though the bottom-up approach, were used as the examples to demonstrate the model.

\subsection{Validation of the Case Study}

This case study was validated by three validations: construct validity, content validity, and criteria-related validity. More detail of each validation is provided below.

\section{- Construct Validity}

Construct validity is the assessment of the quality of the model structure. The model was presented to the tree expert panels. They verified that the structure is appropriate and reasonable. 


\section{- Content Validity}

Content validity is the assessment of the validity of the model contents. Before the research instruments were distributed, they were tested by a group of related people at NSTDA, who validate the contents.

\section{- Criterion-related Validity}

Criteria-related validity is the assessment of the predictive power of the model. The criteria-related validity was completed after the results of the model were obtained. The experts were asked to check the model results and evaluate the degree to which they represent reality. The experts validated the results. 


\section{Chapter 6: Conclusions, Contributions, Limitations and Challenges and Future Research}

\subsection{Conclusions}

Here are the conclusions of the research.

- The model developed in this research shows that a systematic approach to ICST proposal evaluations can bridge the gap between top-down and bottom-up approaches.

- The use of desirability curves allows the evaluation of an unlimited number of ICST proposals.

- The proposals with desirable project characteristics corresponding to important subcriteria will have higher values.

- Strengths and weaknesses of the proposals can readily be identified by analyzing the match between sub-criteria and project characteristics.

\subsection{Contributions}

This research is based on three research gaps in the area of international collaboration in S\&T. These three research gaps were filled by developing a Strategic Policy Model for International Collaboration in Science and Technology as shown in Figure 32. 


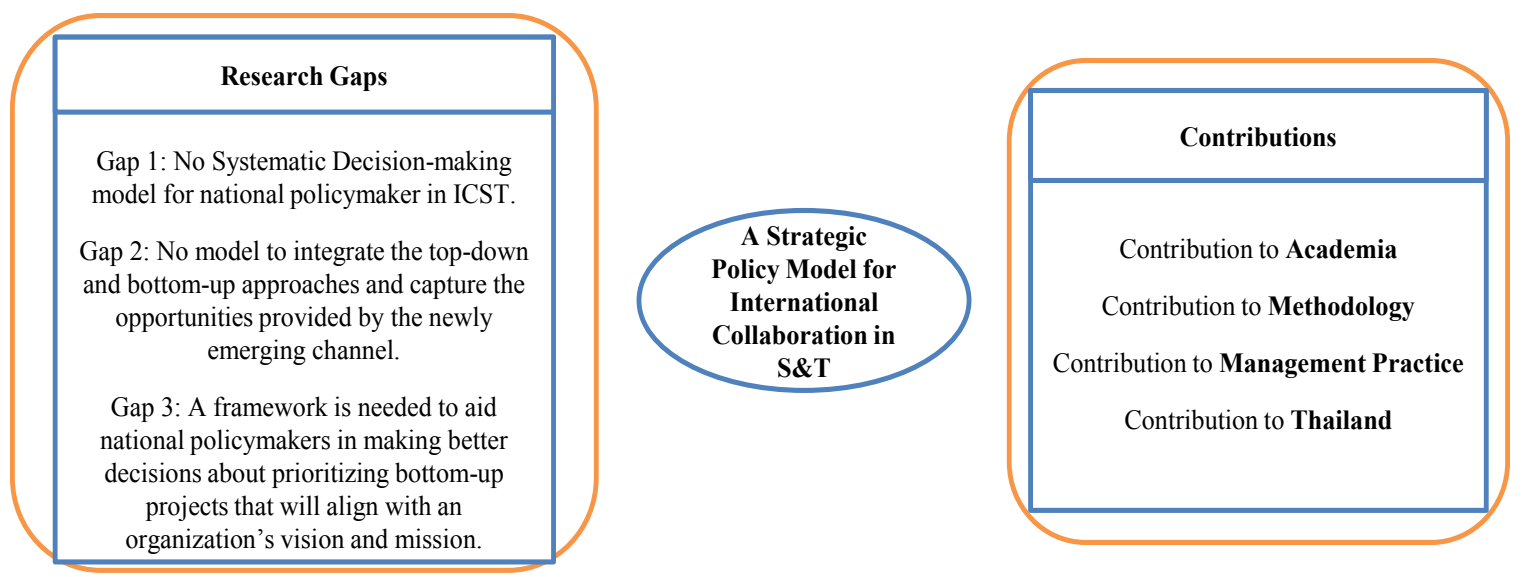

Figure 32: The Schematic Framework of the Research: Gaps and Contributions

This research has various contributions as described below.

\section{- Contribution to Academia:}

The intellectual merit of this research is the development of a strategic policy model that bridges the gap between the top-down and bottom-up approaches. Every organization and country can benefit from the model by applying this comprehensive approach and using the structure of this Strategic Policy Model in ICST with their own data.

\section{- Contribution to Methodology:}

Having a comprehensive approach which integrates multiple methodologies, such as HDM and expert judgment quantification, significantly helps in developing a strategic policy model for international collaboration in S\&T. 


\section{- Contribution to Management Practice:}

Understanding the process of international collaboration in S\&T provides great opportunities for all stakeholders. National policymakers, researchers, and project analysts can work together with the same expectations and understanding.

\section{- Contribution to Thailand:}

This model was demonstrated by using data from NSTDA, Thailand. This research provides practical insight into how the process of international scientific collaboration in Thailand should be done in order to bridge the gap between the top-down and bottom-up approach.

The analysis of these results can help Thailand's national policymakers to make better decisions about participating in international collaboration in S\&T. This model is also robust enough for any type of international collaboration in S\&T in the future.

At the same time, this model enhances the ability of NSTDA researchers to manage their ICST research. It helps them to adjust their research interests to align with the organization's objectives and the country's needs. 


\subsection{Limitations and Challenges}

There are several limitations and challenges that should be considered as listed below.

- A country's absorptive capability, partnerships and cultural differences are outside the scope of this study. The recommended rankings of ICST proposals are based on the expected benefits of the proposals in terms of their characteristic features, e.g., strategic importance, potential impact, human resource development, etc.

- Intellectual property rights (IPR) is another important issue when discussing ICST. Issues about IPR related to the ICST topic must be considered, e.g., how to manage IPR between collaborative partners.

- The outputs of this research depend on the subjective data provided by the expert panels. Individual bias of experts from each panel might affect the validity of the model. However, the selection of appropriate experts increases the reliability of the results.

- The research case study is limited to Thailand's International Collaboration in S\&T Proposals. However, the model can be modified and expanded for a wide range of applications in other countries. 
- $\quad$ There were a few unexpected factors that the researcher had to deal with while conducting the research, for example, the challenges of the data collection process. A web-based survey is a useful tool. However, it is quite difficult to control the results within a time limit. Other methods had to be incorporated into the data collection process such as face-to-face interviews.

\subsection{Future Research}

Following are proposed ideas for future research.

- Demonstration of this Strategic Policy Model for International Collaboration in Science and Technology with the data from other countries will be the interesting case studies.

- The process of obtaining information on the ICST research proposals using the bottom-up approach proved to be the most challenging part of this research. It can be improved by introducing a dynamic knowledge repository. Researchers will be able to submit their research proposals easily and at any time. With this dynamic knowledge respiratory database, more features can be added to help researchers find more partners through other tools, e.g., social networking, technology trend analysis, etc. 


\section{References:}

[1] D. F. Kocaoglu, “A Participative Approach to Program Evaluation,” IEEE Trans, vol. EM-30, no. 3, pp. 112-118, 1983.

[2] T. Saaty, "How to make a decision: The analytic hierarchy process," European Journal of Operational Research, vol. 48, no. 1, pp. 9-26, Sep. 1990.

[3] P. Gerdsri and D. Kocaoglu, "A systematic approach to developing national technology policy and strategy for emerging technologies: A case study of nanotechnology for Thailand's agriculture industry," PICMET '09 - 2009 Portland International Conference on Management of Engineering \& Technology. Ieee, pp. 447-461, Aug-2009.

[4] D. F. K. Nathasit Gerdsri, "Applying the Analytic Hierarchy Process Nathasit," Mathematical and Computer Modelling, vol. 46, no. 7-8, pp. 1071-1080, 2007.

[5] J. Gaillard, R. Kastens, and A. M. Cetto, "Priority setting in technical cooperation : expanding the demand for knowledge-based development," in Anthem Press, 2006, pp. 177-190.

[6] M.S. Lipsett and J.A.D.Holbrook, "Reflections on Indicators of International Cooperation in S\&T," 1997.

[7] B. R. M. J. Sylvan Katz, "What is research collaboration?," Research Policy, vol. 26, no. 1, pp. 1-18, Mar. 1997.

[8] D. H. Sonnenwald, "Scientific Collaboration: A Synthesis of Challenges and Strategies,” Review of Information Science, vol. 41, no. January, 2007.

[9] D. L. Olson, G.M. Teasley, S. Bietz, M. \& Cogburn, "Collaboratories to support distributed science: The example of international HIV/AIDS Research," in Collaboratories to support distributed science: The example of international HIV/AIDS Research, 2000, pp. 44-51.

[10] R. B. Duque, M. Ynalvez, R. Sooryamoorthy, P. Mbatia, D. Dzorgbo, and W. Shrum, "Collaboration paradox: Scientific productivity, the Internet, and problems of research in developing areas," vol. 35. Social Studies of Science, pp. 755-785, 2005.

[11] C. Wagner, "International collaboration in science and technology: promises and pitfalls," Science and Technology Policy for Development, pp. 165-176, 2006. 
[12] A. F. J. Van Raan, "The influence of international collaboration on the impact of research results," Scientometrics, vol. 42, no. 3, pp. 423-428, Oct. 1998.

[13] J. D. F. A. M. P.Carperter, "International collaboration in research," Social Studies of Science, vol. 9, no. 4, pp. 481-497.

[14] F. N. A. E.S.Whitlow, "Measurement of scientific cooperation and coauthorship in CEC-related Areas of Science," Office for Official Publications of the European Communities, EC -Report, p. 116.

[15] L. Georghiou, "Global cooperation in research," Research Policy, vol. 27, no. 6, pp. 611-626, Sep. 1998.

[16] C. W. Loet Leydesdorff, "International collaboration in science and the formation of a core group," Journal of Informetrics, Amsterdam School of Communication Research, vol. 2, no. 4, pp. 317-325, 2009.

[17] C. W. Loet Leydesdorff, "Network structure, self-organization, and the growth of international collaboration in science," Research Policy, vol. 34, no. 10, pp. 1608$1618,2005$.

[18] Global Engagement Working Group, "Australia’s Science and Technology Priorities for Global Engagement," 2006.

[19] J. Kimikazu IWASE Science And Tecnology Policy Bureau, Ministry Of Education, Culture, Sports, Science And Technology, “Japan's View on Opportunities and New Approaches for Enhanced Multinational S \& T Cooperation," in OECD Conference.

[20] M. Von Zedtwitz, "International R \& D Strategies in Companies from Developing Countries - the Case of China," Research Policy, pp. 117-140.

[21] P. A. Sabatier, "Top-Down and Bottom-Up Approaches to Implementation Research: a Critical Analysis and Suggested Symthesis," Journal of Public Policy, vol. 6, pp. 21-48, 1986.

[22] S. H. Allison Yezril, Caroline S. Wagner, "International Cooperation in Research and Development: An Update to an Inventory of U.S. Government Spending," RAND, 2001.

[23] M. Dodgson, "Learning, Trust, and Technological Collaboration," Human Relations, vol. 46, no. 1, pp. 77-95, Jan. 1993. 
[24] J. Hagedoorn, "Understanding the rationale of strategic technology partnering: Nterorganizational modes of cooperation and sectoral differences," Strategic Management Journal, vol. 14, no. 5, pp. 371-385, Jul. 1993.

[25] J. B. Tucker, "Partners and rivals: a model of international collaboration in advanced technology," International Organization, vol. 45, no. 01, pp. 83-120, Dec. 1991.

[26] D. D. BEAVER, "Reflections on scientific collaboration ( and its study ): past, present , and future *," Scientometrics, vol. 52, no. 3, pp. 365-377, 2001.

[27] R. Kraut, J. Galegher, and C. Egido, "Relationships and Tasks in Scientific Research Collaboration,” Human-Computer Interaction, vol. 3, no. 1, pp. 31-55, Mar. 1988.

[28] European Commisision, "Research Priority Setting for International Cooperation," Brussels, 2009.

[29] I. Chompalov, J. Genuth, and W. Shrum, "The organization of scientific collaborations," Research Policy, vol. 31, no. 5, pp. 749-767, Jul. 2002.

[30] European Commission, "Opening to the world: International cooperation in Science and Technology," 2008.

[31] European Commission, "The International Dimension of the European Research Area. Communication from the Commission," Brussels, 2001.

[32] Advisory Council for Science Technology and Innovation, "Ireland's International Engagement in Science, Technology and Innovation," 2008.

[33] J. H. Rajneesh Narula, "Innovating through strategic alliances: moving towards international partnerships and contractual agreements," Techno, vol. 19, pp. 283284, 1999.

[34] J. Hagedoorn, "Trends and Patterns in Strategic Technology Partnering Since the early Seventies," Review of industrial Organization, vol. 11, pp. 601-616, 1996.

[35] A. N. L. N. S. V. John Hagedoorn, "Research partnerships," Research Policy, vol. 29, no. 4-5, pp. 567-586, Apr. 2000.

[36] F. Gagnon-Lebrun, "International Energy Technology Collaboration and Climate Change Mitigation," Paris, France, 2004. 
[37] M. S. Jorn Sonnenburg, "Exploring synergies through coordinating policy measures between the EU Member States, Associated Countries and the European Commission - An element of the 'New Partnership' for ERA governance Summary of discussions and recommendations,” Brussels, 2008.

[38] B. Dachs and A. Pyka, "What drives the internationalisation of innovation? Evidence from European patent data," Economics of Innovation and New Technology, vol. 19, no. 1, pp. 71-86, Jan. 2010.

[39] United Nations, "World Investment Transnational Corporations and the Internationalization of R \& D," New York and Geneva, 2005.

[40] National Science Board 2010, "Science and Engineering Indicators 2010."

[41] L. L. Caroline S. Wagner, "Mapping the network of global science: comparing international co-authorships from 1990 to 2000," International Journal of Technology and Globalisation, vol. 1, no. 2, pp. 185-208, 2005.

[42] OECD, "Compendium of Patent Statistics," Oct. 2008.

[43] T. Luukkonen, R. J. W. Tijssen, O. Persson, and G. Sivertsen, "The measurement of international scientific collaboration," Scientometrics, vol. 28, no. 1, pp. 15-36, Sep. 1993.

[44] J. M. Russell, "The increasing role of international cooperation in science and technology research in Mexico," Scientometrics, vol. 34, no. 1, pp. 45-61, Sep. 1995.

[45] T. Luukkonen, O. Persson, and G. Sivertsen, "Understanding Patterns of International Scientific Collaboration," Science, Technology \& Human Values, vol. 17, no. 1, pp. 101-126, Jan. 1992.

[46] M. Y. Abraham Bookstein, Henk Moed, "IndicaSciences - Measures of international collaboration in scientific literature : Part II," Information Processing \& Management, vol. 42, no. 6, pp. 1422-1427, 2006.

[47] D. Guellec and B. v. Pottelsberghe de la Potterie, "The internationalisation of technology analysed with patent data," Research Policy, vol. 30, no. 8, pp. $1253-$ 1266.

[48] B. Biglia and O. Wenholz, "A Bibliometric Analysis of Australia's International Research Collaboration in Science and Technology: Analytical Methods and Initial Findings," 2009. 
[49] M. Arunachalam, Subbiah, Jinandra Doss, "Mapping international collaboration in science in Asia through coauthorship analysis," Scientometrics, vol. 79, no. 5, pp. 621-628, Sep. 2000.

[50] R. P. Suttmeier, "State, Self-Organization, And Identify in the Building of SinoU.S. Cooperation in Science and Technology," ASIAN PERSPECTIVE, vol. 32, no. 1, pp. 5-31, 2008.

[51] J. Ben-David, “The Scientist's Role in Society: A Comparative Study," PrenticeHall, Englewood Cliffs, Mar. 1971.

[52] T. Schott, "Ties between Center and Periphery in the Scientific World System: Accumulation of Rewards, Dominance and Self Reliance in the Center," Journal of World-Systems Research, vol. 4, no. 2, pp. 112 - 144, 1998.

[53] E. Shils, "Center \& Periphery: an idea and its career, 1935-1987," Center: Ideas and Institutions. University of Chicago Press, Chicago, pp. 250-282, 1988.

[54] R. Stichweh, "Science in the system of world society," Social Science Information, vol. 35, no. 2, pp. 327-340, Jun. 1996.

[55] P. Galison and B. W. Hevly, Big science: The Growth of Large-Scale Research. Stanford University Press, 1992, p. 392.

[56] D. D. Beaver and R. Rosen, "Studies in scientific collaboration," Scientometrics, vol. 1, no. 1, pp. 65-84, Sep. 1978.

[57] C. Limoges, S. Schwartzman, H. Nowotny, M. Trow, and P. Scott, The New Production of Knowledge: The Dynamics of Science and Research in Contemporary Societies. Sage Publications Ltd London, 1994.

[58] C. J. Friedrich, Man and his government; an empirical theory of politics. McGrawHill, 1963, p. xiii, 737 p.

[59] Richard Rose, "Policy Making in Britian A Reader in Government." Macmillan and Co Ltd., 1969.

[60] Robert Eyestone, The threads of public policy: A study in policy leadership. Irvington Publishers, p. 216.

[61] T. R. Dye, Understanding public policy. Prentice Hall, 1972, pp. xvii, 356.

[62] W. I. Jenkins, Policy Analysis: A Political and Organizational Perspective. Martin Robertson*, 1978. 
[63] T. A. Birkland, An Introduction to the Policy Process: Theories, Concepts, and Models of Public Policy Making. M.E. Sharpe, 2005, p. xiii, 294 p.

[64] UNESCO, “World Science Report 2010,” Paris, France, 2010.

[65] H. N. Michael Gibbons, Camille Limoges, The new production of knowledge: the dynamics of science and research in contemporary societies. Sage Publications Ltd, 1994, p. 192.

[66] E. G. A. A. Carayannis J M, Knowledge Creation, Diffusion and Use in Innovation Networks and Knowledge Clusters: A comparative Systems Approach Across the United States, Europe and Asia. Praeger, 2006, p. xxvi.

[67] UNDP, The Creative Economy Report 2008: The challenge of assessing the creative economy. Towards informed policy-making. United Nations, 2008.

[68] B Ruivo, “'Phases' or'paradigms' of science policy?, Science and Public Policy, vol. 21, no. 3, p. 157, 1994.

[69] Y. Dror, Public Policy Reexamined, 1st ed. Chandler Publishing Company, 1968, p. 370.

[70] M. A. C. Stella Z. Theodoulou, Public Policy: The Essential Readings, 1st ed. Prentice Hall, 1994, p. 464.

[71] E. Borenstein, E. Sharon, and S. Ullman, "Combining Top-Down and Bottom-Up Segmentation," 2004 Conference on Computer Vision and Pattern Recognition Workshop, vol. 00, no. C, pp. 46-46, 2004.

[72] A. A. Zekveld, D. J. Heslenfeld, J. M. Festen, and R. Schoonhoven, "Top-down and bottom-up processes in speech comprehension.," NeuroImage, vol. 32, no. 4, pp. 1826-1836, 2006.

[73] T. Vaneker, G. Vanouwerkerk, K. Nilsen, P. Koenis, and F. Vanhouten, "Integrated bottom up and top down approach to optimization of the extrusion process," CIRP Annals Manufacturing Technology, vol. 57, no. 1, pp. 183-186, 2008.

[74] M. Thomas and F. McGarry, "Top-down vs. bottom-up process improvement," IEEE Software, vol. 11, no. 4, pp. 12-13, 1994.

[75] P. De Grauwe, “Top-Down versus Bottom-Up Macroeconomics," Social Science Research Network, vol. 49, no. October, 2010. 
[76] C. Böhringer and T. F. Rutherford, "Combining bottom-up and top-down," Energy Economics, vol. 30, no. 2, pp. 574-596, 2008.

[77] J. L. Pressman and A. B. Wildavsky, Implementation: How Great Expectations in Washington Are Dashed in Oakland; Or, Why It's Amazing that Federal Programs Work at All, This Being a Saga of the Economic Development Administration as Told by Two Sympathetic Observers Who Seek to Build Morals. University of California Press, 1974, pp. xxvi, 281.

[78] D. S. Van Meter and C. E. Van Horn, "The Policy Implementation Process: A Conceptual Framework," Administration Society, vol. 6, no. 4, pp. 445-488, 1975.

[79] E. Bardach, The Implementation Game: What Happens After a Bill Becomes a Law. MIT Press, 1977.

[80] B. W. Hogwood and L. A. Gunn, Policy Analysis for the Real World. Oxford University Press, 1984.

[81] P. A. Sabatier, Theories of the policy process, vol. 7, no. 1. Westview Press, 1999, pp. viii, 289.

[82] H. A. Linstone and M. Turoff, "The Delphi Method: Techniques and Applications," Technometrics, vol. 18, no. 3, p. 363, 1976.

[83] K. Rohatgi and P. Rohatgi, "Delphi as a tool for identifying future appropriate technologies in India," Technological Forecasting and Social Change, vol. 14, no. 1, pp. 65-76, 1979.

[84] J. A. CANTRILL, B. SIBBALD, and S. BUETOW, "The Delphi and nominal group techniques in health services research," International Journal of Pharmacy Practice, vol. 4, no. 2, pp. 67-74, Jun. 1996.

[85] J. P. Martino, Technological forecasting for decision making. North-Holland, 1983.

[86] E. D. Pellegrino, "Decision making in a technological society.," The Pharos of Alpha Omega AlphaHonor Medical Society Alpha Omega Alpha, vol. 41, no. 1. p. 33, 1978.

[87] Y. Dror, "Required Breakthroughs in Think Tanks," Policy Sciences, vol. 16, pp. 199-225, Jan. 1984.

[88] Y. Dror, "How Think Tank Improve Public Policy,” Today, Economic Reform, no. May, pp. 34-38, 1996. 
[89] R. Phaal, C. Farrukh, and D. Probert, "Technology Roadmapping : linking technology resources to business objectives,” Technology, pp. 1-18, 2001.

[90] R. Phaal, C. J. P. Farrukh, and D. R. Probert, "Fast-Start Technology Roadmapping," Technology Management, vol. 17, no. 5, pp. 1-12, 2000.

[91] G. J. Van Helden and S. Tillema, "In Search of a Benchmarking Theory for the Public Sector," Financial Accountability and Management, vol. 21, no. 3, pp. $337-$ $361,2005$.

[92] P. M. Haas, "Introduction: epistemic communities and international policy coordination," International Organization, vol. 46, no. 1, pp. 1-35, 1992.

[93] H. Kim, "Research Foresight Activities and Technological Development in Korea Science and Technology Policies in National R \& D Programs," Technological Forecasting and Social Change, no. January 1993, pp. 25-28, 1994.

[94] Michio Seya, "Technology Foresight in Japan," in International Seminar Foresight Studies on Science and Technology, 2000, no. 2.

[95] T. Kuwahara, "Technology Foresight in Japan - The Potential and Implications of DELPHI Approach," in The proceeding of international conference on technology foresight The approach to and the potential for New Technology Foresight, 2001, pp. 1-17.

[96] M. Lipsky, "Street-Level Bureaucracy," 1983.

[97] B. Hjern and D. O. Porter, "Implementation Structures: A New Unit of Administrative Analysis," Organization Studies, vol. 2, no. 3, pp. 211-227, 1982.

[98] S. Barrett and C. Fudge, Policy and Action: Essays on the Implementation of Public Policy. London: Methuen*jan 94, 1981.

[99] R. F. Elmore, "Backward Mapping: Implementation Research and Policy Decisions," Political Science Quarterly, vol. 94, no. 4, pp. 601-616, 1979.

[100] H. W. Chesbrough, "The Era of Open Innovation," MIT Sloan Management Review, vol. 44, no. 3, pp. 35-42, 2003.

[101] F. M. Scherer, "The Sources of Innovation. Eric von Hippel. Oxford University Press, New York, 1988 xii, 218 pp. 27.," Science, vol. 243, no. 4897, pp. $1497-$ 1498, 1989.

[102] Frederick Betz, Managing Science: Methodology and Organization of Research, 1st. Springer, 2010, p. 200. 
[103] U. Alon, "How to choose a good scientific problem.," Molecular Cell, vol. 35, no. 6, pp. 726-728, 2009.

[104] National Science Foundation (NSF), "NSF Proposals, Awards and Status," 2011. [Online]. Available: https://www.fastlane.nsf.gov/jsp/homepage/proposals.jsp. [Accessed: 16-May-1BC].

[105] National Institutes of Health (NIH), "NIH Funding opportunity," 2011. [Online]. Available: http://grants.nih.gov/grants/guide/. [Accessed: 16-May-1BC].

[106] European Commission, "The Seventh Framework programme: the future of European Union research policy," 2011. [Online]. Available: http://cordis.europa.eu/fp7/home_en.html. [Accessed: 16-May-1BC].

[107] R. N. Kostoff, R. G. Koytcheff, and C. G. Y. Lau, "Global nanotechnology research metrics," Scientometrics, vol. 70, no. 3, pp. 565-601, 2007.

[108] R. N. Kostoff, R. G. Koytcheff, and C. G. Y. Lau, "Global nanotechnology research literature overview," Technological Forecasting and Social Change, vol. 74, no. 9, pp. 1733-1747, 2007.

[109] X. Liu, S. Yu, F. Janssens, W. Glänzel, Y. Moreau, and B. De Moor, "Weighted hybrid clustering by combining text mining and bibliometrics on a large-scale journal database," Journal of the American Society for Information Science, vol. 61, no. 6, pp. 1105-1119, 2010.

[110] F. Janssens, "Clustering of scientific fields by integrating text mining and bibliometrics," Katholieke Universiteit Leuven, 2007.

[111] R. N. Kostoff and J. A. R1, "Citation Mining : Integrating Text Mining and Bibliometrics for Research User Profiling," Journal of the American Society for Information Science, vol. 52, no. 13, pp. 1148-1156, 2001.

[112] S. LOH, F. LORENZI, R. GRANADA, D. LICHTNOW, L. K. WIVES, and J. P. M. De OLIVEIRA, "Identifying Similar Users by their Scientific Publications to Reduce Cold Start in Recommender Systems," International Conference on Web Information Systems and Technologies WEBIST, vol. 1, pp. 593-600, 2009.

[113] S. Loh, F. Lorenzi, R. Granada, D. Lichtnow, and L. K. Wives, "Using Scientific Publications to Identify People with Similar Interests," Web Information Systems and Technologies, pp. 229-241, 2010.

[114] T. T. Chen and L. Q. Xie, "Identifying critical focuses in research domains," in Information Visualisation 2005 Proceedings Ninth International Conference on, 2005, pp. 135-142. 
[115] J. K. Leidecker and A. V Bruno, "Identifying and Using Critical Success Factors," Long Range Planning, vol. 17, no. 1, pp. 23-32, 1984.

[116] Q. Zhou, W. Huang, and Y. Zhang, "Identifying critical success factors in emergency management using a fuzzy DEMATEL method," Safety Science, vol. 49, no. 2, pp. 243-252, 2011.

[117] R. M. Sibly and R. H. Smith, "Identifying key factors using 1 contribution analysis," Journal of Animal Ecology, vol. 67, no. 1, pp. 6-13, 1998.

[118] P. Van Bodegom, C. Bakker, and H. D. Van Der Gon, "Identifying key issues in environmental wetland research using scaling and uncertainty analysis," Regional Environmental Change, vol. 4, pp. 100-106, 2004.

[119] Peter Suber, “Open Access Overview,” 2002-2010, 2011. [Online]. Available: http://www.earlham.edu/ peters/fos/overview.htm.

[120] K. Simiyu, H. Masum, J. Chakma, and P. A. Singer, "Turning science into health solutions: KEMRI's challenges as Kenya's health product pathfinder," BMC International Health and Human Rights, vol. 10, no. Suppl 1, p. S10, 2010.

[121] World Health Organization WHO, “ Health InterNetwork Access to Research Initiative (HINARI)," www.healthinternetwork.org, 2011. [Online]. Available: http://www.biomedcentral.com/openaccess/www/?issue $=12$.

[122] National Institute of health (NIH), "PubMed:U.S. National Library of Medicine," 2011. [Online]. Available: http://www.ncbi.nlm.nih.gov/pubmed/.

[123] T. Bloom, C. Ferguson, L. Gross, C. J. MacCallum, J. Milton, R. Shields, S. Wai, J. Weaver, and L. Williams, "PLoS Biology at 5: The Future Is Open Access," PLoS Biology, vol. 6, no. 10, p. 2, 2008.

[124] Peter Suber, "Bethesda Statement on Open Access Publishing," 2003, 2011. [Online]. Available: http://www.earlham.edu/ peters/fos/bethesda.htm.

[125] J. Royall, I. Van Schayk, M. Bennett, N. Kamau, and M. Alilio, “Crossing the digital divide: The contribution of information technology to the professional performance of malaria researchers in Africa," African Health Sciences, vol. 5, no. 3, pp. 246-254, 2005.

[126] National Institutes of Health Public Access, "NIH Public Access Policy," 2011. [Online]. Available: http://publicaccess.nih.gov/. 
[127] D. C. Brabham, "Crowdsourcing as a Model for Problem Solving: An Introduction and Cases," Convergence: The International Journal of Research into New Media Technologies, vol. 14, no. 1, pp. 75-90, 2008.

[128] D. C. Brabham, "Moving the Crowd at Threadless: Motivations for Participation in a Crowdsourcing Application,” AEJMC conference August 2009, vol. 13, no. August, pp. 1-16, 2009.

[129] I. InnoCentive, "InnoCentive: Where the World Innovates." [Online]. Available: http://www.innocentive.com/.

[130] L. Huston and N. Sakkab, "Connect and develop," Harvard Business Review, vol. 84 , no. 3, pp. 58-66, 2006.

[131] J. Hagel and J. S. Brown, "The Next Wave of Open Innovation How InnoCentive aims to exploit sophisticated technology and networking capabilities to connect problems with their potential solvers," Innovation, pp. 8-10, 2009.

[132] D. S. Alpheus Bingham, The Open Innovation Marketplace: Creating Value in the Challenge Driven Enterprise, 1st ed. FT Press, p. 272.

[133] E. Group and P. Limited, "InnoCentive takes the incentive: How open innovation boosts R\&D," Strategic Direction, vol. 21, no. 8, pp. 6-8, 2005.

[134] J. Bughin, M. Chui, and B. Johnson, "The next step in open innovation," McKinsey Quarterly, vol. 2008, no. 4, pp. 112-122, 2008.

[135] "LabRoots - is a social networking site for the scientific community." [Online]. Available: http://www.labroots.com/aboutus.php. [Accessed: 05-Jun-2011].

[136] T. L. Friedman, The world is flat: A brief history of the twenty-first century (2nd ed.). Farrar, Straus and Giroux, 2006.

[137] A. Herod and M. W. Wright, Eds., Geographies of Power. Oxford, UK: Blackwell Publishers Ltd, 2002.

[138] R. F. Elmore and K. In Hanf, "Forward and Backward Mapping: Reversible Logic in the Analysis of Public Policy," Martinus Nijhoff Publishers, 1985, p. 3370.

[139] J. P. Lester, A. O. M. Bowman, M. L. Goggin, and L. J. O’Toole, "Public policy Implementation: evolution of the field and agenda for future research," Review of Policy Research, vol. 7, no. 1, pp. 200-216, 1987.

[140] F. Betz, Executive strategy strategic management and information technology. John Wiley, 2001, p. 534 S. 
[141] P. Sabatier, Policy change and learning : an advocacy coalition approach. Westview Press, 1993.

[142] H. C. Jenkins-Smith and P. A. Sabatier, "Evaluating the Advocacy Coalition Framework," Journal of Public Policy, vol. 14, no. 02, pp. 175-203, 1994.

[143] P. A. Sabatier and C. M. Weible, "The Advocacy Coalition Framework: Innovations and Clarifications," in Theories of the Policy Process, P. A. Sabatier, Ed. Westview Press, 2007, pp. 189-222.

[144] E. Schlager, "Policy making and collective action: Defining coalitions within the advocacy coalition framework," Policy Sciences, vol. 28, no. 3, pp. 243-270, 1995.

[145] I. Sue Wing, "The synthesis of bottom-up and top-down approaches to climate policy modeling: Electric power technology detail in a social accounting framework," Energy Economics, vol. 30, no. 2, pp. 547-573, 2008.

[146] V. V. and T. T. Krishna, Science, Technology Policy and the Diffusion of Knowledge: Understanding the Dynamics of Innovation Systems in the Asia Pacific, 1st ed. Edward Elgar Pub, 2007, p. 452.

[147] "Thailand's Ministry of Science and Technology," 2011. [Online]. Available: http://www.most.go.th/eng/.

[148] "Office of National Research Council of Thailand (NRCT)," 2011. [Online]. Available: http://www.nrct.go.th/.

[149] National Science Foundation (NSF), "NSF Proposal Processing and Review," 2012. [Online]. Available: http://www.nsf.gov/pubs/policydocs/pappguide/nsf13001/gpg_3.jsp\#IIIA.

[150] National Academies, "The Selection Criteria of Pakistan - U.S. Science and Technology Cooperation Program," 2012. [Online]. Available: http://sites.nationalacademies.org/pga/dsc/pakistan/index.htm.

[151] K. F. Edler, Jakob, Paul Cunningham, "Drivers of International collaboration in research,” Brussels, Belgium, 2009. 
Appendix A: Description of Desirability Value of ICST Evaluation Sub-criteria

- Desirability Values of "Strategic Importance"

SI 1) To build up national S\&T capability

\begin{tabular}{|c|c|}
\hline Level & Description \\
\hline Excellent & $\begin{array}{c}\text { All dimensions of S\&T capability building up are } \\
\text { mentioned e.g. Personnel, Education, Infrastructure, } \\
\text { Regulation \& Framework, and Investment. }\end{array}$ \\
\hline Good & $\begin{array}{l}\text { More than one dimensions of S\&T capability building } \\
\text { up is mentioned e.g. Personnel, Education, } \\
\text { Infrastructure, Regulation \& Framework, and } \\
\text { Investment. }\end{array}$ \\
\hline Medium & $\begin{array}{c}\text { At least one dimension of S\&T capability building up } \\
\text { is mentioned e.g. Personnel, Education, Infrastructure, } \\
\text { Regulation \& Framework, and Investment. }\end{array}$ \\
\hline Low & $\begin{array}{l}\text { There is a mention about S\&T capability building up in } \\
\text { incomprehensively. }\end{array}$ \\
\hline None & $\begin{array}{l}\text { No mention about how to build up the national S\&T } \\
\text { capability. }\end{array}$ \\
\hline
\end{tabular}

SI 2) To establish global partnership

\begin{tabular}{|c|c|}
\hline Level & Description \\
\hline Excellent & $\begin{array}{l}\text { There is (a) partnership (s) with the current } \\
\text { International collaboration partner(s) already at the } \\
\text { "greater level" of collaboration. } \\
\text { And } \\
\text { There will be (a) partnership(s) with the new } \\
\text { International Collaboration partner(s). }\end{array}$ \\
\hline Good & $\begin{array}{l}\text { There is (a) partnership(s) with the current International } \\
\text { collaboration partner(s) already at the "greater level" of } \\
\text { collaboration. } \\
\text { Or } \\
\text { There will be (a) partnership(s) with the new } \\
\text { International Collaboration partner(s). }\end{array}$ \\
\hline Medium & $\begin{array}{l}\text { There is (a) partnership(s) with the current International } \\
\text { collaboration partner(s) already at the same level of } \\
\text { collaboration (Maintaining the current partnership(s). }\end{array}$ \\
\hline Low & There is an opportunity to set up a new partnership. \\
\hline None & No new global partnership \\
\hline
\end{tabular}


SI 3) To obtain and access to State-of-the-Art Knowledge aboard

\begin{tabular}{|c|c|}
\hline Level & Description \\
\hline Excellent & $\begin{array}{l}\text { To be a part of the High-end research project at the } \\
\text { Global Research Group or Organization e.g. CERN. }\end{array}$ \\
\hline Good & $\begin{array}{l}\text { Having a potential opportunity to tap in to the High-end } \\
\text { research project at the Global Research Group or } \\
\text { Organization. }\end{array}$ \\
\hline Medium & $\begin{array}{l}\text { To be a part of the high-end Research Group or } \\
\text { Organization e.g. Member of the IEEE and so on. }\end{array}$ \\
\hline Low & $\begin{array}{l}\text { Having an opportunity to get involved with the experts in } \\
\text { that specific area. }\end{array}$ \\
\hline None & $\begin{array}{l}\text { No new state-of-the-art knowledge will be learned or } \\
\text { acquired. }\end{array}$ \\
\hline
\end{tabular}

SI 4) To attract highly skilled professionals (Brain Gain)

\begin{tabular}{|c|c|}
\hline Level & Description \\
\hline Excellent & $\begin{array}{l}\text { There will be at least one of the highly skilled } \\
\text { professionals come back to work for their home country. } \\
\text { And } \\
\text { There will be a connection or collaboration project } \\
\text { between their home country and their current country } \\
\text { occasionally. }\end{array}$ \\
\hline Good & $\begin{array}{l}\text { There will be at least one of the highly skilled } \\
\text { professionals come back to work for their home country } \\
\text { occasionally. }\end{array}$ \\
\hline Medium & $\begin{array}{l}\text { There is a strong interest from the highly skilled } \\
\text { professional. }\end{array}$ \\
\hline Low & $\begin{array}{l}\text { There is a mild interest from the highly skilled } \\
\text { professional. }\end{array}$ \\
\hline None & No interest \\
\hline
\end{tabular}




\section{- Desirability Values of "Potential Benefit"}

PI 1) Meeting Local Challenge

\begin{tabular}{|c|c|}
\hline Level & \multicolumn{1}{c|}{ Description } \\
\hline Excellent & $\begin{array}{c}\text { There is a serious interest to solve the national } \\
\text { challenge(s) and the result will come out soon, in a year. }\end{array}$ \\
\hline Good & $\begin{array}{c}\text { There is a serious interest to solve the national } \\
\text { challenge(s) and the result will come out within the } \\
\text { next3-5 years. }\end{array}$ \\
\hline Medium & $\begin{array}{c}\text { There is a serious interest to solve the national } \\
\text { challenge(s) but there is no committed result. }\end{array}$ \\
\hline Low & There is a possibility to solve the national challenge(s). \\
\hline None & No interest in problem solving for the national issues. \\
\hline
\end{tabular}

PI 2) Tackling Global Challenge

\begin{tabular}{|c|c|}
\hline Level & Description \\
\hline Excellent & $\begin{array}{c}\text { This is an International Collaboration project with the } \\
\text { global partner to solve the Global Challenges e.g. } \\
\text { HIV/AIDS, Bird Flu, Global Warming, Biodiversity loss, } \\
\text { and so on. }\end{array}$ \\
\hline Good & $\begin{array}{c}\text { There is a possibility to tackle the global challenge(s) in } \\
\text { the next phase of this International Collaboration project. }\end{array}$ \\
\hline Medium & There is an interest to tackle the Global challenge(s). \\
\hline Low & $\begin{array}{c}\text { No obvious impact from the project about tackling the } \\
\text { Global Challenges. }\end{array}$ \\
\hline None & No interest in the Global Challenges. \\
\hline
\end{tabular}


PI 3) Having Knowledge or Technology Transfer

\begin{tabular}{|c|c|}
\hline Level & Description \\
\hline Excellent & $\begin{array}{c}\text { There will be a significant impact from the knowledge or } \\
\text { technology transfer from this project to others outside the } \\
\text { group. }\end{array}$ \\
\hline Good & $\begin{array}{c}\text { At least the researcher(s) who participate in this project } \\
\text { will be benefit from the knowledge or technology } \\
\text { transfer of this project perfectly. }\end{array}$ \\
\hline Low & $\begin{array}{c}\text { At least the researcher(s) who participate in this project } \\
\text { will acquire knowledge or technology transfer with } \\
\text { minor challenges. }\end{array}$ \\
\hline None & $\begin{array}{c}\text { It will be a possibility to discuss about the knowledge or } \\
\text { technology transfer in the future project. }\end{array}$ \\
\hline No interest in pursuing knowledge or technology will be \\
transferred among partner(s).
\end{tabular}

PI 4) Creating Joint Academic Papers

\begin{tabular}{|c|c|}
\hline Level & Description \\
\hline Excellent & $\begin{array}{c}\text { There will be one or more potential joint academic } \\
\text { paper(s) with the high citation index journal. } \\
\text { Good }\end{array}$ \\
$\begin{array}{c}\text { There will be at least one potential joint academic } \\
\text { paper(s) with the International journal or International } \\
\text { conference. }\end{array}$ \\
\hline Medium & $\begin{array}{r}\text { There will be a potential joint academic paper at the } \\
\text { National journal conference. }\end{array}$ \\
\hline Low & $\begin{array}{c}\text { There might be a potential joint academic paper at the } \\
\text { National journal conference. }\end{array}$ \\
\hline None & No interest in creating the joint academic paper. \\
\hline
\end{tabular}

PI 5) Creating Joint Research Program or Consortia

\begin{tabular}{|c|c|}
\hline Level & Description \\
\hline Excellent & $\begin{array}{l}\text { They are creating the joint research program or consortia } \\
\text { from this International Collaboration project. }\end{array}$ \\
\hline Good & $\begin{array}{l}\text { There is a strong interest to create the joint research } \\
\text { program or consortia from this project in the future. }\end{array}$ \\
\hline Medium & $\begin{array}{l}\text { There is a possibility to lead to the joint research } \\
\text { program or consortia from the current project. }\end{array}$ \\
\hline Low & Nobody mention about this potential benefit yet. \\
\hline None & $\begin{array}{l}\text { No interest in creating the joint research program or } \\
\text { consortia. }\end{array}$ \\
\hline
\end{tabular}


- Desirability Values of "Human Resource Development" Sub-criterion

HRD 1) No. of researchers who will benefit from this collaboration

\begin{tabular}{|c|c|}
\hline $\begin{array}{c}\text { No. of researcher } \\
\text { (persons) }\end{array}$ & Description \\
\hline$>20$ & More than 20 researchers will benefit from this project. \\
\hline 20 & 20 researchers will benefit from this project. \\
\hline 15 & 15 researchers will benefit from this project. \\
\hline 10 & 10 researchers will benefit from this project. \\
\hline 5 & 5 researchers will benefit from this project. \\
\hline 4 & 4 researchers will benefit from this project. \\
\hline 3 & 3 researchers will benefit from this project. \\
\hline 2 & 2 researchers will benefit from this project. \\
\hline 1 & At least one researcher will benefit from this project. \\
\hline
\end{tabular}

HRD 2) Significance benefits to researchers e.g. training, workshop

\begin{tabular}{|c|c|}
\hline Level & Description \\
\hline Excellent & $\begin{array}{c}\text { The researcher who participate in this project can transfer } \\
\text { their knowledge to other people in their laboratory and } \\
\text { also to other labs or department in their organization }\end{array}$ \\
\hline Good & $\begin{array}{r}\text { The researcher who participates in this project can } \\
\text { transfer their knowledge to other people in their lab. }\end{array}$ \\
\hline Medium & $\begin{array}{r}\text { The whole group of researcher who participate in this } \\
\text { project gain some benefit. }\end{array}$ \\
\hline Low & One researcher benefit from this project. \\
\hline None & No declared benefit from this purpose. \\
\hline
\end{tabular}


- Desirability Values of Matching Fund Ratio Criterion

\begin{tabular}{|c|c|}
\hline $\begin{array}{c}\text { Matching Fund } \\
\text { Ratio }\end{array}$ & Description \\
\hline $100 \%$ & All of the budget (100\%) comes from International \\
Collaboration partner (s)
\end{tabular}

Note: Matching Fund Ratio = Matching of Budget from the International Collaborative Partner/ Total Budget 


\section{Appendix B: Desirability Curves of all ICST Evaluation Sub-criteria}

- Strategic Importance (SI)

S1: To build up national S\&T capabilities through ICST
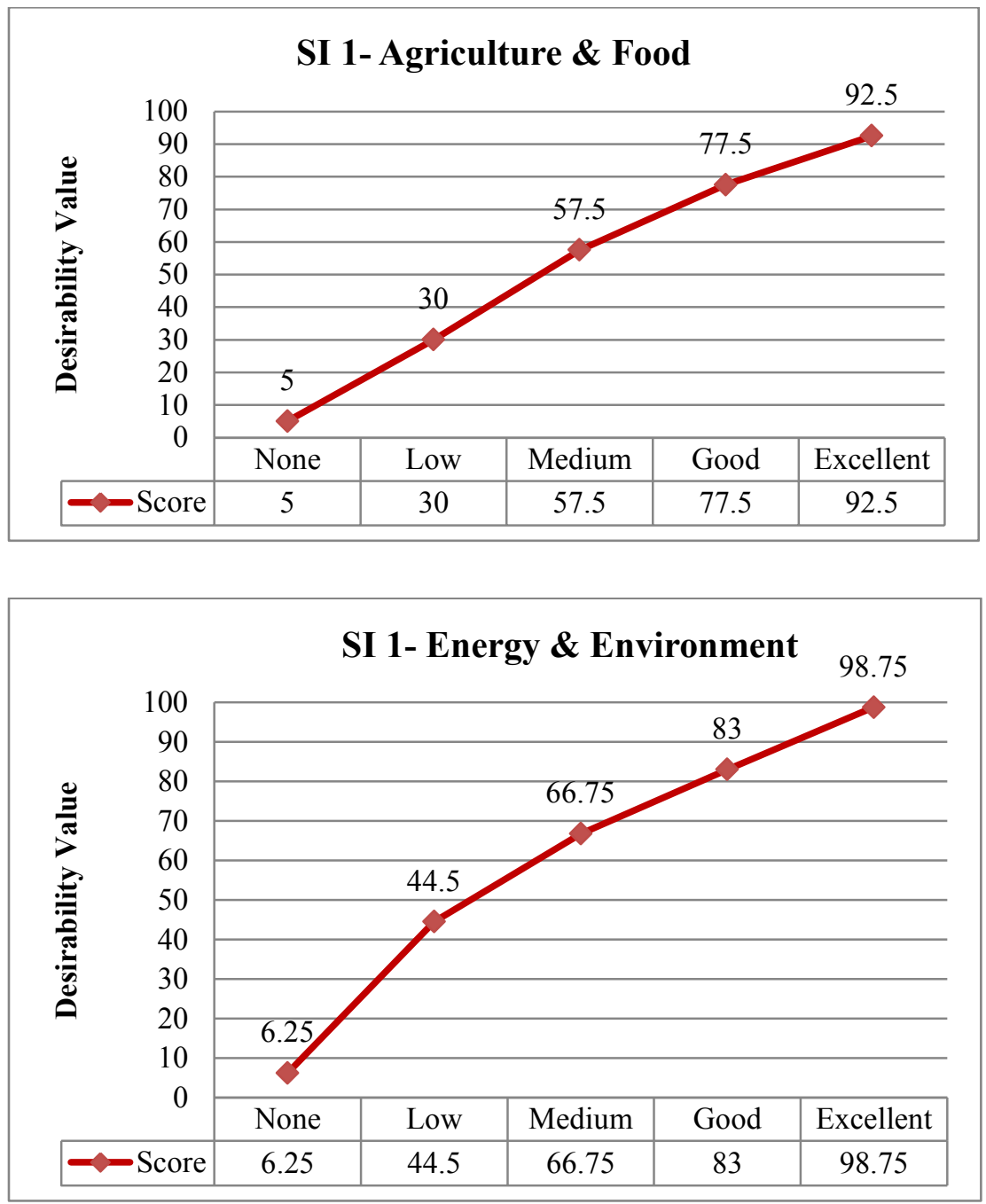

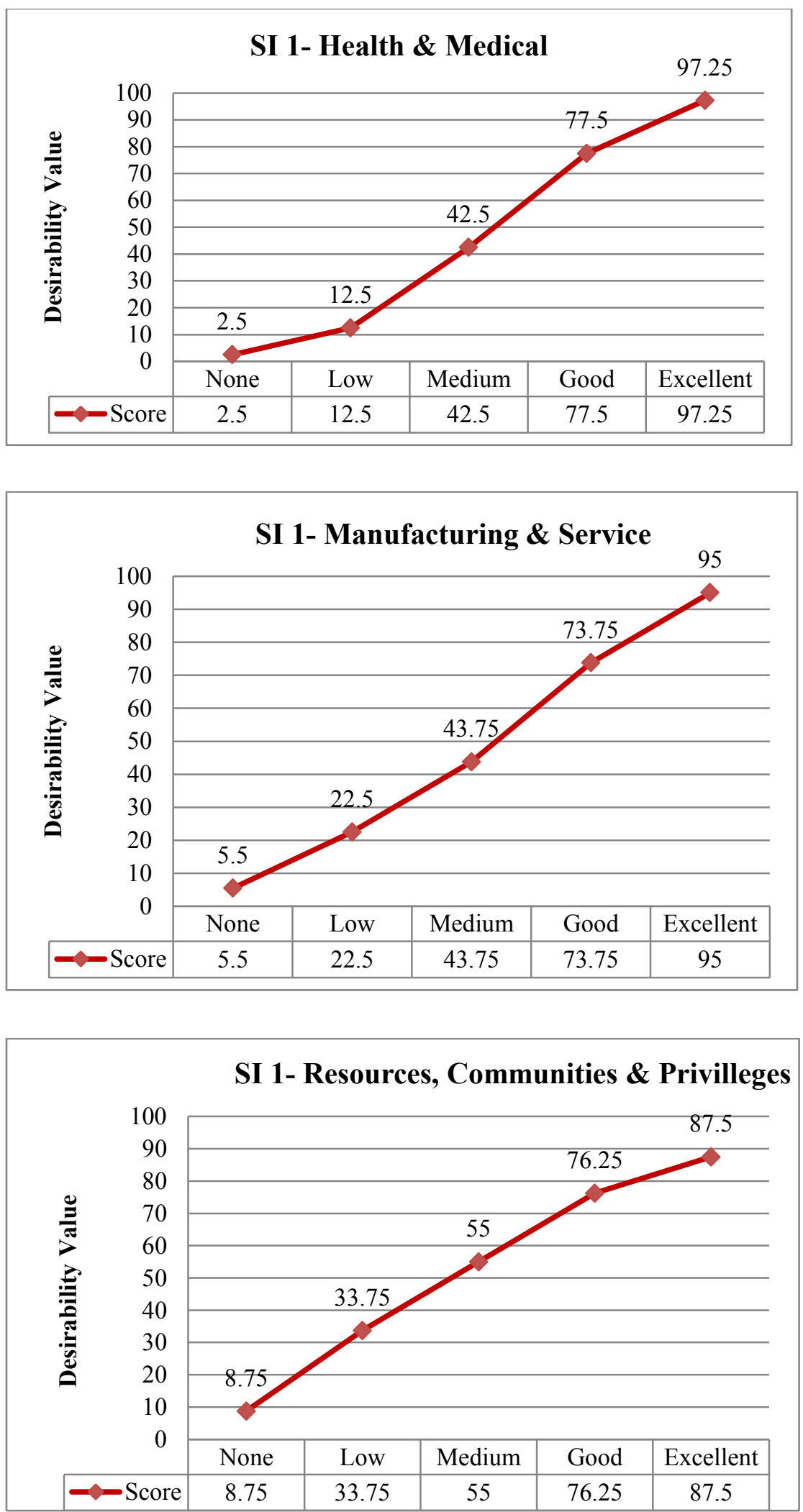
S2: To establish a global partnership
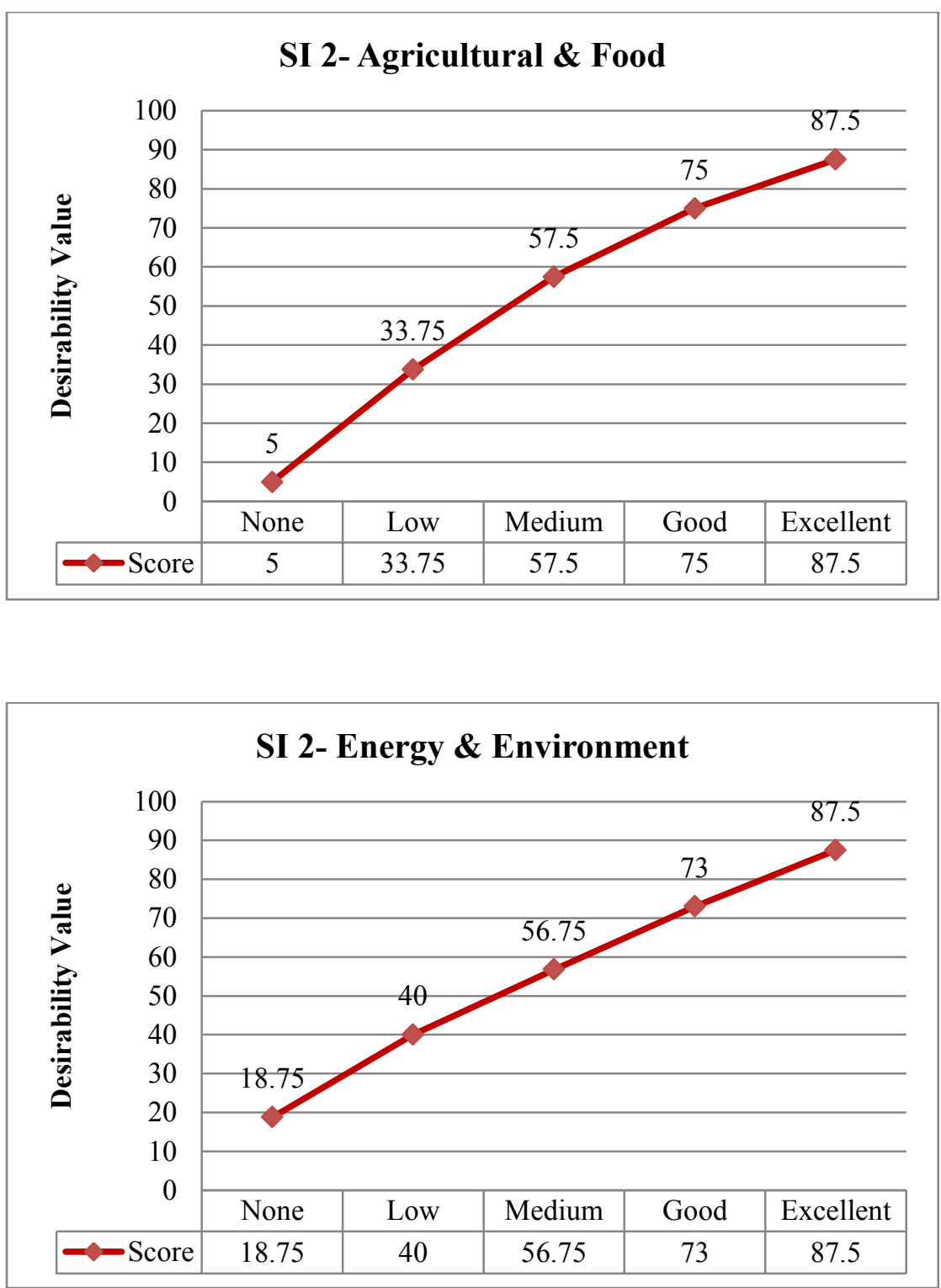

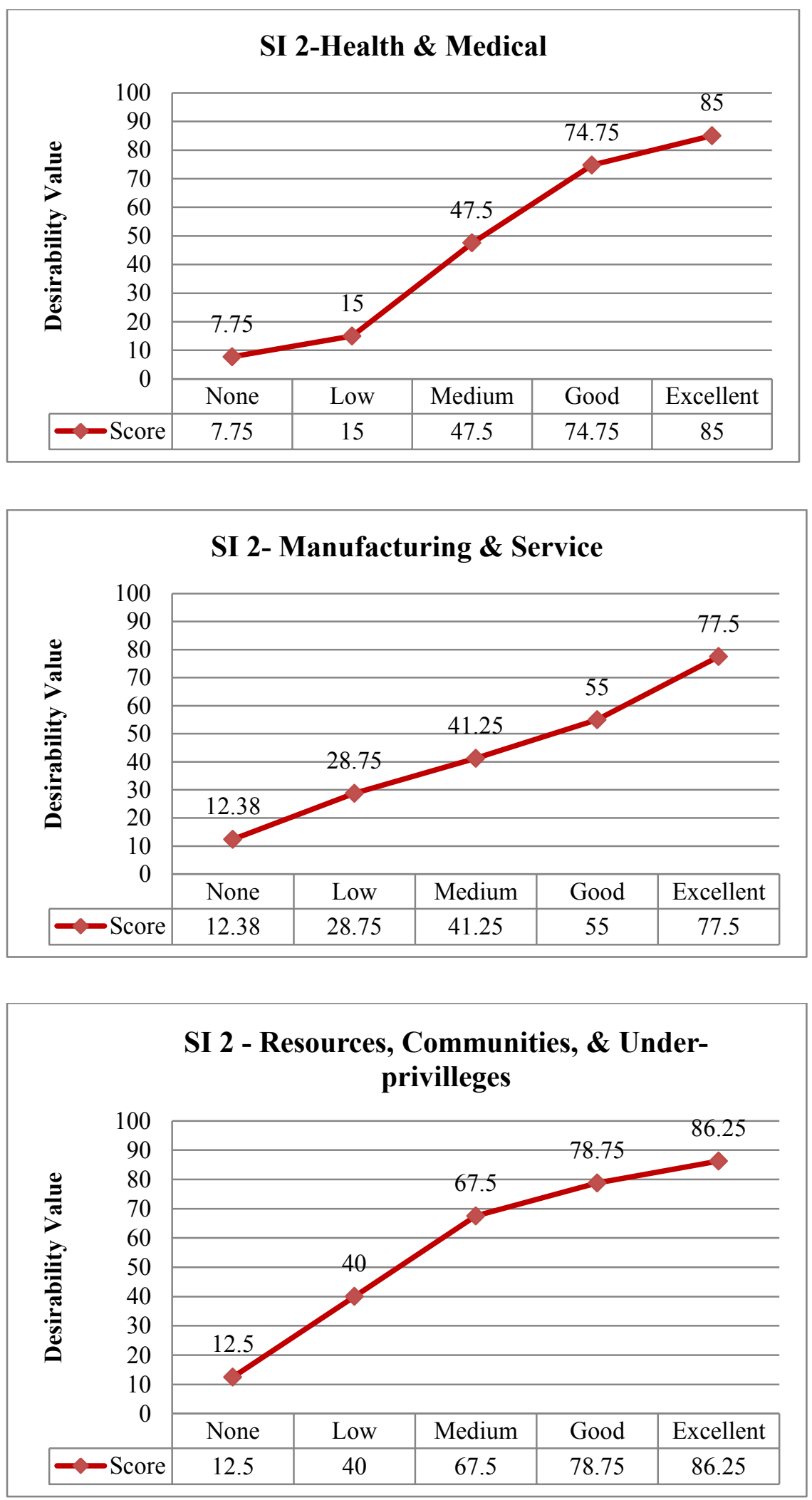
S3: To obtain access to State-of-the-art knowledge aboard
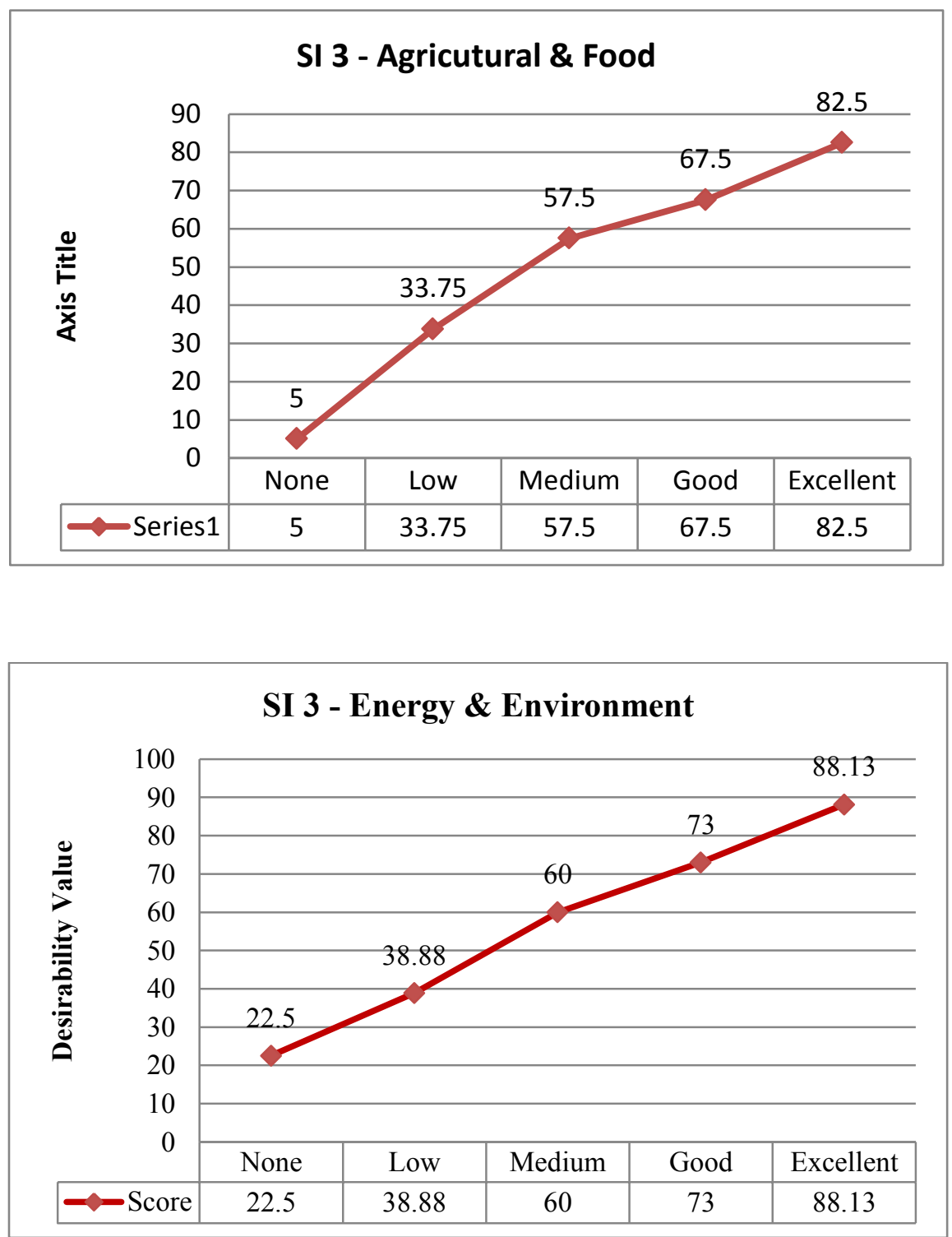

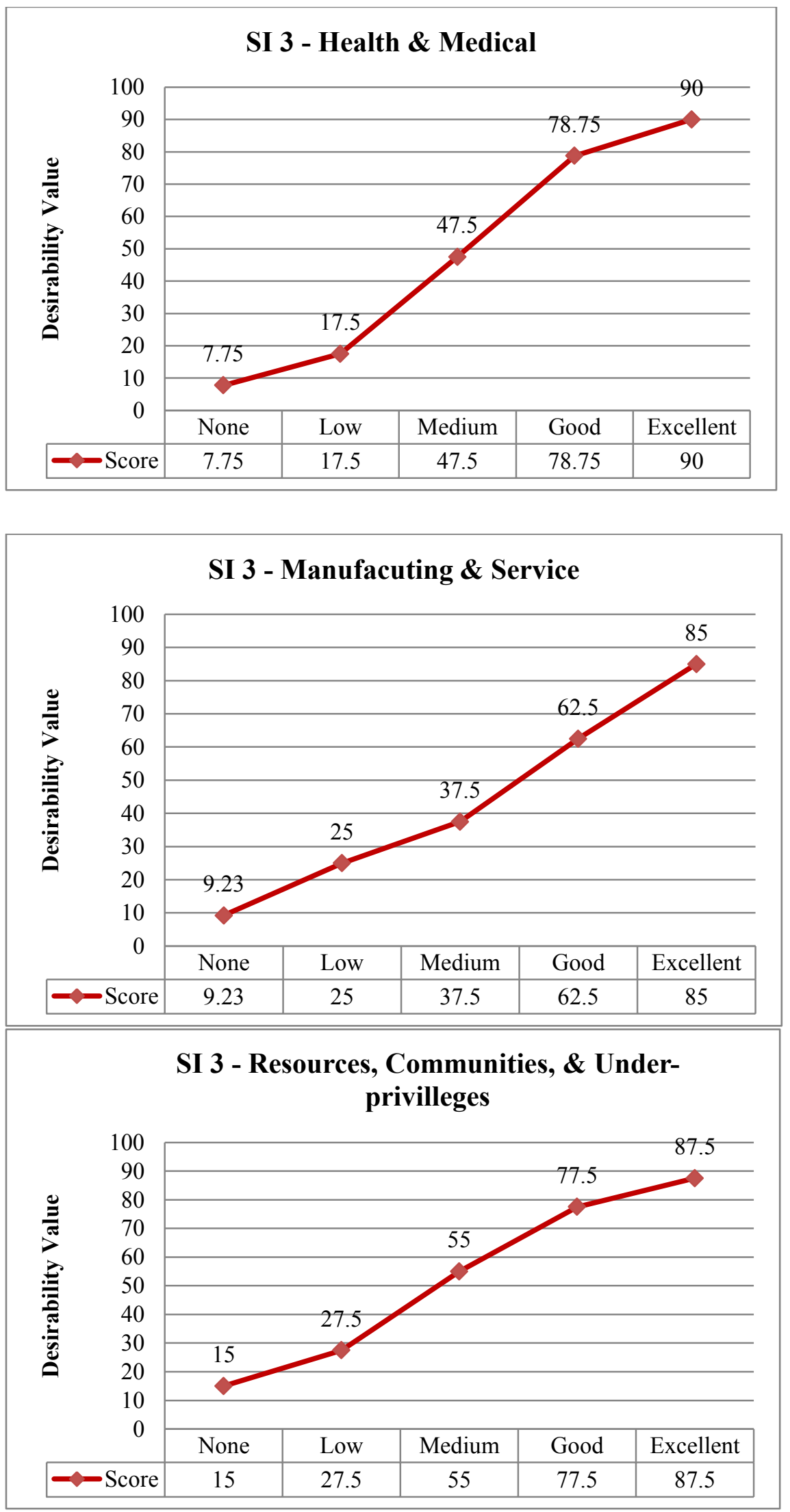

187 
S4: Brain Gain
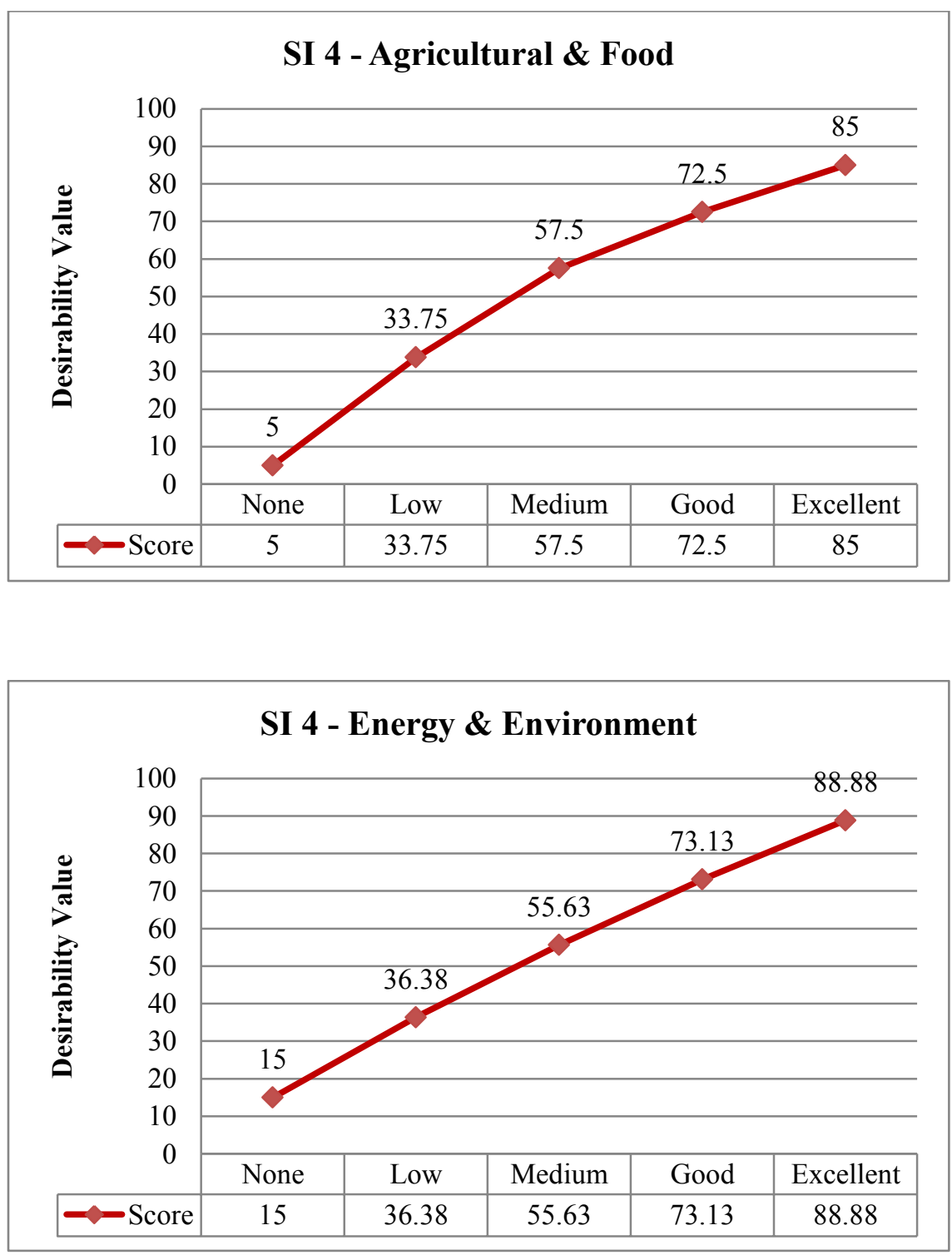

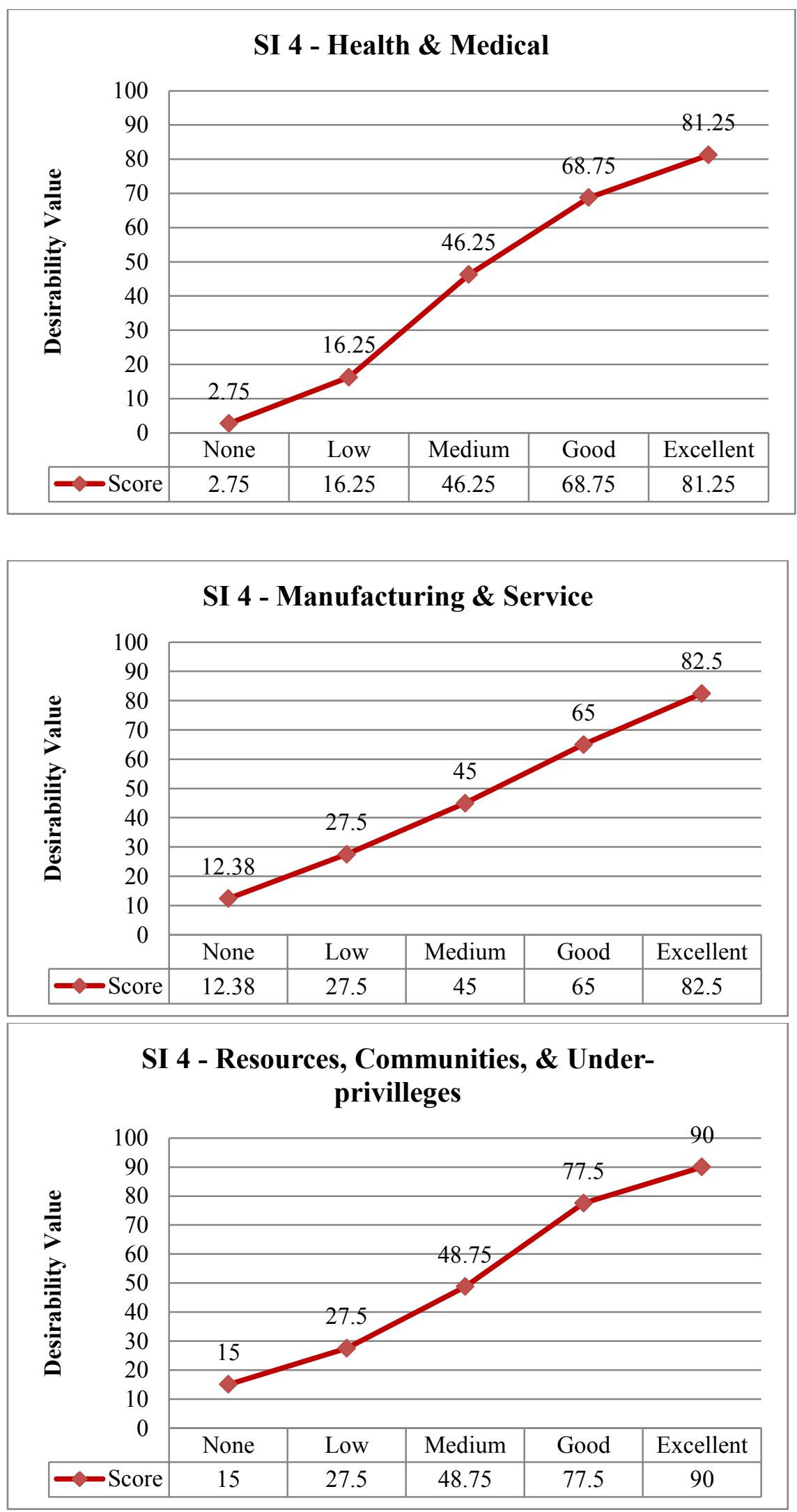
- Potential Impact (PI)

PI 1: Meeting Local challenge
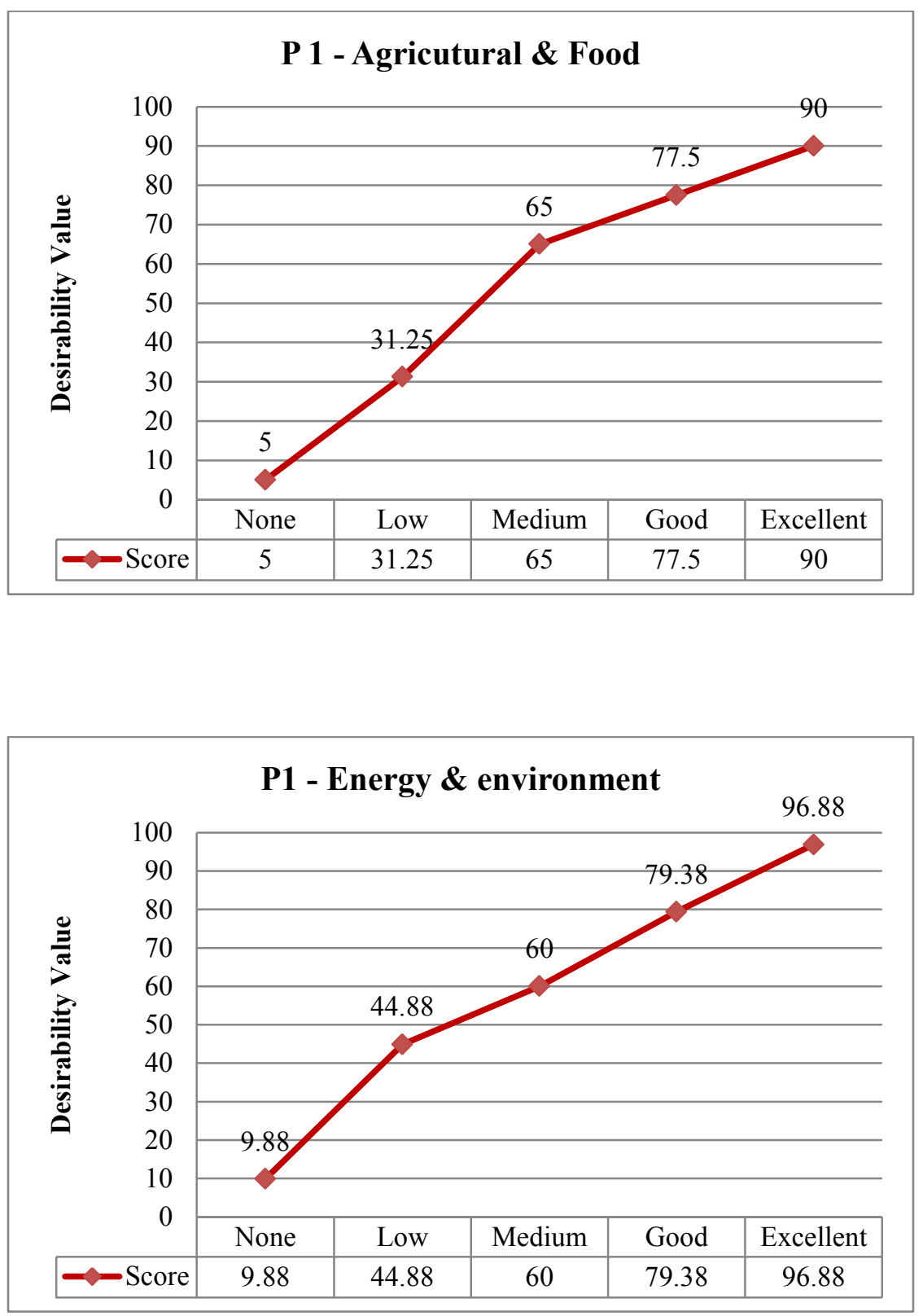

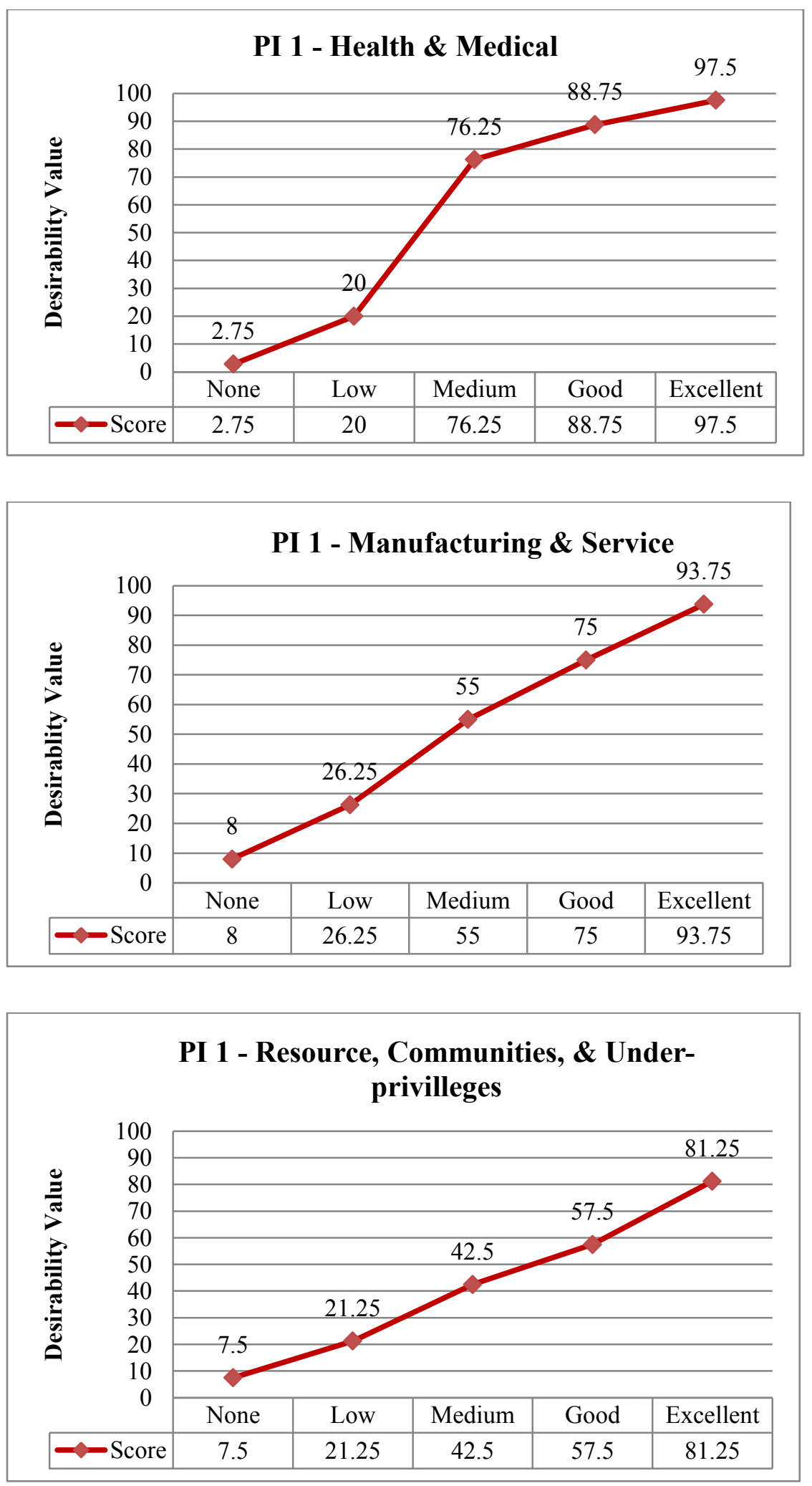
PI 2: Tackling Global Challenge
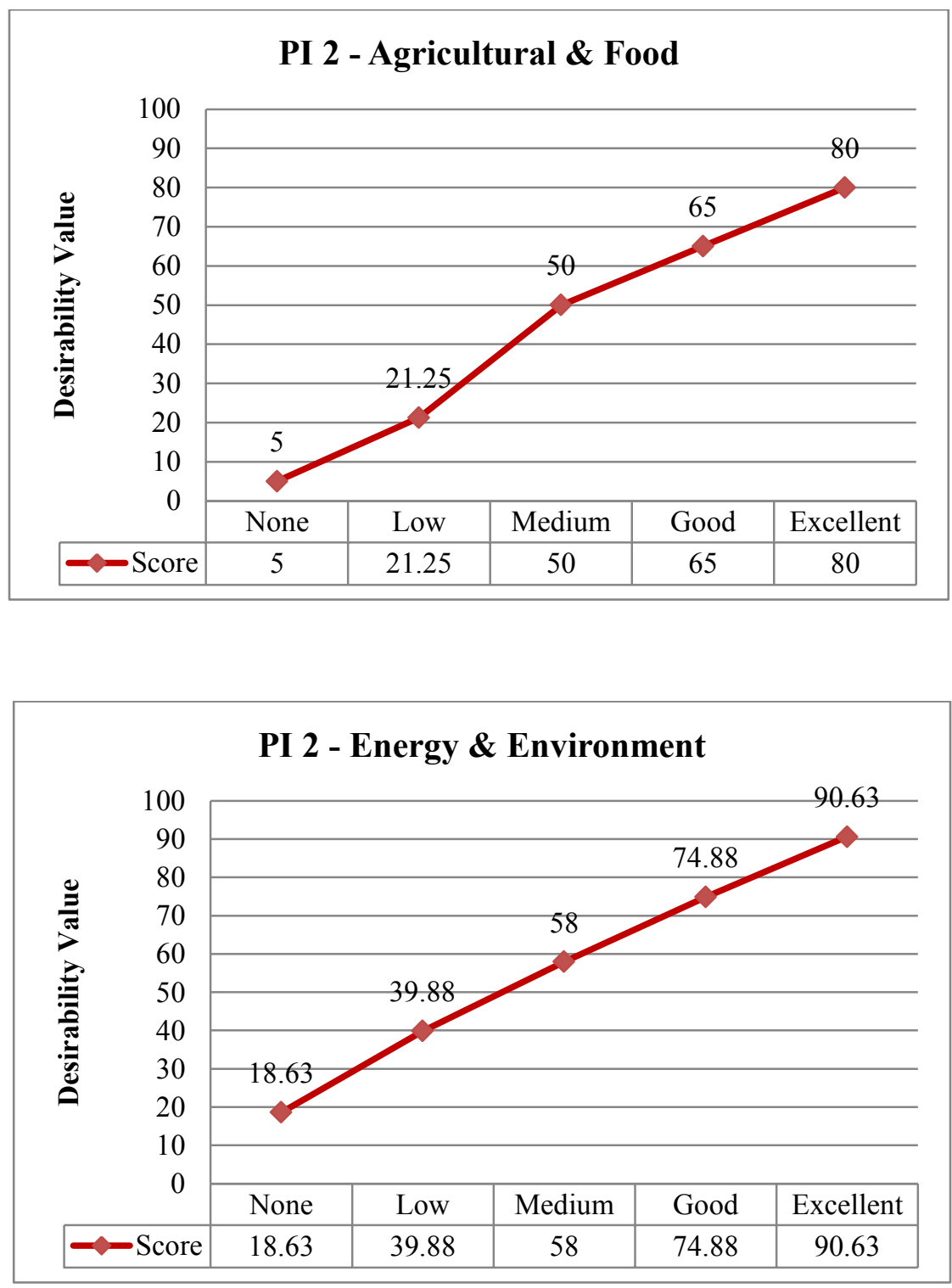

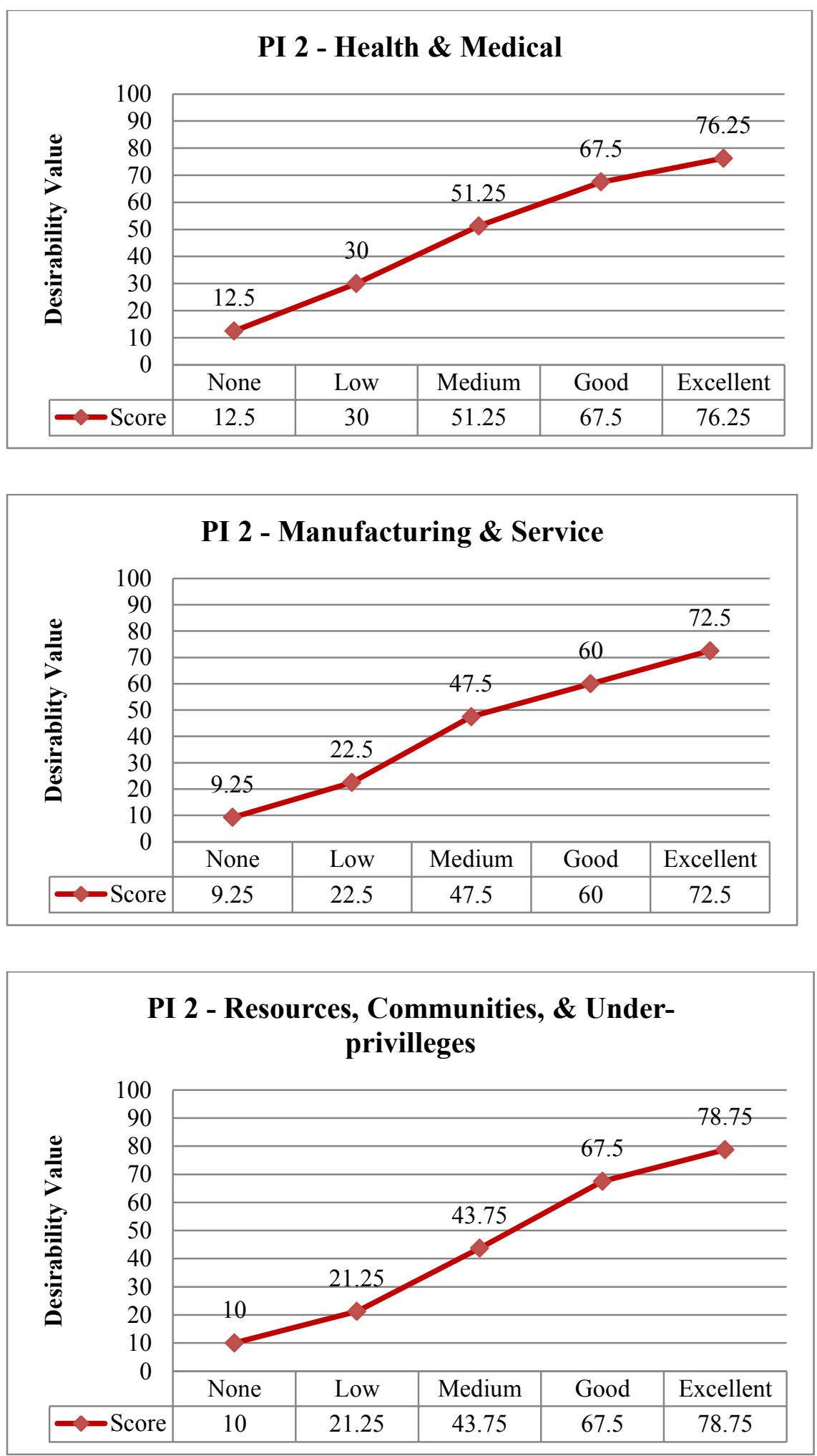
PI 3: Having Knowledge or Technology Transfer
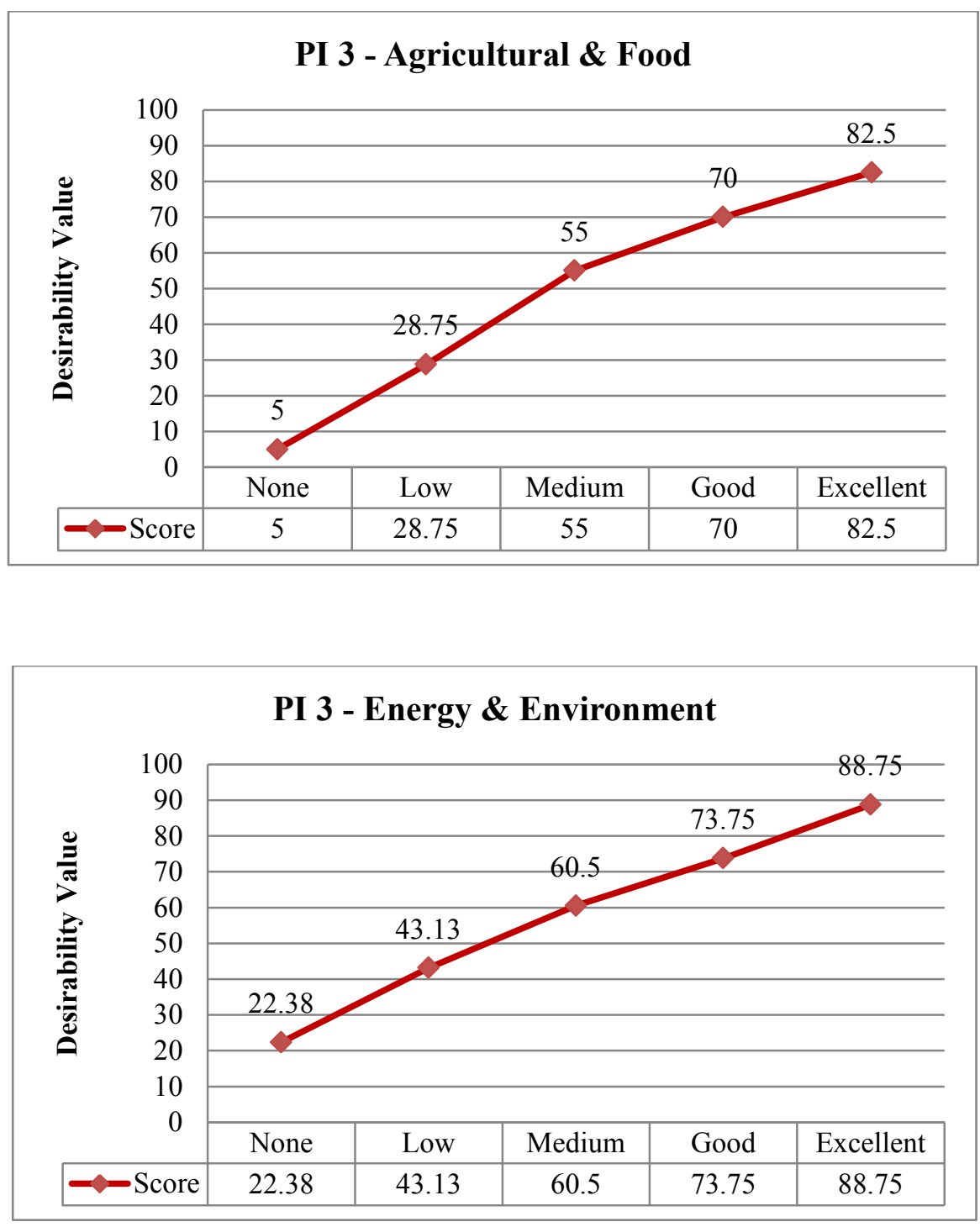

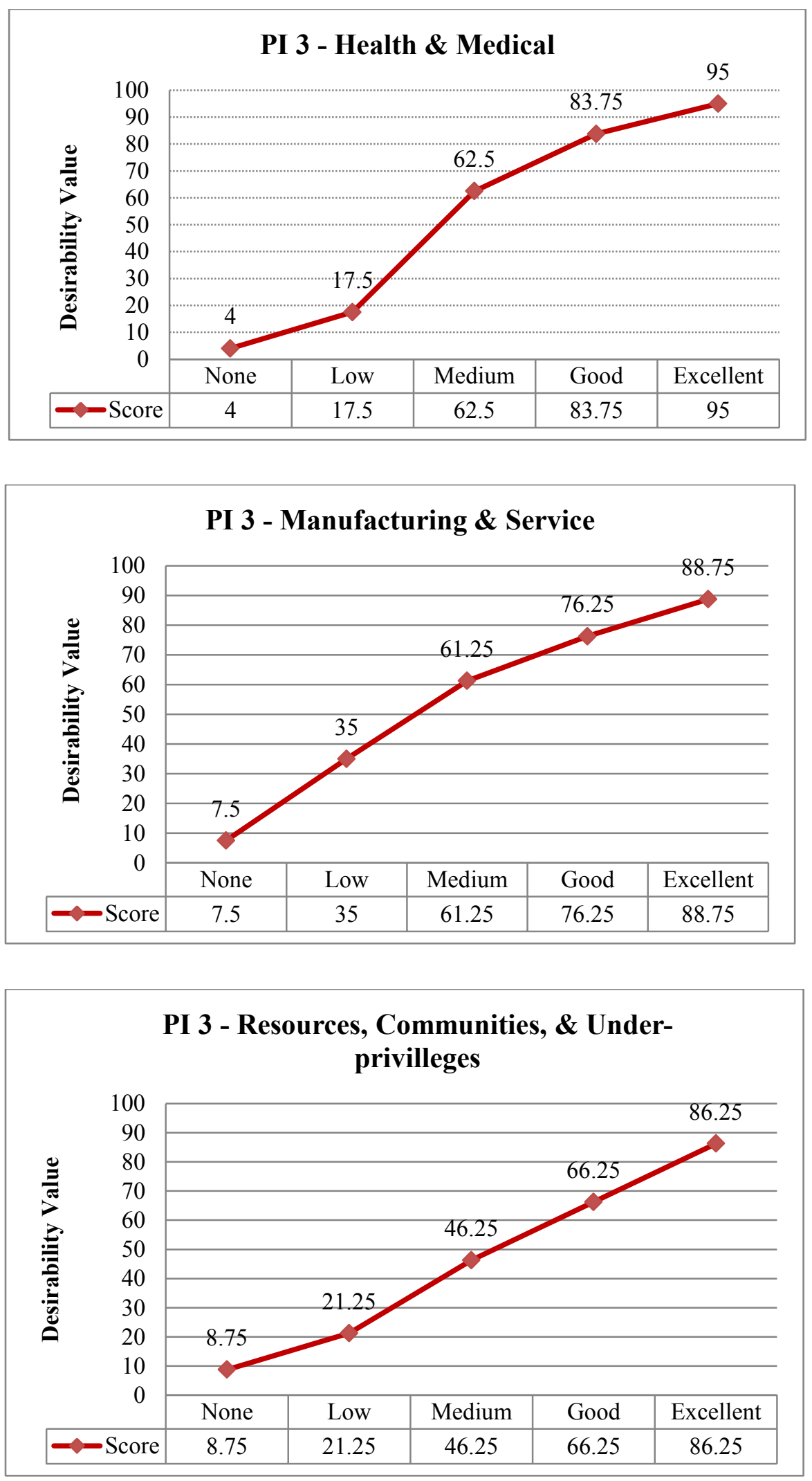
PI4: Creating Joint Academic Papers
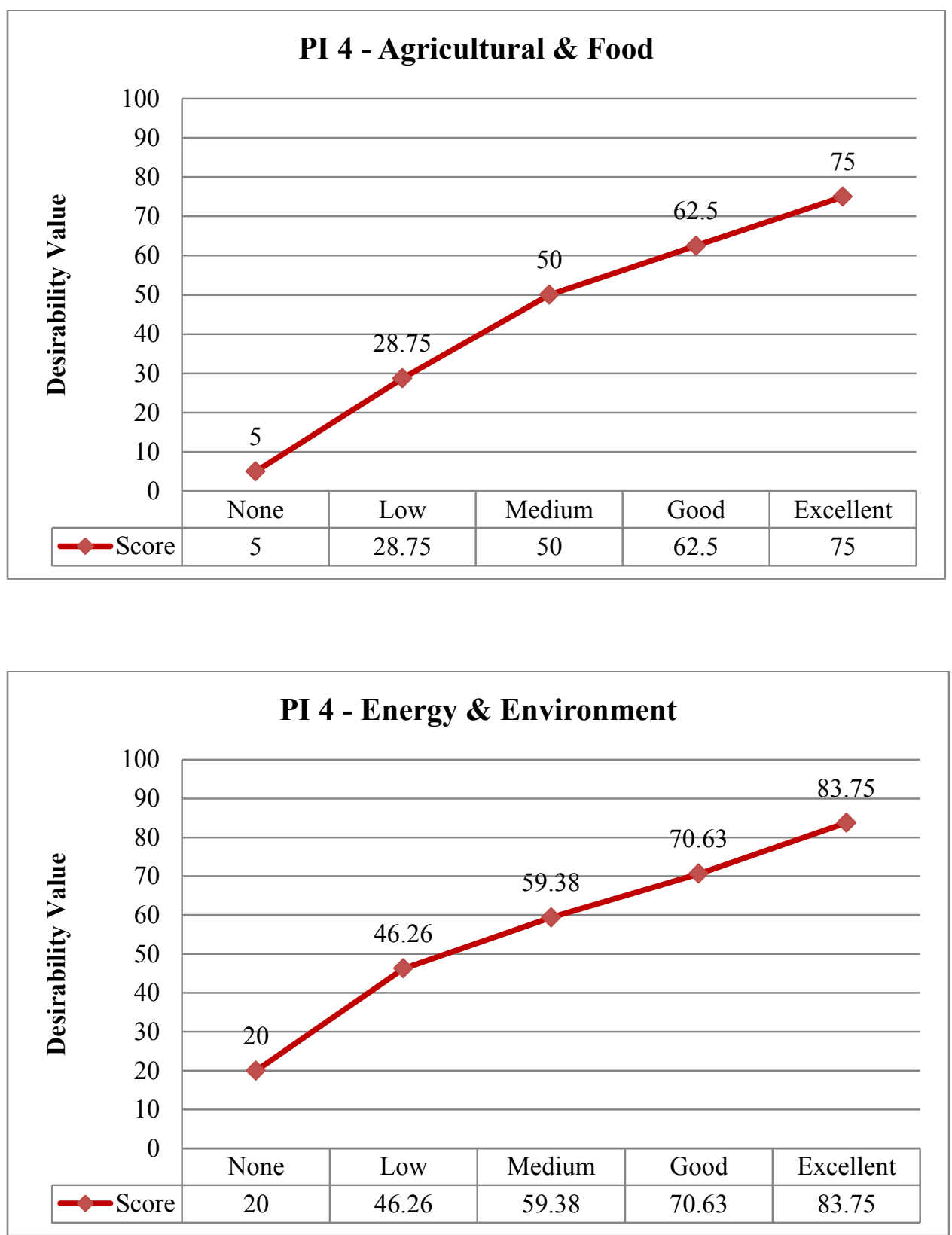

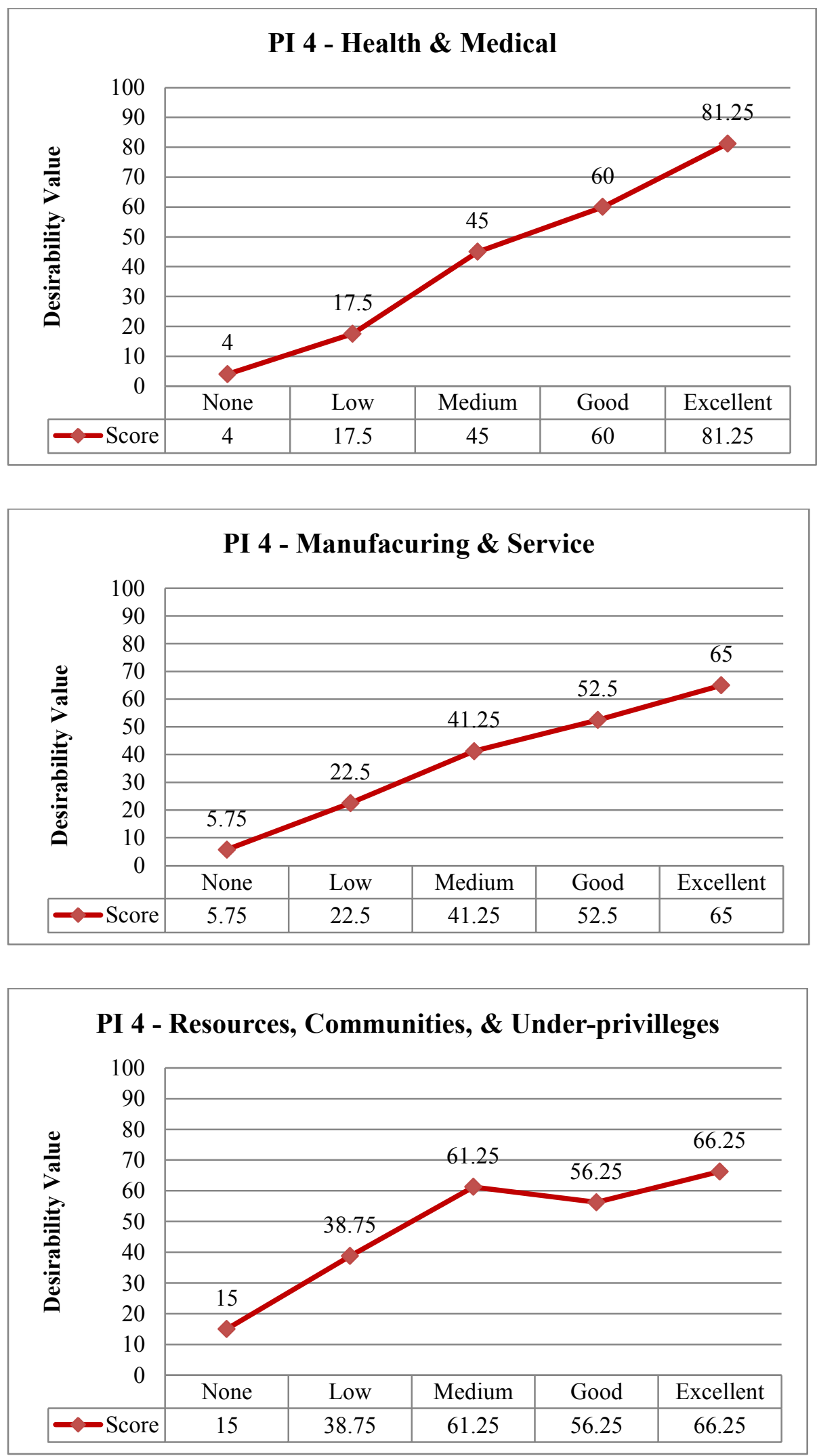
PI 5: Creating Joint Research Programs or Consortia
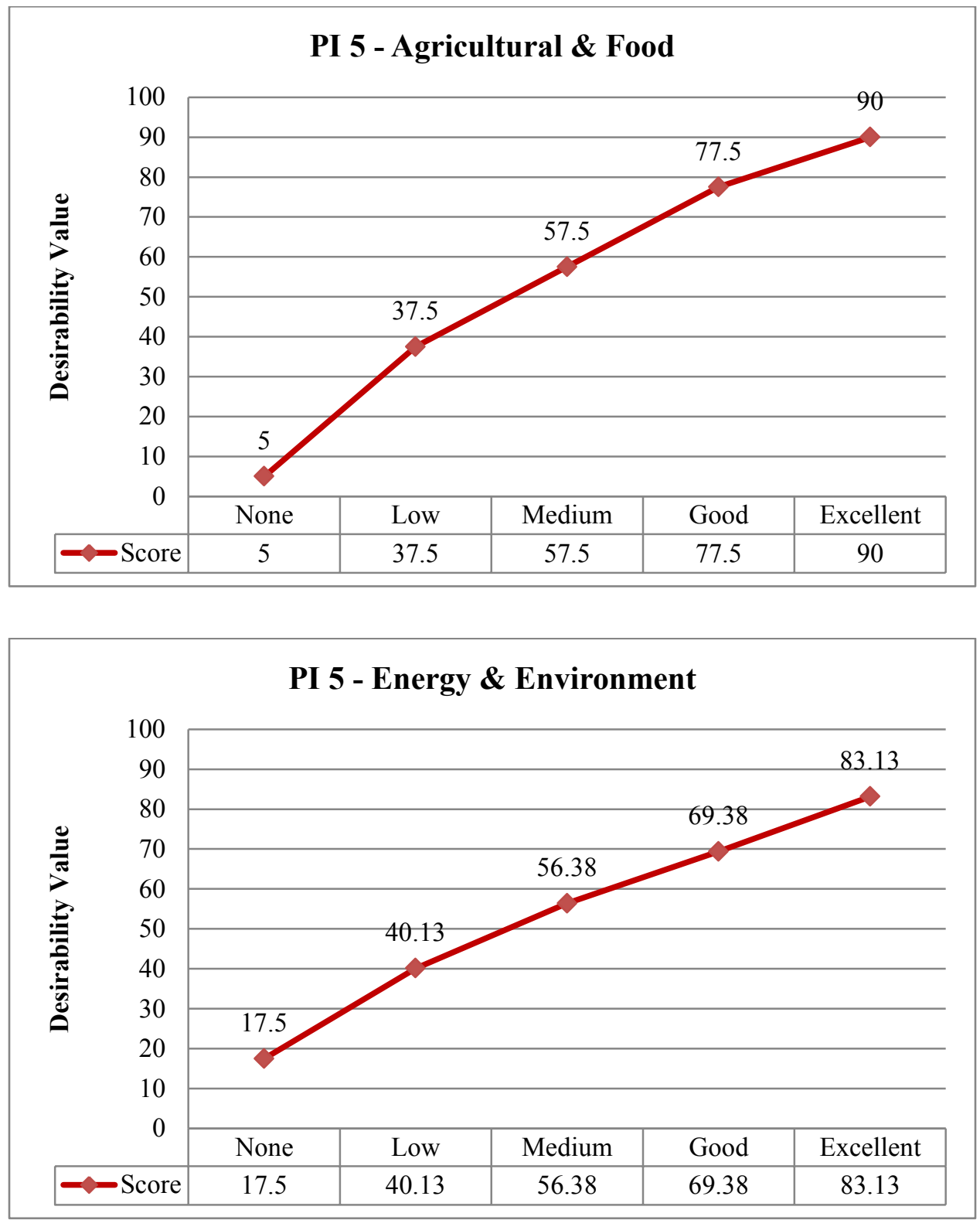

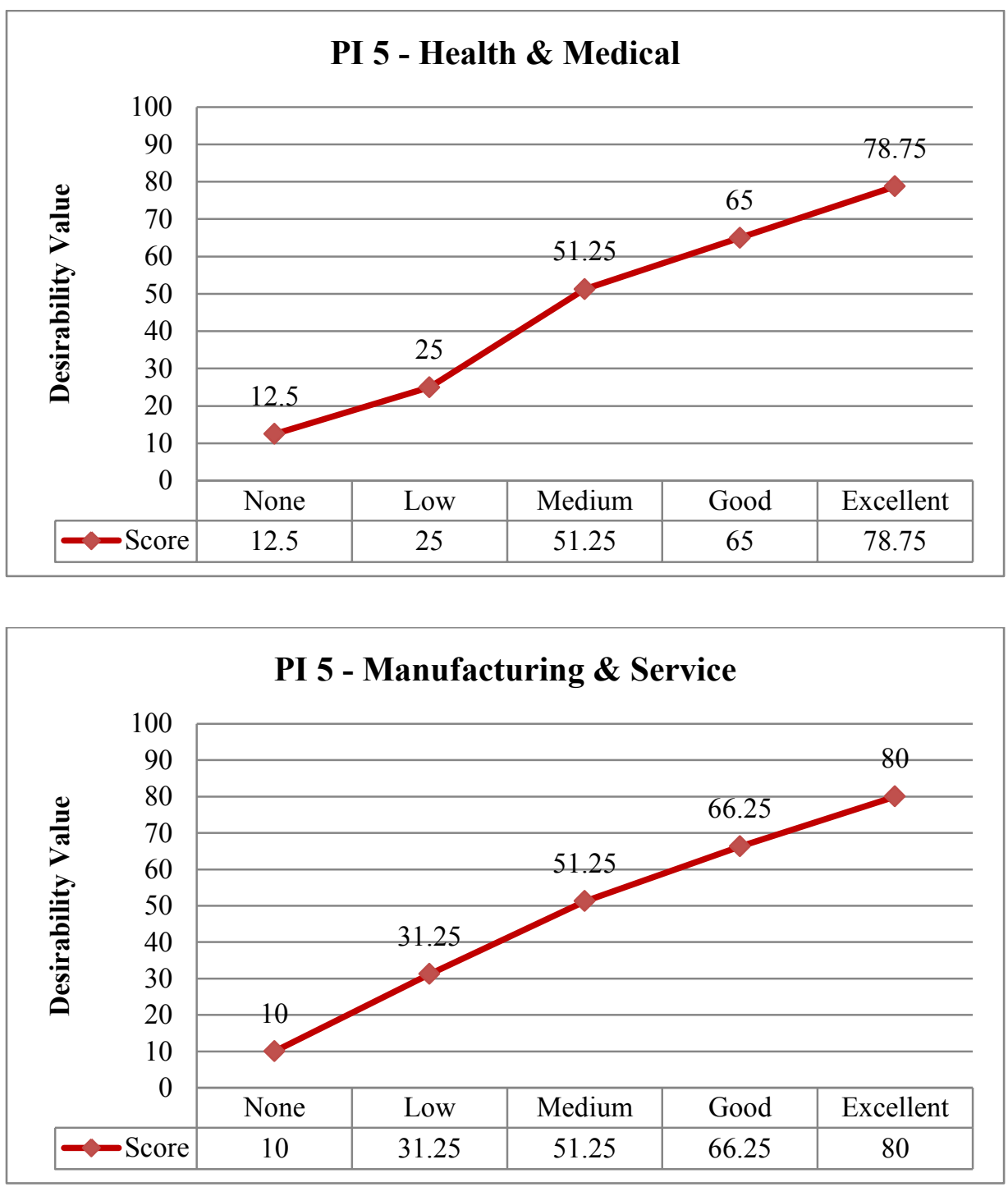

\section{PI 5 - Resources, Communities, \& Under-previlleges}

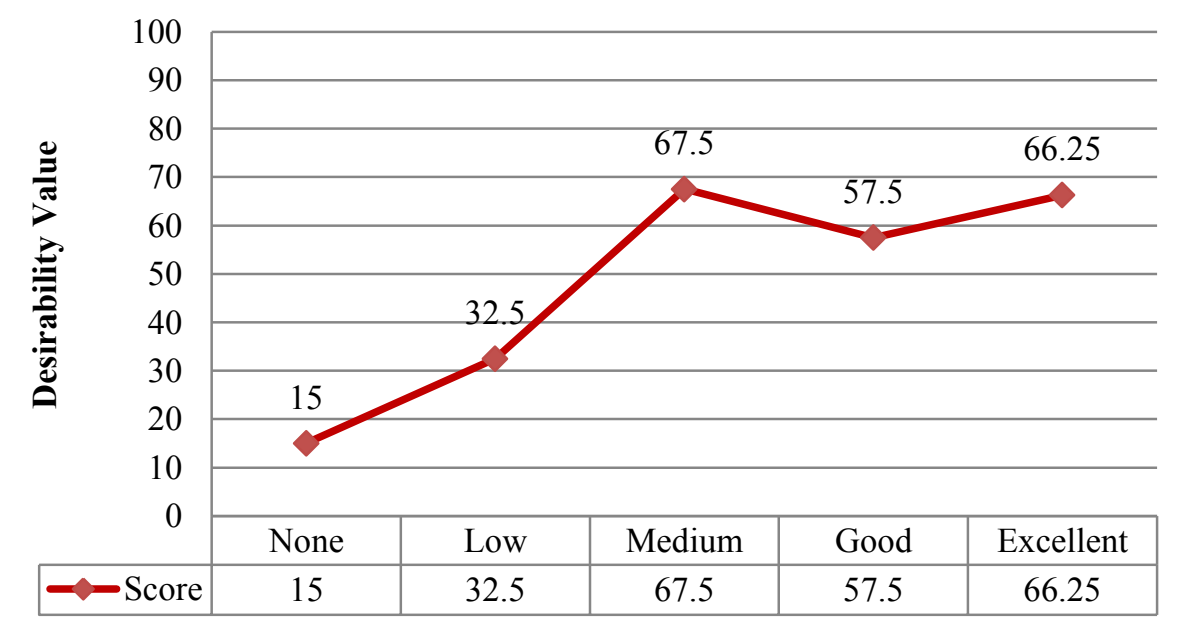


- Human Resource Development (HRD)

HRD 1: Number of researcher(s) who will benefit from the international collaboration project
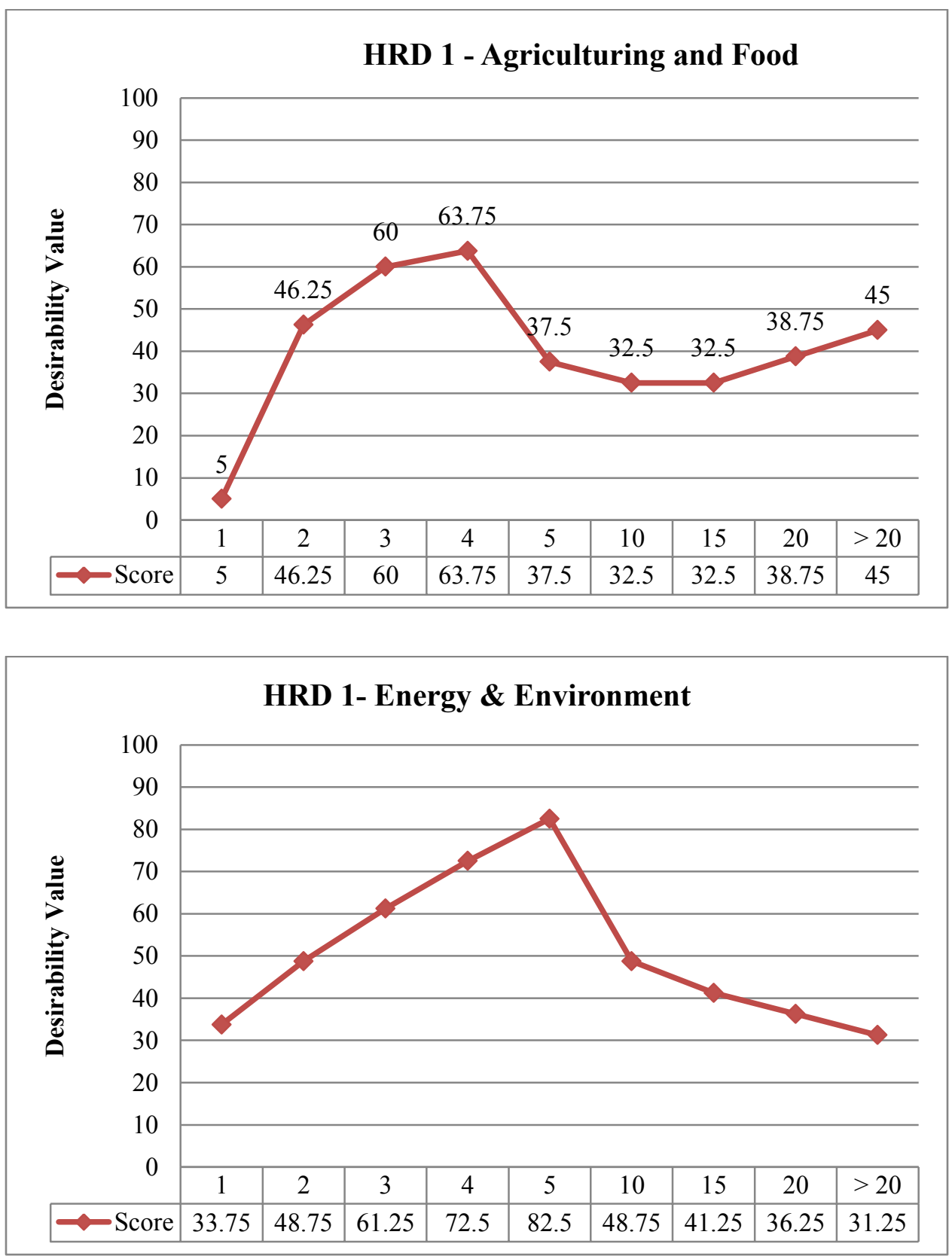

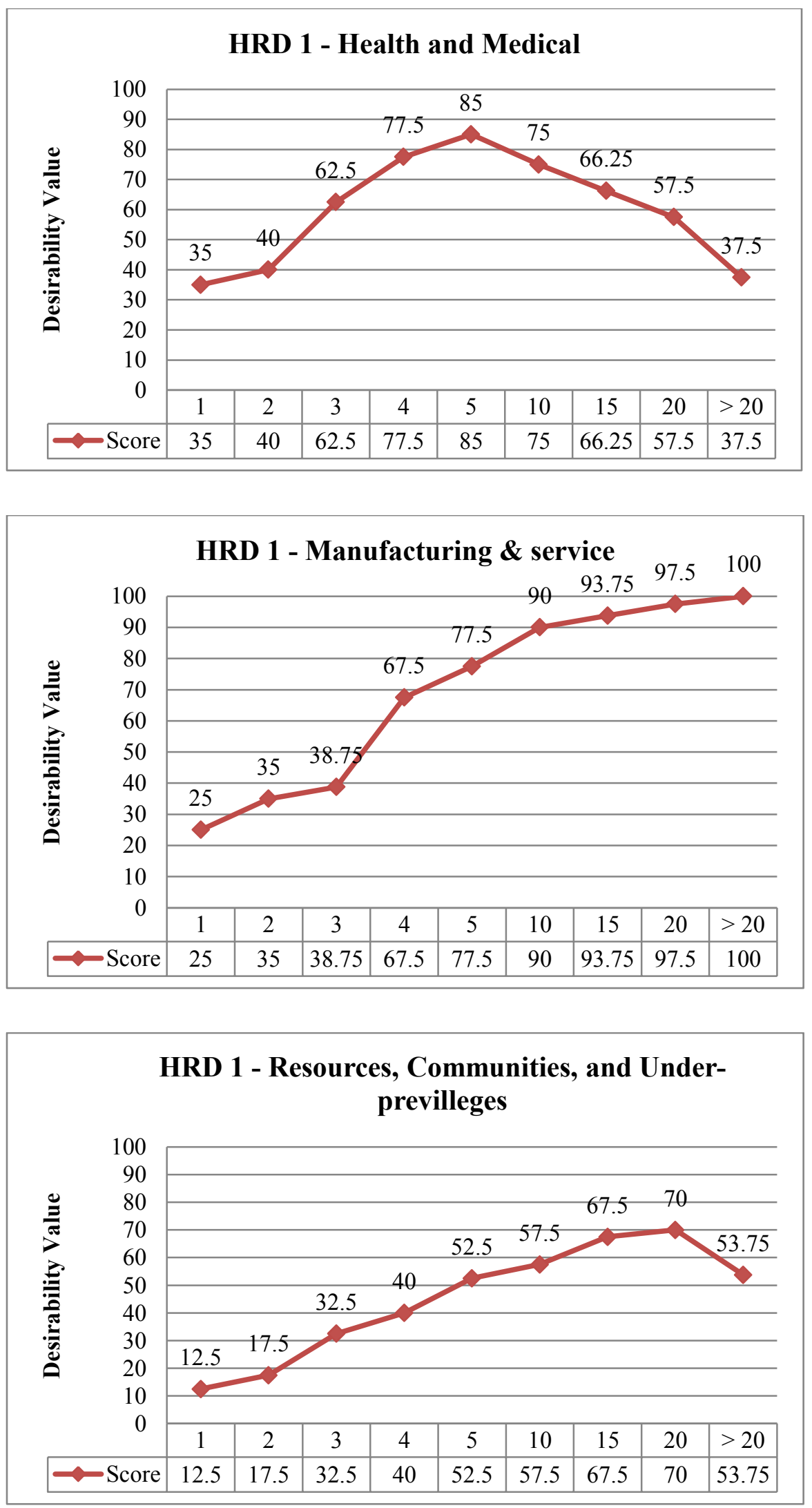
HRD 2: The significant benefit to researcher(s) from ICST project
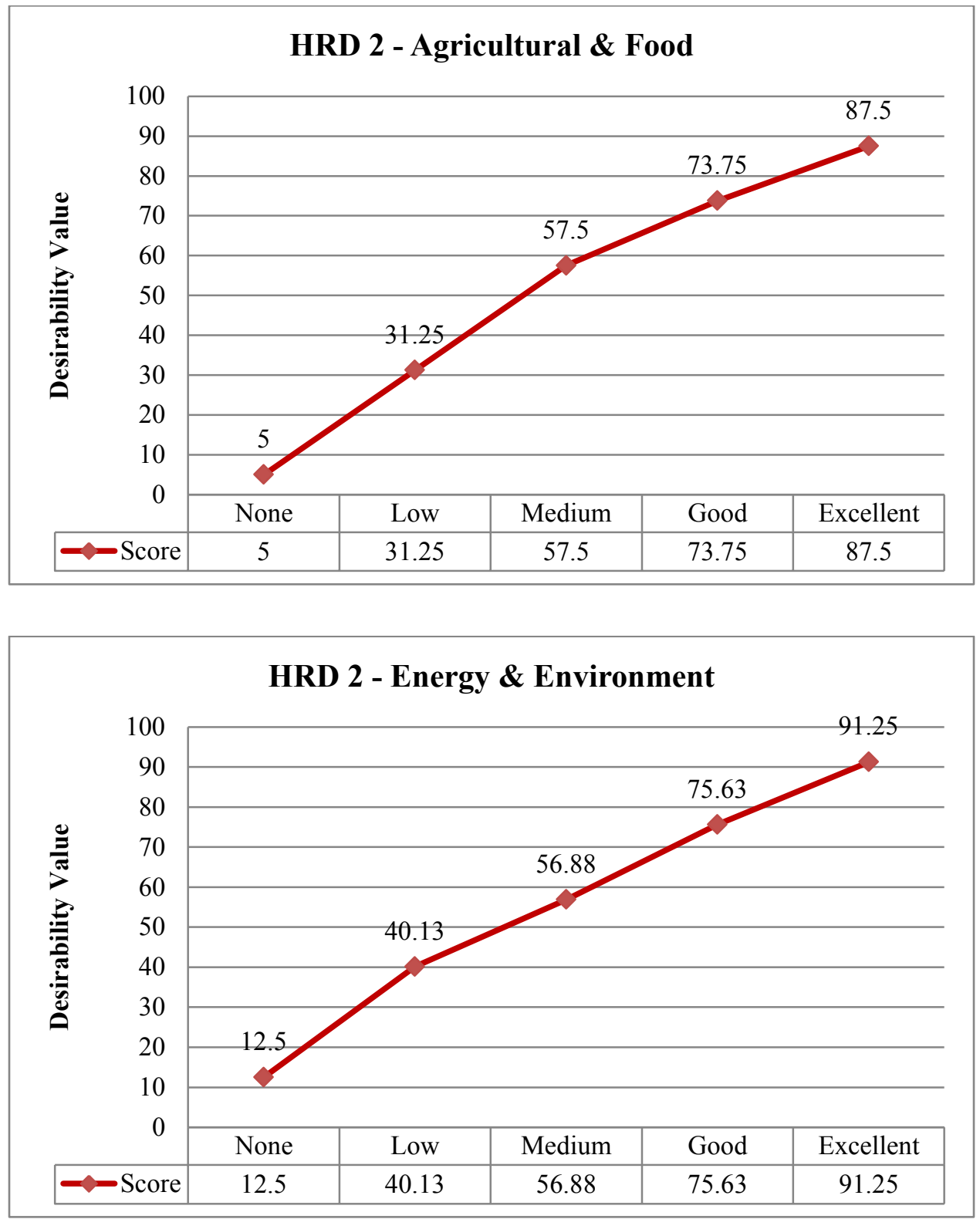

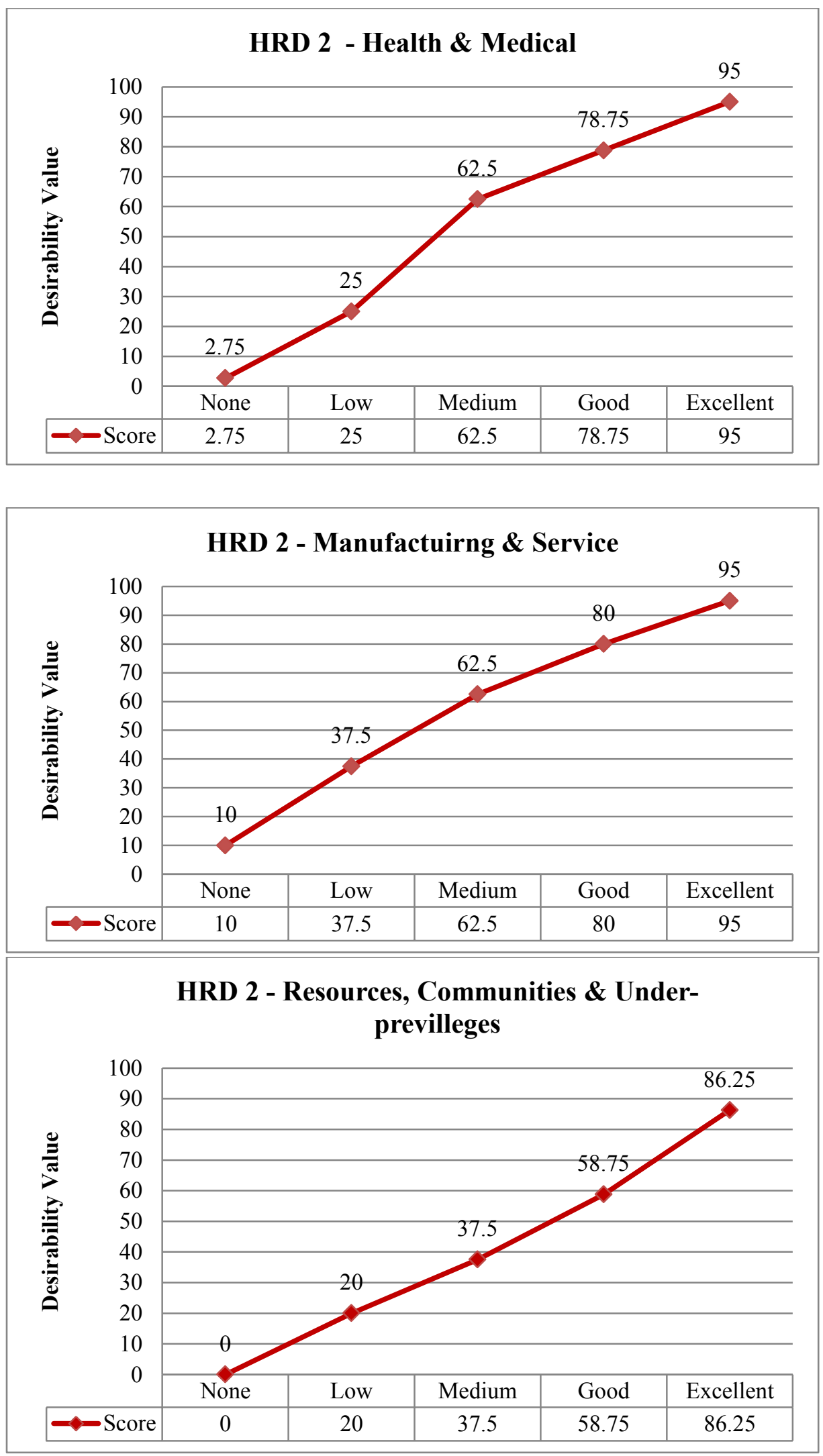
- Matching Fund Ratio (MF)
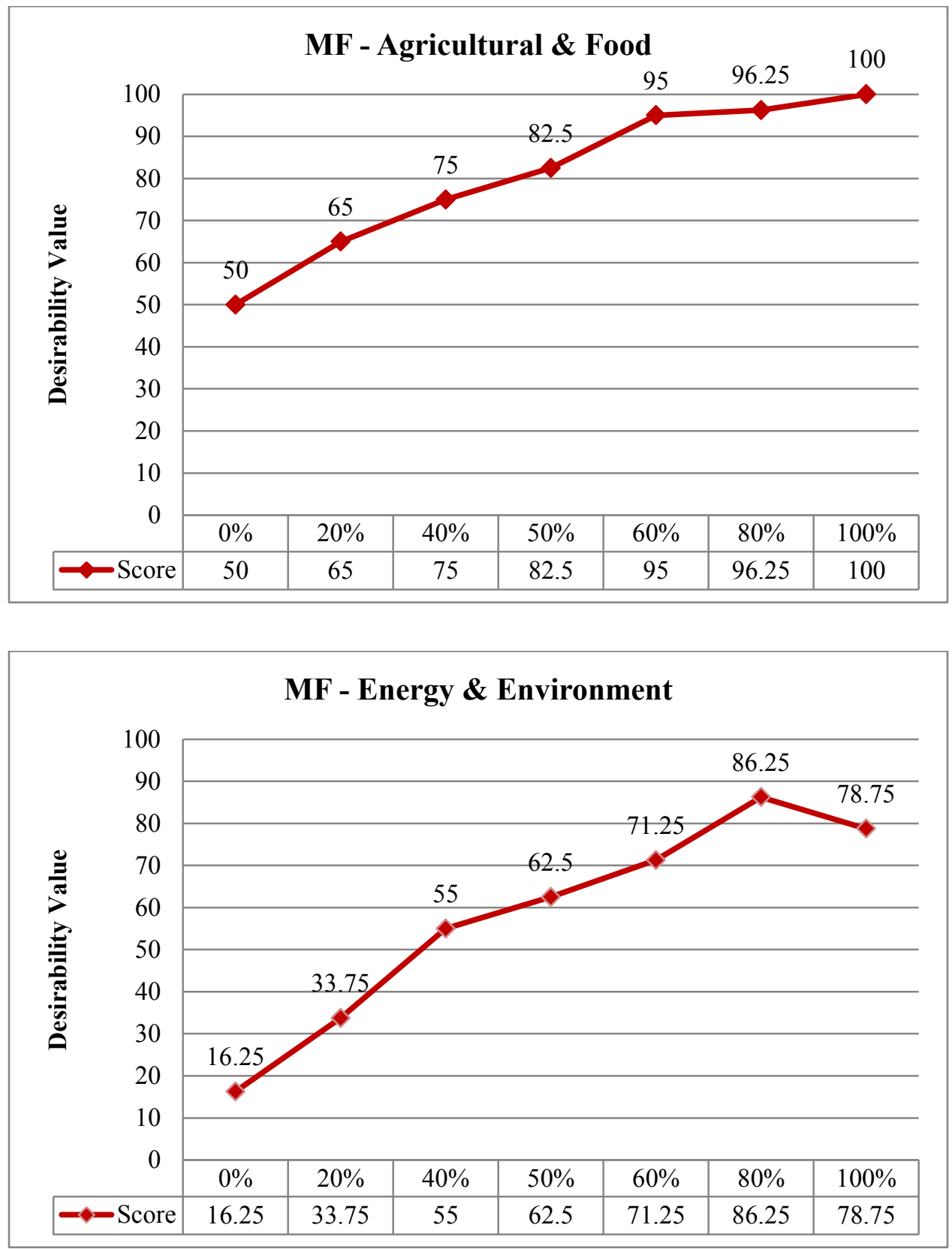

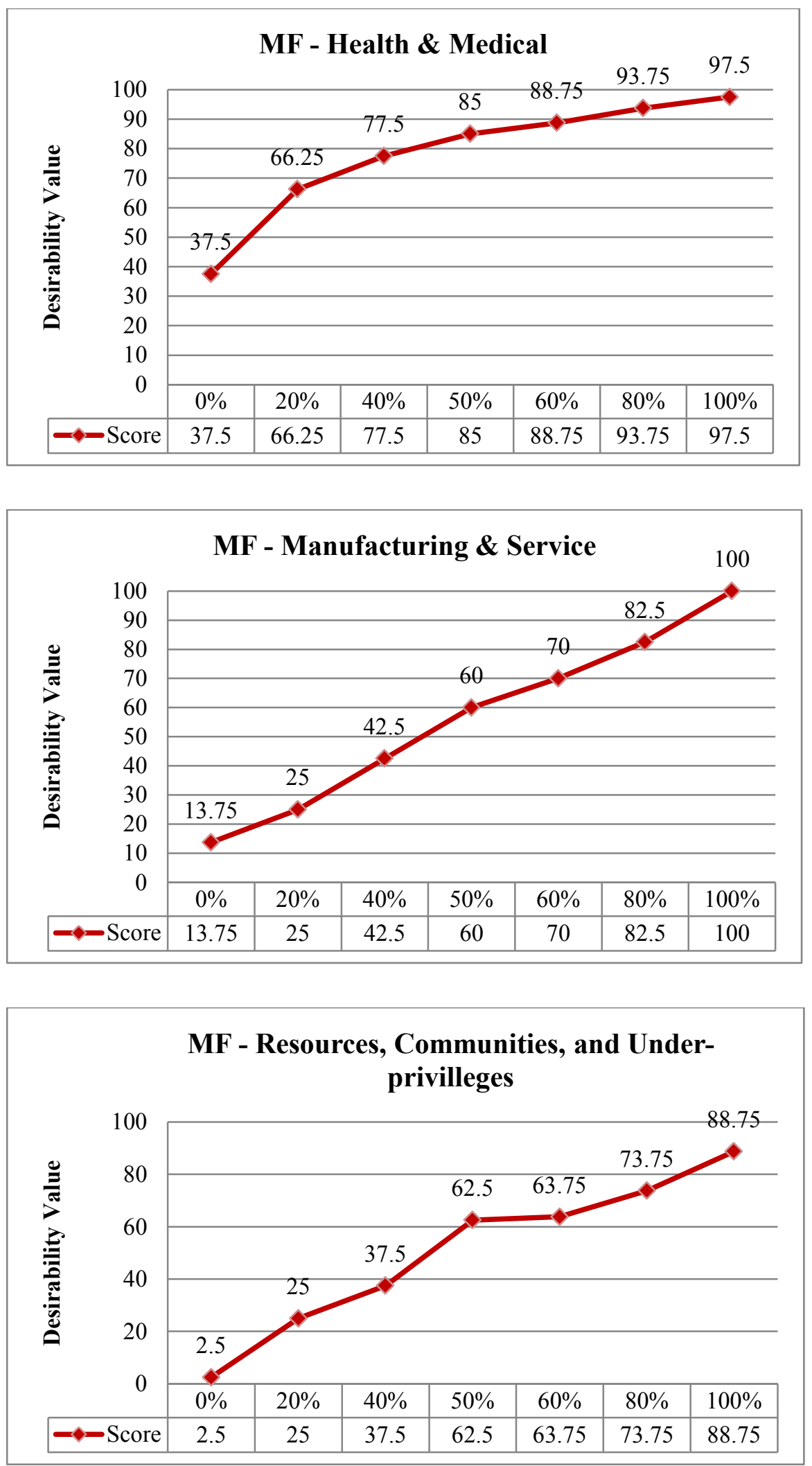


\section{Appendix C: Research Instruments}

\section{Appendix C-1: Research Instrument 1}

\section{Questionnaire for Thailand S\&T Objectives}

You are invited to participate in a research study conducted by Pattharaporn (Patt) Suntharasaj from Engineering and Technology Management Department, Portland State University. The researcher hopes to propose a decision making model for national policy makers to make a better decision in participating in International Collaboration in Science and Technology. This project is being conducted in partial fulfillment for the requirements of a PhD's degree under supervision by Dr. Dundar F. Kocaoglu.

I am in the process of forming an expert panel to provide quantified judgments about the relative importance of the five target sectors (1.Agricultural and Food 2. Energy and Environment 3.Health and Medical 4.Manufacturing and Service industry 5. Resources and Under-privileged people) with respect to Thailand's Science and Technology four objectives which are 1) Sustainable Competitiveness 2) Community Economy 3) Learning Society and 4) Quality of Life and Environment.

Because of your deep knowledge and experience in the development of Science and Technology in Thailand, I am inviting you to join the expert panel. If you decided to participate, you will complete a survey instrument which will take about 20-30 minutes.

Your participation is totally voluntary. Your name and individual response will be confidential and will not be identified in any published journal article. During the research, you may choose to withdraw at any time. You may not receive any direct benefit from taking part in this study, but the study will help to increase knowledge that may help others in the future. We highly appreciate your opinion and suggestions throughout the study.

If you have any concerns about your participation in this study or your rights as a research subject, please contact the Human Subjects Research Review committee, Office of Research Strategic Partnerships, 1600 SW Fourth Avenue, Suite 620, Portland, OR, $97201,503.725 .3423$. If you have any questions about the study itself, please send email to patts@pdx.edu. 


\section{Part 1- General information (Confidential)}

- Name

- Organization Position

- Area of expertise Working Experience years

\section{Part 2 - The Judgment Quantification Instrument}

At NSTDA, the five Target Industries with respect to the Thailand's S\&T four objectives are identified as illustrated below.

- Agriculture and Food

- Energy and Environment

- Health and Medicine

- Manufacturing and Service Industry

- Resources, Communities, and Under-privileges

- Please express your judgment about the relative importance of an element with respect to the other one in each of the pairs below.

- Divide a total of 100 points between the two elements in proportion of their relative importance.

- For example, if the first element is 3 times as important as the other one, give 75 points to the first and 25 points to the other element. Do not use Zero in your evaluations. If you consider one of the elements has no importance in comparison to the other element, allocate 1 and 99, respectively. 
Thailand S\&T Objective

\begin{tabular}{|c|c|c|c|}
\hline \multicolumn{3}{|c|}{ Objective 1: Sustainable Competitiveness } \\
\hline Criterion & Weight & Weight & Criterion \\
\hline Agriculture and Food & & & $\begin{array}{c}\text { Energy and } \\
\text { Environment }\end{array}$ \\
\hline
\end{tabular}

\begin{tabular}{|l|l|l|l|}
\hline Agriculture and Food & & & Health and Medicine \\
\hline
\end{tabular}

\begin{tabular}{|c|l|l|l|}
\hline Agriculture and Food & & $\begin{array}{c}\text { Manufacturing and } \\
\text { Service Industry }\end{array}$ \\
\hline
\end{tabular}

\begin{tabular}{|c|l|l|c|}
\hline Agriculture and Food & & $\begin{array}{c}\text { Resources, } \\
\text { Communities, and } \\
\text { Under-privileges }\end{array}$ \\
\hline
\end{tabular}

\begin{tabular}{|c|l|l|}
\hline $\begin{array}{c}\text { Energy and } \\
\text { Environment }\end{array}$ & & Health and Medicine \\
\hline \begin{tabular}{c|c|c|}
\hline Energy and \\
Environment
\end{tabular} & & $\begin{array}{c}\text { Manufacturing and } \\
\text { Service Industry }\end{array}$ \\
\hline
\end{tabular}

\begin{tabular}{|c|l|l|c|}
\hline $\begin{array}{c}\text { Energy and } \\
\text { Environment }\end{array}$ & & $\begin{array}{c}\text { Resources, } \\
\text { Communities, and } \\
\text { Under-privileges }\end{array}$ \\
\hline
\end{tabular}

\begin{tabular}{|l|l|l|l|}
\hline Health and Medicine & & $\begin{array}{c}\text { Manufacturing and } \\
\text { Service Industry }\end{array}$ \\
\hline
\end{tabular}

\begin{tabular}{|l|l|l|c|}
\hline Health and Medicine & & $\begin{array}{c}\text { Resources, } \\
\text { Communities, and } \\
\text { Under-privileged }\end{array}$ \\
\hline
\end{tabular}

\begin{tabular}{|c|l|l|c|}
\hline $\begin{array}{c}\text { Manufacturing and } \\
\text { Service Industry }\end{array}$ & & $\begin{array}{c}\text { Resources, } \\
\text { Communities, and } \\
\text { Under-privileges }\end{array}$ \\
\hline
\end{tabular}


Thailand S\&T Objective

\begin{tabular}{|l|c|c|c|}
\hline \multicolumn{4}{|c|}{ Objective 2: Community Economy } \\
\hline Criterion & Weight & Weight & Criterion \\
\hline
\end{tabular}

\begin{tabular}{|c|c|c|c|}
\hline Agriculture and Food & & & $\begin{array}{c}\text { Energy and } \\
\text { Environment }\end{array}$ \\
\hline
\end{tabular}

\begin{tabular}{|l|l|l|l|}
\hline Agriculture and Food & & & Health and Medicine \\
\hline
\end{tabular}

\begin{tabular}{|c|l|l|l|}
\hline Agriculture and Food & & $\begin{array}{c}\text { Manufacturing and } \\
\text { Service Industry }\end{array}$ \\
\hline
\end{tabular}

\begin{tabular}{|c|l|l|c|}
\hline Agriculture and Food & & $\begin{array}{c}\text { Resources, } \\
\text { Communities, and } \\
\text { Under-privileges }\end{array}$ \\
\hline
\end{tabular}

\begin{tabular}{|c|c|c|c|}
\hline $\begin{array}{c}\text { Energy and } \\
\text { Environment }\end{array}$ & & Health and Medicine \\
\hline \begin{tabular}{|l|l|}
\hline \multicolumn{2}{|c|}{ Energy and } \\
Environment
\end{tabular} & & $\begin{array}{c}\text { Manufacturing and } \\
\text { Service Industry }\end{array}$ \\
\hline \begin{tabular}{|l|l|}
\hline Energy and \\
Environment
\end{tabular} & & $\begin{array}{c}\text { Resources, } \\
\text { Communities, and } \\
\text { Under-privileges }\end{array}$ \\
\hline
\end{tabular}

\begin{tabular}{|c|l|l|c|}
\hline Health and Medicine & & $\begin{array}{c}\text { Manufacturing and } \\
\text { Service Industry }\end{array}$ \\
\hline
\end{tabular}

\begin{tabular}{|l|l|l|c|}
\hline Health and Medicine & & $\begin{array}{c}\text { Resources, } \\
\text { Communities, and } \\
\text { Under-privileged }\end{array}$ \\
\hline
\end{tabular}

Manufacturing and
Service Industry

Resources,

Communities, and

Under-privileges 
Thailand S\&T Objective

\begin{tabular}{|l|c|c|c|}
\hline \multicolumn{4}{|c|}{ Objective 3: Learning Society } \\
\hline Criterion & Weight & Weight & Criterion \\
\hline
\end{tabular}

\begin{tabular}{|c|c|c|c|}
\hline Agriculture and Food & & & $\begin{array}{c}\text { Energy and } \\
\text { Environment }\end{array}$ \\
\hline
\end{tabular}

\begin{tabular}{|l|l|l|l|}
\hline Agriculture and Food & & & Health and Medicine \\
\hline
\end{tabular}

\begin{tabular}{|c|l|l|l|}
\hline Agriculture and Food & & $\begin{array}{c}\text { Manufacturing and } \\
\text { Service Industry }\end{array}$ \\
\hline
\end{tabular}

\begin{tabular}{|c|l|l|c|}
\hline Agriculture and Food & & $\begin{array}{c}\text { Resources, } \\
\text { Communities, and } \\
\text { Under-privileges }\end{array}$ \\
\hline
\end{tabular}

\begin{tabular}{|c|l|l|l|}
\hline $\begin{array}{c}\text { Energy and } \\
\text { Environment }\end{array}$ & & & Health and Medicine \\
\hline
\end{tabular}

\begin{tabular}{|c|l|l|c|}
\hline $\begin{array}{c}\text { Energy and } \\
\text { Environment }\end{array}$ & & $\begin{array}{c}\text { Manufacturing and } \\
\text { Service Industry }\end{array}$ \\
\hline \begin{tabular}{c|c|c|} 
Energy and \\
Environment
\end{tabular} & & $\begin{array}{c}\text { Resources, } \\
\text { Communities, and } \\
\text { Under-privileges }\end{array}$ \\
\hline
\end{tabular}

\begin{tabular}{|l|l|l|}
\hline Health and Medicine & & $\begin{array}{c}\text { Manufacturing and } \\
\text { Service Industry }\end{array}$ \\
\hline
\end{tabular}

\begin{tabular}{|l|l|l|}
\hline Health and Medicine & & $\begin{array}{c}\text { Resources, } \\
\text { Communities, and } \\
\text { Under-privileged }\end{array}$ \\
\hline
\end{tabular}
Manufacturing and
Service Industry

Resources,

Communities, and Under-privileges 
Thailand S\&T Objective

Objective 4: Quality of Life and Environment

\begin{tabular}{|l|l|l|l|}
\hline Criterion & Weight & Weight & Criterion \\
\hline
\end{tabular}

\begin{tabular}{|l|l|l|c|}
\hline Agriculture and Food & & & $\begin{array}{c}\text { Energy and } \\
\text { Environment }\end{array}$ \\
\hline
\end{tabular}

\begin{tabular}{|l|l|l|l|}
\hline Agriculture and Food & & & Health and Medicine \\
\hline
\end{tabular}

\begin{tabular}{|c|l|l|l|}
\hline Agriculture and Food & & $\begin{array}{c}\text { Manufacturing and } \\
\text { Service Industry }\end{array}$ \\
\hline
\end{tabular}

\begin{tabular}{|c|l|l|c|}
\hline Agriculture and Food & & $\begin{array}{c}\text { Resources, } \\
\text { Communities, and } \\
\text { Under-privileges }\end{array}$ \\
\hline
\end{tabular}

\begin{tabular}{|c|l|l|l|}
\hline $\begin{array}{c}\text { Energy and } \\
\text { Environment }\end{array}$ & & & Health and Medicine \\
\hline
\end{tabular}

\begin{tabular}{|c|l|c|}
\hline $\begin{array}{c}\text { Energy and } \\
\text { Environment }\end{array}$ & & $\begin{array}{c}\text { Manufacturing and } \\
\text { Service Industry }\end{array}$ \\
\hline \begin{tabular}{|c|c|c|}
\hline Energy and \\
Environment
\end{tabular} & & $\begin{array}{c}\text { Resources, } \\
\text { Communities, and } \\
\text { Under-privileges }\end{array}$ \\
\hline
\end{tabular}

\begin{tabular}{|c|l|l|l|}
\hline Health and Medicine & & $\begin{array}{c}\text { Manufacturing and } \\
\text { Service Industry }\end{array}$ \\
\hline
\end{tabular}

\begin{tabular}{|l|l|l|c|}
\hline Health and Medicine & & $\begin{array}{c}\text { Resources, } \\
\text { Communities, and } \\
\text { Under-privileged }\end{array}$ \\
\hline
\end{tabular}

Manufacturing and
Service Industry

Resources,

Communities, and Under-privileges 


\section{Appendix C-2: Research Instrument 2}

\section{Questionnaire for NSTDA Target Sectors}

You are invited to participate in a research study conducted by Pattharaporn (Patt) Suntharasaj from Engineering and Technology Management Department, Portland State University. The researcher hopes to propose a decision making model for national policy makers to make a better decision in participating in International Collaboration in Science and Technology. This project is being conducted in partial fulfillment for the requirements of a PhD's degree under supervision by Dr. Dundar F. Kocaoglu.

I am in the process of forming an expert panel to provide quantified judgments about the relative importance of the five target sectors (1.Agricultural and Food 2. Energy and Environment 3.Health and Medical 4.Manufacturing and Service industry 5. Resources and Underprivileged people) with respect to Thailand's Science and Technology objective of "Sustainable Competitiveness".

Because of your deep knowledge and experience in the development of Science and Technology in Thailand, I am inviting you to join the expert panel. If you decided to participate, you will complete a survey instrument which will take about 15-20 minutes.

Your participation is totally voluntary. Your name and individual response will be confidential and will not be identified in any published journal article. During the research, you may choose to withdraw at any time. You may not receive any direct benefit from taking part in this study, but the study will help to increase knowledge that may help others in the future. We highly appreciate your opinion and suggestions throughout the study.

If you have any concerns about your participation in this study or your rights as a research subject, please contact the Human Subjects Research Review committee, Office of Research Strategic Partnerships, 1600 SW Fourth Avenue, Suite 620, Portland, OR, 97201, 503.725.3423. If you have any questions about the study itself, please send email to patts@pdx.edu . 


\section{Part 1- General information (Confidential)}

- Name

- Organization

Position

- Area of expertise

years

\section{Part 2 - The Judgment Quantification Instrument}

At National Science and Technology Development Agency (NSTDA), the five Target Sectors that response to the Thailand S\&T Objectives are identified as illustrated below.

1. Agricultural and Food

2. Energy and Environment

3. Health and Medical

4. Manufacturing and Service Industry

5. Resources, Communities, and Under privileges

- Please express your judgment about the relative importance of an element with respect to the other one in each of the pairs below.

- Divide a total of 100 points between the two elements in proportion of their relative importance.

- For example, if the first element is 3 times as important as the other one, give 75 points to the first and 25 points to the other element. Do not use Zero in your evaluations. If you consider one of the elements has no importance in comparison to the other element, allocate 1 and 99, respectively. 


\section{Thailand S\&T's Objective}

\section{"Sustainable Competitiveness"}

\begin{tabular}{|l|l|l|l|}
\hline Criterion & Weight & Weight & Criterion \\
\hline
\end{tabular}

Agricultural and Food

Agricultural and Food
Energy and Environment

Health and Medical

Agricultural and Food

Manufacturing and Service Industry

Agricultural and Food

Resources, Communities, and Under-privileges

\begin{tabular}{|l|l|l|l|}
\hline Energy and Environment & & & Health and Medical \\
\hline
\end{tabular}

\begin{tabular}{|c|l|l|c|}
\hline Energy and Environment & & $\begin{array}{c}\text { Manufacturing and Service } \\
\text { Industry }\end{array}$ \\
\hline
\end{tabular}

\begin{tabular}{|c|c|c|c|}
\hline Energy and Environment & & $\begin{array}{c}\text { Resources, Communities, } \\
\text { and Under-privileges }\end{array}$ \\
\hline Health and Medical & & & $\begin{array}{c}\text { Manufacturing and Service } \\
\text { Industry }\end{array}$ \\
\hline
\end{tabular}

Health and Medical

Manufacturing and Service Industry
Resources, Communities, and Under-privileges

Resources, Communities, and Under-privileges 


\section{Appendix C-3: Research Instrument 3 \\ Questionnaire for ICST Evaluation Criteria}

You are invited to participate in a research study conducted by Pattharaporn (Patt) Suntharasaj from Engineering and Technology Management Department, Portland State University. The researcher hopes to propose a decision making model for national policy makers to make a better decision in participating in International Collaboration in Science and Technology. This project is being conducted in partial fulfillment for the requirements of a PhD's degree under supervision by Dr. Dundar F. Kocaoglu.

The researcher is in the process of forming an expert panel to provide quantified judgments about the relative importance of the Four Evaluation Criteria and their subcriteria for the International Collaboration in S\&T project.

Because of your deep knowledge and experience in analyzing the Science and Technology Project in Thailand, I am inviting you to join the expert panel. If you decided to participate, you will complete a survey instrument which will take about 20-30 minutes.

Your participation is totally voluntary. Your name and individual response will be confidential and will not be identified in any published journal article. During the research, you may choose to withdraw at any time. You may not receive any direct benefit from taking part in this study, but the study will help to increase knowledge that may help others in the future. We highly appreciate your opinion and suggestions throughout the study.

If you have any concerns about your participation in this study or your rights as a research subject, please contact the Human Subjects Research Review committee, Office of Research Strategic Partnerships, 1600 SW Fourth Avenue, Suite 620, Portland, OR, 97201, 503.725.3423. If you have any questions about the study itself, please send email to patts@pdx.edu.

Part 1- General information (Confidential)

- Name

- Area of Expertise 


\section{Part 2 - The Judgment Quantification Instrument}

For Thailand's International Collaboration in Science and Technology Project, the following four evaluation criteria have been identified.

- Strategic Importance (SI)

- Potential Impact (PI)

- Human Resource Development (HRD)

- Matching Fund Ratio (MF)

Please express your judgment about the relative importance of an element with respect to the other one in each of the pairs below. Divide a total of 100 points between the two elements in proportion of their relative importance. For example, if the first element is 3 times as important as the other one, give 75 points to the first and 25 points to the other element. Do not use Zero in your evaluations. If you consider one of the elements has no importance in comparison to the other element, allocate 1 and 99, respectively.

\section{Target Sector 5: Resources, Communities, and Under-privileged People}

\begin{tabular}{|c|c|c|c|}
\hline Criterion & Weight & Weight & Criterion \\
\hline Strategic Importance & & & Potential Impact \\
\hline Strategic Importance & & & $\begin{array}{c}\text { Human Resource } \\
\text { Development }\end{array}$ \\
\hline Strategic Importance & & & Matching Fund \\
\hline Potential Impact & & & $\begin{array}{c}\text { Human Resource } \\
\text { Development }\end{array}$ \\
\hline Potential Impact & & & Matching Fund \\
\hline $\begin{array}{c}\text { Human Resource } \\
\text { Development }\end{array}$ & & & Matching Fund \\
\hline
\end{tabular}




\section{Appendix C-4: Research Instrument 4 \\ Questionnaire for ICST Evaluation Sub-criteria}

You are invited to participate in a research study conducted by Pattharaporn (Patt) Suntharasaj from Engineering and Technology Management Department, Portland State University. The researcher hopes to propose a decision making model for national policy makers to make a better decision in participating in International Collaboration in Science and Technology. This project is being conducted in partial fulfillment for the requirements of a PhD's degree under supervision by Dr. Dundar F. Kocaoglu.

The researcher is in the process of forming an expert panel to provide quantified judgments about the relative importance of the Four Evaluation Criteria and their subcriteria for the International Collaboration in S\&T project.

Because of your deep knowledge and experience in analyzing the Science and Technology Project in Thailand, I am inviting you to join the expert panel. If you decided to participate, you will complete a survey instrument which will take about 20-30 minutes.

Your participation is totally voluntary. Your name and individual response will be confidential and will not be identified in any published journal article. During the research, you may choose to withdraw at any time. You may not receive any direct benefit from taking part in this study, but the study will help to increase knowledge that may help others in the future. We highly appreciate your opinion and suggestions throughout the study.

If you have any concerns about your participation in this study or your rights as a research subject, please contact the Human Subjects Research Review committee, Office of Research Strategic Partnerships, 1600 SW Fourth Avenue, Suite 620, Portland, OR, 97201, 503.725.3423. If you have any questions about the study itself, please send email to patts@pdx.edu. 


\section{Part 1- General information (Confidential)}

- Name

- Area of Expertise

\section{Part 2 - The Judgment Quantification Instrument}

For the First Evaluation Criteria, Strategic Importance (SI), there are four sub-criteria which are listed below.

- To build up national S\&T Capabilities

- To establish a global partnership

- To obtain access to state-of-the-art knowledge aboard

- To attract highly skilled professionals (Brain Gain)

\section{Strategic Importance}

\begin{tabular}{|l|l|l|l|}
\hline Criterion & Weight & Weight & Criterion \\
\hline
\end{tabular}

\begin{tabular}{|l|l|l|l|}
\hline National S\&T Capability & & & Global Partnership \\
\hline
\end{tabular}

\begin{tabular}{|l|l|l|l|}
\hline National S\&T Capability & & & State-of-the-art knowledge \\
\hline
\end{tabular}

\begin{tabular}{|c|c|}
\hline National S\&T Capability & Brain Gain \\
\hline Global Partnership & State-of-the-art knowledge \\
\hline Global Partnership & Brain Gain \\
\hline
\end{tabular}

\begin{tabular}{|l|l|l|l|}
\hline State-of-the-art knowledge & & & Brian Gain \\
\hline
\end{tabular}


For the Second Evaluation Criteria, Potential Impact (PI), there are five sub-criteria which are listed below.

- Meeting Local Challenge

- Tackling Global Challenge

- Having Knowledge or Technology Transfer

- Creating Joint Academic Papers

- Creating Joint Research Program or Consortia

\begin{tabular}{|l|c|c|c|}
\hline \multicolumn{4}{|c|}{ Potential Impact (PI) } \\
\hline Criterion & Weight & Weight & Criterion \\
\hline
\end{tabular}

\begin{tabular}{|l|l|l|l|}
\hline National S\&T Capability & & & Global Partnership \\
\hline
\end{tabular}

\begin{tabular}{|l|l|l|l|}
\hline National S\&T Capability & & & State-of-the-art knowledge \\
\hline
\end{tabular}

\begin{tabular}{|l|l|l|l|}
\hline National S\&T Capability & & & Brain Gain \\
\hline
\end{tabular}

\begin{tabular}{|c|l|l|l|}
\hline Global Partnership & & & State-of-the-art knowledge \\
\hline
\end{tabular}

\begin{tabular}{|l|l|l|l|}
\hline Global Partnership & & & Brain Gain \\
\hline
\end{tabular}

\begin{tabular}{|l|l|l|l|}
\hline State-of-the-art knowledge & & & Brian Gain \\
\hline
\end{tabular}

\begin{tabular}{|l|l|l|l|}
\hline National S\&T Capability & & & Brain Gain \\
\hline
\end{tabular}

\begin{tabular}{|c|l|l|l|}
\hline Global Partnership & & & State-of-the-art knowledge \\
\hline
\end{tabular}

\begin{tabular}{|c|l|l|l|}
\hline Global Partnership & & & Brain Gain \\
\hline
\end{tabular}

State-of-the-art knowledge

Brian Gain 
For the Third Evaluation Criteria, Human Resource Development (HRD), there are two sub-criteria which are listed below.

- No. of researchers who will benefit from this collaboration

- Significance benefits to researchers e.g. training, workshop, etc.

\section{Human Resource Development}

\begin{tabular}{|l|l|l|l|}
\hline Criterion & Weight & Weight & Criterion \\
\hline
\end{tabular}

No. of researcher

Significance benefit to researchers 


\section{Appendix C-5: Research Instrument 5}

\section{Questionnaire for Desirability Value of Evaluation Sub-criteria}

You are invited to participate in a research study conducted by Pattharaporn (Patt) Suntharasaj from Engineering and Technology Management Department, Portland State University. The researcher hopes to propose a decision making model for national policy makers to make a better decision in participating in International Collaboration in Science and Technology. This project is being conducted in partial fulfillment for the requirements of a PhD's degree under supervision by Dr. Dundar F. Kocaoglu.

The researcher is in the process of forming an expert panel to provide quantified judgments about the relative importance of the Four Evaluation Criteria and their subcriteria for the International Collaboration in S\&T project.

Because of your deep knowledge and experience in analyzing the Science and Technology Project in Thailand, I am inviting you to join the expert panel. If you decided to participate, you will complete a survey instrument which will take about 20-30 minutes.

Your participation is totally voluntary. Your name and individual response will be confidential and will not be identified in any published journal article. During the research, you may choose to withdraw at any time. You may not receive any direct benefit from taking part in this study, but the study will help to increase knowledge that may help others in the future. We highly appreciate your opinion and suggestions throughout the study.

If you have any concerns about your participation in this study or your rights as a research subject, please contact the Human Subjects Research Review committee, Office of Research Strategic Partnerships, 1600 SW Fourth Avenue, Suite 620, Portland, OR, 97201, 503.725.3423. If you have any questions about the study itself, please send email to patts@pdx.edu. 


\section{Part 1- General information (Confidential)}

- Name

- Area of Expertise

\section{Part II- 1) Desirability Value of "Strategic Importance" Sub-criterion}

S1: To build up national S\&T capability

\begin{tabular}{|c|c|}
\hline Level & Score (100) \\
\hline Excellent & \\
\hline Good & \\
\hline Medium & \\
\hline Low & \\
\hline None & \\
\hline
\end{tabular}

S2: To establish global partnership

\begin{tabular}{|c|c|}
\hline Level & Score (100) \\
\hline Excellent & \\
\hline Good & \\
\hline Medium & \\
\hline Low & \\
\hline None & \\
\hline
\end{tabular}


S3: To obtain access to state-of-the-art knowledge aboard

\begin{tabular}{|c|c|}
\hline Level & Score (100) \\
\hline Excellent & \\
\hline Very Good & \\
\hline Medium & \\
\hline Low & \\
\hline None & \\
\hline
\end{tabular}

S4: To attract highly skilled professional (Brain Gain)

\begin{tabular}{|c|c|}
\hline Level & Score (100) \\
\hline Excellent & \\
\hline Good & \\
\hline Medium & \\
\hline Low & \\
\hline None & \\
\hline
\end{tabular}

\section{Part II-2) Desirability Value of "Potential Impact" Sub-criterion}

P1: Meeting Local Challenge

\begin{tabular}{|c|c|}
\hline Level & Score (100) \\
\hline Excellent & \\
\hline Good & \\
\hline Medium & \\
\hline Low & \\
\hline None & \\
\hline
\end{tabular}


P2: Tackling Global Challenge

\begin{tabular}{|c|c|}
\hline Level & Score (100) \\
\hline Excellent & \\
\hline Good & \\
\hline Medium & \\
\hline Low & \\
\hline None & \\
\hline
\end{tabular}

P3: Having Knowledge or Technology Transfer

\begin{tabular}{|c|c|}
\hline Level & Score (100) \\
\hline Excellent & \\
\hline Good & \\
\hline Medium & \\
\hline Low & \\
\hline None & \\
\hline
\end{tabular}

P4: Creating Joint Academic Papers

\begin{tabular}{|c|c|}
\hline Level & Score (100) \\
\hline Excellent & \\
\hline Good & \\
\hline Medium & \\
\hline Low & \\
\hline None & \\
\hline
\end{tabular}


P5: Creating Joint Research Program or Consortia

\begin{tabular}{|c|c|}
\hline Level & Score (100) \\
\hline Excellent & \\
\hline Good & \\
\hline Medium & \\
\hline Low & \\
\hline None & \\
\hline
\end{tabular}

Part II-3) Desirability Value of "Human Resource Development" Sub-criterion

HRD1: No. of researchers who will benefit from this collaboration

\begin{tabular}{|c|c|}
\hline $\begin{array}{c}\text { No. of researcher } \\
\text { (persons) }\end{array}$ & Score (100) \\
\hline$>20$ & \\
\hline 20 & \\
\hline 15 & \\
\hline 10 & \\
\hline 5 & \\
\hline 4 & \\
\hline 3 & \\
\hline 2 & \\
\hline 1 & \\
\hline 0 & \\
\hline
\end{tabular}


HRD2: Significance benefits to researchers e.g. training, workshop, etc.

\begin{tabular}{|c|c|}
\hline Level & Score (100) \\
\hline Excellent & \\
\hline Good & \\
\hline Medium & \\
\hline Low & \\
\hline None & \\
\hline
\end{tabular}

\section{Part II-4) Desirability Value of "Matching Fund" Sub-criterion}

\begin{tabular}{|c|c|}
\hline Matching Budget ratio & Score (100) \\
\hline $100 \%$ & \\
\hline $80 \%$ & \\
\hline $60 \%$ & \\
\hline $50 \%$ & \\
\hline $40 \%$ & \\
\hline $20 \%$ & \\
\hline 0 & \\
\hline
\end{tabular}

Remark: Matching Fund Ratio $=$ Matching of Fund from the collaborative partner/Total Budget 


\section{Appendix C-6: Research Instrument 6 \\ ICST Research Proposal Form}

Part 1- General information (Confidential)

- Name

- Organization

Position

- Working Experience

years

Part 2-Your proposed International Collaboration in S\&T project(s):

Please describe the key points of your proposed International Collaboration Project in Science and Technology project.

2.1 Title of your proposed International Collaboration in S\&T project:

2.2 Potential Target Sector (s) to which it contributes (Please note: your project can serve more than one target sector):

[ ] Agricultural and Food ..... \% [ ] Energy and Environment ..... \%

[ ] Health and Medical.... \% [ ] Manufacturing and Service Industry.... \%

[ ] Resources, and Underprivileged people..... \%

\subsection{Proposed International Collaborator(s):}

Name: Organization:

Name: Organization: 


\subsection{Type of Collaboration:}

[ ] Bilateral between NSTDA and

[ ] Multilateral, among NSTDA and

[ ] Others, please specify

2.6 Requested Budget: Matching Fund:

2.7 Please give the brief detail about your proposed project:

Objective (s) of the project:

How will the objectives be achieved?

2.8 Strategic Importance of the proposed project (Please note: your project can serve more than one aspect):

[ ] To build up national S\&T capabilities through international collaboration

[ ] To establish a global partnership

[ ] To obtain access to state-of-the-art knowledge abroad

[ ] To attract state-of-the-art knowledge and people (Brain Gain) 
2.9 Potential Benefits to the Thai Society (Local) and the Global (Please note: your project can serve more than one aspect and please briefly explain in the space provided for each benefit)

[ ] Meeting the Local challenge e.g. tsunami warning, flooding preparedness system

[ ] Tackling the Global challenge e.g. Global warming, HIV, etc.

[ ] Having Knowledge or Technology Transfer from experts in other countries:

[ ] Creating Joint Academic Papers for journals or conference proceedings:

[ ] Creating Joint Research Programs or Consortia resulting from this project:

\subsection{Human Resource Development:}

[ ] No. of researchers who will benefit from this collaboration project person(s)

[ ] Significance of the benefits to researchers e.g. training, workshop (please explain) 


\section{Appendix D: Research Instruments}

Calculation of ICST Value of Proposal 2, 3, and 4

\section{Appendix D-1: The Calculation of Proposal ICST 2}

\section{- ICST Proposal Characteristic of ICST 2 Target Sector 4}

Target Sector 4: Manufacturing and Service (50\%) Relative Importance: 0.17

\begin{tabular}{|c|c|c|}
\hline Evaluation Criteria \& Sub-criteria & $\begin{array}{c}\text { Project } \\
\text { Characteristic }\end{array}$ & $\begin{array}{l}\text { Desirability } \\
\text { Value }\end{array}$ \\
\hline \multicolumn{3}{|l|}{ 1) Strategic Importance (SI) } \\
\hline \multicolumn{3}{|l|}{$\begin{array}{l}\text { Relative Importance of SI of Manufacturing Sector is } \\
0.33\end{array}$} \\
\hline - National S\&T Capability & Good & 73.75 \\
\hline - Global Partnership & Good & 55 \\
\hline - State of the Art Knowledge & Good & 62.5 \\
\hline - Brain Gain & 0 & 0 \\
\hline 2) Potential Impact (PI) & & \\
\hline \multicolumn{3}{|l|}{$\begin{array}{l}\text { Relative Importance of PI of Manufacturing Sector is } \\
0.37\end{array}$} \\
\hline - Local Challenge & 0 & 0 \\
\hline - Global Challenge & 0 & 0 \\
\hline - Tech/Knowledge Transfer & 0 & 0 \\
\hline - Joint Academic Paper & Good & 52.5 \\
\hline - Research Consortia & Good & 66.25 \\
\hline \multicolumn{3}{|l|}{ 3) Human Resource Development (HRD) } \\
\hline \multicolumn{3}{|l|}{$\begin{array}{l}\text { Relative Importance of HRD of Manufacturing Sector } \\
\text { is } 0.14\end{array}$} \\
\hline - Number of researcher(s) & 10 & 65 \\
\hline - Significant Benefit to researcher(s) & 0 & 0 \\
\hline 4) Matching Fund (MF) & & \\
\hline $\begin{array}{l}\text { Relative Importance of MF of Manufacturing Sector is } \\
0.16\end{array}$ & $50 \%$ & 60 \\
\hline
\end{tabular}


Calculation of ICST Value of Proposal 2 -Target Sector $4\left(\operatorname{ICST}_{2}^{4}\right)$

- Relative Value of Strategic Importance $=C_{14}^{4} * S_{j 14}^{1} * \mathrm{D}\left(\mathrm{P}_{\mathrm{j} 14}\right)_{2}$

$$
\begin{aligned}
& =0.33 *(0.40,0.17,0.25,0.18) *\left[\begin{array}{c}
73.75 \\
55 \\
62.5 \\
0
\end{array}\right] \\
& =17.98
\end{aligned}
$$

- Relative Value of Potential Impact

$$
\begin{aligned}
& =C_{24}^{4} * S_{j 24}^{2} * \mathrm{D}\left(\mathrm{P}_{\mathrm{j} 24}\right)_{2} \\
& =0.37 *(0.33,0.14,0.21,0.13,0.19) *\left[\begin{array}{c}
0 \\
0 \\
0 \\
52.50 \\
66.25
\end{array}\right]
\end{aligned}
$$$$
=7.19
$$

- Relative Value of Human Resource Development

$$
\begin{aligned}
& =C_{34}^{4} * S_{j 34}^{3} * \mathrm{D}\left(\mathrm{P}_{\mathrm{j} 34}\right)_{2} \\
& =0.14 *(0.31,0.69) *\left[\begin{array}{c}
65 \\
0
\end{array}\right] \\
& =2.82
\end{aligned}
$$

- Relative Value of Matching Fund

$$
\begin{aligned}
& =C_{44}^{4} * S_{j 44}^{4} * \mathrm{D}\left(\mathrm{P}_{\mathrm{j} 44}\right)_{2} \\
& =0.16 *[60] \\
& =9.6
\end{aligned}
$$

Thus, the ICST Value for Project II - Target Sector $4\left(\mathrm{ICST}_{2}^{4}\right)$ is calculated as illustrated below.

$$
\operatorname{ICST~P}{ }_{2}^{4}=0.17 *(17.98+7.19+2.82+9.6)=6.39
$$


However, this project serves Manufacturing and Service Sector for 50\%, thus the final $\operatorname{ICST~} \mathrm{P}_{2}^{4}$ is $6.39 * \frac{50}{100}$ which is 3.20 .

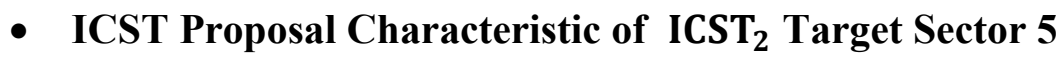

Target Sector 5: Resources, Communities and Under-privileged People (50\%)

Relative Importance: $\mathbf{0 . 1 3}$

\begin{tabular}{|c|c|c|}
\hline Evaluation Criteria \& Sub-criteria & $\begin{array}{c}\text { Project } \\
\text { Characteristic }\end{array}$ & $\begin{array}{l}\text { Desirability } \\
\text { Value }\end{array}$ \\
\hline \multicolumn{3}{|l|}{ 1) Strategic Importance (SI) } \\
\hline \multicolumn{3}{|l|}{$\begin{array}{l}\text { Relative Importance of SI of Resources, } \\
\text { Communities and Under-privileged People is } 0.22\end{array}$} \\
\hline - National S\&T Capability & 0 & 0 \\
\hline - Global Partnership & Good & 76.25 \\
\hline - State of the Art Knowledge & Good & 78.50 \\
\hline - Brain Gain & Good & 77.50 \\
\hline \multicolumn{3}{|l|}{ 2) Potential Impact (PI) } \\
\hline \multicolumn{3}{|l|}{$\begin{array}{l}\text { Relative Importance of PI of Resources, } \\
\text { Communities and Under-privileged People is } 0.28\end{array}$} \\
\hline - Local Challenge & 0 & 0 \\
\hline - Global Challenge & 0 & 0 \\
\hline - Tech/Knowledge Transfer & 0 & 0 \\
\hline - Joint Academic Paper & Good & 56.25 \\
\hline - Research Consortia & Good & 57.50 \\
\hline \multicolumn{3}{|l|}{ 3) Human Resource Development (HRD) } \\
\hline \multicolumn{3}{|l|}{$\begin{array}{l}\text { Relative Importance of HRD of Resources, } \\
\text { Communities and Under-privileged People is } 0.34\end{array}$} \\
\hline - Number of researcher(s) & 10 & 57.50 \\
\hline - Significant Benefit to researcher(s) & 0 & 0 \\
\hline \multicolumn{3}{|l|}{ 4) Matching Fund (MF) } \\
\hline $\begin{array}{l}\text { Relative Importance of MF of Resources, } \\
\text { Communities and Under-privileged People is } 0.16\end{array}$ & $50 \%$ & 62.50 \\
\hline
\end{tabular}


Calculation of ICST Value of Proposal 2-Target Sector 5 (ICST 25

- Relative Value of Strategic Importance

$$
\begin{aligned}
& =C_{15}^{5} * S_{j 15}^{1} * \mathrm{D}\left(\mathrm{P}_{\mathrm{j} 15}\right)_{2} \\
& =0.22(0.33,0.27,0.24,0.17) *\left[\begin{array}{c}
76.25 \\
78.50 \\
77.50 \\
0
\end{array}\right] \\
& =18.45
\end{aligned}
$$

- Relative Value of Potential Impact

$$
\begin{aligned}
& =C_{25}^{5} * S_{j 25}^{2} * \mathrm{D}\left(\mathrm{P}_{\mathrm{j} 25}\right)_{2} \\
& =0.28 *(0.26,0.14,0.19,0.24,0.15,0.16) *\left[\begin{array}{c}
0 \\
0 \\
0 \\
56.25 \\
57.50
\end{array}\right] \\
& =5.57
\end{aligned}
$$

- Relative Value of Human Resource Development

$$
\begin{aligned}
& =C_{35}^{5} * S_{j 35}^{3} * \mathrm{D}\left(\mathrm{P}_{\mathrm{j} 35}\right)_{2} \\
& =0.34 *(0.33,0.67) *\left[\begin{array}{c}
57.50 \\
0
\end{array}\right] \\
& =6.45
\end{aligned}
$$

- Relative Value of Matching Fund

$$
\begin{aligned}
& =C_{45}^{5} * S_{j 45}^{4} * \mathrm{D}\left(\mathrm{P}_{\mathrm{j} 45}\right)_{2} \\
& =10
\end{aligned}
$$


Thus, the ICST Value for Project 2 - Target Sector $5\left(\right.$ ICST $\left.{ }_{2}^{5}\right)$ is calculated as illustrated below.

$$
\operatorname{ICST~P} P_{2}^{5}=0.13 *(18.45+5.57+6.45+10)=5.26
$$

However, this project serves Resources, Communities, and Under-privileged People Target Sector for $50 \%$, thus the final ICST $\mathrm{P}_{2}^{5}$ is $\left(5.26 * \frac{50}{100}\right)$, which is 2.63 .

Then, the total $\mathrm{ICST}_{2}=\mathrm{ICST}_{2}^{4}+\mathrm{ICST}_{2}^{5}=5.83$ 


\section{Appendix D-2: The Calculation of Proposal 3 ( $\mathrm{ICST}_{3}$ )}

\section{- ICST Proposal Characteristic of ICST $_{3}$}

Target Sector: Health and Medicine Relative Importance: 0.20

\begin{tabular}{|c|c|c|}
\hline Evaluation Criteria \& Sub-criteria & $\begin{array}{c}\text { Project } \\
\text { Characteristic }\end{array}$ & $\begin{array}{l}\text { Desirability } \\
\text { Value }\end{array}$ \\
\hline \multicolumn{3}{|l|}{ 1) Strategic Importance (SI) } \\
\hline \multicolumn{3}{|l|}{$\begin{array}{l}\text { Relative Importance of SI of Health \& Medicine is } \\
0.37\end{array}$} \\
\hline - National S\&T Capability & Excellent & 97.23 \\
\hline - Global Partnership & Excellent & 85 \\
\hline - State of the Art Knowledge & Excellent & 90 \\
\hline - Brain Gain & 0 & 0 \\
\hline \multicolumn{3}{|l|}{ 2) Potential Impact (PI) } \\
\hline \multicolumn{3}{|l|}{$\begin{array}{l}\text { Relative Importance of PI of Health \& Medicine is } \\
0.40\end{array}$} \\
\hline - Local Challenge & Excellent & 97.50 \\
\hline - Global Challenge & Excellent & 76.25 \\
\hline - $\quad$ Tech/Knowledge Transfer & Excellent & 95 \\
\hline - Joint Academic Paper & Excellent & 81.25 \\
\hline - Research Consortia & Excellent & 78.75 \\
\hline \multicolumn{3}{|l|}{ 3) Human Resource Development (HRD) } \\
\hline \multicolumn{3}{|l|}{$\begin{array}{l}\text { Relative Importance of HRD of Health \& Medicine is } \\
0.15\end{array}$} \\
\hline - Number of researcher(s) & $>20$ & 37.50 \\
\hline - Significant Benefit to researcher(s) & Excellent & 95 \\
\hline \multicolumn{3}{|l|}{ 4) Matching Fund (MF) } \\
\hline $\begin{array}{l}\text { Relative Importance of MF of Health \& Medicine is } \\
0.08\end{array}$ & $100 \%$ & 97.50 \\
\hline
\end{tabular}

Calculation of ICST Value of Proposal 3: $\mathrm{ICST}_{3}$

- Relative Value of Strategic Importance 


$$
\begin{aligned}
& =C_{13}^{3} * S_{j 13}^{1} * \mathrm{D}\left(\mathrm{P}_{\mathrm{j} 13}\right)_{3} \\
& =0.37 *(0.51,0.15,0.19,0.14) *\left[\begin{array}{c}
97.23 \\
85 \\
90 \\
0
\end{array}\right] \\
& =29.39
\end{aligned}
$$

- Relative Value of Potential Impact

$$
\begin{aligned}
& =C_{23}^{3} * S_{j 23}^{2} * \mathrm{D}\left(\mathrm{P}_{\mathrm{j} 23}\right)_{3} \\
& =0.40 *(0.30,0.15,0.27,0.14,0.15) *\left[\begin{array}{c}
97.50 \\
76.25 \\
95 \\
81.25 \\
78.75
\end{array}\right] \\
& =35.81
\end{aligned}
$$

- Relative Value of Human Resource Development

$$
\begin{aligned}
& =C_{33}^{3} * S_{j 33}^{3} * \mathrm{D}\left(\mathrm{P}_{\mathrm{j} 33}\right)_{3} \\
& =0.15 *(0.30,0.70) *\left[\begin{array}{c}
37.50 \\
95
\end{array}\right] \\
& =11.66
\end{aligned}
$$

- Relative Value of Matching Fund

$$
\begin{aligned}
& =C_{43}^{3} * S_{j 43}^{4} * \mathrm{D}\left(\mathrm{P}_{\mathrm{j} 43}\right)_{3} \\
& =7.80
\end{aligned}
$$

Thus, the ICST Value for Project 3 (ICST 3 ) is calculated as illustrated below.

$$
\begin{aligned}
\mathrm{ICST}_{3} & =0.20 *(29.39+35.81+11.66+7.80) \\
& =0.20 * 84.66 \\
& =16.93
\end{aligned}
$$




\section{Appendix D-3: The Calculation of Proposal $4\left(\mathrm{ICST}_{4}\right)$}

- ICST Proposal Characteristic of ICST $_{4}$

Target Sector: Energy and Environment Relative Importance: 0.22

\begin{tabular}{|c|c|c|}
\hline Evaluation Criteria \& Sub-criteria & $\begin{array}{c}\text { Project } \\
\text { Characteristic }\end{array}$ & $\begin{array}{l}\text { Desirability } \\
\text { Value }\end{array}$ \\
\hline \multicolumn{3}{|l|}{ 1) Strategic Importance (SI) } \\
\hline \multicolumn{3}{|l|}{$\begin{array}{l}\text { Relative Importance of SI of Energy and } \\
\text { Environment is } 0.27\end{array}$} \\
\hline - National S\&T Capability & 0 & 0 \\
\hline - Global Partnership & 0 & 0 \\
\hline - State of the Art Knowledge & Good & 73 \\
\hline - Brain Gain & 0 & 0 \\
\hline \multicolumn{3}{|l|}{ 2) Potential Impact (PI) } \\
\hline \multicolumn{3}{|l|}{$\begin{array}{l}\text { Relative Importance of PI of Energy and } \\
\text { Environment is } 0.32\end{array}$} \\
\hline - Local Challenge & Good & 79.38 \\
\hline - Global Challenge & 0 & 0 \\
\hline - Tech/Knowledge Transfer & 0 & 0 \\
\hline - Joint Academic Paper & 0 & 0 \\
\hline - Research Consortia & 0 & 0 \\
\hline \multicolumn{3}{|l|}{ 3) Human Resource Development (HRD) } \\
\hline \multicolumn{3}{|l|}{$\begin{array}{l}\text { Relative Importance of HRD of Energy and } \\
\text { Environment is } 0.28\end{array}$} \\
\hline - Number of researcher(s) & $>20$ & 31.25 \\
\hline - Significant Benefit to researcher(s) & Excellent & 91.25 \\
\hline \multicolumn{3}{|l|}{ 4) Matching Fund (MF) } \\
\hline $\begin{array}{l}\text { Relative Importance of MF of Energy and } \\
\text { Environment is } 0.14\end{array}$ & $75 \%$ & 39.06 \\
\hline
\end{tabular}

Calculation of ICST Value of Proposal 4:ICST 4

- Relative Value of Strategic Importance 


$$
\begin{aligned}
& =C_{12}^{2} * S_{j 12}^{1} * \mathrm{D}\left(\mathrm{P}_{\mathrm{j} 12}\right)_{4} \\
& =0.27 *(0.44,0.23,0.17,0.17) *\left[\begin{array}{c}
0 \\
0 \\
73 \\
0
\end{array}\right] \\
& =3.35
\end{aligned}
$$

- Relative Value of Potential Impact

$$
\begin{aligned}
& =C_{22}^{2} * S_{j 22}^{2} * \mathrm{D}\left(\mathrm{P}_{\mathrm{j} 22}\right)_{4} \\
& =0.32 *(0.41,0.21,0.14,0.08,0.16) *\left[\begin{array}{c}
79.38 \\
0 \\
0 \\
0 \\
0
\end{array}\right]
\end{aligned}
$$$$
=11.43
$$

- Relative Value of Human Resource Development

$$
\begin{aligned}
& =C_{32}^{2} * S_{j 32}^{3} * \mathrm{D}\left(\mathrm{P}_{\mathrm{j} 32}\right)_{4} \\
& =0.28 *(0.35,0.65) *\left[\begin{array}{l}
31.25 \\
91.25
\end{array}\right] \\
& =19.67
\end{aligned}
$$

- Relative Value of Matching Fund

$$
\begin{aligned}
& =C_{42}^{2} * S_{j 42}^{4} * \mathrm{D}\left(\mathrm{P}_{j 42}\right)_{4} \\
& =0.14 *[39.06] \\
& =5.47
\end{aligned}
$$

Thus, the ICST Value for Project 4 (ICST 4 ) is calculated as illustrated below.

$$
\begin{aligned}
\operatorname{ICST}_{4} & =0.22 *(3.35+11.43+19.67+5.47) \\
& =8.78
\end{aligned}
$$

